UNIVERSIDADE DE SÃO PAULO

FACULDADE DE ECONOMIA, ADMINISTRAÇÃO E CONTABILIDADE

DEPARTAMENTO DE CONTABILIDADE E ATUÁRIA

PROGRAMA DE PÓS-GRADUAÇÃO EM CONTROLADORIA E CONTABILIDADE

Daiana Bragueto Martins

Contribuição do uso do controle gerencial para o desenvolvimento da resiliência organizacional 
Prof. Dr. Vahan Agopyan

Reitor da Universidade de São Paulo

Prof. Dr. Fábio Frezatti

Diretor da Faculdade de Economia, Administração e Contabilidade

Prof. Dr. Valmor Slomski

Chefe do Departamento de Contabilidade e Atuária

Prof. Dr. Lucas Ayres Barreira de Campos Barros

Coordenador do Programa de Pós-Graduação em Controladoria e Contabilidade. 
DAIANA BRAGUETO MARTINS

\section{Contribuição do uso do controle gerencial para o desenvolvimento da resiliência organizacional}

Tese apresentada ao Programa de PósGraduação de Controladoria e Contabilidade do Departamento de Contabilidade e Atuária da Faculdade de Economia, Administração e Contabilidade da Universidade de São Paulo, como requisito parcial para obtenção do título de Doutora em Ciências.

Área de Concentração: Controladoria e Contabilidade

Orientador: Prof. Dr. Fábio Frezatti

Coorientadora: Profa. Dra. Tania Casado

Versão Corrigida

(versão original disponível na Faculdade de Economia, Administração e Contabilidade)

São Paulo

2019 
Autorizo a reprodução e divulgação total ou parcial deste trabalho, por qualquer meio convencional ou eletrônico, para fins de estudo e pesquisa, desde que citada a fonte.

Catalogação na publicação

Serviço de Biblioteca e Documentação

Faculdade de Economia, Administração e Contabilidade

Universidade de São Paulo

Ficha catalográfica

Elaborada pela Seção de Processamento Técnico do SBD/FEA com os dados inseridos pelo(a) autor(a)

Martins, Daiana Bragueto.

Contribuição do uso do controle gerencial para o desenvolvimento da resiliência organizacional / Daiana Bragueto Martins. - São Paulo, 2019. $222 \mathrm{p}$.

Tese (Doutorado) - Universidade de São Paulo, 2019.

Orientador: Fábio Frezatti.

Co-orientador: Tania Casado.

1. Sistema de controle gerencial. 2. Resiliência organizacional. 3. Resiliência estratégica. 4. Gestão da resiliência. 5. Survey Single Entity. I. Universidade de São Paulo. Faculdade de Economia, Administração e Contabilidade. II. Título. 

Nome: Martins, Daiana Bragueto

Título: Contribuição do uso do controle gerencial para o desenvolvimento da resiliência organizacional

Tese apresentada ao Programa de PósGraduação de Controladoria e Contabilidade do Departamento de Contabilidade e Atuária da Faculdade de Economia, Administração e Contabilidade da Universidade de São Paulo, como parte dos requisitos para obtenção do título de Doutora em Ciências.

Aprovado em:

Banca Examinadora

Prof. Dr. Fábio Frezatti

Universidade de São Paulo

Prof $^{\mathrm{a}}$. Dra . Tania Casado

Universidade de São Paulo

Prof. Dr. Carlos Eduardo Facin Lavarda

Universidade Federal de Santa Catarina

Prof $^{\mathrm{a}}$. Dra . Ilse Maria Beuren

Universidade Federal de Santa Catarina

Prof. Dr. José Carlos Tiomatsu Oyadomari

Universidade Presbiteriana Mackenzie 

Aos meus pais, Valdemir e Claudete, e ao meu irmão, Daniel, pelo apoio em todos os momentos da minha vida.

Ao Paulo, que com muito amor e companheirismo se fez presente em todos os momentos desta caminhada.

Ao meu filho Pietro quia sicut nati. 



\section{AGRADECIMENTOS}

Ao meu orientador, professor Fábio Frezatti, que por meio de suas orientações encorajou o desenvolvimento desta tese. Meu muito obrigado pelas inúmeras orientações, conselhos, contribuições e ensinamentos ao longo da minha trajetória no doutorado, tornando-se uma referência para minha vida profissional.

À minha coorientadora, professora Tania Casado, que muito enriqueceu este trabalho com o seu olhar crítico e suas contribuições, trazendo uma nova perspectiva a esta pesquisa, sendo um exemplo de pesquisadora na minha trajetória acadêmica.

Aos professores e professoras da Faculdade de Economia, Administração e Contabilidade por participarem da minha formação acadêmica ao compartilharem seus ensinamentos no decorrer de suas valiosas aulas.

Aos professores membros das bancas examinadoras que acompanharam a evolução desta pesquisa e proporcionaram discussões, críticas e contribuições acadêmicas que enriqueceram esta tese.

À empresa objeto de estudo desta pesquisa por acreditar, apoiar, intermediar, viabilizar e autorizar a realização da presente pesquisa, permitindo o acesso e incentivando a participação dos gestores.

Aos meus colegas que trilharam junto comigo as veredas da pós-graduação, Maiara Sasso, Vitor Nasu, Alan Gois, Camilla Nganga, Elise Zaro e todos que me auxiliaram e compartilharam experiencias, conhecimentos e diversos momentos de alegrias e de tristezas.

Aos colegas pesquisadores integrantes do Laboratório de Pesquisas em Práticas Gerenciais, por proporcionarem momentos enriquecedores ao compartilharem suas experiencias com pesquisa e apresentarem ricas contribuições a minha pesquisa. Em especial agradeço: Carolina Venturini, Daniel Mucci, Franciele Beck e Diógenes de Souza Bido.

Aos colegas do Departamento de Ciências Contábeis da Universidade Estadual de Londrina (UEL) pelo apoio e compreensão nesta trajetória.

À CAPES pelo apoio financeiro. O presente trabalho foi realizado com apoio da Coordenação de Aperfeiçoamento de Pessoal de Nível Superior - Brasil (CAPES) - Código de Financiamento 001.

Ao Governo do Estado do Paraná, por meio da Universidade Estadual de Londrina, que viabilizou a Licença parcial para Capacitação, permitindo o desenvolvimento da presente pesquisa.

À minha família que mesmo sentindo a minha falta em função da dedicação à esta pesquisa, lançaram olhares de carinho, compreensão e apoio incondicional. Aos meus pais, Valdemir e Claudete, e ao meu irmão, Daniel, que com muito carinho e orações sempre me apoiaram. Ao meu marido Paulo pelo amor, compreensão e presença nesta jornada. Ao meu amado filho, Pietro.

A Deus pelas bênçãos e à Mãe, Rainha e Vencedora Três Vezes Admirável de Schoenstatt pela intercessão, fontes de vida e inspiração. 

A pedra

O distraído, nela tropeçou, o bruto a usou como projétil, o empreendedor, usando-a construiu, o campônio, cansado da lida, dela fez assento.

Para os meninos foi brinquedo,

Drummond a poetizou,

Davi matou Golias...

Por fim;

o artista concebeu a mais bela escultura.

Em todos os casos, a diferença não era a pedra. Mas o homem.

Antonio Pereira (Apon) 



\section{RESUMO}

Martins, D. B. (2018). Contribuição do uso do controle gerencial para o desenvolvimento da resiliência organizacional. (Tese de Doutorado). Faculdade de Economia, Administração e Contabilidade, Universidade de São Paulo, São Paulo.

Esta tese investigou como o uso do Sistema de Controle Gerencial influencia na gestão da resiliência organizacional de uma empresa brasileira. A escolha pelo modelo teórico "Levers of Control" de Robert Simons $(1995,2000)$ está vinculada ao seu objetivo que é analisar quais são os sistemas de controle gerencial utilizados pela organização para promover a renovação da estratégia organizacional, com isto auxiliar na gestão da resiliência estratégica da organização. Desenvolveu-se um survey single entity em uma empresa do setor de comércio de derivados de petróleo, com estrutura, porte e sistema de controle gerencial demandados para a investigação. A empresa escolhida foi conveniente pois, no momento da pesquisa, estava vivenciando um momento de tensão em relação a sua estrutura e modo de funcionamento. O levantamento dos dados ocorreu a partir de um questionário enviado aos executivos de diversas áreas da organização abrangendo uma amostra de 64 gestores organizacionais. Os resultados suportam a hipótese de que o uso do sistema de controle gerencial impacta positivamente na resiliência estratégica porque permite uma visão estruturada para ação e reação das organizações. Observou-se que elevados níveis do uso do sistema de controle gerencial nas formas de sistemas de crenças, restrições, uso diagnóstico e uso interativo aumentam a capacidade da organização para a resiliência ao atuarem de forma proativa, com visão estratégica frente às adversidades do cenário empresarial, proporcionando a renovação da estratégica proposta por Simons (1995). Dentre as contribuições da pesquisa, destacam-se: (i) a discussão sobre o sistema de controle gerencial sob o prisma das alavancas de controle gerencial de Simons $(1995,2000)$ no cenário nacional e sua associação com a teoria da resiliência organizacional; (ii) o desenvolvimento e a validação de uma ferramenta para mensurar resiliência estratégica no nível empresarial; e (iii) do ponto de vista prático, este estudo auxilia os gerentes a decidirem qual padrão de controle melhor se adequa às circunstâncias em que operam e aos seus desafios estratégicos, contribuindo para a compreensão de como o uso do sistema de controle gerencial impacta a resiliência no ambiente organizacional.

Palavras-chave: Resiliência organizacional. Sistema de controle gerencial. Survey Single Entity. Gestão da resiliência. Resiliência estratégica. 



\begin{abstract}
Martins, D. B. (2018). Contribution of the use of management control to the development of organizational resilience. (Tese de Doutorado). Faculdade de Economia, Administração e Contabilidade, Universidade de São Paulo, São Paulo.
\end{abstract}

This Ph.D. dissertation investigated how the use of the Management Control System influences in the management of organizational resilience in a Brazilian company. The choice by the theoretical model named "Levers of Control" by Robert Simons $(1995,2000)$ is linked to its purpose to analyze which are the management control systems used by the organization to provide the strategic renewal and helping with the organization's strategic resilience management. A survey single entity developed in a Brazilian oil derivative trading company with structure, size and management control system required for the research. The chosen company was convenient because, at the time of the research, it was experiencing a moment of tension in relation to its structure and mode of operation. The data were collected based on a questionnaire sent to executives from different departments, covering a sample of 64 organizational managers. The results support the hypothesis that the use of the management control system has a positive impact on the strategic resilience because it allows a structured view for organizations' action and reaction. Thus, it was observed that high levels of the use of the management control system in the forms of beliefs systems, boundary systems, diagnostic control system and interactive control system increase the organization's capacity for resilience by acting in a proactive way, with strategic vision facing the business context's adversities, providing the strategic renewal proposed by Simons (1995). Among the research contributions, the following stand out: (i) the theoretical discussion about the Management Control System through the prism of Levers of Control by Simons $(1995,2000)$ in the national scenario, and its association with the organizational resilience theory; (ii) the development and validation of a tool to measure strategic resilience at the organizational level; and (iii) the practical point of view, this research helps managers to decide which pattern of control best fits the circumstances in which they operate and their strategic challenges, contribute to understanding how the use of management control system impacts on the resilience in the organizational environment.

Keywords: Organizational resilience. Management control system. Survey Single Entity. Resilience management. Strategic resilience 



\section{LISTA DE FIGURAS}

Figura 2.1 - Área de concentração das pesquisas acadêmicas internacionais sobre resiliência ............ 19

Figura 2.2 - Resiliência Organizacional: da abordagem tradicional à resiliência estratégica ............... 23

Figura 2.3 - Conceitos apresentados às variáveis de Resiliência Organizacional ................................ 31

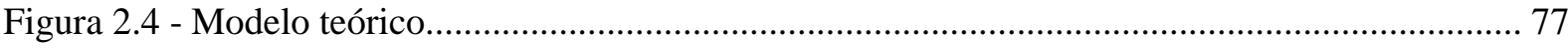

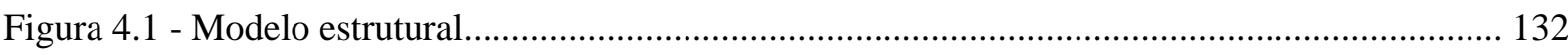

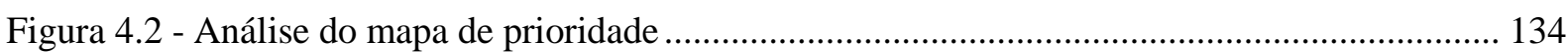





\section{LISTA DE GRÁFICOS}

Gráfico 3.1 - Representação da população pelo vínculo empresarial ................................................... 91

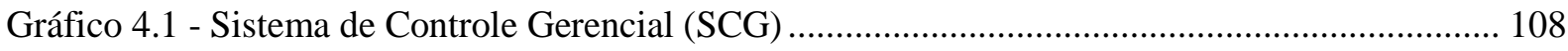

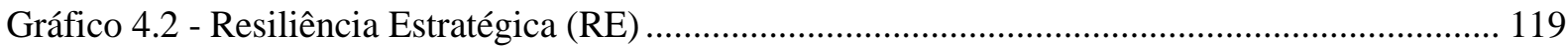

Gráfico 4.3 - Mapa de prioridade no nível do constructo ……........................................................... 135

Gráfico 4.4 - Mapa de prioridade no nível dos indicadores .............................................................. 137 



\section{LISTA DE QUADROS}

Quadro 2.1 - Escala de maturidade de resiliência organizacional.......................................................... 25

Quadro 2.2 - Quadro teórico-empírico do Organisation Resilience Benchmark ................................. 32

Quadro 2.3 - Framework “Organizational Resilience Capacity” ....................................................... 36

Quadro 2.4 - Conceitos apresentados às variáveis de Resiliência Estratégica ...................................... 38

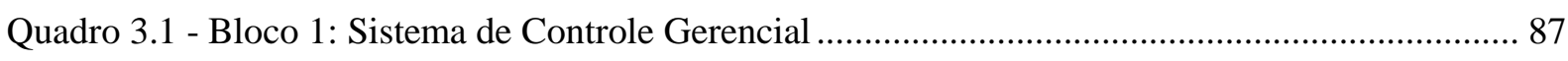

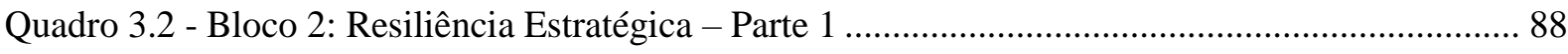

Quadro 3.3 - Bloco 2: Resiliência Estratégica - Parte 2 ..................................................................... 89

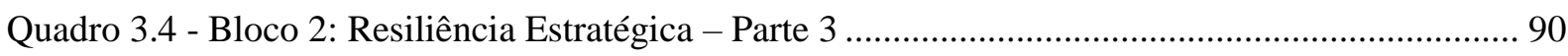

Quadro 4.1 - Indicadores formativos da variável latente de viés do método (MLMV)..................... 131 



\section{LISTA DE TABELAS}

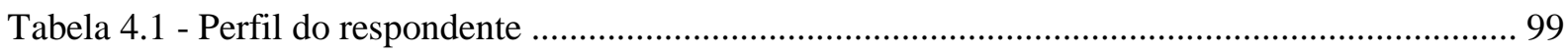

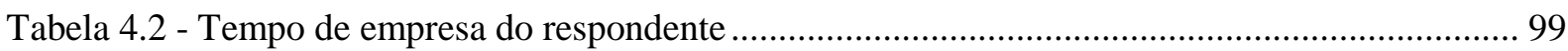

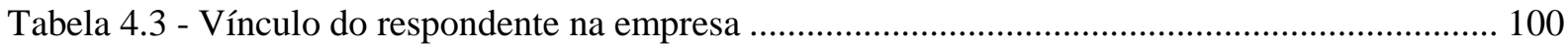

Tabela 4.4 - Análise descritiva do Sistema de Crenças (SC) ............................................................... 102

Tabela 4.5 - Análise descritiva do Sistema de Restrições (SR) ........................................................ 103

Tabela 4.6 - Análise descritiva do Uso do Diagnóstico do Sistema de Controle Gerencial (SD)....... 105

Tabela 4.7 - Análise descritiva do Uso Interativo do Sistema de Controle Gerencial (SI) ................. 106

Tabela 4.8 - Análise descritiva das alavancas de controle ................................................................ 106

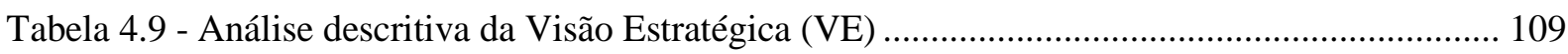

Tabela 4.10 - Análise descritiva da Postura Proativa (PP) ............................................................ 111

Tabela 4.11 - Análise descritiva da Aprendizagem Organizacional (AO) ........................................ 112

Tabela 4.12 - Análise descritiva da Comunicação Organizacional (CO)............................................ 113

Tabela 4.13 - Análise descritiva da Inovação e Criatividade (IC) ...................................................... 114

Tabela 4.14 - Análise descritiva da Autonomia na Tomada de Decisão (TD) .................................... 114

Tabela 4.15 - Análise descritiva da Liderança (LD) ....................................................................... 115

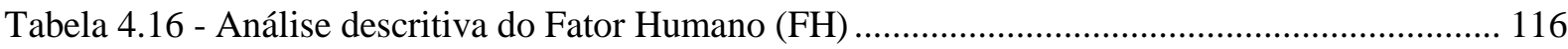

Tabela 4.17 - Análise descritiva da Parceria Eficaz (PE) ...................................................................... 117

Tabela 4.18 - Análise descritiva dos Recursos Disponíveis (RD)...................................................... 117

Tabela 4.19 - Análise descritiva da Resiliência Estratégica............................................................. 118

Tabela 4.20 - Matriz de Cargas Fatoriais representando os fatores do constructo Sistema de Controle Gerencial e seus respectivos itens de mensuração (variáveis).

Tabela 4.21 - Matriz de Cargas Fatoriais representando os fatores do constructo Resiliência Estratégica e seus respectivos itens de mensuração (variáveis) - Parte 1.

Tabela 4.22 - Matriz de Cargas Fatoriais representando os fatores do constructo Resiliência Estratégica e seus respectivos itens de mensuração (variáveis) - Parte 2

Tabela 4.23 - Matriz de correlações com os constructos de primeira ordem ....................................... 125

Tabela 4.24 - Matriz de correlações com os constructos de segunda ordem ...................................... 129 



\section{SUMÁRIO}

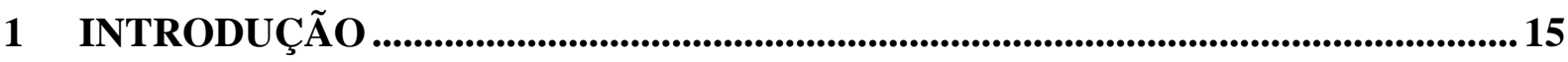

2 MARCO TEÓRICO E REVISÃO DA LITERATURA ............................................. 19

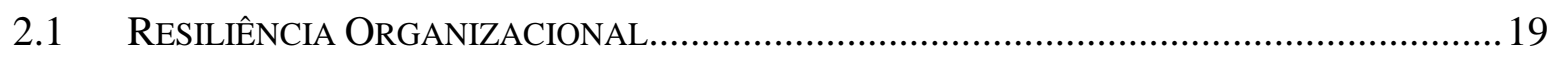

2.1.1 Resiliência: origem e áreas de pesquisa ....................................................... 19

2.1.2 Conceito de Resiliência Organizacional ............................................................. 20

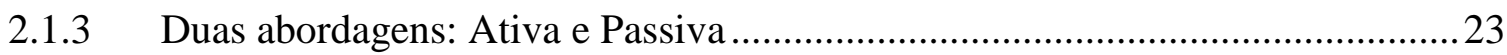

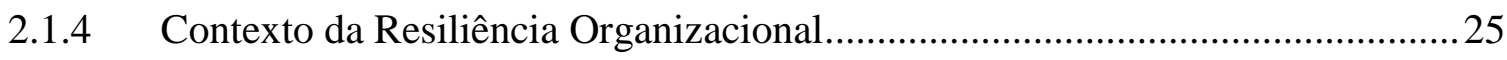

2.1.5 Resiliência Organizacional: a literatura.......................................................26

2.1.6 Implementação, aperfeiçoamento e mensuração da Resiliência Organizacional29

2.1.6.1 Organisation Resilience Benchmark Framework ........................................... 30

2.1.6.2 Capacidade da Organização para a Resiliência ............................................. 33

2.1.6.3 Resiliência Organizacional sob a Perspectiva Estratégica ............................. 36

2.1.7 Modelo para Resiliência Estratégica .................................................................. 38

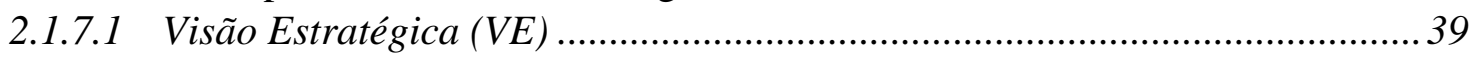

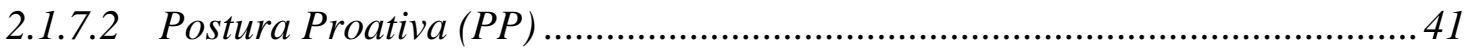

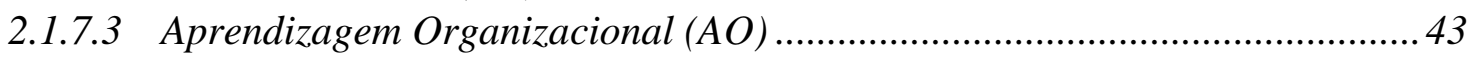

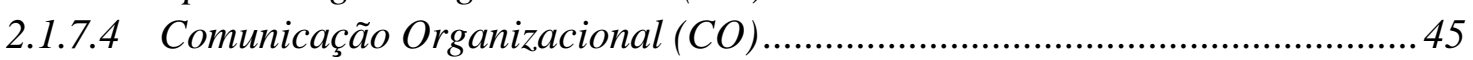

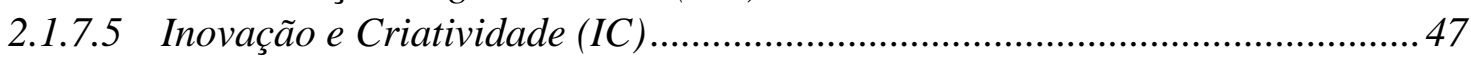

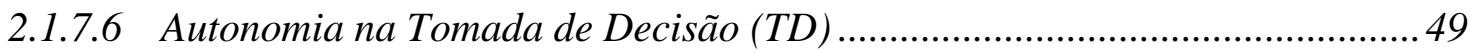

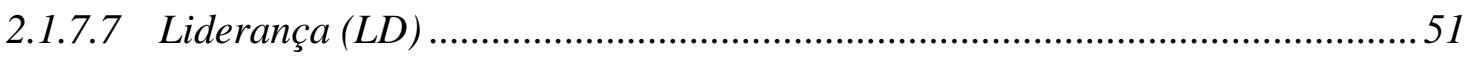

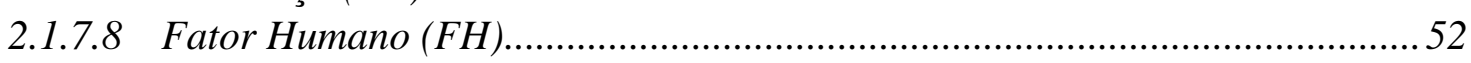

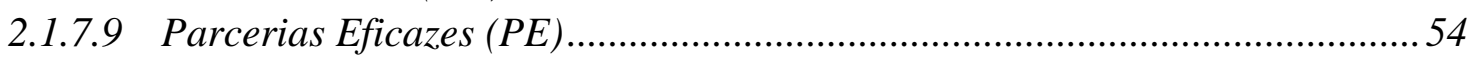

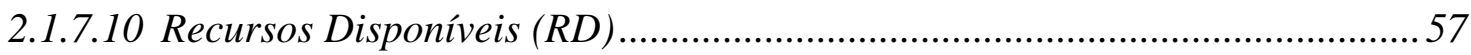

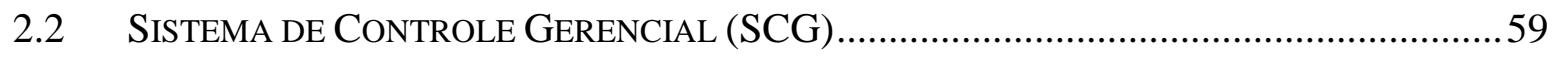

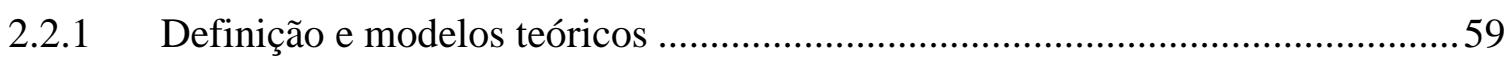

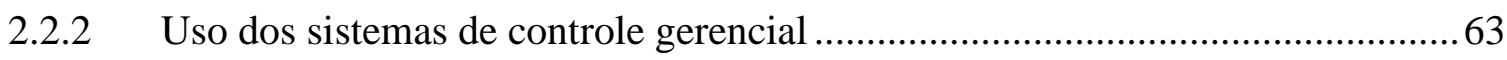

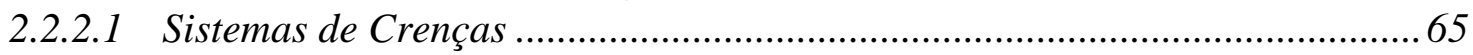

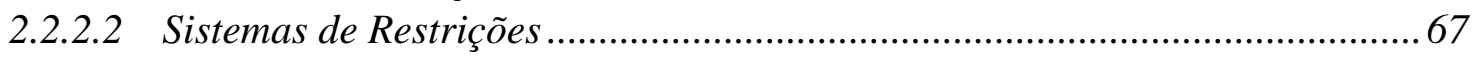

2.2.2.3 Uso Diagnóstico dos Sistemas de Controle Gerencial ................................... 70

2.2.2.4 Uso Interativo dos Sistemas de Controle Gerencial...................................... 71

2.3 DESENVOLVIMENTO DA HiPóTESE E do MOdELO TEÓRICO........................................ 74

3 PROCEDIMENTOS METODOLÓGICOS ................................................................ 79

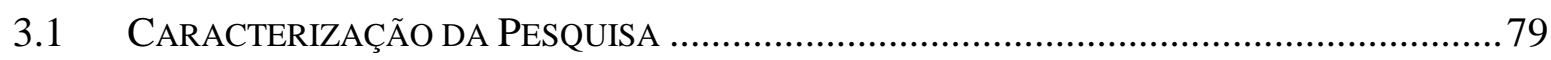

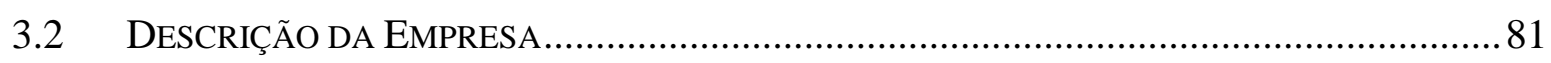

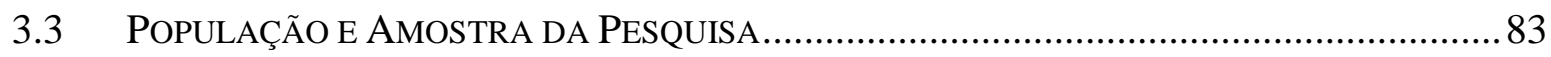

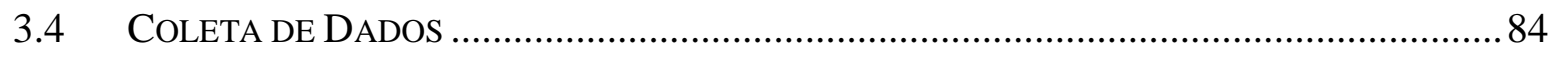

3.4.1 Questionário - Instrumento de coleta de dados .................................................. 84

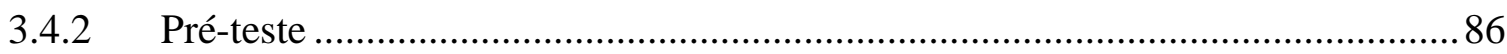

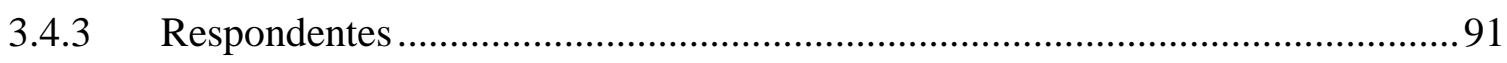

3.4.4 Implementação do survey (processo de aplicação do questionário) .................... 93 


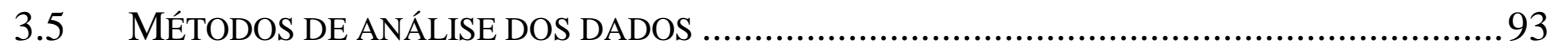

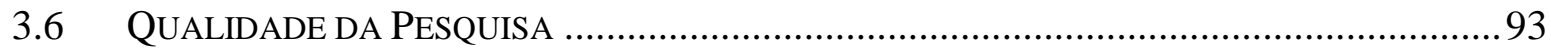

4 TRATAMENTO E ANÁLISE DOS RESULTADOS .................................................... 97

4.1 CARACTERIZAÇÃO DA AMOSTRA E DOS RESPONDENTES ….......................................98

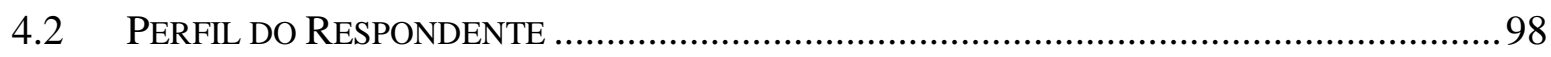

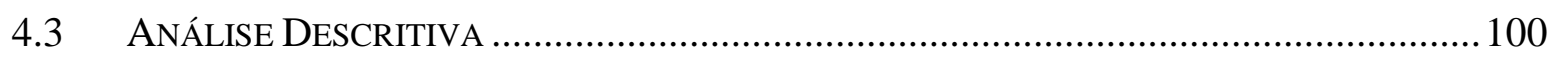

4.3.1 Análise Descritiva do Sistema de Controle Gerencial......................................100

4.3.2 Análise Descritiva da Resiliência Estratégica ................................................ 109

4.4 ANÁLISE do ModELO DE MENSURAÇÃo ........................................................... 120

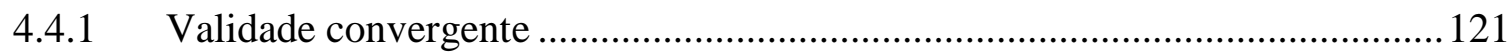

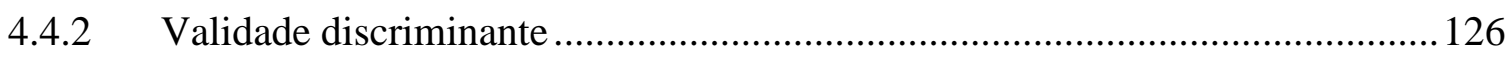

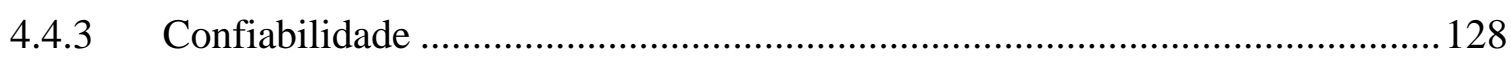

4.4.4 Avaliação da mensuração no nível das variáveis latentes de $2^{\mathrm{a}}$ ordem.............129

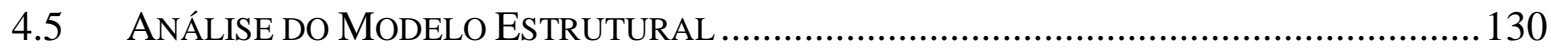

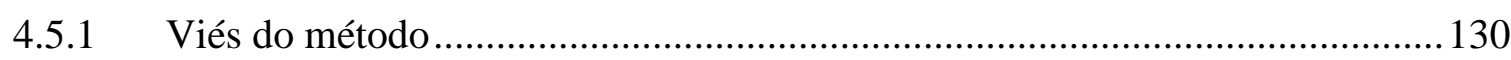

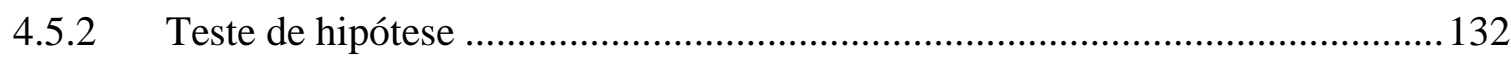

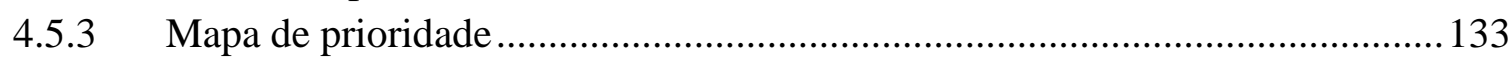

5 DISCUSSÃO DOS RESULTADOS E CONCLUSÕES ........................................... 141

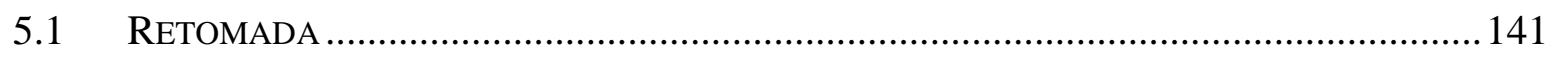

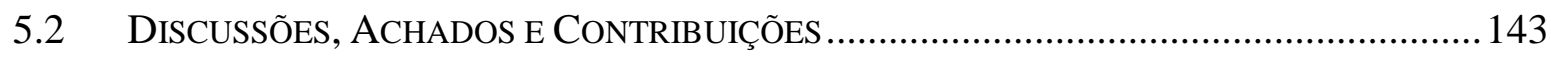

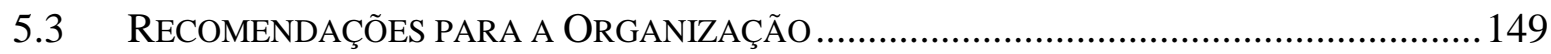

5.4 LiMITAÇÕES E SUGESTÕES PARA FUTURAS PESQUISAS ......................................... 151

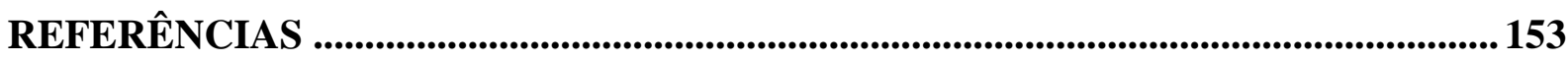

APÊNDICE A - O PROTOCOLO ÉTICO ...................................................................... 177

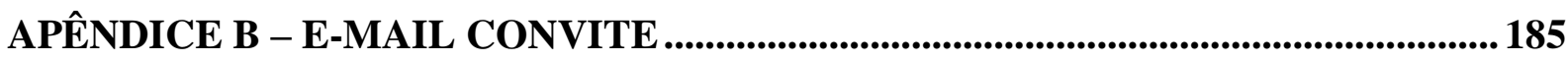

APÊNDICE C - LEMBRETES .......................................................................... 189

APÊNDICE D - MODELO ESTRUTURAL SmartPLS .............................................. 197

APÊNDICE E - RELATÓRIO EMITIDO PELO SmartPLS ............................................ 203

APÊNDICE F - QUESTIONÁRIO .................................................................................. 207 


\section{INTRODUÇÃO}

O ambiente de negócios está em constante mutação e gerir a mudança, adaptar-se ao futuro incerto são desafios que requerem, das empresas, resiliência (Hamel \& Välikangas, 2003). Isto é, que as empresas desenvolvam a capacidade de sobreviver, adaptar-se e de sustentar o negócio em face das mudanças. Os sistemas de controle gerencial são relevantes para a continuidade das atividades organizacionais à medida que direcionam as estratégias adotadas pelas organizações (Berry, Broadbent, \& Otley, 2005).

Observa-se que o tema resiliência, oriundo da física, tem crescido nos últimos anos dentro do cenário da teoria organizacional, principalmente em pesquisas acadêmicas na área das ciências sociais com ênfase em estudos da resiliência estratégica e da resiliência organizacional como mostram os trabalhos de Annarelli e Nonino (2016) e de Hosseini, Barker e Ramirez-Marquez (2016). Nota-se que as pesquisas de Acquaah, Amoako-Gyampah e Jayaram (2011), Lengnick-Hall, Beck e Lengnick-Hall (2011), Livramento, Oliveira e Moraes (2015), Meneghel, Salanova e Martínez (2013), Teixeira e Werther Junior (2013), entre outros, investigaram práticas gerenciais sob a luz da resiliência. Assim sendo, o estímulo desta pesquisa em trazer a temática da resiliência para as discussões na área de controle gerencial, tanto no âmbito empresarial quanto no acadêmico, está em promover o fortalecimento da gestão empresarial e garantir que as metas organizacionais sejam alcançadas, especialmente, em situações de adversidades.

O tema resiliência traz como motivação o estudo sobre à capacidade das organizações de recuperar-se perante problemas e dificuldades, pois uma organização resiliente é capaz de atingir seus objetivos em face das adversidades e, ao mesmo tempo, reduzir a vulnerabilidade e desenvolver a capacidade adaptativa, isto é, a empresa aumenta a velocidade para gerir eficazmente os problemas e os incidentes críticos presentes e futuros, pois, em um ambiente competitivo, uma organização que tem ciência dos seus pontos fortes de resiliência é mais equipada para encontrar oportunidades fora de uma situação de adversidade. De acordo com Starr, Newfrock e Delurey (2003), isto é possível à medida que a organização alinha sua estratégia aos sistemas de controle gerencial.

Esta pesquisa visa verificar a existência ou não da associação entre o sistema de controle gerencial e a resiliência estratégica da organização estudada, tendo em vista que o sistema de controle gerencial é fundamental para a continuação das atividades empresariais e para o desenvolvimento de rotinas e de processos apropriados para promover a resiliência organizacional em ambientes incertos. Nesta tese, argumenta-se que estas capacidades e rotinas 
organizacionais, por sua vez, derivam de combinação de elementos de resiliência que são sistematicamente desenvolvidos e integrados por meio do sistema de controle gerencial de uma empresa.

Visualizou-se a possibilidade de realizar uma investigação acadêmica na contabilidade gerencial sob o prisma do modelo teórico "Levers of Control” de Robert Simons (1995, 2000), cujo propósito é analisar quais são os mecanismos do sistema de controle gerencial utilizados para implementar e controlar a estratégia organizacional. E, assim, entender como os gestores controlam a estratégia utilizando os quatro níveis de controle: sistema de crenças, sistema de restrições, sistema de diagnóstico e sistema interativo.

Com intuito de promover pesquisa no meio acadêmico que tenha consonância com as atividades organizacionais que emergem das empresas no tocante ao sistema de controle gerencial, este estudo tem por desafio responder à seguinte questão de pesquisa: o uso do sistema de controle gerencial contribui para o desenvolvimento da resiliência organizacional de uma empresa brasileira?

O objetivo desta pesquisa é investigar como o uso do sistema de controle gerencial influencia na gestão da resiliência estratégica de uma empresa brasileira. Para alcançar o objetivo geral, esta investigação compreende os objetivos específicos a seguir:

- $\quad$ propor modelo para a percepção de oportunidades para a resiliência estratégica;

- averiguar como os sistemas de controle gerencial são utilizados pela organização no processo de tomada de decisão de acordo com o framework "Levers of Control";

- identificar qual é o nível de resiliência presente na empresa investigada no momento da pesquisa; e

- proporcionar um diagnóstico do papel que os sistemas de controle gerencial da organização assumem no processo de desenvolvimento da capacidade da empresa para a resiliência.

Entretanto, existe na literatura uma lacuna que é a ausência de investigações que relacionem o conjunto de elementos do controle gerencial e a capacidade de resiliência das empresas. Encontrou-se, na pesquisa de Davila e Foster (2008), a resiliência como uma das características do uso de controle gerencial, ao passo que descrevem como os elementos de controle promovem nas organizações direcionamento para que elas sejam capazes de se adaptar aos eventos inesperados. Porém, não se encontraram evidências empíricas que comprovem o poder do uso do sistema de controle gerencial em alavancar o nível de resiliência das 
organizações. Faz-se necessário compreender o papel do sistema de controle gerencial na gestão da resiliência estratégica.

Esta pesquisadora detectou a oportunidade de investigar um caso empírico que contempla uma empresa brasileira que atua no setor de estocagem, engarrafamento, transporte, distribuição e comércio de derivados de petróleo que, no momento da pesquisa, estava se preparando para adentrar em um processo de mudança na sua estrutura e modo de funcionamento. No decorrer da pesquisa, a empresa havia anunciado a sua decisão e estava aguardando autorização junto ao Conselho Administrativo de Defesa Econômica (CADE), cujo processo estava em fase de análise. Em função da sua atuação em vinte e três estados com uma das maiores redes de comercialização e distribuição do produto A no país, a empresa atua com mais de três mil funcionários e está entre as primeiras no Market-share com mais de $22 \%$ do mercado brasileiro. Além de a empresa possuir diversos prêmios em relação à qualidade de sua gestão, nas visitas técnicas foi possível observar que possui sistema de controle gerencial. Assim, tem-se nesta tese como premissa que a empresa investigada possui sistema de controle gerencial e espera-se que a empresa apresente um determinado nível de resiliência organizacional, pois atua no cenário nacional há mais de 60 anos.

Esta pesquisa é inovadora ao ter como tese a proposta de relacionar o uso dos sistemas de controle gerencial com o desenvolvimento da resiliência estratégica e, desta forma, auxiliar a empresa a desenvolver estratégias para aumentar o seu nível de resiliência de modo a sobreviver e prosperar no ambiente competitivo. A relevância deste trabalho está em investigar como o uso dos mecanismos do sistema de controle gerencial faz interface com a resiliência organizacional e, também, no apoio às mudanças estratégicas.

Além de estar alinhada com a agenda de pesquisa desenvolvida junto ao Laboratório de Pesquisa sobre Práticas Gerenciais da Faculdade de Economia, Administração e Contabilidade da Universidade de São Paulo (FEAUSP), o presente trabalho tem como intuito promover a investigação no meio acadêmico que esteja vinculada com as atividades empresariais que emergem no contexto corporativo brasileiro no tocante ao sistema de controle gerencial.

A principal contribuição da presente pesquisa à empresa investigada neste estudo é a identificação dos impactos dos elementos de controle gerencial sobre a resiliência, que é de extrema relevância para legitimar a identificação e a utilização destes elementos. A pesquisa utilizou a percepção e a experiência dos gestores organizacionais para identificar como a empresa utiliza os sistemas de controle gerencial e, também, para mapear as iniciativas estratégicas utilizadas na redução das adversidades presentes e futuras oriundas do ambiente competitivo que promovem o desenvolvimento da resiliência organizacional, de modo, a 
proporcionar uma reflexão sobre cada área da organização, apresentando o grau de resiliência que a empresa possui no ato da investigação e identificando qual das áreas possui maior nível de resiliência.

A contribuição teórica desta pesquisa ocorreu por meio da extensão dos estudos envolvendo sistemas de controle gerencial, visto que o presente trabalho proporcionou, através da lente da teoria da resiliência organizacional, um modelo emergente que poderá ser utilizado para mensurar, comparar e identificar benchmark em um determinado departamento dentro da organização. Espera-se que a ferramenta desenvolvida nesta pesquisa possa auxiliar outras organizações a mensurar a forma como operacionalizam a resiliência organizacional por meio dos sistemas de controle gerencial.

Os resultados da presente pesquisa visam abordar lacunas na literatura, particularmente aquelas relacionadas ao uso dos sistemas de controle gerencial no cenário brasileiro. No tocante à resiliência organizacional, ainda são incipientes as pesquisas na área de contabilidade, tanto no cenário nacional quanto internacional. Do ponto de vista prático, este estudo contribui ao mostrar a interdependência e o entrelaçamento das quatro alavancas de controle gerencial propostas por Simons $(1995,2000)$ com os elementos de resiliência organizacional e entender como o uso dos sistemas de controle gerencial alavancam a resiliência organizacional, de modo que os gerentes possam decidir qual padrão de controle melhor se adequa às circunstâncias em que operam e aos seus desafios estratégicos.

A tese está estruturada em cinco capítulos a contar da introdução que contempla as diretrizes da pesquisa. O segundo capítulo é composto pelo marco teórico, revisão da literatura e o desenvolvimento da hipótese da presente tese. Este subdivide-se em dois subitens: resiliência organizacional e sistema de controle gerencial. Os procedimentos metodológicos estão descritos no terceiro capítulo, bem como o tipo de pesquisa, as características da empresa investigada na pesquisa de campo, o método aplicado, o instrumento para coleta de dados e os procedimentos utilizados para tratamento estatístico destes dados. No quarto capítulo apresentam-se a descrição da pesquisa empírica, a análise e o tratamento estatístico dos dados. O capítulo cinco contempla a discussão dos resultados evidenciados por meio da pesquisa empírica, a reflexão crítica sobre as descobertas e as considerações finais com ênfase na discussão da hipótese, verificando-se a sua confirmação ou refutação; resgata-se o objetivo da pesquisa; e contemplam-se as limitações da presente pesquisa e as recomendações para as futuras investigações. Por fim, foram elencadas as obras que alicerçaram esta pesquisa, assim como são apresentados os anexos e apêndices. 


\section{MARCO TEÓRICO E REVISÃO DA LITERATURA}

\subsection{ResilitînCIA OrganizaCIONAL}

\subsubsection{Resiliência: origem e áreas de pesquisa}

O termo resiliência tem origem no latim do verbo "resilire" que significa "voltar ao estado natural". Cabe destacar que, no âmbito científico, o termo apresenta uma característica multidisciplinar, o qual foi empregado primeiramente pela Física e pela Engenharia, expandiuse para outras áreas como a Educação, a Sociologia, a Psicologia, a Matemática, a Ecologia e a Administração (Hosseini, Barker, \& Ramirez-Marquez, 2016; Yunes, 2003).

A pesquisa de Hosseini et al. (2016) apresenta um panorama das pesquisas em resiliência em que se pode observar, conforme ilustrado na Figura 2.1, que ainda é incipiente na área da Contabilidade. No entanto, nota-se que, com menor intensidade do que nas áreas de conhecimento envolvendo a psicologia e a ecologia, há pesquisas em áreas correlatas como a área de negócios, administração, ciências sociais e economia.

Figura 2.1 - Área de concentração das pesquisas acadêmicas internacionais sobre resiliência

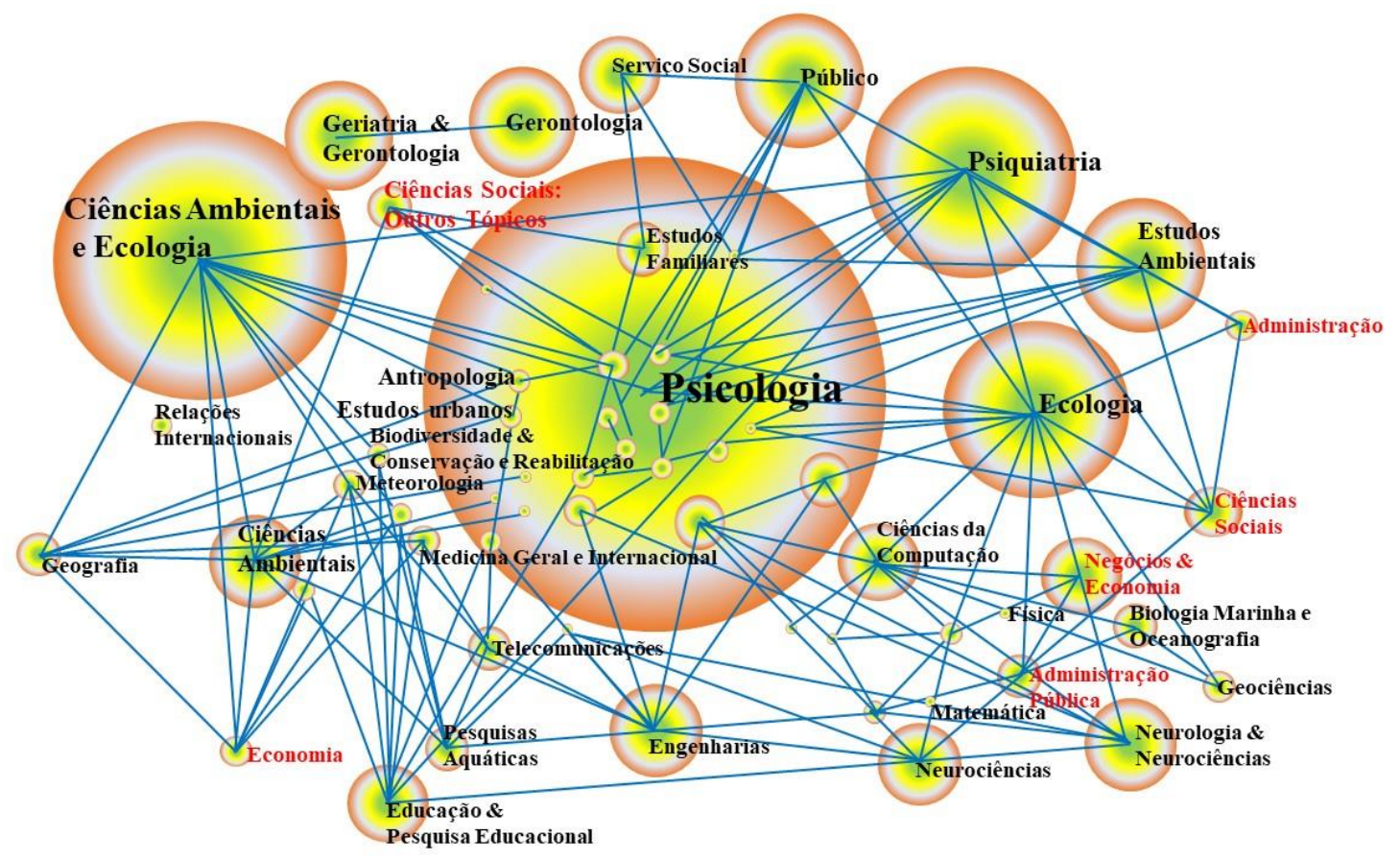

Fonte: Traduzida e adaptada de Hosseini et al. (2016, p. 50). 
Linnenluecke (2017) mostra que a origem do conceito de resiliência na literatura de business and management surge no final da década de 1980 com as pesquisas de Staw, Sandelands e Dutton (1981) e Meyer (1982) que investigaram como as organizações respondem às ameaças externas, tendo em vista que tais ameaças colocam automaticamente uma organização em risco. Apontam ainda que, quando os indivíduos, grupos e organizações enfrentam a adversidade, enfatizam respostas a estas situações que já foram vivenciadas e aprendidas, mostrando domínio da situação ao invés de serem resilientes mostrando flexibilidade e capacidade adaptativa a tal ocorrência.

A principal contribuição das pesquisas de Staw et al. (1981) e Meyer (1982) está em observar de que forma as organizações respondem as ameaças externas desencadeando processos organizacionais que ora são bem-sucedidos ora não, influenciando o posicionamento estratégico de uma organização, bem como a sua sobrevivência. A pesquisa realizada por Meyer (1982) foi pioneira na literatura de business and management ao utilizar os termos "resiliência" nos estudos organizacionais e ao empregar o termo "resiliência da organização", tendo em vista que em sua pesquisa foram testadas "a integridade e a resiliência das estruturas organizacionais" (Meyer, 1982, p. 516).

\subsubsection{Conceito de Resiliência Organizacional}

Entre os conceitos de resiliência organizacional destaca-se o de Hamel e Välikangas (2003) que a definem como a necessidade de as entidades responderem a um ambiente empresarial de mudanças constantes e rápidas. Para Whitehorn (2011), a resiliência implica na capacidade e na vontade de se adaptar às mudanças ao longo do tempo, especialmente em ambiente ameaçador. Nesta perspectiva, o conceito de resiliência abarca a sensibilização, a antecipação, a detecção, a comunicação, a proatividade, a recuperação e a adaptabilidade. Corrobora com a percepção, Somers (2009) e Bhamra, Dani e Burnard (2011) ao definirem a resiliência organizacional como: as medidas proativas para mitigação das ameaças e voltadas para o futuro da organização.

Para Brown, Seville e Vargo (2014, p. v), a resiliência organizacional é definida como "a habilidade de sobreviver a uma crise e prosperar em um mundo de incertezas". LengnickHall et al. (2011) definem a resiliência organizacional como a habilidade das organizações de perceber, evitar, absorver, responder, adaptar-se e recuperar-se de situações que possam ameaçar a sua existência. Assim, observa-se que a resiliência oferece a possibilidade de a empresa possuir uma estratégia que seja intuitivamente plausível e atraente, de modo a auxiliar 
as organizações a lidar com os vários tipos de adversidades (Boin \& van Eeten, 2013). Ou seja, a resiliência organizacional consiste "num conjunto de rotinas que permite à organização se recuperar da adversidade e dos obstáculos, como também, criar novas oportunidades para ir além do ponto de equilíbrio inicial”' (Lengnick-Hall, Beck, \& Lengnick-Hall, 2011, p. 251). Tal fato é apresentado por Sutcliffe e Vogus (2003) ao afirmarem que a resiliência organizacional se baseia em processos e recursos focados no desenvolvimento da competência e no crescimento da organização, isto contempla a capacidade de restaurar a eficácia, de processar eficazmente ofeedback ambiental, reorganizar e transferir com flexibilidade os conhecimentos e os recursos para superar uma adversidade.

Starr et al. (2003) enfatizam que uma empresa resiliente é aquela que possui a habilidade e a capacidade para suportar descontinuidades sistêmicas e se adaptar a novos ambientes de risco. Segundo Lengnick-Hall et al. (2011), as organizações resilientes são aquelas que prosperam apesar de enfrentarem condições que são surpreendentemente incertas, frequentemente adversas e geralmente instáveis. Para Vogus e Sutcliffe (2007), a resiliência está ancorada em processos organizacionais destinados a reforçar a competência global da organização, especialmente a capacidade de aprender com os erros. A resiliência é desencadeada por um acontecimento inesperado e incorpora renovação, transformação e criatividade dinâmica da empresa de dentro para fora (Lengnick-Hall et al., 2011). Nascimento (2014, p. 184) afirma que:

\footnotetext{
uma empresa tem resiliência quando ela é afetada por uma ruptura (situação de crise) e consegue se recuperar, retornando ao seu estado anterior de performance, no menor tempo possível e com menores danos a sua operação, serviço e nível de serviço. Não se trata da capacidade de se recuperar apenas de eventos de grande impacto (terremoto, ataque terrorista, enchentes). Cada empresa tem seu estado crítico que pode ser a falha na entrega de um fornecedor-chave, greve de trabalhadores, ou falha na importação, e a empresa necessitará enfrentar e recuperar-se desses problemas diários.
}

Por outro lado, observa-se que, na pesquisa de Teixeira e Werther Junior (2013), a discussão sobre resiliência organizacional está relacionada com quatro elementos do ambiente interno das organizações: liderança, cultura organizacional, planejamento estratégico e inovação. Com base nas variáveis que impactam a resiliência organizacional, observa-se que o medo do fracasso determina as variáveis críticas de desempenho cujos fatores estão relacionados com a dinâmica competitiva do negócio e são suficientes para fazer com que a estratégia não obtenha sucesso. Dependendo da organização, estes fatores podem estar relacionados com as necessidades dos clientes, com a implementação de novas tecnologias, 
com a construção de novas competências ou com a habilidade para acessar novos mercados (Simons, 2000, p.234).

Hamel e Välikangas (2003) apontam que o impacto da resiliência no modelo de negócios de uma organização passa por quatro desafios: (i) o desafio cognitivo, que se refere ao fato de a organização estar consciente da mudança, à medida que utiliza os controles internos para observar os comportamentos e os eventos que apresentam maior risco ao seu negócio; (ii) no desafio estratégico, a resiliência requer da organização a capacidade de elaborar uma vasta gama de novas alternativas que sejam atraentes perante as estratégias existentes, ou seja, neste quesito é necessário que a empresa possua um sistema de gestão estratégica; (iii) o desafio político, que compreende a capacidade da organização para realocar recursos de programas anteriores para os novos planos à proporção que estes sejam alinhados com o seu sistema de crença, isto é, aos objetivos, à missão e aos valores da organização; e (iv) o desafio ideológico visa promover a otimização dos resultados no sentido de a organização direcionar-se de forma contínua e orientada às oportunidades.

Langvardt (2007) afirma que um dos grandes motivos para o fracasso das organizações, ao gerenciar a mudança organizacional, refere-se à escolha entre consertar ou reinventar o modelo de negócios. Segundo Hamel e Välikangas (2003), as organizações devem ser capazes de reinventar seus modelos de negócios antes que as circunstâncias se encarreguem de fazê-lo. Os autores defendem que a resiliência não se contrapõe às adversidades pontuais ou perdas momentâneas, mas sim à capacidade da empresa de antecipar-se às mudanças com intuito de evitar que tais riscos ambientais afetem seus negócios.

A Figura 2.2, a seguir, mostra as duas perspectivas da resiliência organizacional, a tradicional e a estratégica. Nesta pesquisa foi adotada a resiliência estratégica no nível organizacional, isto é, investiga-se a capacidade da organização de adaptar-se, ser flexível e recuperar-se de problemas diários. 
Figura 2.2 - Resiliência Organizacional: da abordagem tradicional à resiliência estratégica

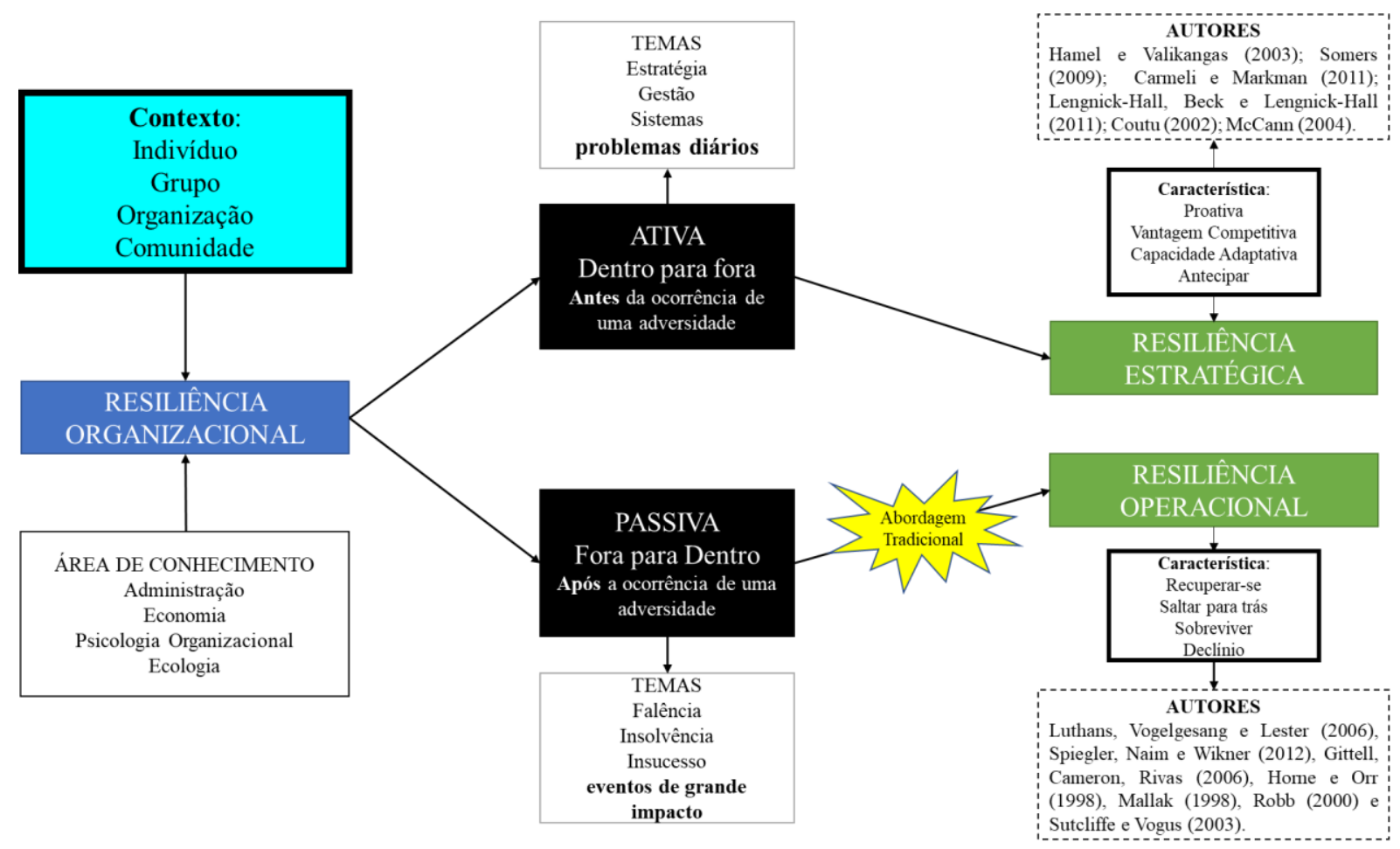

Fonte: Elaborada pela autora.

\subsubsection{Duas abordagens: Ativa e Passiva}

A literatura oferece duas perspectivas diferentes sobre o que significa resiliência organizacional, sendo elas: a resiliência organizacional ativa e a resiliência organizacional passiva (Lengnick-Hall et al., 2011; Sawalha, 2015; Somers, 2009; Pasteur, 2011).

A resiliência organizacional ativa ocorre nas organizações antes de uma adversidade e remete ao esforço deliberado da organização para tornar-se mais capacitada para lidar com adversidades futuras. Trata-se de identificar potenciais riscos, desenvolver sistemas de alerta precoce e tomar medidas proativas. O objetivo está na capacidade que a organização apresenta de gerenciar o mercado e agir proativamente de modo a antecipar-se perante as adversidades à medida que alterna suas estratégias permitindo que aproveite as oportunidades, maximize os ganhos e minimize os problemas (Nascimento, 2014; Lengnick-Hall \& Beck, 2009; LengnickHall et al., 2011). Corroborando, Akgün e Keskin (2014) afirmam que estas medidas proativas garantem o crescimento da empresa em face da adversidade. No entendimento de LengnickHall et al. (2011), nesta abordagem, a resiliência organizacional está vinculada à vantagem competitiva e à capacidade adaptativa da empresa de absorver a complexidade, à medida que permite à empresa o desenvolvimento de novas capacidades, e de alavancar seus recursos não 
apenas para resolver dilemas atuais, mas para explorar novas oportunidades e construir um futuro bem-sucedido. Salgado (2013, p. 23) afirma que esta vertente da resiliência organizacional apresenta a capacidade da organização de adaptar-se e ser flexível às mudanças como forma de manter a vantagem competitiva, apresentando uma abordagem de dentro para fora. Complementando, Seeger, Ulmer e Novak (2005) também argumentaram que a resiliência proporciona uma orientação prática e prospectiva para o futuro, ao invés de uma atitude defensiva em que a empresa fica justificando e defendendo suas ações passadas. Entre os autores desta abordagem, destacam-se: Hamel e Välikangas (2003), Lengnick Hall e Beck (2005), Somers (2009), Carmeli e Markman (2011), Lengnick-Hall et al. (2011), Coutu (2002), Freeman, Hirschhorn e Maltz (2004) e McCann (2004).

A segunda perspectiva é denominada de resiliência organizacional passiva e ocorre nas organizações após um incidente e está ligada à habilidade com que a organização entende a situação e se recupera, refletindo a rapidez com que uma organização retorna ao normal sem incorrer em grandes perdas, danos ou descontinuidade, conectado a origem do primeiro conceito de resiliência, a capacidade de "saltar para trás" após uma crise ou desastre, ou seja, a habilidade de uma organização de se recuperar de situações inesperadas, estressantes e adversas e de retornar a um estado estável depois de uma interrupção. Na percepção de Salgado (2013, p. 23), esta vertente da resiliência organizacional apresenta a identificação e a recuperação de riscos de forma a diminuir a vulnerabilidade da organização, numa abordagem de fora para dentro, ou seja, é a avaliação ou o próprio contexto externo que origina um comportamento na organização. Na perspectiva passiva, a resiliência organizacional, segundo Akgün e Keskin (2014), é influenciada pelas discussões realizadas na física, na engenharia, bem como pela psicologia positiva.

Para Lengnick-Hall et al. (2011), nesta abordagem, a

ênfase é geralmente em estratégias de enfrentamento e uma rápida capacidade de retomar os níveis de desempenho esperado. Os esforços organizacionais visam reestabelecer um forte vínculo entre a empresa e uma nova realidade, ao mesmo tempo que evitam ou limitam comportamentos disfuncionais ou regressivos. (Lengnick-Hall et al., 2011, p. 244).

Entre as pesquisas, destacam-se as de: Luthans, Vogelgesang e Lester (2006), Spiegler, Naim e Wikner (2012), Gittell, Cameron, Lim e Rivas (2006), Horne e Orr (1998), Mallak (1998), Robb (2000) e Sutcliffe e Vogus (2003).

Dentro desta abordagem, Valastro (2011) descreve os principais objetivos da resiliência organizacional por meio de uma escala de maturidade de resiliência, que contempla os quatro primeiros níveis do Quadro 2.1 (a seguir). Cabe enfatizar que Sawalha (2015) adiciona o nível 
5 à escala de Valastro (2011), no qual a resiliência pode ser otimizada substancialmente pelo desenvolvimento e manutenção de uma cultura de resiliência e tem como alicerce as pesquisas de Pasteur (2011) e Somers (2009).

Quadro 2.1 - Escala de maturidade de resiliência organizacional

\begin{tabular}{|l|l|l|l|l|l|}
\hline & \multicolumn{3}{|c|}{ Resiliência Organizacional Passiva } & \multicolumn{2}{c|}{ Resiliência Organizacional Ativa } \\
\hline $\begin{array}{l}\text { Nível de } \\
\text { Maturidade }\end{array}$ & $\begin{array}{l}\text { Nível 1: } \\
\text { Declínio }\end{array}$ & $\begin{array}{l}\text { Nível 2: } \\
\text { Sobreviver }\end{array}$ & $\begin{array}{l}\text { Nível 3: } \\
\text { Recuperar }\end{array}$ & $\begin{array}{l}\text { Nível 4: } \\
\text { Antecipar }\end{array}$ & $\begin{array}{l}\text { Nível 5: } \\
\text { Cultura de } \\
\text { Resiliência }\end{array}$ \\
\hline $\begin{array}{l}\text { O objetivo da } \\
\text { resiliência } \\
\text { organizacional } \\
\text { é: }\end{array}$ & $\begin{array}{l}\text { Aceitar que } \\
\text { uma } \\
\text { adversidade } \\
\text { pode causar } \\
\text { consequências } \\
\text { negativas. }\end{array}$ & $\begin{array}{l}\text { Atuar com } \\
\text { recursos } \\
\text { reduzidos, } \\
\text { após a } \\
\text { adversidade. }\end{array}$ & $\begin{array}{l}\text { Recuperar-se } \\
\text { rapidamente e } \\
\text { de forma } \\
\text { eficaz após } \\
\text { uma } \\
\text { adversidade. }\end{array}$ & $\begin{array}{l}\text { Melhorar a } \\
\text { gestão de } \\
\text { riscos futuros, } \\
\text { para que a } \\
\text { organização } \\
\text { não apenas } \\
\text { sobreviva, mas } \\
\text { se beneficie } \\
\text { das } \\
\text { adversidades. }\end{array}$ & $\begin{array}{l}\text { adversidades, ao } \\
\text { possuir uma } \\
\text { estrutura integrada } \\
\text { que promova o } \\
\text { desenvolvimento da } \\
\text { cultura de resiliência } \\
\text { organizacional. }\end{array}$ \\
\hline
\end{tabular}

Fonte: Adaptado de Sawalha (2015).

Nesta perspectiva, quanto maior o nível de maturidade, mais resistente a organização se torna, pois a organização deixa de exercer uma resiliência organizacional passiva (níveis de 1 a 3) e passa a assumir os aspectos ativos da resiliência organizacional (níveis 4 e 5).

\subsubsection{Contexto da Resiliência Organizacional}

As pesquisas de Linnenluecke (2017), Sawalha (2015), Sutcliffe e Vogus (2003), Rankin, Lundberg e Woltjer (2011), Salanova, Llorens, Acosta e Torrente (2013), Youssef e Luthans (2007), Hoopes (2012) e Meneghel et al. (2013) apontam que a resiliência nas organizações pode ser provocada por fatores em vários níveis:

- no nível individual: busca-se dentro da organização mensurar o quão resiliente é o indivíduo. As principais pesquisas giram em torno do tema capital psicológico, com destaque para as pesquisas de Avey, Wernsing e Luthans (2008), Luthans, Avey, Avolio e Peterson (2010) e Hoopes (2012);

- $\quad$ no nível de grupos de empregados (setorial): investiga-se a resiliência dentro de um grupo específico de trabalhadores, de modo a enfatizar a atuação do grupo na organização, por exemplo, a pesquisa de Carmeli, Friedman e Tishler (2013) em que examinaram as conexões relacionadas à decisão estratégica e à resiliência da equipe de gestão. Outras pesquisas são os de: Alliger, Cerasoli, Tannenbaum e 
Vessey (2015), Carmeli et al. (2013), King e Clarkson (2015), Rees, Breen, Cusack e Hegney (2015), Vidal, Carvalho, Santos e Santos (2009), Wang, Cooke, e Huang (2014) e Waterman Jr., Waterman e Collard (1994);

- no nível organizacional: os indivíduos, os sistemas, as estruturas, as infraestruturas, os procedimentos e os parâmetros da organização são investigados (Bhamra et al., 2011). Apresentam-se as seguintes pesquisas: Acquaah et al. (2011), Akgün e Keskin (2014), Aleksić, Stefanović, Arsovski, e Tadić (2013), Ayala e Manzano (2014), Burnard e Bhamra (2011), Dalziell e McManus (2004), Lengnick-Hall e Beck (2005), Lengnick-Hall et al. (2011), McManus (2008), McManus, Seville, Brunsdon e Vargo (2007), McManus, Seville, Vargo e Brunsdon (2008), Seville, Brunsdon, Dantas, Le Masurier, Wilkinson e Vargo (2006), Stephenson (2010), Stephenson, Vargo e Seville (2010) e Whitman, Kachali, Roger, Vargo e Seville (2013); e

- no nível da comunidade (sociedade/social): analisa-se o impacto do ambiente externo no qual está inserida a organização sob a ótica das organizações não estarem preparadas para responder às emergências e às crises, bem como as comunidades também não estarem preparadas (Lee, Vargo, \& Seville, 2013). Nesta área, destacam-se: Cox (2012), Graugaard, (2012), Coaffee (2008), Sapountzaki (2007), Boin e McConnell (2007), Reich (2006), Pelling (2003), Berkes e Ross (2013), Garcia, Mavrodiev e Schweitzer (2013), Gooch e Warburton (2009), Lee et al. (2013), Norris, Stevens, Pfefferbaum, Wyche e Pfefferbaum (2008), Whitehorn (2011), Pasteur (2011) e Sawalha (2015).

Linnencluecke (2017), também, enfatiza a existência de pesquisas no âmbito da resiliência organizacional que abordam questões que contemplam multiníveis, tais como as de Linnenluecke e Griffiths (2013), Sutcliffe e Vogus (2003) e Staw et al. (1981).

\subsubsection{Resiliência Organizacional: a literatura}

O tema resiliência dentro do cenário da teoria organizacional tem crescido nos últimos anos, principalmente em pesquisas acadêmicas na área das ciências sociais com ênfase em estudos da resiliência estratégica e da resiliência operacional como mostram os trabalhos de Annarelli e Nonino (2016) e de Hosseini, Barker e Ramirez-Marquez (2016). Observa-se que, nesta tese, se optou por abordar a resiliência no nível organizacional. 
Neste sentido, internacionalmente, destacam-se as pesquisas desenvolvidas por Aleksić et al. (2013), Annarelli e Nonino (2016), Ayala e Manzano (2014), Boin e van Eeten (2013), Burnard e Bhamra (2011), Hamel e Välikangas (2003), Lee, Vargo e Seville (2013), LengnickHall e Beck (2005, 2009), Lengnick-Hall et al. (2011), McManus et al. (2008), Pal, Torstensson e Mattila (2011, 2014), Seville, Brunsdon, Dantas, Le Masurier, Wilkinson e Vargo (2006, 2008), Salgado (2013), Starr et al. (2003), Stephenson, Vargo e Seville (2010), Teixeira e Werther Junior (2013), entre outras.

Contudo, no tocante à literatura nacional, os estudos sobre a resiliência organizacional no nível organizacional são mais incipientes do que no nível do indivíduo com evidência para as seguintes pesquisas:

- Vasconcelos, Cyrino, D’Oliveira e Prallon (2015) relacionam o conceito de organização inovadora sustentável com o conceito de resiliência organizacional, de modo a identificar quais são as práticas da gestão de pessoas da empresa brasileira de energia EBE S.A., que contribuem para que a empresa seja uma Organização Inovadora Sustentável Resiliente.

- Livramento et al. (2015) apresentaram a influência da cultura organizacional nos processos de gestão da inovação e buscaram compreender se uma cultura inovadora pode ser uma via estratégica para o estabelecimento da resiliência empresarial.

- Nogueira e Gonçalo (2014) analisaram a percepção de gestores sobre a relação entre a capacidade estratégica de resiliência de uma organização e o desenvolvimento de pesquisas e de inovação no setor de equipamentos médicos, possibilitando um desempenho diferenciado das demais empresas que atuam neste mesmo setor.

- Santos e Kato (2014) realizaram, por meio de um trabalho teórico, uma análise de fatores ambientais relativos à mudança combinados à resiliência organizacional.

- Tanoue (2012) realizou uma pesquisa empírica para identificar como as organizações de uma cadeia automotiva aplicam as práticas relacionadas à gestão de risco para aumentar a sua resiliência. Foram realizadas entrevistas com três diretores de empresas envolvidos na cadeia automotiva.

- Dabul (2012) analisou como as características de resiliência identificadas em lideranças organizacionais favorecem a implantação de uma estratégia de comunicação corporativa. A pesquisa investigou a resiliência organizacional por meio de um estudo de caso tanto no nível da organização quanto do indivíduo. Esta 
pesquisa remete aos estudos internacionais de Hamel e Välikangas (2003) e de Lengnick-Hall et al. (2011).

- Baiardi e Alencar (2014) buscaram entender a capacidade de resiliência da agricultura familiar.

Há maior incidência de pesquisas que investigam a resiliência no ambiente empresarial sobre a perspectiva do indivíduo, tais como, Minello (2010), Minello, Scherer e Alves (2012), Minello e Scherer (2014), Scherer e Minello (2014), as quais investigam as competências presentes em empreendedores antes, durante e depois do insucesso empresarial, envolvendo análises dos comportamentos resilientes e os estilos de enfrentamento de empreendedores que tiveram seus negócios descontinuados, ou seja, situação de insucesso empresarial.

Outras pesquisas como a de Bedani (2008), Santos (2011) e Onça (2011) focam na gestão de pessoas. A primeira estuda a resiliência em gestão de pessoas, a partir da utilização do Questionário de Índice de Resiliência: Adultos - Reivich- Shatté / Barbosa (2006). A segunda, investiga o grau de associação entre a resiliência do gestor e o sucesso do seu empreendimento e identifica o grau de resiliência dos gestores; a amostra foi constituída por 41 gestores de empresas selecionadas aleatoriamente, com base nas cinco características de resiliência identificadas por Conner (1995) contendo 37 proposições. E a terceira verifica a capacidade da autoeficácia e da percepção de suporte social no trabalho sobre a resiliência de trabalhadores.

No tocante ao nível de grupos, destaca-se a dissertação de Emilio (2011), na qual se verificou a capacidade preditiva do conflito intragrupal, do suporte social no trabalho e do autoconceito profissional sobre a resiliência de policiais militares. Participaram 133 policiais militares de um batalhão do interior do estado de São Paulo.

Nota-se que algumas pesquisas investigam práticas e ou artefatos de contabilidade gerencial sob o prisma da resiliência, com destaque para as pesquisas de Acquaah et al. (2011), D’Oliveira (2014), Livramento et al. (2015), Meneghel et al. (2013), Mistry, Sarkis e Dhavale (2014), Nogueira e Gonçalo (2014) e Teixeira e Werther Junior (2013). No cenário nacional, a pesquisa realizada por Beuren e Santos (2017) investigou a relação entre as configurações coercitivas e habilitantes dos sistemas de controle gerencial na resiliência organizacional, utilizando o instrumento elaborado por Akgün e Keskin (2014). Porém, não foram encontrados trabalhos científicos que investigaram o impacto do Sistema de Controle Gerencial (SCG), utilizando o framework de Simons $(1995,2000)$ na resiliência organizacional tanto no cenário nacional quanto no internacional. 


\subsubsection{Implementação, aperfeiçoamento e mensuração da Resiliência Organizacional}

Observa-se que muitos são os caminhos que buscam a mensuração de quão resiliente é uma determinada organização, a saber:

- Pettit (2008) e Pettit, Fiksel e Croxton (2010): utilizam o framework denominado Supply Chain Resilience Assessment and Management (SCRAM ${ }^{\mathrm{TM}}$ ), o qual foi desenvolvido por um grupo de pesquisadores de resiliência do Centro de Resiliência na Universidade do Estado de Ohio, cujo objetivo é identificar possíveis lacunas de resiliência e a simulação de diferentes cenários de vulnerabilidade, a fim de manter a lucratividade e evitar a perda de vendas nas organizações, tendo em vista que o foco é investigar a resiliência por meio da cadeia de suplementos das organizações.

- Caralli, Allen e White (2010): apresentam o CERT ${ }^{\circledR}$ - Resilience Management Model (RMM), modelo de gerenciamento de resiliência desenvolvido pelo CERT ${ }^{\circledR}$ - Software Engineering Institute da Universidade de Carnegie Mellon. Contempla processos para gerenciar a resiliência operacional em ambientes complexos e com alto risco de evolução. O modelo engloba e integra atividades de engenharia, gerenciamento de empresa, operações e gerenciamento de processos. A ferramenta fornece um caminho para tornar a resiliência operacional um processo contínuo, previsível, gerenciável e aprimorado sobre o qual uma organização tem um nível significativo de controle.

Cabe enfatizar que estes modelos apresentam menor disseminação no universo acadêmico envolvendo o objeto de análise investigado nesta tese. Além destas duas abordagens, Sawalha (2015) afirma que os fatores que promovem a resiliência organizacional também podem ser apresentados sob outras perspectivas, com destaque para:

- Foster e Dye (2005): a resiliência organizacional é composta por três elementos fundamentais: pessoas, core business e networks.

- Engemann e Henderson (2011): apontam que gerenciamento para a continuidade dos negócios promove a melhoria da resiliência organizacional ao identificar e mitigar as vulnerabilidades operacionais, ao passo que cria planos para responder a interrupções e impregnar uma cultura de prevenção.

- Bigg (2011): argumenta que a idade da empresa, tamanho e experiência, bem como os valores e o estilo de vida dos proprietários estão significativamente relacionados com os níveis de resiliência. 
- Pasteur (2011): apresenta o framework Vulnerability to Resilience (V2R), traduzido como "vulnerabilidade à resiliência", originalmente desenvolvido para pesquisas que investigam a resiliência sob a perspectiva da sociedade (resiliência social), este é composto por quatro elementos distintos: incertezas futuras, riscos, modo de vida e governança.

A título de inovação, para compor o modelo teórico testado nesta pesquisa que melhor se adapta à estrutura e aos objetivos do presente trabalho, levou-se em consideração as pesquisas desenvolvidas que utilizaram como base: (i) o framework denominado de Organisation Resilience Benchmark proposto por McManus (2008), e testado empiricamente nas pesquisas de Lee et al. (2013), Burnard e Bhamra (2011), Erol, Henry, Sauser e Mansouri (2010), entre outros; (ii) o modelo teórico Organisational Resilience Capacity foi apresentado nas pesquisas de Lengnick-Hall e Beck (2005) e Lengnick-Hall et al. (2011), cujo instrumento para testá-lo empiricamente foi desenvolvido por Akgün e Keskin (2014) e, no Brasil, utilizado na investigação de Beuren e Santos (2017); e (iii) o framework desenvolvido por Nascimento (2014) que traz os elementos essenciais da resiliência estratégica, para o qual, até o momento do desenvolvimento desta tese, não tinham sido encontrados trabalhos que o tivessem testado empiricamente.

\subsubsection{Organisation Resilience Benchmark Framework}

O programa denominado "Resilient Organisations: a colaboration between research \& industry" cujo grupo de pesquisadores é da Nova Zelândia, especialmente das Universidades de Canterbury e de Auckland, tem aprimorado a ferramenta conhecida por "Resilient Organisations Resilience Benchmark Tool". Esta foi "projetada para ajudar a medir a capacidade de resistência de uma organização, para monitorar o progresso ao longo do tempo, e comparar pontos fortes e fracos de resiliência em relação a outras organizações dentro do seu setor ou de mesmo porte" (Resilient Organisation, 2014). Segundo Sawalha (2015), é o quadro teórico mais popular para compreender e medir a resiliência organizacional sob diferentes perspectivas. A ferramenta é constituída por meio de três indicadores que são interdependentes e mensurados por meio de treze variáveis cujos detalhes se encontram a seguir, na Figura 2.3. 
Figura 2.3 - Conceitos apresentados às variáveis de Resiliência Organizacional

Capacidade Adaptativa: a organização identifica suas lideranças e sua

cultura organizacional

- Liderança: Forte liderança durante os incidentes críticos proporciona uma boa gestão, bem como proporciona a avaliação contínua das estratégias e dos programas de trabalho que atuam contra objetivos organizacionais.

- Engajamento da Equipe de Trabalho: Há o engajamento e o envolvimento de funcionários de modo que estes entendam a ligação entre o seu próprio trabalho, a resiliência da organização e o sucesso a longo prazo. Os funcionários são capacitados e utilizam suas habilidades para resolver problemas.

- Consciência da situação: Os funcionários são incentivados a serem vigilantes sobre a organização, o desempenho empresarial e os potenciais problemas. Os funcionários são recompensados ao partilhar tanto as boas quanto as más notícias sobre a organização, incluindo os sinais de alerta precoce e estes são rapidamente informados aos líderes organizacionais.

- Tomada de Decisão: Os funcionários têm autoridade para tomar decisões relacionadas ao seu trabalho e esta é claramente delegada para permitir uma resposta à adversidade. Os funcionários que são altamente qualificados estão envolvidos por serem capazes de tomar decisões, pois seu conhecimento específico acrescenta valor significativo, ou quando o seu envolvimento contribui na implementação da decisão.

- Inovação e Criatividade: Os funcionários são encorajados e recompensados por utilizar seus conhecimentos de modo criativo e inovador ao solucionar problemas.

Network: a organização desenvolve relacionamentos interpessoais

interna e externamente

- Parcerias eficazes: Conhecer a relação e os recursos organizacionais, pois durante uma adversidade pode ser necessário o acesso a outras organizações; faz-se necessário ter planejamento e gerenciamento para assegurar este acesso.

- Alavancagem de conhecimento: Informação crítica é armazenada em diversos lugares e de formas distintas e permite que os funcionários tenham acesso às opiniões de especialistas quando necessário. As funções são compartilhadas e os funcionários são treinados para que sempre haja alguém capaz de executar os principais papéis na empresa.

- Quebra de sigilo: Redução de barreiras sociais, culturais e comportamentais que, na maioria das vezes, se manifestam como limitações de comunicação à medida que promovem elementos desconexos, desarticulados e prejudiciais ao trabalho.

- Recursos Internos: A gestão e a mobilização de recursos na organização para assegurar a sua capacidade de operar os negócios como de costume, bem como ser capaz de fornecer a capacidade extra necessária durante uma adversidade.

Mudanças Imediatas: contemplam o planejamento realizado e a direção

pré-estabelecida que permitem à organização promover mudanças.

- Unidade de Propósito: Ampla consciência da organização sobre suas prioridades em situação de adversidade, bem como há um entendimento dos requisitos mínimos para o funcionamento da organização.

- Postura proativa: Prontidão estratégica e comportamental para responder aos sinais de alerta da mudança, tanto no ambiente interno quanto externo da organização, antes que esta se transforme em incidente crítico.

- Planejamento estratégico: O desenvolvimento e a avaliação de planos e estratégias para gerenciar as vulnerabilidades em relação ao ambiente empresarial e aos stakeholders.

- Planos para teste de stress: A participação dos funcionários em simulações ou cenários projetados para praticar as possíveis modalidades de respostas e para validar os planos.

Fonte: Adaptado de Lee, Vargo e Seville (2013), McManus et al. (2007), McManus et al. (2008), McManus (2008), Stephenson (2010), Stephenson, Vargo e Seville (2010) e Whitman et al. (2013).

O Quadro 2.2 evidencia as principais pesquisas que contribuíram com a elaboração do presente framework e com o instrumento de mensuração de resiliência apresentado. 
Quadro 2.2 - Quadro teórico-empírico do Organisation Resilience Benchmark

\begin{tabular}{|c|c|c|c|}
\hline AUTORES & $\begin{array}{c}\text { TIPO DE } \\
\text { PRODUÇÃO }\end{array}$ & ABORDAGEM METODOLÓGICA E OBJETIVO & ESCALA DE MENSURAÇÃO \\
\hline $\begin{array}{l}\text { McManus } \\
(2008)\end{array}$ & $\begin{array}{l}\text { Tese de } \\
\text { doutorado }\end{array}$ & $\begin{array}{l}\text { Realizou estudos de caso múltiplos com } 10 \text { organizações da Nova } \\
\text { Zelândia para identificar aspectos de resiliência organizacional que } \\
\text { possam ser genéricos, isto é, aspectos do sistema organizacional que } \\
\text { contribuem para a resiliência, independentemente do tamanho, } \\
\text { natureza, setor ou localização da organização. }\end{array}$ & $\begin{array}{l}\text { Constrói um instrumento de mensuração de resiliência dividido em } 3 \text { fatores } \\
\text { com um total de } 45 \text { elementos que foram comuns nas empresas investigadas. }\end{array}$ \\
\hline $\begin{array}{l}\text { McManus, } \\
\text { Seville, Vargo } \\
\text { e Brunsdon } \\
(2008)\end{array}$ & $\begin{array}{l}\text { Natural Hazards } \\
\text { Review }\end{array}$ & $\begin{array}{l}\text { Este artigo realizou estudo de caso múltiplo com } 10 \text { organizações da } \\
\text { Nova Zelândia, cuja proposta foi elaborar uma definição específica } \\
\text { para a resiliência organizacional e elaborar uma ferramenta de gestão } \\
\text { da resiliência organizacional. }\end{array}$ & $\begin{array}{l}\text { O processo de gerenciamento da resiliência consiste em um conjunto de } \\
\text { elementos, incluindo: sensibilização; seleção de componentes organizacionais } \\
\text { essenciais; autoavaliação de vulnerabilidade; identificação e priorização de } \\
\text { vulnerabilidades; e aumento da capacidade de adaptação. }\end{array}$ \\
\hline $\begin{array}{l}\text { Stephenson } \\
(2010)\end{array}$ & $\begin{array}{l}\text { Tese de } \\
\text { Doutorado }\end{array}$ & $\begin{array}{l}\text { Desenvolveu e testou, a partir da teoria da resiliência organizacional } \\
\text { (McManus, 2008), uma ferramenta para medir, avaliar e mensurar a } \\
\text { resiliência das organizações. }\end{array}$ & $\begin{array}{l}\text { No modelo, a resiliência é composta por duas dimensões; capacidade adaptativa } \\
\text { e planejamento, que são medidos por um conjunto de treze elementos, } \\
\text { contemplando cinquenta e três itens. }\end{array}$ \\
\hline $\begin{array}{l}\text { Stephenson, } \\
\text { Vargo e } \\
\text { Seville (2010) }\end{array}$ & $\begin{array}{l}\text { The Australian } \\
\text { Journal of } \\
\text { Emergency } \\
\text { Management }\end{array}$ & $\begin{array}{l}\text { Coletaram dados por meio de um survey com } 249 \text { respondentes } \\
\text { representando } 68 \text { organizações em Auckland, Nova Zelândia. O } \\
\text { objetivo foi medir e comparar a resiliência organizacional. A } \\
\text { ferramenta permite que as organizações identifiquem os pontos fortes } \\
\text { e fracos da resiliência e avaliem seus programas de gestão da } \\
\text { resiliência organizacional. }\end{array}$ & $\begin{array}{l}\text { A ferramenta de mensuração conta com aproximadamente } 90 \text { elementos de } \\
\text { resiliência organizacional oriundos do framework de McManus (2008) que foi } \\
\text { anteriormente publicado no Relatório do de pesquisa: Resilience Management } \\
\text { A Framework for Assessing and Improving the Resilience of Organisations de } \\
\text { McManus et al. (2007). }\end{array}$ \\
\hline $\begin{array}{l}\text { Kachali et al. } \\
\text { (2012) }\end{array}$ & $\begin{array}{l}\text { Australasian } \\
\text { Journal of } \\
\text { Disaster and } \\
\text { Trauma Studies }\end{array}$ & $\begin{array}{l}\text { Realizou um levantamento com } 376 \text { organizações da região de } \\
\text { Canterbury, Nova Zelândia, com intuito de analisar os efeitos iniciais } \\
\text { do evento de } 4 \text { de setembro, o terremoto de Darfield que provocou } \\
\text { efeitos físicos, econômicos e sociais nas organizações. }\end{array}$ & $\begin{array}{l}\text { A pesquisa utilizou apenas } 7 \text { elementos de resiliência organizacional contido no } \\
\text { "Benchmark Resilience Tool" (McManus, 2008; Stephenson, 2010), para obter } \\
\text { o perfil de resiliência das organizações investigadas no momento da pesquisa. }\end{array}$ \\
\hline $\begin{array}{l}\text { Lee, Vargo e } \\
\text { Seville (2013) }\end{array}$ & $\begin{array}{l}\text { Natural Hazards } \\
\text { Review }\end{array}$ & $\begin{array}{l}\text { Testou e verificou a validade da ferramenta de pesquisa proposta na } \\
\text { pesquisa de McManus (2008), com uma amostra de } 1.009 \\
\text { organizações da região de Auckland da Nova Zelândia, selecionada } \\
\text { aleatoriamente. }\end{array}$ & $\begin{array}{l}\text { A pesquisa de McManus (2008) apresentou uma ferramenta com } 73 \text { itens. } \\
\text { Utilizando análise fatorial, o resultado desta pesquisa apontou para uma solução } \\
\text { de dois fatores, denominados "capacidade adaptativa" " "planejamento" em que } \\
53 \text { itens foram mantidos para medir a resiliência organizacional. Esta ferramenta } \\
\text { foi denominada de "Benchmark Resilience Tool (BRT-53)" }\end{array}$ \\
\hline $\begin{array}{l}\text { Whitman et al. } \\
\text { (2013) }\end{array}$ & $\begin{array}{l}\text { Measuring } \\
\text { Business } \\
\text { Excellence }\end{array}$ & $\begin{array}{l}\text { Utilizou três bases de dados (Auckland e Hurunui e Canterbury) que } \\
\text { foram utilizadas para comparar a eficácia do Benchmark Resilience } \\
\text { Tool (BRT)-13 com o BRT-53. O objetivo foi o desenvolvimento e a } \\
\text { validação de uma versão curta da ferramenta de pesquisa BRT-53 } \\
\text { (Apresentada na pesquisa de Lee, Vargo e Seville, 2013). }\end{array}$ & $\begin{array}{l}\text { Usando técnicas de análise fatorial exploratória, os } 53 \text { itens são limitados por } 13 \\
\text { construções teóricas definidas como "indicadores" que são consideradas } \\
\text { constituintes de um modelo de dois fatores de resiliência organizacional. Os dois } \\
\text { fatores latentes são denominados "capacidade adaptativa" e "planejamento". }\end{array}$ \\
\hline $\begin{array}{l}\text { Aleksić et al. } \\
(2013)\end{array}$ & $\begin{array}{l}\text { Journal of Loss } \\
\text { Prevention in the } \\
\text { Process } \\
\text { Industries }\end{array}$ & $\begin{array}{l}\text { Mostrou, através do modelo matemático fuzzy, a avaliação do } \\
\text { potencial de resiliência organizacional de Pequenas e Médias } \\
\text { empresas da República da Sérvia. }\end{array}$ & \multirow{2}{*}{$\begin{array}{l}\text { Mensuram a resiliência por meio de } 11 \text { fatores. Os internos são: (1) estratégias } \\
\text { de planejamento, (2) recursos internos, (3) monitoramento e comunicação da } \\
\text { situação interna, (4) fatores humanos e (5) qualidade. Os externos são: (6) } \\
\text { monitoramento e comunicação da situação externa, (7) recursos externos. Os } \\
\text { fatores potenciais: (8) fator de projeto, (9) potencial de detecção, (10) resposta } \\
\text { à emergência, e (11) sistema de gerenciamento de segurança. }\end{array}$} \\
\hline $\begin{array}{l}\text { Tadić et al. } \\
\text { (2014) }\end{array}$ & $\begin{array}{l}\text { Mathematical } \\
\text { Problems in } \\
\text { Engineering }\end{array}$ & $\begin{array}{l}\text { Utilizou a abordagem da lógica fuzzy para obter o fator de resiliência } \\
\text { organizacional que possua maior grau de satisfação para todos os } \\
\text { processos empresariais relevantes. }\end{array}$ & \\
\hline
\end{tabular}

Fonte: Elaborado pela autora. 
Observa-se que, até o momento de desenvolvimento desta pesquisa, não foram encontradas pesquisas no cenário nacional que tenham utilizado como instrumento o "Resilient Organisations Resilience Benchmark Tool”.

\subsubsection{Capacidade da Organização para a Resiliência}

As pesquisas de Akgün e Keskin (2014) e Lengnick-Hall et al. (2011) discutem o aspecto ativo da resiliência organizacional denominado pelos pesquisadores de Organizational Resilience Capacity. Ao contrário das visões tradicionais de resiliência, que indicam que ela é necessária em situações desencadeadas por eventos distintos e descontínuos, a capacidade de resiliência organizacional emerge de práticas adaptativas relativamente comuns (estruturas, valores e rotinas) que promovem competência, eficácia e estimulam o crescimento empresarial (Akgün \& Keskin, 2014; Sutcliffe \& Vogus, 2003; Lengnick-Hall et al., 2011). Neste sentido, será adotado o conceito de resiliência organizacional proposto por Lengnick-Hall et al. (2011, p. 244) que é a habilidade das organizações de perceber, evitar, absorver, responder, adaptar-se e recuperar-se de situações que possam ameaçar a sua existência.

Para Lengnick-Hall e Beck (2009) e Lengnick-Hall et al. (2011), a capacidade de uma organização de desenvolver a resiliência é oriunda de um conjunto de competências, rotinas, práticas e processos organizacionais pelos quais uma empresa se orienta conceitualmente e atua decisivamente com intuito de avançar e de se estabelecer em um cenário de diversidade e integração, de modo a permitir que supere com eficácia as consequências oriundas de uma situação de adversidade.

Para Akgün e Keskin (2014, p. 691), “a capacidade de resiliência reflete um processo dinâmico de mudança e evolução" organizacional, sendo um processo de desenvolvimento. (Akgün \& Keskin, 2014; Lengnick-Hall \& Beck, 2005, 2009; Lengnick-Hall et al., 2011). Lengnick-Hall et al. (2011) argumentam que a capacidade de resiliência é desenvolvida a partir de uma combinação única de capacidades e rotinas cognitivas, comportamentais e contextuais no nível organizacional. A dimensão cognitiva refere-se à capacidade da empresa de observar as mudanças, interpretar as situações desconhecidas, analisar as alternativas e oportunidades, e descobrir como responder a estas condições que promovem rupturas.

- Dimensão cognitiva: indica uma orientação conceitual através de um propósito forte da organização, de valores fundamentais, de uma visão genuína e da construção de sentido (sense-making), o que permite às organizações interpretar e 
fornecer significado previamente às adversidades (Lengnick-Hall \& Beck 2005, 2009; Lengnick-Hall et al., 2011; Akgün \& Keskin, 2014). Os resultados dos fatores cognitivos que promovem a resiliência permitem à empresa diagnosticar com maior precisão as condições ambientais e selecionar a postura estratégica mais eficaz, de modo a auxiliar a empresa a decidir se deve aproveitar as fontes/recursos atuais como vantagem competitiva ou criar outras fundamentalmente diferentes (Lengnick-Hall et al., 2011, p. 252).

No tocante à resiliência comportamental, está a capacidade da entidade em compreender os comportamentos e as rotinas, de modo a proporcionar conhecimento sobre a nova situação, implementar novas práticas e utilizar plenamente seus recursos em condições de rupturas, de incertezas e de mudanças tecnológicas, mercadológicas e intelectuais.

- Dimensão comportamental: mostra traços e características que permitem criatividade; envolve a habilidade das pessoas de seguir um curso de ação dramaticamente diferente da norma e ter agilidade (respostas rápidas); denota rotinas e práticas que fornecem a primeira resposta a qualquer ameaça inesperada; e a tendência para agir de forma proativa (Lengnick-Hall \& Beck, 2005; LengnickHall et al., 2011; Akgün \& Keskin, 2014). Os elementos comportamentais que suportam a resiliência garantem que as empresas tomem ações necessárias para transformar o potencial competitivo em estratégia realizada. Regras simples fornecem diretrizes efetivas para alavancar os novos recursos que a capacidade dinâmica produz (Lengnick-Hall et al., 2011, p. 252).

Por fim, o contexto promove inter-relação interna e externa à organização proporcionando respostas efetivas às complexidades ambientais.

- Dimensão contextual: indica a extensão com que as pessoas percebem seu ambiente de trabalho como propício para assumir riscos interpessoais (segurança psicológica) e desenvolver relações interpessoais efetivas (capital social); incorpora a responsabilidade individual e de grupo (poder difundido e responsabilidade), e amplas redes de recursos (network) (Lengnick-Hall \& Beck 2005, 2009; Lengnick-Hall et al., 2011; Akgün \& Keskin, 2014). As condições contextuais que suportam a resiliência oferecem mecanismos para auxiliar a empresa a escolher, por meio de seus gestores, sabiamente a estratégia entre as alternativas disponíveis (Lengnick-Hall et al., 2011, p. 252, 254). 
De acordo com Akgün e Keskin (2014) e Elliott e Macpherson (2010), a capacidade de resiliência fornece uma oportunidade proativa para o crescimento e produz um alinhamento decisivo na organização em torno da necessidade de mudança. Lengnick-Hall et al. (2011, p. 252) afirmam que "uma forte capacidade de resiliência cria um sistema de orientação interna útil para análise organizacional e tomada de decisão".

Complementando, Lengnick-Hall e Beck (2005, p. 755) apontam a capacidade de resiliência como uma importante característica organizacional que influencia tanto as rotinas que uma empresa tem disponíveis para responder às mudanças ambientais quanto à escolha que faz em relação ao tipo de resposta que deseja implementar, pois fornece a base para que a empresa responda à incerteza, aumentando o fluxo de informações, iniciando o aprendizado em duplo circuito, elaborando seu repertório de ação e realizando alterações nos sistemas de controle (Volberda, 1996).

Lengnick-Hall e Beck (2005, p. 749-750) afirmam que a capacidade de resiliência é uma construção multidimensional no nível organizacional que, por um lado, encoraja a empresa a desenvolver um amplo e variado repertório de rotinas para responder à incerteza e à complexidade e, por outro, encoraja a empresa a pensar sobre o seu ambiente, de forma a melhorar a sua capacidade de determinar tanto o conteúdo quanto a duração da mudança. A capacidade de resiliência aumenta a capacidade de uma empresa de entender sua situação atual e desenvolver respostas personalizadas que refletem esta compreensão, à medida que auxilia a empresa a decidir se a opção mais eficaz a ser seguida é o ajuste adaptativo ou a transformação robusta, ou seja, a empresa passa a ser capaz de distinguir com precisão entre mudanças temporárias, permanentes e contínuas.

Nas palavras de Lengnick-Hall et al. (2011), este framework propõe uma abordagem que permite desenvolver e gerenciar a capacidade de resiliência organizacional. Esta capacidade permite à organização realizar mais plenamente os benefícios e observar as oportunidades de mudança. Pois, similar aos esforços de uma empresa para incentivar a flexibilidade estratégica (isto é, a capacidade de mudar de direção em curto prazo a baixo custo), os esforços para construir uma capacidade de resiliência supõem que a mudança e a surpresa podem ser fontes de oportunidade, mas que capitalizar estas oportunidades muitas vezes requer transformação organizacional.

A pesquisa de Akgün e Keskin (2014) testa empiricamente o modelo teórico de capacidade de resiliência organizacional apresentado por Lengnick-Hall e Beck (2005) e Lengnick-Hall et al. (2011). O Quadro 2.3, a seguir, evidencia as pesquisas realizadas nesta perspectiva. 
Quadro 2.3 - Framework "Organizational Resilience Capacity"

\begin{tabular}{|c|c|c|c|}
\hline AUTORES & PUBLICAÇÃO & MODALIDADE & OBJETIVO \\
\hline $\begin{array}{l}\text { Beuren \& } \\
\text { Santos } \\
(2017)\end{array}$ & $\begin{array}{l}\text { Anais EnANPAD } \\
2017\end{array}$ & $\begin{array}{l}\text { Pesquisa empírica com } \\
114 \text { gestores de } \\
\text { empresas que foram } \\
\text { compradas } \\
\text { adquiridas no Brasil }\end{array}$ & $\begin{array}{l}\text { Examina os } \begin{array}{c}\text { reflexos } \\
\text { configurações } \\
\text { habilitantes }\end{array} \\
\text { coercitivas dos } \\
\text { organizacional. }\end{array}$ \\
\hline $\begin{array}{l}\text { Akgün \& } \\
\text { Keskin } \\
(2014)\end{array}$ & $\begin{array}{l}\text { International } \\
\text { Journal of } \\
\text { Production } \\
\text { Research }\end{array}$ & $\begin{array}{l}\text { Pesquisa empírica com } \\
112 \text { empresas do } \\
\text { diretório da Câmara } \\
\text { Industrial de Istambul }\end{array}$ & $\begin{array}{l}\text { Investigar o papel das variáveis } \\
\text { relacionadas à capacidade de } \\
\text { resiliência organizacional sobre a } \\
\text { inovação e o desempenho do } \\
\text { produto. }\end{array}$ \\
\hline $\begin{array}{l}\text { Lengnick- } \\
\text { Hall et al. } \\
\text { (2011) }\end{array}$ & $\begin{array}{l}\text { Human Resource } \\
\text { Management } \\
\text { Review }\end{array}$ & Conceitual & $\begin{array}{l}\text { Propõe que a capacidade de } \\
\text { resiliência de uma organização seja } \\
\text { desenvolvida através da gestão } \\
\text { estratégica de recursos humanos. }\end{array}$ \\
\hline $\begin{array}{l}\text { Lengnick- } \\
\text { Hall \& Beck } \\
\text { (2009) }\end{array}$ & $\begin{array}{l}\text { Capítulo de Livro } \\
(e \text {-book) }\end{array}$ & Conceitual & $\begin{array}{l}\text { A capacidade de resiliência } \\
\text { organizacional como um } \\
\text { antecedente da agilidade estratégica } \\
\text { e como moderador da relação entre } \\
\text { as atividades dinâmicas de uma } \\
\text { empresa e o desempenho. }\end{array}$ \\
\hline $\begin{array}{l}\text { Lengnick- } \\
\text { Hall \& Beck } \\
(2005)\end{array}$ & $\begin{array}{l}\text { Journal of } \\
\text { Management }\end{array}$ & Conceitual & $\begin{array}{l}\text { A capacidade de resiliência é } \\
\text { introduzida como um fator interno } \\
\text { que influencia o repertório de } \\
\text { rotinas disponíveis e ajuda a } \\
\text { empresa a decidir quais rotinas serão } \\
\text { implementadas, as de adaptação ou } \\
\text { de transformação robusta. }\end{array}$ \\
\hline
\end{tabular}

Fonte: Elaborado pela autora.

\subsubsection{Resiliência Organizacional sob a Perspectiva Estratégica}

A resiliência estratégica tem por alicerce as pesquisas de Hamel e Välikangas (2003), Välikangas e Romme (2013, 2012), Välikangas (2004), Välikangas e Merlyn (2005) que apresentaram as primeiras discussões teóricas utilizando a terminologia Resiliência Estratégica. Entre as pesquisas empíricas que utilizaram esta abordagem, destacam-se as de England (2015), Ismail, Poolton e Sharifi (2011), Nascimento (2014), Nogueira e Gonçalo (2014), Nogueira e Hallal (2013), e Vidal, Carvalho e Cruz-Machado (2014). A discussão da resiliência estratégica é enriquecida com a pesquisas de Lengnick-Hall e Beck (2005, 2009), Lengnick-Hall et al. (2011) e Akgün e Keskin (2014), que, embora não tenham utilizado o termo Resiliência Estratégica e sim Capacidade da Resiliência, apresentam uma discussão sobre a capacidade de resiliência e a agilidade estratégica das organizações originando o framework discutido no item 2.1.6.2, especialmente na pesquisa de Lengnick-Hall e Beck (2009). 
A ênfase neste tópico é para o modelo teórico de resiliência organizacional proposto por Nascimento (2014) que tem por fundamento as bases da Teoria de Desenvolvimento Organizacional e da Teoria Contingencial, cujos fatores foram criados sob o prisma da resiliência estratégica. Ambas abordam as influências geradas pelo ambiente externo à organização. Enquanto a primeira tem por objetivo investigar o ambiente externo no sentido do desenvolvimento planejado, do processo de mudança, da capacidade de adaptação à mudança e cultura organizacional, envolvendo liderança, estratégia, comunicação e relacionamentos pessoais, a segunda, por outro lado, considera o ambiente externo para orientar seu desempenho, flexibilidade e capacidade de mudança contínua, e ainda envolve a capacidade de reconhecer, diagnosticar e adaptar-se à mudança (Nascimento, 2014). A pesquisa propôs um instrumento de mensuração da Resiliência Estratégica (Quadro 2.4), composto por doze variáveis que são interdependentes.

O instrumento do Quadro 2.4 tem por objetivo: fornecer às organizações recomendações sobre o nível de Resiliência Estratégica, de modo que desenvolvessem uma cultura de planejamento para a resiliência que visa ser proativo ao invés de contornar os problemas e as adversidades que ocorrem no dia a dia empresarial; preparar as empresas para absorver os impactos das mudanças no ambiente em que estão inseridas, capacitando-as para diagnosticar, interpretar, compreender e antecipar-se às adversidades que surgem no cenário empresarial (Starr, Newfrock, \& Delurey, 2003; Lengnick-Hall \& Beck, 2005, 2009; Lengnick-Hall et al., 2011; Akgün \& Keskin, 2014). Cabe enfatizar que, até o momento de realização da presente pesquisa, exceto a aplicação empírica realizada por Nascimento (2014), não havia incidências de outras aplicações no contexto acadêmico. 
Quadro 2.4 - Conceitos apresentados às variáveis de Resiliência Estratégica

\begin{tabular}{|c|c|c|}
\hline Variáveis & $\begin{array}{l}\text { Número de } \\
\text { Indicadores }\end{array}$ & Autores \\
\hline $\begin{array}{l}\text { Aprendizagem Organizacional: A organização } \\
\text { que aprende é aquela na qual as pessoas } \\
\text { expandem sua capacidade de criar e são } \\
\text { estimuladas a buscar novos padrões de } \\
\text { pensamentos. }\end{array}$ & 2 & $\begin{array}{l}\text { Luthans, Vogelgesang, \& Lester, (2006); } \\
\text { Coutu (2002); McAllister \& McKinnon, } \\
\text { (2009); Sutcliffe \& Vogus (2003). }\end{array}$ \\
\hline $\begin{array}{l}\text { Liderança: Processo onde um indivíduo } \\
\text { influencia os demais a alcançarem um objetivo } \\
\text { em comum. }\end{array}$ & 10 & $\begin{array}{l}\text { Everly Jr (2011); L. Vieira (2010); Stoltz, } \\
\text { (2004); Margoliz \& Stoltz (2010); Denhardt } \\
\text { \& Denhardt (2010). }\end{array}$ \\
\hline $\begin{array}{l}\text { Inovação Organizacional: Diz respeito a } \\
\text { implementar as ideias geradas pela criatividade. }\end{array}$ & 4 & Reinmoeller \& Baardwijk (2005). \\
\hline $\begin{array}{l}\text { Criatividade: É o processo de gerar ideias } \\
\text { originais. }\end{array}$ & 4 & $\begin{array}{l}\text { Mallak (1998); Barlach (2005); Barlach, } \\
\text { Limonge-França, \& Malvezzi (2008); } \\
\text { Hamel \& Välikangas (2003). }\end{array}$ \\
\hline $\begin{array}{l}\text { Fator Humano: Considera a dimensão humana } \\
\text { dentro das organizações, envolvendo as relações } \\
\text { pessoais. }\end{array}$ & 5 & $\begin{array}{l}\text { Wilson \& Ferch (2005); Cameron, Dutton, } \\
\text { \& Quinn (2003); Masten \& Reed (2002); } \\
\text { Lengnick-Hall, Beck, \& Lengnick-Hall, } \\
\text { (2011). }\end{array}$ \\
\hline $\begin{array}{l}\text { Gestão de Riscos: Foca-se na investigação de } \\
\text { probabilidades da ocorrência de acidentes que } \\
\text { perturbem a operação das organizações. }\end{array}$ & 3 & $\begin{array}{l}\text { Hollnagel (2006); Gittell, Cameron, Lim, \& } \\
\text { Rivas (2006). }\end{array}$ \\
\hline $\begin{array}{l}\text { Cultura Organizacional: } \hat{E} \text { a identidade da } \\
\text { organização que se traduz num conjunto de } \\
\text { normas, crenças e valores partilhados dentro da } \\
\text { organização. }\end{array}$ & 9 & $\begin{array}{l}\text { Mallak (1998); Wreathall (2006); Ates \& } \\
\text { Bititci (2011); Pettit (2008); Wreathall, } \\
\text { (2006); Sheffi (2005); Denhardt \& Denhardt } \\
\text { (2010). }\end{array}$ \\
\hline $\begin{array}{l}\text { Capacidade de Mudança: Envolve flexibilidade e } \\
\text { capacidade de adaptar-se. }\end{array}$ & 8 & $\begin{array}{l}\text { Mallak (1998); Starr, Newfrock \& Delurey } \\
\text { (2003); Hamel \& Välikangas (2003); Fiksel, } \\
\text { (2006, 2003); Infante (2005); Metzl (2009); } \\
\text { Carvalho, Duarte, \& Cruz Machado (2011); } \\
\text { Välikangas \& Romme (2012). }\end{array}$ \\
\hline $\begin{array}{l}\text { Sistema de Informação: Disponibilizar a } \\
\text { informação correta ao utilizador e no tempo certo, } \\
\text { pois cada líder tem uma necessidade particular de } \\
\text { informações para auxiliá-lo no processo de } \\
\text { decisão. }\end{array}$ & 4 & $\begin{array}{l}\text { Mallak (1998); McManus, Seville, } \\
\text { Brunsdon, \& Vargo (2007); Moresi, (2000). }\end{array}$ \\
\hline $\begin{array}{l}\text { Visão estratégica: refere-se à capacidade de ver a } \\
\text { organização como um todo e reconhecer que ela } \\
\text { faz parte de um ambiente que a influencia. }\end{array}$ & 9 & Hamel \& Välikangas (2003) \\
\hline $\begin{array}{l}\text { Comunicação: Processo de interação entre os } \\
\text { indivíduos para transmitir mensagens. }\end{array}$ & 4 & $\begin{array}{l}\text { McManus, Seville, Brundson \& Vargo } \\
\text { (2007) }\end{array}$ \\
\hline $\begin{array}{l}\text { Empowerment: refere-se à delegação de } \\
\text { autoridade/poder. }\end{array}$ & 3 & Austin \& Bartunek (2003) \\
\hline
\end{tabular}

Fonte: Adaptado de Nascimento (2014).

\subsubsection{Modelo para Resiliência Estratégica}

Esta pesquisa desenvolveu-se sob o prisma da resiliência organizacional, tendo como parâmetros os estudos desenvolvidos sob a abordagem ativa no nível organizacional, cuja proposta é discutir estratégia, gestão, sistemas e problemas diários que se desencadeiam nas organizações antes da ocorrência de uma adversidade. Nesta perspectiva, como visto 
anteriormente na Figura 2.2, as empresas apresentam as seguintes características: proatividade, vantagem competitiva, capacidade adaptativa de modo que possam se antecipar e se preparar para os momentos de adversidades.

A seguir são apresentados os indicadores oriundos da compilação dos frameworks contidos nos itens 2.1.6.1, 2.1.6.2 e 2.1.6.3, tendo em vista as características dos gestores respondentes, o contexto nacional em que a organização investigada está inserida, a aproximação com os mecanismos de sistema de controle gerencial, o processo de guiar a organização ao implementar a sua estratégia em um ambiente de mudança. Além dos indicadores, são evidenciados os seus respectivos itens que auxiliaram a mensurar o constructo denominado, nesta tese, de resiliência estratégica. A resiliência estratégica é definida nesta pesquisa como: a capacidade da organização de estar atenta, antecipar-se, responder, evitar e adaptar-se para atender às expectativas do mercado agindo proativamente à medida que percebe os sinais das mudanças, alternando as suas estratégias de modo a aproveitar as oportunidades, maximizando os ganhos e minimizando os problemas (Nascimento, 2014; Lengnick-Hall \& Beck, 2009).

A gestão da resiliência sob a perspectiva estratégica contempla dez elementos que são elucidados a seguir, sendo eles: visão estratégica, postura proativa, aprendizagem organizacional, comunicação organizacional, inovação e criatividade, autonomia na tomada de decisão, liderança, fator humano, parcerias eficazes e recursos disponíveis.

\subsubsection{Visão Estratégica (VE)}

A visão estratégia refere-se à capacidade de ver a organização como um todo e reconhecer que ela está inserida em um ambiente externo, o qual influencia e é por ele influenciada. A visão estratégica da organização direciona as tomadas de decisões, sendo assim um fator decisivo para a sobrevivência das organizações em cenários de constante mudança (Nascimento, 2014). A visão estratégica de uma organização relaciona-se às decisões referentes ao ambiente externo, à tecnologia utilizada e ao inter-relacionamento das áreas organizacionais (Akgün \& Keskin, 2014; McManus, 2008). Complementando, Fleury e Fleury (2001) apontam que a visão estratégica direciona a organização no enfretamento dos desafios estabelecidos no desenvolvimento da atividade empresarial, cujo foco permeia a identificação das oportunidades e das ameaças oriundas do ambiente externo e do domínio do ambiente interno no qual se identificam as forças e as fraquezas da organização. 
O processo cognitivo de considerar o presente, de entender a real situação da empresa, de desenvolver uma percepção do ambiente e de compreender os mecanismos de mudança, é valorizado, por Nascimento (2014), elemento essencial no desenvolvimento da Resiliência Estratégica. Nesta perspectiva, Akgün e Keskin (2014), Lengnick-Hall e Beck (2005) e Lengnick-Hall et al. (2011) afirmam que a resiliência na esfera cognitiva indica uma orientação conceitual por meio dos objetivos, dos valores, da missão, da visão da organização e da implantação de sentido construtivo, permitindo à empresa interpretar e fornecer significado a eventos e condições sem precedentes.

Assim sendo, a visão estratégica com expectativa de resultado futuro refere-se à declaração formal e clara do propósito, dos valores e da visão que sustentam a operação de uma organização, demonstram os significados e o comprometimento esperados tanto das diversas áreas de atividade da organização quanto das pessoas envolvidas (McManus, 2008; Fleury \& Fleury, 2000; Nussbaum, 2016).

Uma organização com visão estratégica possui uma visão ampla do negócio (Nascimento, 2014), apresenta uma percepção real da situação do negócio no momento atual (Hamel \& Välikangas, 2003), tem a capacidade de transformar ameaças em oportunidades (Nascimento, 2014), muda suas estratégias para atender as mudanças e aos anseios do mercado (Nascimento, 2014), conhece e entende o negócio da organização e o seu ambiente, identificando oportunidades e alternativas (Fleury \& Fleury, 2001), identifica novas oportunidades no mercado (Minello, Scherer, \& Alves, 2012), reconhece as vulnerabilidades do negócio e os sinais de fraquezas que indicam uma crise (Nascimento, 2014), alinha suas prioridades, isto é, sua missão e sua visão às mudanças que acontecem no ambiente externo e interno, explora novas estratégias (Hamel \& Välikangas, 2003), prevê as oportunidades e as ameaças (McManus, 2008), explora soluções antes dos problemas (Välikangas \& Merlyn, 2005; Nascimento, 2014), possui maior consciência sobre os recursos disponíveis internamente e externamente (McManus, 2008), direciona recursos para novos produtos e projetos (Hamel \& Välikangas, 2003) e realiza a declaração clara da visão e missão da organização (Simons, 1995, 2000).

De acordo com Stephenson (2010), o indicador visão estratégica é projetado para medir se a organização tem uma visão estratégica definida e se esta visão é compreendida e compartilhada em toda a organização. A visão estratégica refere-se à capacidade da organização de:

- VE1. Ter uma visão ampla da organização/do negócio como um todo (Nascimento, 2014; Fleury \& Fleury, 2001). 
- VE2. Dedicar tempo e energia para reavaliar regularmente as metas a serem alcançadas e explorar novas opções estratégicas, o que permite constantemente mudar a direção da organização (Nascimento, 2014; Stephenson, 2010; Lee et al. 2013; Hamel \& Välikangas, 2003).

- VE3. Os aspectos de mudança são identificados como novas oportunidades para a organização (Nascimento, 2014; Minello, Scherer, \& Alves, 2012).

- VE4. Ter condições e capacidade para reconhecer as vulnerabilidades e as fraquezas do negócio para ajustar à nova realidade (Nascimento, 2014; Stephenson, 2010; Lee et al., 2013).

- VE5: O entendimento amplo da organização e de sua atividade permite diagnosticar, interpretar, compreender e antecipar às adversidades, aos eventos e às mudanças no cenário empresarial (Starr et al., 2003; Lengnick-Hall \& Beck, 2005, 2009; Lengnick-Hall et al., 2011; Akgün \& Keskin, 2014).

A visão estratégica de uma organização direciona o seu futuro e a auxilia no desenvolvimento da Resiliência Estratégica, na medida em que, com o conhecimento proporcionado por este indicador, permite que a organização desenvolva uma postura proativa e a capacidade de aplicação dos recursos internos e externos em condições de incertezas, evitando rupturas ou tornando as ameaças em oportunidades (Lengnick-Hall \& Beck, 2009; Nascimento, 2014).

Assim tem-se a definição de visão estratégica que é a capacidade da organização de conhecer a organização como um todo e os desafios da atividade empresarial, alinhando as prioridades organizacionais frente às mudanças e aos anseios do mercado.

\subsubsection{Postura Proativa (PP)}

A organização resiliente identifica e gerencia de forma proativa as vulnerabilidades que ameaçam a sua capacidade de sobrevivência (Stephenson, 2010), encara a mudança como algo positivo e desenvolve a capacidade adaptativa, pois busca oportunidades de crescimento perante as situações de adversidades (Mallak, 1998; Carmeli \& Markman, 2011; Lengnick-Hall et al., 2011; Akgün \& Keskin, 2014) e não as consideram como um problema (Hamel \& Välikangas, 2003; Nascimento, 2014; Akgün \& Keskin, 2014). Nascimento (2014) aponta que aceitar as mudanças de forma proativa envolve um processo de transformação na cultura da organização. Lengnick-Hall e Beck (2005) e Stephenson (2010) destacam que a atitude proativa 
de uma organização passa por um processo de previsão e julgamento preventivo, tem vínculo nos recursos que esta possui e na sua capacidade de explorá-los, e exige a capacidade da organização de antecipar-se às mudanças de modo a reduzir as vulnerabilidades em ambientes altamente complexos. Assim, uma organização assume a postura proativa quando apresenta disposição estratégica e comportamental para responder antecipadamente aos sinais das adversidades tanto no ambiente interno quanto externo antes que se transformem em crise (Stephenson, 2010; Lee et al., 2013). Para Akgün e Keskin (2014), a organização toma medidas proativas para garantir seu crescimento em face da adversidade.

Seeger et al. (2005), Sawik (2013) e Annarelli e Nonino (2016) argumentam que a resiliência enfatiza uma orientação prática e prospectiva para o futuro ao invés de uma atitude defensiva em relação a eventos extremos oriundos de um momento passado. Assim, a organização transforma a resiliência em vantagem competitiva e a organização desenvolve uma gestão proativa da resiliência em todos os níveis organizacionais (Sawik, 2013; Annarelli \& Nonino, 2016). Annarelli e Nonino (2016) apontam que o desafio gerencial é transformar a resiliência organizacional de um conjunto de ações preventivas, contemplando a gestão de recursos, em estratégia proativa e práticas capazes de promover a efetividade diária das operações e dos processos. Nesta perspectiva, a capacidade de resiliência oferece uma oportunidade proativa de crescimento e produz um alinhamento decisivo em torno da necessidade de mudança (Elliott \& Macpherson, 2010; Akgün \& Keskin, 2014).

Para mensurar a postura proativa da organização são elencados os seguintes itens:

- PP1. Ter uma estrutura que permita agir de forma rápida e eficaz em resposta a uma oportunidade e aos eventos inesperados (Nascimento, 2014; Stephenson, 2010; Lee et al., 2013).

- PP2. Ter uma diversidade de ações competitivas disponíveis para adotar em resposta às inesperadas e oportunas mudanças que ocorrem no mercado (Akgün \& Keskin, 2014).

- PP3. Tomar decisões e realizar investimentos preventivamente para garantir benefícios em situações futuras que possam surgir na organização. (Akgün \& Keskin, 2014).

- PP4. A organização monitora proativamente o que está acontecendo em seu setor para agir antecipadamente nas questões emergentes (Stephenson, 2010; Lee et al., 2013). 
- $\quad$ PP5. Buscar oportunidades de crescimento perante as situações de adversidades (Mallak, 1998; Carmeli \& Markman, 2011; Lengnick-Hall et al., 2011; Akgün \& Keskin, 2014).

Desta feita, a postura proativa refere-se à capacidade da organização de antecipar-se às mudanças de modo a reduzir as vulnerabilidades em ambientes altamente complexos.

\subsubsection{Aprendizagem Organizacional (AO)}

Vinculada à cultura organizacional, a aprendizagem organizacional articula padrões comportamentais nas organizações que alicerçam o processo de adaptação ao ambiente em mudança. A aprendizagem organizacional contempla a conscientização coletiva da situação presente, a mudança na estrutura organizacional em resposta à mudança no ambiente (Appelbaum \& Gallagher, 2000; Senge, 1990; Edmondson \& Moingeon, 1998), desenvolve a motivação organizacional, a eficácia e as habilidades de ajuste às novas situações (Edmondson, 1999, Sutcliffe \& Vogus, 2003). Para Argyris (1990), a aprendizagem ocorre em dois momentos nas organizações: (i) quando a empresa alcança os resultados elencados em sua estratégia; e (ii) quando o resultado alcançado não está alinhado com a estratégia da organização e há um

processo de corrigi-lo. A aprendizagem organizacional promove vantagem competitiva à medida que melhora a elaboração de estratégias e promove o gerenciamento do conhecimento (Hitt, 1996).

A aprendizagem organizacional é considerada, por Nascimento (2014), L.Vieira (2010), Sutcliffe e Vogus (2003), Lengnick-Hall e Beck (2005, 2009), Lengnick-Hall et al. (2011), um elemento essencial na construção da capacidade organizacional para a resiliência. Segundo Sutcliffe e Vogus (2003), a resiliência é a capacidade de uma organização de aprender com os erros, pois destina-se à competência da organização para o crescimento organizacional, restaura a eficácia organizacional à medida que processa rapidamente o feedback e transfere, de forma flexível, os conhecimentos e os recursos de modo a sobreviver às situações adversas. Por outro lado, Nascimento (2014) afirma que a resiliência como um processo organizacional pode ser aprendida e aperfeiçoada, assegura que se pode aprender a obter resiliência e a construir um alto nível de resiliência tanto nos indivíduos quanto nas organizações (Coutu, 2002; McAllister \& McKinnon, 2009; Everly Jr., 2011; Margolis \& Stoltz, 2010). A construção da resiliência depende de treino, de experiência e do desenvolvimento de conhecimento especializado (Sutcliffe \& Vogus, 2003). Uma organização resiliente desenvolve as capacidades de aprender, 
adaptar-se e se auto-organizar (Linnenluecke \& Griffits, 2010), apresenta uma cultura que valoriza a aprendizagem de problemas passados (Akgün \& Keskin, 2014).

Lengnick-Hall e Beck (2005, 2009), Lengnick-Hall et al. (2011) e Akgün e Keskin (2014) apresentam os mecanismos relevantes para promover a resiliência cognitiva no nível organizacional, a saber: o conhecimento acumulado, a eficácia coletiva e a crença compartilhada. Operacionalmente tais capacidades de aprendizagem alinham a organização não só estrutural e estrategicamente, mas também cognitivamente para as turbulências de mercado e para torná-la pronta para enfrentar desafios (Weick \& Sutcliffe 2007). Segundo Walker, Anderies, Kinzig e Ryan (2006), é essencial, na resiliência estratégica, o aprendizado dinâmico em uma organização, o qual ocorre por meio da experimentação, da construção de sentidos e da aprendizagem colaborativa (combinando informação e conhecimento).

Por outro lado, Weick e Sutcliffe (2007) apresentam que a aprendizagem organizacional promove a resiliência a partir: (i) do entendimento dos padrões emergentes; (ii) do aprendizado com erros depois que eles ocorrem, é uma atividade de melhoria que reduz erros futuros e ou as consequências dos erros futuros; (iii) da capacidade que a organização tem de lidar e aprender com a experiência; e (iv) das práticas de gestão que incentivam o questionamento da realidade. Epstein e Roy (2003) acrescentam que a aprendizagem ocorre por meio de processo de feedback e sensemaking nas organizações.

Uma cultura organizacional orientada para a aprendizagem promove vantagem competitiva ao apresentar agilidade e rapidez no processo de tomada de decisão, na capacidade de aprendizagem e em sua comunicação interna (Nascimento, 2014). Assim sendo, uma organização resiliente apresenta os seguintes mecanismos referentes à aprendizagem organizacional:

- AO1. Durante uma adversidade, tem-se a capacidade de identificar um problema, aprender sobre ele, apresentar solução e implantar a solução (Nascimento, 2014).

- AO2. Aprender lições do passado e garantir que estas lições sejam executadas no futuro, pois evoluímos e nos adaptamos às novas situações (Stephenson, 2010; Lee et al., 2013; Nascimento, 2014).

- AO3. Ter estruturas organizacionais que são projetadas para promover a aprendizagem e mudar os comportamentos com base nas novas informações e nos novos insights (Akgün \& Keskin, 2014). 
- AO4: Ter práticas de gestão e normas organizacionais que incentivam o questionamento do que está acontecendo de modo a exigir uma sólida compreensão da realidade (Weick \& Sutcliffe, 2007; Riolli \& Savicki, 2003).

Nesta pesquisa, entende-se que a aprendizagem organizacional é a capacidade da organização de aprender com os erros e problemas ocorridos, com a experiência vivenciada e com as práticas de gestão que incentivam o questionamento da realidade.

\subsubsection{Comunicação Organizacional (CO)}

A comunicação organizacional tem sido valorizada pelas entidades que buscam qualidade e vantagem competitiva, principalmente em ambientes de constante mudança. (Nascimento, 2014). Nascimento (2014, p. 82) define a comunicação organizacional como "o processo de interação entre os indivíduos para transmitir mensagens", enquanto para Weick e Sutcliffe (2007) a comunicação organizacional proporciona aos funcionários o compartilhamento da visão e dos valores da organização, bem como o pensamento em grupo.

Na perspectiva da resiliência estratégica, o processo de comunicação organizacional é essencial, pois compartilha as estratégias, expectativas, metas e a direção que a organização pretende seguir, socializa novos conhecimentos e proporciona sua transmissão para todos os níveis organizacionais. É a comunicação organizacional que proporciona uma tomada de decisão consistente, eficaz e proativa. Assim, a comunicação é uma ferramenta que auxilia a evitar problemas e a identificar ameaças e oportunidades (R.Vieira, 2004; Nascimento, 2014). Na visão de Sheffi (2006), as organizações resilientes investem recursos em ferramentas de comunicação e tempo disseminando a informação com intuito de manter os gestores cientes e atualizados perante os objetivos estratégicos e os fatores táticos.

As ferramentas de comunicação permitem disponibilizar, transmitir e compartilhar informações; em organizações resilientes elas proporcionam uma comunicação aberta, clara, que ocorre tanto na vertical quanto na horizontal (Nascimento, 2014). A informação é considerada um recurso de gestão e, portanto, precisa estar disponível para que o gestor a utilize no processo de decisão (Moresi, 2000; Mallak, 1998). De acordo com Cho (1996), as organizações utilizam a informação para entender seu ambiente operacional, gerar novos conhecimentos por meio da aprendizagem organizacional e acessar informações para tomar decisões. Neste sentido, a organização precisa prover um sistema de informação rápido e eficaz, que possibilite aos usuários o acesso à informação tempestiva, pois, para auxiliar o gestor no 
processo de decisão, as necessidades de acesso às informações são as mais diversas possíveis. De acordo com Nascimento (2014), a organização que deseja aumentar a sua resiliência precisa disponibilizar àqueles que tomam decisões o "acesso à informação de qualidade que os permita tomar decisões rapidamente e responder à crise quando ela ocorrer" (p. 57).

Para Vargo e Seville (2010), a resiliência organizacional auxilia a empresa na busca por vantagem competitiva estimulando a organização a desenvolver a capacidade de interpretar informações sobre seu ambiente de negócio e entender o que estas informações significam para a organização agora e no futuro, ou seja, ter consciência da sua situação presente em relação aos concorrentes e ao ambiente em que está inserida. Para Stephenson (2010), a informação na tomada de decisão é definida como

a medida com que a organização olha para seu ambiente interno e externo a fim de obter informações relevantes sobre e para suas atividades organizacionais e utiliza essas informações para informar decisões em todos os níveis da organização, para prevenir ou para responder a uma situação de crise ou de emergência. (Stephenson, 2010, p. 86).

McManus (2008) argumenta que a informação e o conhecimento estão relacionados com a comunicação interna, as relações interpessoais, os papéis que cada indivíduo desempenha, e a minimização das barreiras entre as áreas ou entre os indivíduos na organização promovendo troca de informação, pois considera que o conhecimento e a informação devem ser reunidos e compartilhados entre todos na organização. Stephenson (2010) apresenta que a gestão da informação em uma organização deve assegurar que aqueles que tomam decisões tenham acesso à informação útil em situação de crise ou emergência. Tal fato impacta a natureza e o formato da informação, envolvendo como a informação é armazenada, onde é armazenada, como será acessada e compartilhada.

Para mensurar capacidade da organização na esfera da comunicação organizacional foram utilizados os seguintes elementos:

- CO1. O processo de comunicação compartilha a direção e as estratégias organizacionais nos diversos níveis hierárquicos (Nascimento, 2014).

- CO2. A organização tem uma linguagem comum (ou seja, palavras, imagens e histórias) e predominante que implica capacidade, influência, competência, valores fundamentais consistentes e um sentido claro de direção na organização (Akgün \& Keskin, 2014).

- CO3. O sistema de informação ao disponibilizar informação com qualidade dá suporte à tomada de decisão rápida e eficaz (Nascimento, 2014). 
- CO4. Funcionários possuem formação para utilizar o sistema, sabem quais informações acessar em situações críticas e têm consciência das implicações para as possíveis soluções (Nascimento, 2014).

- CO5. As informações cruciais estão disponíveis em diferentes meios (Stephenson, 2010; Lee et al., 2013).

Isto posto, define-se Comunicação Organizacional como o processo de interação entre os indivíduos da organização para transmitir e compartilhar informações, socializar novos conhecimentos e, por meio dos sistemas de informação, proporcionar a transmissão destes para todos os níveis organizacionais.

\subsubsection{Inovação e Criatividade (IC)}

A inovação e a criatividade estão relacionadas com a cultura organizacional, com a formação dos indivíduos e com o envolvimento de todos os níveis da organização (Nascimento, 2014; Stephenson, 2010). Segundo Nascimento (2014), a criatividade auxilia os integrantes da organização no processo de tomada de decisões e a desenvolverem suas atividades de maneira diferente, facilitando a Resiliência Estratégica. A inovação, para a autora, auxilia a identificar novas oportunidades e a estimular o espírito empreendedor nas equipes de trabalho. Cabe destacar que, na perspectiva ativa da resiliência organizacional, é necessário que a organização possua uma contínua agregação e reconstrução de suas estratégias de inovação, ao invés de uma gestão de crises/riscos ou programas de recuperação (reviravolta) (Somers, 2009; Carmeli \& Markman, 2011; Lengnick-Hall et al., 2011).

As organizações resilientes encorajam o comportamento empreendedor visando à inovação (Reinmoeller \& Baardwijk, 2005). Além disso, as organizações resilientes incorporam a inovação na cultura organizacional, destacando-a no centro da sua estratégia de crescimento (Teixeira \& Werther Jr., 2013). Para Nascimento (2014), as organizações que valorizam a busca por novos produtos e novas oportunidades se enquadram no que Miles, Snow, Meyer e Coleman Jr. (1978) definiram como Estratégia Prospectiva. Segundo Nascimento (2014), as organizações que adotam esta estratégia apresentam uma rápida resposta às mudanças do ambiente, tendo em vista que possuem as seguintes características: investem em equipes para análise do ambiente interno e externo em busca de novas oportunidades; utilizam mecanismos criadores de mudança; utilizam a mudança para ganhar vantagem competitiva sobre seus concorrentes; percebem mais rápido as mudanças no ambiente e as incertezas; e lidam bem com a 
flexibilidade das suas tecnologias e de seus sistemas administrativos. Na percepção de Hamel e Välikangas (2003), entre as principais mudanças ambientais que desafiam as organizações a investir em inovação, estão aquelas que promovem descontinuidades tecnológicas, mudanças rápidas nas preferências dos clientes e no know-how tecnológico.

Guimarães e Langley (1994) argumentam que a inovação da empresa é importante para o crescimento e a sobrevivência a longo prazo. Além disso, as empresas resilientes contam com a criatividade de sua equipe para vencer os desafios e as mudanças contínuas do ambiente (Nascimento, 2014). A criatividade no cenário empresarial é contemplada pelas organizações que apresentam visão de futuro e valorizam não apenas a capacidade de antecipar-se às adversidades, mas também a capacidade de construir soluções inovadoras e criativas aos problemas, processos e produtos (Nascimento, 2014; Barlach, 2005; Denhardt \& Denhardt, 2010). Assim, ao combinar a criatividade e a resiliência, as organizações passam a responder com maior eficácia às adversidades em ambientes desfavoráveis e com alta competitividade (Oliveira \& Nakano, 2011).

A mensuração da resiliência organizacional por meio do indicador Inovação e Criatividade é utilizado nas pesquisas de Stephenson (2010, p. 181) e Lee et al. (2013, p. 34) associada ao fator humano, a saber: "Os funcionários são encorajados e recompensados por utilizar seus conhecimentos de modo criativo e inovador ao solucionar problemas". Este indicador visa contemplar a criatividade na tomada de decisões gerenciais (Stephenson, 2010; Ford \& Gioia, 2000), a inovação em um processo de mudança contínua (Brown \& Eisenhardt, 1997), a agilidade organizacional (Plant \& Murrell, 1997) e o comportamento emergente durante a resposta à crise (Quarantelli, 1995).

Na esfera da resiliência estratégica, a inovação e a criatividade referem-se à capacidade da organização de:

- IC1. Estimular o espírito empreendedor visando à mudança (Nascimento, 2014).

- IC2. Utilizar o conhecimento de forma inovadora e criativa na solução de problemas (Stephenson, 2010; Lee et al., 2013; Nascimento, 2014).

- IC3. Incentivar a criatividade e a busca por oportunidades para desenvolver novas habilidades, ao invés de ter como foco a padronização (Akgün \& Keskin, 2014).

- IC4. Recompensar por "pensar fora da caixa" (Stephenson, 2010; Lee et al., 2013). Trata-se de Inovação e Criatividade como a capacidade da organização de construir soluções inovadoras e criativas para os problemas, processos e produtos. 


\subsubsection{Autonomia na Tomada de Decisão (TD)}

Organizações resilientes atuam com um processo de tomada de decisão que acompanha o ritmo das mudanças no ambiente interno e externo, por meio de lideranças que apoiam suas equipes a terem poder e liberdade para tomar decisões que estejam dentro de suas alçadas (Nascimento, 2014). Para McManus et al. (2007), uma organização resiliente desenvolve a capacidade de adaptação às mudanças que ocorrem em seu ambiente operacional, trabalha no gerenciamento das vulnerabilidades e do conhecimento, e age com rapidez na tomada de decisão diária e em momentos de crise.

Nascimento (2014, p. 82) define empowerment como "processo de delegar autoridade e poder aos colaboradores da organização”. Para Mallak (1998), este é um conceito chave de resiliência e destaca que a expansão da tomada de decisão está intimamente ligada à garantia de recursos externos adequados. Alesi (2008) e Sheffi (2006) argumentam que organizações resilientes permitem aos indivíduos autonomia para tomarem decisões e que estes reajam aos eventos sem que haja uma hierarquia de resposta.

$\mathrm{Na}$ resiliência estratégica, o processo de tomada de decisão pode ser descentralizado, responsivo, autônomo (Stephenson, 2010), proativo, rápido e eficaz (Nascimento, 2014). A tomada de decisão tem por alicerce o sistema de informação que proporcione a comunicação a todos os níveis organizacionais de modo a disseminar as estratégias da organização e a direcionar em face às ameaças e às oportunidades (Nascimento, 2014). Stephenson (2010) ressalta que a autonomia e a autoridade são designadas às pessoas envolvidas no processo de tomada de decisão, pois são qualificadas e seus conhecimentos específicos agregam valor significativo na solução de problemas e visam uma tomada de decisão com responsabilidade. Além disso, o autor defende a ideia de que, em uma situação de adversidade, as decisões sejam tomadas por aqueles qualificados para fazê-lo, e não aqueles com autoridade para tomar decisões como resultado de sua posição hierárquica dentro da organização. Weick e Sutcliffe (2007) defendem que pessoas mais qualificadas para tomar uma decisão devem fazê-lo independentemente do seu tempo de atuação dentro da organização.

Além disso, Stephenson (2010) argumenta que a tomada de decisão descentralizada e responsiva exige estruturas, formais e informais, e processos que sejam flexíveis para proporcionar a capacidade de adaptação que a organização necessita em um contexto de adversidade/mudança. Para isto, a cultura organizacional deve permitir que o processo de tomada de decisão seja autônomo e que os indivíduos tenham autoridade para tomar as decisões diretamente ligadas ao seu trabalho (Mallak, 1998), incluindo a alocação de recursos, para que 
a organização se ajuste dependendo da situação, visando minimizar as interrupções e proporcionar a continuidade das operações.

Cho (1996) argumenta que, nas organizações, as decisões são tomadas racionalmente, pois avaliam-se as informações antes de tomar decisões importantes. As organizações coletam todas as informações relevantes, avaliam suas opções e, em seguida, selecionam uma opção baseada no pensamento lógico racional e na comparação (Eisenhardt \& Zbaracki, 1992).

Na percepção de Weick e Sutcliffe (2007) e Bigley e Roberts (2001), o processo de tomada de decisão nas organizações é categorizado em dois cenários, o primeiro engloba a tomada de decisão dentro da rotina cotidiana da organização "business-as-usual" e o segundo quando a organização passa por um processo de mudança. No primeiro, o controle sobre o processo de tomada de decisões é centralizado, hierárquico e a responsabilidade é delegada. No segundo, a tomada de decisão passa para a linha de frente da organização onde as pessoas possuem informações e conhecimentos sobre a complexidade do sistema, ou seja, a estrutura da tomada de decisão demanda a busca por especialistas na organização, tendo como base a experiência e o conhecimento e não a posição hierárquica que o indivíduo possui. Esta abordagem apresenta uma estrutura flexível de tomada de decisão, a qual é considerada como uma ferramenta para responder a mudanças rápidas do mercado ou para resolver problemas sistêmicos na organização (Bigley \& Roberts, 2001). Ou seja, a organização em que o processo de tomada de decisão é estruturado no conhecimento especializado de sua equipe de trabalho atua com base no conhecimento e na experiência em oposição à hierarquia (Stephenson, 2010).

Stephenson (2010) atenta para que a organização resiliente esteja ciente da sua situação presente e do seu ambiente de negócios, a qual contempla fatores internos e externos, de modo que a organização aproveite ativamente estas informações ao tomar decisões e planejar estrategicamente suas ações. Crichton, Lauche e Flin (2005) argumentam que avaliar a situação é o primeiro passo no processo de tomada de decisão, especialmente em uma crise. Apresentam a importância da conscientização da situação compartilhada como uma estratégia cooperativa informal entre os trabalhadores e destacam que a organização que tem consciência da situação possui habilidade de comando vital em uma crise.

Assim sendo, os elementos utilizados neste indicador são apresentados a seguir:

- TD1. Os líderes delegam responsabilidades e autoridade a sua equipe permitindo aos profissionais autonomia para tomarem decisões (Nascimento, 2014).

- TD2. Compartilha-se a tomada de decisão amplamente (Akgün \& Keskin, 2014).

- TD3. Toma-se decisões difíceis rapidamente (Stephenson, 2010). 
- TD4. Caso ocorram problemas, os colaboradores possuem acesso direto a alguém com autoridade que possa tomar decisões (Stephenson, 2010).

Nesta pesquisa define-se Autonomia na Tomada de Decisão como a capacidade de delegar autoridade e poder aos colaboradores da organização visando uma tomada de decisão com autonomia, agilidade e responsabilidade por pessoas qualificadas.

\subsubsection{Liderança $(L D)$}

Stephenson (2010) e Nascimento (2014) afirmam que a liderança é essencial em organizações que buscam desenvolver a resiliência. Organizações resilientes precisam de uma liderança forte que seja capaz de reconhecer e compreender o ambiente (ter consciência da situação), alavancar os pontos fortes da organização de modo a antecipar ou superar as adversidades e vulnerabilidades e responder com rapidez e eficácia às mudanças em seu setor, adaptando-se à frente dos seus concorrentes (Stephenson, 2010). Para Stoltz (2004), as organizações que almejam estas características devem atuar com líderes resilientes, os quais apresentam as seguintes competências: otimismo, determinação, integridade, comunicação aberta, aptidão ao risco e proatividade (Everly Jr., 2011; Nascimento, 2014).

Pariès (2006) discute o papel dos líderes como facilitadores da resiliência. Para o desenvolvimento da resiliência organizacional é necessário que a organização possua uma liderança inspiradora que equilibre com êxito as necessidades dos stakeholders internos e externos e as prioridades empresariais, que seja capaz de proporcionar uma boa gestão e tomada de decisões em tempos de crise (Stephenson, 2010; McManus, 2007). Uma liderança que realize avaliação contínua das estratégias e dos programas de trabalho em relação às metas da organização (Stephenson, 2010). Complementando, Westrum (2006, p. 61) afirma que, no âmbito organizacional, "tudo depende da liderança, que molda o clima e, assim, define as prioridades".

Friedman (2005) assegura que organizações resilientes trabalham com o envolvimento de seu pessoal, e não apenas das lideranças, para garantir a flexibilidade suficiente para adaptarse às mudanças tanto no ambiente interno quanto externo. É necessário reconhecer o papel que os trabalhadores da linha de frente desempenham no processo de desenvolvimento da Resiliência Organizacional, especialmente no decorrer de uma crise (Mallak, 1998). Stephenson (2010) argumenta que boas relações de trabalho, visão compartilhada em toda 
organização, lideranças fortes, pessoas envolvidas e capazes de atuarem continuamente para responder ou antecipar-se às mudanças, proporcionam à organização a capacidade de adaptação aumentando a resiliência organizacional. Isto significa que um dos desafios da empresa para alcançar a Resiliência está relacionada a seus gestores (L.Vieira, 2010).

As organizações resilientes atuam com líderes que delegam responsabilidades a sua equipe permitindo aos profissionais autonomia para tomarem decisões, geram feedback constante, desenvolvem uma comunicação aberta entre o líder e os colaboradores, estimulam a inovação e a criatividade (Nascimento, 2014), permitem aos funcionários relatarem informações que podem ajudar na melhoria organizacional (Akgün \& Keskin, 2014), geram espaço para discussão em que os gestores ouvem os problemas e soluções oriundos dos diversos níveis organizacionais, prezam pelo bom relacionamento e incentivam os colaboradores a discutirem problemas junto aos seus gestores (Stephenson, 2010). Complementando, Stephenson (2010) afirma que muitas organizações concordam com a necessidade de melhorar sua resiliência, porém não dispõem de tempo e ou recursos.

Desta feita, a seguir são apresentados os atributos que mensuram liderança na resiliência estratégica:

- LD1. Líderes abertos às mudanças contínuas nas estratégias da organização e aos novos desafios; consideram a mudança como oportunidade (Nascimento, 2014).

- $\quad$ LD2. Os gestores entendem como liderança o próprio exemplo (Stephenson, 2014; Nascimento, 2014).

- LD3. A liderança preza pelo bom relacionamento e incentiva os colaboradores a discutirem problemas junto aos seus gestores (Stephenson, 2010).

- LD4. A liderança gera feedback constante e desenvolve uma comunicação aberta entre o líder e sua equipe (Nascimento, 2014).

Entende-se por Liderança a capacidade de compreender o ambiente e responder com rapidez e eficácia às mudanças em seu setor adaptando-se à frente dos seus concorrentes. Além disso, é a liderança que promove espaço para discussão em que os gestores ouvem os problemas e soluções oriundos dos diversos níveis organizacionais proporcionando feedback constante.

\subsubsection{Fator Humano $(F H)$}

O fator humano nas organizações é altamente relevante, pois, segundo os pesquisadores Lengnick-Hall et al. (2011), a Gestão Estratégica de Recursos Humanos promove a capacidade 
organizacional para a Resiliência. Nascimento (2014) afirma que a vertente humana na organização tem grande influência na construção da resiliência estratégica. De acordo com Gittell et al. (2006), o bom relacionamento social no ambiente de trabalho (tais como: compartilhamento de objetivos, de conhecimentos e práticas de respeito mútuo) é considerado um pré-requisito à Resiliência Organizacional. Os comportamentos pró-sociais entre as pessoas promovem emoções e expectativas positivas que acarretam benefícios, tais como: a adoção de metas mais desafiadoras; maior compromisso com as metas; e desenvolvimento de soluções criativas e inovadoras para os problemas (Akgün \& Keskin, 2014).

Para Nascimento (2014), a gestão da resiliência estratégica tem por objetivo auxiliar a organização no processo de tomada de decisão apresentando atributos que os gestores possam utilizar para justificarem as suas ações de melhoria, tanto no tocante à alocação de recursos quanto no desenvolvimento de recursos humanos. Para Akgün e Keskin (2014), Lengnick-Hall e Beck (2005) e Lengnick-Hall et al. (2011), a capacidade organizacional para a resiliência ocorre na esfera contextual quando as pessoas na organização percebem seu ambiente de trabalho como propício para assumir riscos interpessoais, para desenvolver relações interpessoais efetivas e estabelecer responsabilidades tanto individuais quanto em grupo.

O engajamento do pessoal na construção da resiliência organizacional é discutido por Stephenson (2010) e Mallak (1998), ao evidenciarem a sua importância tanto na gestão de vulnerabilidades que ocorrem envolvendo toda a organização quanto na importância da formação do pessoal para incorporar a resiliência, pois a capacidade de resiliência expande os conhecimentos, as habilidades e as capacidades técnicas das pessoas, bem como os repertórios comportamentais, que podem lhes proporcionar opções para improvisar e buscar diferentes alternativas sob condições ambientais altamente turbulentas (Akgün \& Keskin, 2014).

Stephenson (2010) salienta que o engajamento dos trabalhadores no desenvolvimento da resiliência organizacional ocorre, principalmente, em três situações, quando eles: (i) compreendem a ligação entre o seu próprio trabalho, a resiliência da organização e o sucesso da organização a longo prazo; (ii) possuem empowerment; e (iii) utilizam suas habilidades para resolver problemas. À medida que as pessoas, ao executarem suas tarefas, passam a atribuir significado a elas e às dos outros e transformam as informações e os conhecimentos externos fornecidos por variáveis relacionadas à capacidade de resiliência em uma experiência pessoalmente significativa, contribuem com a construção da resiliência organizacional (Akgün \& Keskin, 2014). Além disso, Stephenson (2010) afirma que, para promover a resiliência organizacional no ambiente de trabalho, é necessário que o pessoal seja incentivado a estar em constante vigilância sobre a organização, o seu desempenho e os possíveis problemas, pois, ao 
serem encorajados a redefinirem a si mesmos e suas ações para um melhor desempenho da empresa, trabalham na construção da capacidade organizacional para a resiliência (Akgün \& Keskin, 2014).

As assertivas que mensuram este indicador são:

- FH1: As pessoas estabelecem relações com outras pessoas permitindo o compartilhamento de recursos, de objetivos, de conhecimentos, de informações e de práticas de respeito mútuo (Nascimento, 2014; Akgün \& Keskin, 2014; Gittell, Cameron, Lim, \& Rivas, 2006).

- FH2: Cada membro da organização tem a descrição e a responsabilidade de assegurar a obtenção dos interesses organizacionais (Akgün \& Keskin, 2014; Stephenson, 2010).

- FH3: Trabalham com outras pessoas independente das fronteiras departamentais e organizacionais (Stephenson, 2010).

- FH4: As pessoas na organização se sentem responsáveis pela eficácia da organização (Stephenson, 2010).

- FH5: As pessoas na organização buscam informações, solicitam ajuda, admitem que erraram e ou geraram feedbacks críticos no desenvolvimento de suas atividades (Akgün \& Keskin, 2014; Nascimento, 2014).

A definição utilizada para Fator Humano refere-se às pessoas na organização que percebem seu ambiente de trabalho como propício para assumir riscos interpessoais, para desenvolver relações interpessoais efetivas e estabelecer responsabilidades tanto individuais quanto em grupo sobre a organização, o seu desempenho e os possíveis problemas.

\subsubsection{Parcerias Eficazes (PE)}

As organizações devem perceber que não operam de forma isolada no ambiente em que estão inseridas, à medida que desenvolvem suas atividades afetam e são afetadas por outras organizações, tais como: governo, fornecedores, parceiros, concorrentes, entre outros. As organizações resilientes entendem suas restrições, dependências e, especialmente, as interconexões com a sociedade como uma oportunidade de interação, articulando claramente no seu contexto operacional e observando os limites de suas vulnerabilidades (Seville, Brunsdon, Dantas, Le Masurier, Wilkinson, \& Vargo, 2006; Nascimento, 2014). Neaga (2010) caracteriza o contexto de uma organização como uma rede de colaboração de múltiplos 
parceiros de negócio e, para facilitar a colaboração, é necessário desenvolver uma boa gestão do conhecimento com esta rede. Entende-se por rede (network) a forma como a empresa: (i) estabelece relações, acordos de ajuda mútua e parcerias reguladoras; (ii) promove uma comunicação aberta e minimiza as barreiras internas e externas; e (iii) compreende a interconexão entre a organização e a comunidade (Nogueira \& Gonçalo, 2014). O network é desenvolvido pelas organizações à medida que se alinham às decisões sobre o ambiente externo, à tecnologia utilizada e ao inter-relacionamento das diversas áreas da organização (Akgün \& Keskin, 2014; McManus, 2008).

A capacidade para resiliência de uma organização é construída por meio do relacionamento de cooperação entre a empresa e os seus parceiros de negócio, isto ocorre quando a empresa percebe as inter-relações e interdependências entre os processos, informações e tecnologias que são compartilhados com os seus parceiros (Salgado, 2013). Caralli, Allen e White (2010) defendem que a organização precisa desenvolver estratégias para identificar as suas características internas e as influências externas que as tornam vulneráveis, principalmente em relação ao aumento da dependência com os parceiros externos, cujo relacionamento está em proporcionar à empresa capacidade de desenvolver suas atividades essenciais, o que pode acarretar uma exposição maior aos riscos, às falhas e às incertezas do ambiente (Salgado, 2013; Nascimento, 2014).

Para isto, é importante que a organização desenvolva as relações intra e interorganizacionais, isto é, apresente conectividade entre os parceiros, seja nas relações no interior da organização (envolvendo recursos humanos, operações e processos), seja nos relacionamentos externos envolvendo a organização e os parceiros (fornecedores, clientes, stakeholders) (Salgado, 2013; McManus, 2008; Stephenson, 2010; Stephenson, Vargo, \& Seville, 2010; Whitman, Kachali, Roger, Vargo, \& Seville, 2013). Em outras palavras, Erol, Sauser e Mansouri (2010) identificam a conectividade como um atributo fundamental da resiliência organizacional e apontam que uma organização com uma arquitetura organizacional bem definida apresenta uma visão simplificada e consolidada da organização dando suporte para integração da conectividade tanto no nível interno, no qual se requer uma integração da própria organização, quanto no nível intraorganizacional em que se exige uma integração entre a empresa e os parceiros, fornecedores e clientes.

De acordo com Lengnick-Hall et al. (2011), a gestão do contexto interno é regida pelo capital social que permite às organizações desenvolverem condições contextuais envolvendo as interações cordiais dentro da comunidade organizacional como os diálogos face a face, contínuos, enraizados na confiança, na honestidade e no respeito próprio. O capital social 
capacita a organização no desenvolvimento de colaboração entre as pessoas da organização, tornando-as mais propensas e mais capazes de compartilhar informações tácitas; facilita a troca de recursos, uma vez que os grupos reconhecem sua interdependência gerando parcerias de longo prazo; permite construir pontes que ultrapassam as barreiras internas e externas; e desenvolve uma rede de apoio e recursos.

Salgado (2013) aponta que a gestão do contexto externo da organização, para promover a adaptação e a capacidade de resposta da organização no sentido de dentro para fora, tende a ser realizada com a influência dos sistemas de informações. Complementando, Erol, Sauser e Mansouri (2010) apontam que a conectividade e a informação são dois elementos essenciais para a resiliência e, na perspectiva dos autores, desenvolver a capacidade de resiliência nas organizações consiste na percepção rápida das mudanças que ocorrem no ambiente e na implementação de respostas que antecedem estas adversidades; isto é proporcionado pelo uso efetivo dos sistemas organizacionais que fornecem informação a tempo e proporcionam rápida tomada de decisão que resulta no aumento da flexibilidade, agilidade e adaptabilidade (Erol, Mansouri, \& Sauser, 2009).

Cabe enfatizar que, quanto maior for a trajetória da organização no ambiente, mais atenta estará às adversidades, bem como à busca por práticas de gestão que permitam a continuidade das suas operações no mercado (Nascimento, 2014). As organizações ao lidarem com eventos imprevisíveis, gerindo a mudança e aproveitando as oportunidades, acabam melhorando sua competitividade e atendendo melhor às expectativas dos stakeholders (Nascimento, 2014). Desta forma, o indicador parcerias eficazes contempla a capacidade da organização de:

- PE1. Possuir alianças estratégicas e bom relacionamento com os stakeholders para garantir recursos necessários em apoio às iniciativas de mudanças (Akgün \& Keskin, 2014).

- PE2. Assegurar que os vínculos com vários stakeholders sejam mantidos, reforçando assim o capital social além das fronteiras da empresa (Akgün \& Keskin, 2014; Stephenson, 2010; Lee et al., 2013).

- PE3. Entender como está conectada aos stakeholders e gerenciar ativamente tanto estas parcerias quanto a possibilidade de angariar novas (Stephenson, 2010; Lee et al., 2013).

- PE4. Entender como as ações dos parceiros afetam a capacidade de resposta da organização em caso de adversidade (Stephenson, 2010; Lee et al., 2013). 
Nesta pesquisa o indicador Parcerias Eficazes está atrelado à organização possuir alianças estratégicas ao desenvolver relacionamentos interpessoais internamente e, externamente, a empresa apresentar vínculos com seus stakeholders (parceiros) e ter consciência de sua conexão e interdependência no desenvolvimento de suas atividades, especialmente em situações de adversidade.

\subsubsection{Recursos Disponíveis $(R D)$}

No tocante aos recursos necessários para a organização operar, Sutcliffe e Vogus (2003) e Stephenson et al. (2010) afirmam que a organização, para superar uma adversidade, deve priorizar e alocar os recursos de modo a alinhá-los com os objetivos, a missão e os valores da organização (Hamel \& Välikangas, 2003). Sob o ponto de vista de Lengnick-Hall et al. (2011), a capacidade organizacional para resiliência contempla a forma como a organização alavanca seus recursos não apenas para resolver dilemas atuais, mas para explorar novas oportunidades e construir um futuro bem-sucedido. Isto ocorre à medida que a organização aplica seus recursos visando ao seu desenvolvimento e ao seu crescimento, tendo em vista que exige a capacidade da organização de reorganizar-se e transferir não apenas os conhecimentos como também os recursos para superar adversidades (Sutcliffe \& Vogus, 2003). Cabe enfatizar que as organizações que desenvolvem comportamento resiliente aplicam de forma mais eficaz seus recursos em condições de incertezas de modo a direcionar o futuro da organização (LengnickHall \& Beck, 2009).

No nível organizacional, a resiliência resulta de processos e dinâmicas que criam e retêm recursos (Vogus \& Sutcliffe, 2007), pode-se supor que um modelo de referência apropriado de uma organização pode ser obtido pela abordagem de processo. Isto implica que uma organização é vista como uma rede de processos inter-relacionados que são direcionados para atingir objetivos e as metas organizacionais (Oakland, 2004; Aleksić, Stefanović, Arsovski, \& Tadić, 2013) e, entre os fatores da resiliência que afetam diretamente os processos organizacionais, Aleksić et al. (2013) e Tadić, Aleksić, Stefanović e Arsovski (2014) destacam os recursos internos e os recursos externos.

O primeiro gera impacto no desenvolvimento core business das organizações, tendo em vista que, sem recursos, nenhum processo pode se recuperar e operar normalmente, que é uma das suposições base de resiliência, o qual deve ser avaliado na forma de gestão adequada do processamento de recursos internos e dos procedimentos existentes em um momento de adversidade (Tadić et al., 2014). Cabe enfatizar que as organizações resilientes monitoram e 
relatam a situação interna por meio do sistema de informação organizacional, sendo este dedicado à conscientização organizacional.

Por outro lado, o segundo está atrelado ao gerenciamento adequado dos recursos que são introduzidos de fora da organização e são fundamentais para a empresa desempenhar seu core business (Tadić et al., 2014). Fato este que é enfatizado por Mallak (1998), ao afirmar que a organização que tem segurança de seus recursos externos expande suas tomadas de decisões. O relato das situações externas à organização deve estar alinhado com o sistema de informações da empresa, permitindo o gerenciamento de tais recursos.

Cabe enfatizar que as empresas que possuem uma abordagem limitada de recursos estão mais vulneráveis ao ambiente externo, de modo que precisam definir uma estratégia apropriada e assegurar os recursos para alcançar a resiliência (Aleksić et al., 2013). Por outro lado, Stephenson (2010) e Lee et al. (2013) afirmam que as organizações que apresentam agilidade em angariar recursos adicionais estão mais propensas a resultados positivos em situações de adversidades.

Complementando, Lengnick-Hall et al. (2011) afirmam que a organização resiliente decide se deve aproveitar os recursos que possui como vantagem competitiva ou alavancar novos recursos à medida que realiza diagnósticos do cenário e emprega ações necessárias para transformar o seu potencial competitivo em estratégias alinhadas aos objetivos organizacionais. Organizações resilientes apresentam gestão e mobilização de recursos para assegurar a sua capacidade de operar o negócio como de costume, bem como ser capaz de alocar recursos extras durante uma adversidade (McManus, 2008).

Porém, estas ações precisam estar ligadas à visão estratégica da organização, pois à medida que esta possui maior consciência sobre os recursos disponíveis interna e externamente (McManus, 2008), tem a possibilidade de direcioná-los a novos produtos e projetos (Hamel \& Välikangas, 2003) em situações de incertezas, proporcionando maior segurança para a organização atingir suas metas e objetivos conforme supera as adversidades, minimiza as interrupções e promove a continuidade de suas atividades (Lengnick-Hall e Beck, 2009; Nascimento, 2014).

O indicador recursos internos e externos disponíveis contempla a capacidade da organização de:

- RD1. Ter conhecimento sobre os recursos internos e externos disponíveis ao tomar uma decisão (Nascimento, 2014).

- RD2. Realocar os recursos para os novos produtos e projetos (Nascimento, 2014). 
- RD3. Manter recursos suficientes para absorver mudanças inesperadas (Stephenson, 2010; Lee et al., 2013).

- RD4. Ter agilidade em obter a aprovação de recursos adicionais para resolver situações de adversidade (Stephenson, 2010; Lee et al., 2013).

Define-se o indicador Recursos Disponíveis como o ato da organização de conhecer os recursos necessários para operar e a capacidade de priorizar e alocar tais recursos de modo a alinhá-los às suas prioridades.

Os 10 elementos de Resiliência Estratégica apresentados no decorrer desta seção mensuram a importância de desenvolver a capacidade das organizações para a gestão da resiliência visando que alcancem seus objetivos e prosperem no seu contexto empresarial. Erol, Mansouri e Sauser (2009) afirmam que os sistemas organizacionais auxiliam no desenvolvimento da resiliência à medida que fornecem informações a tempo e proporcionam rápida tomada de decisão. Para esta pesquisa, o olhar recai sobre o impacto do sistema de controle gerencial no desenvolvimento da resiliência organizacional sob o prisma do modelo teórico proposto por Simons (1995, 2000), o qual é utilizado pelas organizações para manter ou alterar os padrões das atividades organizacionais, apresentado a seguir.

\subsection{Sistema De Controle Gerencial (SCG)}

\subsubsection{Definição e modelos teóricos}

No ambiente empresarial global, contemporâneo, competitivo e complexo, as empresas estão sendo desafiadas a adotar modelos de negócios que lhes permitam lidar com as incertezas e riscos estratégicos que enfrentam em seus ambientes de negócios (Acquaah, 2013). Pesquisadores de contabilidade gerencial argumentam que uma das maneiras pelas quais as empresas podem rejuvenescer continuamente para sobreviver e ter sucesso neses ambientes complexos e incertos é entender o papel dos sistemas de controle gerencial (SCG) na criação de vantagens competitivas (Simons, 2000; Widener, 2007). De acordo com Davila, Foster e Li (2009), os SCG podem fornecer uma disciplina importante ao ajudar a gerenciar a incerteza e apoiam a necessidade de sistemas formais de controle gerencial em cenários incertos, pois, para os autores, os esforços prospectivos tipicamente associados ao SCG complementam a reação rápida a novas informações para melhorar a forma como as organizações lidam com a incerteza. 
A definição de SCG proposta por Simons (1995, p. 5) contempla um conjunto de sistemas de controle gerencial formados por "rotinas formais baseadas em informações e procedimentos que os gerentes utilizam para manter ou alterar padrões nas atividades organizacionais". Complementando, Anthony e Govindarajan (2008) definem SCG como um conjunto de atividades cuja finalidade consiste em promover o cumprimento dos planos gerenciais que estão diretamente vinculados com a operacionalização das estratégias organizacionais, cuja finalidade é alertar os gestores para as incertezas estratégicas de modo a minimizar ameaças e otimizar oportunidades. Abernethy e Brownell (1999) e Chapman (1998) apresentaram evidências consistentes em relação à relevância destes sistemas em ambientes incertos, englobando episódios de mudança estratégica. As pesquisas de Bisbe e Otley (2004), Davila et al. (2009) e Davila (2000) evidenciam como os sistemas de controle gerenciam a incerteza ao promover a inovação.

O sistema de controle gerencial é definido amplamente como um sistema que transmite informações úteis para auxiliar os gerentes em seus trabalhos e ao tomar decisão para atingir de maneira eficiente e efetiva as metas organizacionais desejadas (Anthony \& Govindarajan, 2008; Langfield-Smith, 1997; Otley, 1999; Tekavčič, Peljhan, \& Šević, 2008). A definição apresentada por Berry et al. (2005) apresenta-se mais próxima da perspectiva de Simons (1995), ao definir que o sistema de controle gerencial representa o processo de guiar a organização para padrões viáveis de atividades em um ambiente em mudança.

O objetivo do SCG é fornecer informações úteis para a tomada de decisões gerenciais, planejamento, monitoramento e avaliação de atividades organizacionais para alterar o comportamento dos funcionários (Merchant \& Otley, 2007). Cugueró-Escofet (2013) aponta que, entre os objetivos dos sistemas de controle gerencial (SCG), está o de motivar os gerentes a garantir que os objetivos organizacionais sejam alcançados. Os SCG também fornecem direcionamento estratégico para os esforços inovadores das empresas, e as eficiências que eles produzem podem liberar recursos para atividades inovadoras (Marginson, 2002). Simons (1994) aponta que os SCG são essenciais para ajudar os gerentes a formular estratégias, especificar as ações operacionais necessárias para implementar estas estratégias, esclarecer expectativas mútuas, identificar prioridades para melhorias operacionais e estabelecer metas que possam influenciar o desempenho atual e subsequente.

O SCG de uma organização envolve procedimentos, protocolos e rotinas formais baseados em informações usados pelas empresas para alinhar os comportamentos e decisões de seus funcionários com os objetivos estratégicos da organização (Merchant \& Van der Stede, 2007). Este alinhamento ajuda os funcionários a tomarem decisões ou cumprir suas 
responsabilidades e evita a perda de controle devido à falta de monitoramento (Simons, 1987, 1994).

Nesta pesquisa, os sistemas de controle gerencial são definidos pela maneira como os gerentes usam estes sistemas para a tomada de decisões no processo de gerenciamento de desempenho organizacional, sendo estudado a partir do ponto de vista das quatro alavancas de controle de Simons $(1995,2000)$ que consente o propósito de crescimento empresarial ao gerar motivação a partir do compartilhamento de informações e do aprendizado organizacional. Nesta abordagem, as quatro alavancas de controle (sistemas de crenças, sistemas de restrições, uso diagnóstico e uso interativo do sistema de controle) são utilizadas como um controle estratégico para auxiliar nas práticas organizacionais ao longo do tempo e no alcance dos objetivos organizacionais. As alavancas de controle de Simons (1995) combinam um foco na estratégia com uma visão mais ampla dos mecanismos de controle que podem ser utilizados para implementar a estratégia. O controle da estratégia de negócios é alcançado pela integração das quatro alavancas de controle. O poder destas alavancas na implementação da estratégia não reside em como cada uma é usada individualmente, mas sim em como elas se complementam quando usadas juntas (Simons, 2000).

No tocante aos sistemas de controle gerencial, esta pesquisa investigou sob o prisma do framework desenvolvido por Simons $(1995,2000)$ denominado Levers of Control (LOC), o qual é apropriado para este estudo por diversas razões, com destaque para:

- A essência do framework está no uso de sistemas de controle gerencial que promova direcionamento para a renovação estratégica, ao mesmo tempo que exerce controle de modo que os objetivos estratégicos sejam alcançados (Arjaliès \& Mundy, 2013; Simons, 1995). Busca-se com este trabalho observar como o uso do Sistema de Controle Gerencial influencia na gestão da resiliência organizacional e, também, no apoio às mudanças estratégicas.

- Um elemento central do framework LOC é o seu foco na forma como os gestores asseguram que as estratégias sejam implementadas com sucesso, porém ao mesmo tempo em que possibilitam que elas sofram alterações, ao passo que permaneçam abertas às estratégias que emergem de outras áreas do negócio (Arjaliès \& Mundy, 2013; Simons, 1995).

- Em terceiro lugar, o quadro LOC é uma ferramenta utilizada pelos gestores para lidar com incerteza estratégica (Arjaliès \& Mundy, 2013), bem como para promover a resiliência organizacional. A resiliência é acompanhada de incerteza estratégica, 
pois introduz nos negócios novos conjuntos de riscos e oportunidades que precisam ser gerenciados (Hamel \& Välikangas, 2003).

- De acordo com Arjaliès e Mundy (2013), Simons (1995), Henri (2006), Mundy (2010) e Widener (2007), o pleno potencial das quatro alavancas de controle é realizado quando são mobilizadas em conjunto, de modo a facilitar a implementação e a realização dos objetivos estratégicos de uma organização, que nesta pesquisa está sujeita ao nível com que alavancam a resiliência da organização investigada.

Entre as alternativas para se estudar sistema de controle gerencial, destacam-se dois modelos, sendo um elaborado por Ferreira e Otley (2009) denominado de "Performance Management System" e o segundo modelo em que Malmi e Brown (2008) propõem um estudo do sistema de controle gerencial como um pacote. Cabe enfatizar que Ferreira e Otley (2009) apresentam o framework de forma bem detalhada, o que permite que novas pesquisas possam utilizá-lo, e apresentam pesquisas empíricas já realizadas que contemplaram a proposta do artigo de modo a validarem o modelo. Os autores apresentam um passo a passo a ser desenvolvido à medida que propõem um instrumento de coleta de dados que abrange um checklist para os futuros pesquisadores realizarem suas pesquisas empíricas utilizando o modelo proposto. Além disso, apresentam como ponto positivo a sua utilização por organizações sem foco em lucro e a integração de modelos. Por outro lado, aparentemente o modelo considera apenas uma investigação do sistema diagnóstico, não aprofunda o uso, e as interconexões não são explicitamente tratadas. Este modelo apresenta um forte alinhamento à abordagem apresentada por Simons $(1995,2000)$.

Oframework apresentado por Malmi e Brown (2008) incentiva estudos que contemplem o sistema de controle gerencial como um pacote de forma a proporcionar a construção de uma teoria que mostre o impacto real da inovação e seja mais consistente sobre o desenho do controle organizacional ao contemplar os objetivos, as atividades de controle e os direcionadores do desempenho organizacional.

Cabe enfatizar que há muitos desafios para os pesquisadores ao estudarem empiricamente um Sistema de Controle Gerencial como um pacote, pois são sistemas amplos e complexos. A relevância em se estudar o sistema de controle gerencial como um pacote está ligada ao fato de que, ao entender o pacote dos sistemas de controle como um todo, o pesquisador passa a compreender melhor a organização investigada e reduz os resultados enviesados quando as ferramentas são investigadas isoladamente. 
Desta feita, a escolha pelo modelo teórico de Simons (1995, 2000) está no fato deste framework permitir uma interdependência e o entrelaçamento das quatro alavancas de controle gerencial e contribuir com a resiliência organizacional. Além disso, esse modelo diferente dos modelos de Ferreira e Otley (2009) e de Malmi e Brown (2008) possibilita investigar como a organização faz uso do sistema de controle gerencial, admite a sua operacionalização no cenário nacional e proporciona uma interface com a resiliência. O modelo de Ferreira e Otley (2009) não foi utilizado nesta tese, pois aborda questões já formuladas dificultando a percepção sobre a resiliência, tendo em vista que o objetivo principal desse modelo é verificar a existência dos elementos do sistema de controle gerencial na organização. O modelo de Malmi e Brown (2008) também não foi abordado neste estudo devido ao fato da exigência do modelo em investigar de forma isolada os mecanismos de controle, pois o objetivo deste modelo está no controle e não no suporte ao processo de tomada de decisão.

A seguir é detalhado o framework desenvolvido por Simons $(1995,2000)$ denominado Levers of Control (LOC).

\subsubsection{Uso dos sistemas de controle gerencial}

Sabe-se que, desde o seu desenvolvimento na década de 1990, o framework estruturado por Robert Simons tem sido bastante explorado na academia tanto na esfera internacional quanto nacional nas pesquisas na área de contabilidade e controle gerencial. Este é operacionalizado por quatro alavancas de controle que permitem que as empresas caracterizem o seu modelo de gestão conforme as suas necessidades de informação. A estabilidade entre elas é atribuída por meio das dimensões positivas e negativas do controle que ocorrem conforme o contexto organizacional.

O framework de Simons $(1995,2000)$ propõe-se a analisar quais são as técnicas e os artefatos da implantação da estratégia e como a estratégia empresarial é implementada e controlada. Assim, a proposta de Simons é entender como os gestores controlam a estratégia utilizando os quatro níveis de controle: sistema de crenças, sistema de restrições, sistema de diagnóstico e sistema interativo. Observa-se que os quatro sistemas trabalham simultaneamente, porém com objetivos diferentes.

No framework de Simons (1995, 2000), o foco central é a estratégia empresarial, em segundo nível têm-se quatro constructos chaves que proporcionam o sucesso da implantação da estratégia, os quais são controlados por quatro sistemas diferentes. O sistema de crenças que é utilizado para inspirar e direcionar a busca por novas oportunidades, o sistema de restrições que 
impõe limites na busca por oportunidades, o sistema de diagnóstico que visa à motivação, ao monitoramento e à realização de recompensas por objetivos específicos, e o sistema interativo que estimula a aprendizagem empresarial, do qual emergem novas ideias e novas estratégias.

Observa-se que, na esfera internacional, diversas pesquisas empíricas utilizam este framework, a saber: Acquaah (2013), Anderson, Christ, Dekker e Sedatole (2015), Arjaliès e Mundy (2013), Bedford (2015), Bisbe e Otley (2004), Bruining, Bonne e Wright (2004), Davila e Foster (2008), Fauzi e Rahman (2008), Henri (2006), Hoque e Chia (2012), Kruis, Speklé e Widener (2016), Marginson (2002), Mundy (2010), Pinzón, Vázquez, Elorza e Espejo (2011), Rieckhof, Bergmann e Guenther (2015), Tekavčič, Peljhan e Šević (2008) e Widener (2007). Entre as principais pesquisas internacionais que utilizam o framework, destacam-se as de Widener (2007) e Kruis, Speklé e Widener (2016), as quais são os alicerces para a construção do instrumento de investigação a ser utilizado na presente tese, tendo em vista que ambas desenvolveram e testaram empiricamente o instrumento para coleta de dados de modo a captar os elementos propostos por Simons $(1995,2000)$ em seu modelo teórico. Sob um outro prisma é destaque a investigação realizada por Tessier e Otley (2012), em que apontam as principais lacunas e ambiguidades do modelo proposto por Simons (1995, 2000).

No tocante à literatura de contabilidade gerencial no Brasil, este framework tem sido bastante disseminado em diferentes contextos organizacionais, como pode ser evidenciado pelas pesquisas de Alves (2010), Anzilago, Beuren e Dal Vesco (2015), Canan (2013), Cruz, Frezatti e Bido (2015), Diehl e Souza (2008), Frezatti, Junqueira, Bido, Nascimento e Relvas (2012), Isidoro (2012), Mantovani (2012), Lavarda e Pereira (2012), Nisiyama e Oyadomari (2012), Oro (2015), Oyadomari, Frezatti, Cardoso e Aguiar (2009), Oyadomari, Cardoso, Silva e Perez (2010), Oyadomari, Frezatti, Mendonça Neto, Cardoso e Bido (2011), Utzig (2012), entre outras.

Assim, observa-se que, ao utilizar os sistemas de controle gerencial propostos por Simons (1995, 2000), busca-se o desenvolvimento de uma estrutura organizacional que supervisiona, integra o negócio e monitora os riscos de modo a permitir que a empresa seja capaz de melhorar a tomada de decisões às respostas ao risco à medida que sofre mudanças imprevistas no ambiente, consequentemente, promovendo a capacidade organizacional de resiliência. $\mathrm{O}$ sistema de controle gerencial desempenha um papel na adaptação de atitudes e de comportamentos gerenciais para ser mais consistente com a nova estratégia e o novo ambiente competitivo. 


\subsubsection{Sistemas de Crenças}

Os sistemas de crenças contemplam a comunicação da missão, da visão, das crenças e dos valores da organização aos seus integrantes. Além disso, é por meio destes sistemas de controle gerencial que as prioridades da organização são comunicadas. Entre os resultados pretendidos dos sistemas de crenças estão a motivação e a inspiração da força de trabalho em busca de oportunidades e soluções (Mundy, 2010). Simons (1995) afirma que é pelos sistemas de crenças que ocorre a comunicação formal dos valores básicos, do propósito e da direção da organização.

A finalidade dos sistemas de crenças é inspirar a pesquisa organizacional e a descoberta. Qualquer sistema de controle gerencial que fornece aos gerentes informações sobre os valores e ou sobre as prioridades da organização pode ser categorizado como um sistema de crenças (Mundy, 2010; Lavarda \& Pereira, 2012). Bedford (2015) enfatiza, em sua pesquisa, os quatro atributos dos sistemas de crenças apresentados por Simons (1995, 2000), a saber: (1) codificam os valores fundamentais da firma, (2) comunicam ativamente os valores, (3) são utilizados para criar nos membros da organização compromisso com os objetivos da firma, e (4) inspiram e orientam a busca de novas oportunidades.

Os sistemas de crenças contemplam os procedimentos que a alta gestão utiliza para comunicar a visão, os valores e a estratégia global da empresa, influenciam no estilo de liderança e na cultura organizacional. $\mathrm{O}$ estilo de liderança e a cultura organizacional são considerados controles informais, os quais são influenciados pelos sistemas de crenças (Tekavčič et al., 2008).

No decorrer do processo de mudanças estratégicas, os sistemas de crenças auxiliaram as pessoas continuamente a se desenvolverem e a crescerem dentro da organização, à medida que se construiu uma nova visão e os objetivos foram compartilhados e implementados por meio do trabalho em equipe e com um alto nível de comprometimento. Tal situação também é evidenciada por Arjaliès e Mundy (2013), ao afirmarem que a finalidade do sistema de crenças é garantir o comprometimento dos colaboradores para com os objetivos comuns da organização e ao mesmo tempo inspirando-os a procurar oportunidades organizacionais. Cabe enfatizar que os sistemas de crenças desempenham um papel importante nas organizações, baseados no conhecimento, em que o sucesso organizacional é dependente de fornecimento de um ambiente no qual os funcionários trabalham em equipes em busca de objetivos globais (Abernethy \& Vagnoni, 2004). 
Os sistemas de crenças ajudam a fomentar um sentimento de estabilidade e continuidade, mas também podem permitir a mudança organizacional quando os gerentes os utilizam para introduzir novas prioridades ou novos valores (Bruining, Bonnet, \& Wright, 2004; Simons, 1995). Por outro lado, Widener (2007) e Marginson (2002) defendem que o sistema de crenças proporciona motivação para novas ideias, ações e iniciativas. De tal forma que são complementados pelos resultados evidenciados na pesquisa de Chenhall, Kallunki e Silvola (2011), ao passo que os sistemas formais influenciam positivamente a inovação.

Para Arjaliès e Mundy (2013), o sistema de crenças proporciona uma agenda estratégica corrente entre os membros da organização e, assim como o sistema interativo, promove processos que estimulam o debate e incentivam a inovação. Simons (1995) e Lavarda e Pereira (2012) enfatizam que o sistema de crenças auxilia e direciona os membros da organização na identificação de um problema e na busca por soluções ao ser implantada a estratégia organizacional. Quando a aplicação da estratégia ocorre sem mudanças inesperadas, os sistemas de crenças auxiliam a promover motivação aos indivíduos na busca de novas formas de criação de valor (Simons, 1995).

De acordo com Mundy (2010), o sistema de crenças encoraja os gestores a encontrar as melhores soluções e os auxilia a incentivar o pessoal a contribuir em busca de novas oportunidades. Kominis e Dudau (2012) alertam que o sistema de crenças, ao comunicar formalmente os valores fundamentais da organização aos seus membros, visa ao engajamento dos membros da organização ao mesmo tempo em que tem a intenção de dirigir a atenção e promover compromisso com os valores centrais da organização. Os sistemas de crenças na percepção destes autores podem ser uma inspiração para os membros da organização, chamando a atenção para os princípios-chaves da estratégia organizacional.

Para Arjaliès e Mundy (2013), o sistema de crenças é utilizado para comunicar os valores fundamentais da organização ao passo que estabelece uma visão compartilhada da missão e dos valores da organização; une os funcionários ao redor do conjunto de valores organizacionais; e inspira os funcionários a procurar oportunidades. Widener (2007, p. 759) complementa ao afirmar que "um sistema de crenças comunica valores fundamentais, a fim de inspirar e motivar os funcionários a procurar, a explorar, a criar e a despender esforços para engajar-se em ações apropriadas". Ou seja, são estes controles que inspiram a força de trabalho a tomar as decisões desejadas pela alta administração. De acordo com Pavlovska e KuzminaMerlino (2013), o sistema de crenças apresenta conselhos que determinam o estilo da tomada de decisão. 
Para Rieckhof et al. (2015), os sistemas de crenças fornecem orientações para o desenvolvimento organizacional e para o processo de tomada de decisão, o qual esboça e amplia a gama de oportunidades do empreendimento. Este sistema permite que as pessoas envolvidas possam contribuir com os principais objetivos organizacionais. O sistema de crenças desenvolve uma cultura organizacional que enfatiza a comunicação e o desenvolvimento da aprendizagem organizacional, à medida que permite a comunicação entre departamentos. Segundo Speklé (2001), os sistemas de crenças também são usados pelos gerentes que operam em condições incertas para sinalizar metas estratégicas aos membros da organização, de forma a direcionar o seu comportamento para os resultados desejados.

Sob um outro prisma, Jansen (2011) afirma que os sistemas de crenças proporcionam aos membros da organização mais liberdade na execução das suas tarefas e na tomada de decisões. As empresas utilizam os sistemas de crenças para alinhar / articular os valores e as direções dos funcionários, tendo em vista que a empresa depende dos funcionários para gerar novas ideias e consequentemente alcançar vantagem competitiva (Simons, 1995; Tekavčič et al., 2008). Assim sendo, é importante que os gestores comuniquem ativamente e constantemente os valores e a missão da empresa aos diversos níveis organizacionais, de modo a inspirar todas as pessoas da organização.

\subsubsection{Sistemas de Restrições}

Simons (1995, p. 58) aponta que, tanto os sistemas de crenças quanto os sistemas de restrições, são essenciais na vida da organização, pois são os responsáveis pelo direcionamento da organização, ao passo que orientam preventivamente os gestores na busca de novos horizontes que permitam melhorias em seu desempenho (Oyadomari, 2008). Desta feita, possibilitam a operacionalização da capacidade de resiliência da organização.

Por um lado, o sistema de crenças motiva os colaboradores a buscarem novas oportunidades a serem exploradas. Por outro, o sistema de restrições, ao considerar os riscos que a organização deseja evitar, impõe os limites e as regras para as ações na organização. Estes são utilizados para delinear os comportamentos e as atividades aceitas pela gestão, isto é, proporcionam a exploração de novas oportunidades e o investimento dos recursos em elementos que sejam alinhados com os objetivos, a missão e os valores da organização, pois visa-se manter o seu status quo e melhorar o desempenho organizacional, ao mesmo tempo em que comunica formalmente os riscos a serem evitados (Widener, 2007; Acquaah, 2013; Arjaliès \& Mundy, 2013; Cruz, Frezatti, \& Bido, 2015; Fauzi \& Rahman, 2008; Hoque \& Chia, 2012; Tessier \& 
Otley, 2012). Ao atuar desta forma, segundo Lengnick-Hall e Beck (2009), a organização assume um comportamento resiliente.

Simons (1995, p. 59) afirma que "os sistemas de crenças e de restrições são as rotinas formais baseadas em informações e procedimentos que os gestores utilizam para manter ou alterar os padrões de atividades organizacionais". Ambos proporcionam oportunidade de expansão, bem como são direcionados para o aumento do desempenho da empresa e, à proporção que se tem na organização um sistema de crenças comunicado de forma clara, fazse necessária a existência de um sistema de restrições que proporcione a sua execução. Este fornece impulso e promove o compromisso dos colaboradores. Assim, ao haver na organização um sistema de crenças forte e consolidado e um sistema de restrição claro e disseminado entre seus membros, é possível assegurar aos gestores que seus subordinados não estão envolvidos em atividades que possam colocar em risco a integridade do negócio e que os recursos sejam aplicados em projetos ou ações que visam promover vantagens competitivas no mercado. A integração entre estes sistemas permite aos gestores se concentrarem em posicionar suas empresas para enfrentar os desafios competitivos do mercado (Simons, 1995, p. 58), pois são os sistemas de controle que alicerçam a gestão de riscos estratégicos (Nisiyama \& Oyadomari, 2012).

Os sistemas de restrições comunicam e direcionam o domínio aceitável para a atividade em busca de oportunidades, assim como delimitam aos participantes da organização onde e no que devem exercer as suas energias (Simons, 1995; Frezatti, Junqueira, Bido, \& Relvas, 2012). Simons (1995, p. 42) enfatiza que "o compromisso com os valores e a missão da organização é interagido com a liberdade dentro dos limites claramente definidos e comunicados dentro da empresa". Em outras palavras, Oyadomari (2008) e Mantovani (2012) afirmam que os sistemas de restrição auxiliam os gestores na medida em que delimitam o campo de atuação estratégica da empresa, proporcionando aos membros criatividade e flexibilidade no processo de tomada de decisão, e contribuem ao evitar que estes utilizem tempo e recursos na busca de novos horizontes que não estejam alinhados aos objetivos organizacionais. Estes sistemas surgem nas organizações em condições de alta incerteza ambiental, cujo propósito principal é impor diretrizes claras sobre o comportamento inaceitável dos agentes internos na organização (Widener, 2007; Diehl \& Souza, 2008). Tais sistemas formais de restrições são determinados por meio da análise dos riscos associados à estratégia empresarial e estes são classificados em dois tipos, a saber: os de conduta e os estratégicos (Simons, 2000; Tekavčič et al., 2008; Tessier \& Otley, 2012). 
No tocante aos sistemas de restrições de conduta empresarial, tem-se as limitações quanto às atividades e os comportamentos que propiciariam riscos ao bem-estar da organização, expondo-a a potencial perda de bens, de reputação ou de responsabilidade legal (Simons, 1995), ao passo que delimitam os riscos a serem assumidos pela organização (Nisiyama \& Oyadomari, 2012). Sabe-se que a ausência de compromisso compartilhado com a missão e os objetivos organizacionais pode resultar em comportamentos que visem ao autointeresse no lugar dos interesses organizacionais. Entre os principais sistemas de controle estão o código de ética, as políticas de gestão de risco, a política corporativa anticorrupção e as diretrizes de conduta da empresa em análise (Simons, 1995). Hoque e Chia (2002) e Cruz, Frezatti e Bido (2015) apontam que o planejamento estratégico e as diretrizes operacionais com limites mínimos aceitáveis também podem ser utilizados na alçada dos sistemas de restrições. Simons (1995) e Arjaliès e Mundy (2013) enfatizam que estes documentos e procedimentos estáticos devem ser transformados em sistemas de informações sobre as crenças e as restrições em toda a organização e devem ser reforçados continuamente por meio de programas educativos, treinamentos, documentos, pesquisas da consciência, sessões de feedback, processos internos como a comunicação via intranet.

Por outro lado, os sistemas de restrições devem apoiar as estratégias do negócio à medida que impõem os chamados limites estratégicos, estes podem dificultar a adaptação às mudanças no mercado, seja de produto, de tecnologia e ou de condições ambientais. Observase que tais sistemas direcionam os trabalhadores a procurarem novas oportunidades que estejam alinhadas com o core business da organização (Simons, 1995, 2000; Fauzi \& Rahman, 2008). Nesta perspectiva, Kruis et al. (2016) apontam que o foco dos sistemas de restrições está em identificar as oportunidades que proporcionem a alavancagem de iniciativas estratégicas que acarretem o desenvolvimento da resiliência organizacional ao passo que reduzem a vulnerabilidade permitindo que a organização melhore a sua capacidade adaptativa de gerir as adversidades do mercado (Sheffi \& Rice, 2005; Acquaah, Amoako-Gyampah \& Jayaram, 2011). Desta forma, nota-se que os limites estratégicos mais rígidos deixam claras as regras e as limitações aplicadas a decisões a serem tomadas pelos membros da organização de como deverão ser empregados os recursos em resposta às oportunidades identificadas no sistema de crenças (Simons, 1995, 2000; Fauzi \& Rahman, 2008). 


\subsubsection{Uso Diagnóstico dos Sistemas de Controle Gerencial}

O uso diagnóstico do sistema de controle gerencial ocorre quando os gestores visam comparar o desempenho alcançado com o planejado a fim de identificar as exceções e os desvios críticos de planos. O feedback sobre o desempenho permite aos gestores ajustarem as suas ações quando os resultados estão abaixo das expectativas (Arjaliès \& Mundy, 2013; Simons, 1995; Tessier \& Otley, 2012). De acordo com Bhimani e Langfield-Smith (2007), os processos de diagnóstico permitem aos funcionários visualizarem as atividades que devem ser executadas com intuito de atingir os objetivos estratégicos da organização.

De acordo com Mundy (2010) e Tessier e Otley (2012), quando os sistemas de controle gerencial são utilizados para diagnóstico, o objetivo é comparar o desempenho real com as metas pré-estabelecidas. Os sistemas de controle diagnóstico são utilizados como alavancas para comunicar as variáveis críticas de desempenho e para monitorar a implementação da estratégia (Simons, 2000). Este sistema de controle é definido como "um sistema de informação formal que os gestores utilizam para monitorar os resultados organizacionais e corrigir os desvios de padrões pré-estabelecidos de desempenho" (Simons, 1995, p.59).

Observa-se que tanto Tessier e Otley (2012) quanto Mundy (2010) apontam que os controles alocados neste sistema são utilizados como feedback pela organização, para identificar as exceções e os desvios de planos, de modo a exigir dos gestores medidas corretivas. Assim, legitimam as ideias de Simons (2000) ao enfatizar que as principais razões para o uso diagnóstico do sistema de controle são: para implementar de forma eficaz a estratégia e reter a atenção da gestão.

No tocante aos indivíduos e às equipes de trabalho, cabe destacar que, ao utilizar o sistema de feedback, baseado em definição de meta, medidas e recompensas, a entidade garante que os participantes trabalhem para alcançar metas e dispensa a supervisão constante dos gestores. O uso diagnóstico do sistema de controle permite a autonomia máxima aos participantes da organização, sendo que estes possuem liberdade para escolher como realizar suas tarefas de modo a atingir os objetivos esperados, bem como para ajustar os inputs e os processos quando necessário. Porém, os indivíduos são responsabilizados pelos seus resultados (Simons, 1995). Desta feita, os gestores investem sua atenção ao utilizar para diagnóstico o sistema de controle em cinco momentos: ao definir e negociar as metas; ao alinhar as medidas de desempenho; ao estabelecer os incentivos; ao revisar os relatórios de exceção; e ao acompanhar exceções que são mais significativas (Simons, 2000, p. 211). 
Simons (2000, p.209) apresenta os principais sistemas de controle gerencial e de mensuração de desempenho que são utilizados pelos gestores como diagnóstico: balanced scorecard, orçamento, sistema de monitoramento de projetos, sistema de monitoramento de market-share, sistema de recursos humanos e custo padrão. Porém, enfatiza que qualquer sistema de informação pode ser utilizado de forma diagnóstica desde que assuma as seguintes características: permitir que uma meta seja definida previamente; apresentar medidas de resultados; calcular os desvios de desempenho; e utilizar a informação da variação como feedback para alterar inputs e/ou os processos para obter novamente o desempenho alinhado com a meta e com os padrões que foram preestabelecidos.

Considerando que mudanças e surpresas são inimigas, isto é, os reporters realizados pelo uso diagnóstico dos sistemas de controle são realizados primeiramente para confirmar se o caminho percorrido foi o planejado (Simons, 1995). Busca-se investigar, nesta pesquisa, como o uso diagnóstico do sistema de controle promove a resiliência organizacional ao passo que enfatiza as variáveis críticas de desempenho, também conhecidas como fatores chaves do sucesso, que são os fatores a serem alcançados ou implementados com sucesso para que a estratégia almejada seja alcançada. Simons (1995, p.66) afirma que o sistema de controle gerencial, ao ser utilizado como diagnóstico, proporciona indicadores para garantir que tais fatores sejam gerenciados de forma eficaz e eficiente.

Desta feita, a expectativa deste trabalho é que, ao realizar o uso diagnóstico dos sistemas de controle, tenha-se a atenção dos gestores para os fatores que impactam a resiliência organizacional, para que estejam preparados para solucionar os problemas ao descobrir que "uma estratégia falhou e, em seguida, perguntar quais fatores seriam identificados como causas para esta falha" (Simons, 1995, p.63). Assim sendo, espera-se que o uso diagnóstico dos sistemas de controle seja essencial para a promoção da resiliência organizacional.

\subsubsection{Uso Interativo dos Sistemas de Controle Gerencial}

De acordo com Simons (2000, p. 208), o sucesso da organização é determinado pela habilidade em se comunicar efetivamente a estratégia aos empregados e controlar a sua implementação. Deste modo, os sistemas interativos de controle são utilizados com intuito de direcionar a atenção da empresa nas incertezas estratégicas, por meio de uma alavanca que é utilizada para ajustar e alterar a estratégia com base nas mudanças ocorridas nos mercados competitivos. 
Os sistemas interativos de controle "são sistemas de informação formal que os gestores utilizam para envolver-se pessoalmente nas atividades de decisões dos subordinados" (Simons, 2000, p. 216). No framework apresentado por Simons (1995, 2000), encontram-se diversas exposições ao caracterizar o uso interativos dos sistemas de controle gerencial. Na obra "Levers of Control", publicada em 1995, o autor (p. 97) aponta algumas características para determinar que a empresa está realizando o uso interativo dos sistemas de controle gerencial: (i) a informação gerada por este sistema é um importante e recorrente tema abordado pelos mais altos níveis de gestão; (ii) este sistema exige atenção frequente e regular dos gerentes operacionais em todos os níveis da organização; (iii) os dados gerados por este sistema são interpretados e discutidos em reuniões com os superiores, os subordinados e os pares; e (iv) este sistema é um catalisador para o desafio contínuo e para o debate sobre os dados subjacentes, os pressupostos e os planos de ações.

Observa-se que a principal distinção entre o uso diagnóstico e o uso interativo dos sistemas de controle está na forma como os gestores os utilizam. Por exemplo, o mesmo sistema de planejamento estratégico ou o Balance Scorecard pode ser utilizado tanto diagnosticamente quanto interativamente. Assim, Simons (1995, p.108-109; 2000, p. 220-221) apresenta as condições necessárias para que um sistema de controle possa ser utilizado interativamente:

- Coletar e gerar informações que se relacionem com os efeitos das incertezas estratégicas sobre a estratégia do negócio. Pois as incertezas estratégicas são únicas em cada organização, bem como a estratégia empresarial.

- Apresentar informação de forma simples e de fácil entendimento. Pois almeja a compreensão, a aprendizagem e a revisão dos planos de ação. O debate deve centrar-se sobre as causas e as implicações da informação, e não em como esta foi construída e reportada. Os sistemas complexos que dependem das transformações dos dados por especialistas da equipe não podem ser usados de forma interativa. Além disso, as informações de sistemas complexos muitas vezes sofrem atrasos na coleta e no processamento dos dados.

- Ser utilizado pelos gestores em vários níveis organizacionais, e não apenas pelos gerentes senior. Uma vez que o sistema é um catalisador para as atividades de pesquisa, deve ser útil e amplamente utilizado por diversos integrantes da empresa.

- Exigir o reforecasting de situações futuras com base em uma reavaliação das informações atuais e dos planos de ação. Um sistema interativo de controle 
concentra a atenção sobre padrões de mudança, sua intensidade, frequência e direção. Em situações competitivas, as previsões para as condições de mudança devem fornecer informações significativas sobre a forma de ajustar a estratégia para ganhar vantagem. Este tipo de informação é vital para as organizações que querem adaptar-se em mercados competitivos, permitindo desenvolver novos planos de ação.

Observa-se que Denhardt e Denhardt (2010) compartilham da ideia de Weick e Sutcliffe (2007) ao destacarem que, dentro da perspectiva dos sistemas complexos, os processos de gestão podem ser melhorados, tornando-os adaptáveis e flexíveis, sendo capazes de lidar com a incerteza, surpresa, e adversidade, à medida que promovem a construção da capacidade de adaptação à mudança. Em outras palavras, à medida que a empresa mitiga as incertezas estratégicas, há um aumento no desenvolvimento de sua capacidade organizacional para a resiliência.

Corroborando, as pesquisas de Acquaah (2013), O’Connor, Vera-Muñoz e Chan (2011) e Widener (2007) apontam que o uso interativo do sistema de controle influencia a implementação do custo da liderança estratégica, pois tem como foco os vários tipos de mudanças ambientais e de incerteza estratégica, tais como táticas de concorrentes, mudanças de mercado, mudanças tecnológicas e as variações nos custos de transferência dos clientes. Nesta mesma direção, Langfield-Smith (1997) afirma que o uso interativo de vários sistemas de controle é aplicado na empresa durante curtos períodos, especialmente quando ocorrem adversidades e incidentes críticos, ou quando a organização está em transição. Neste sentido, observa-se que a escolha estratégica por um tipo de sistema de controle para ser utilizado de forma interativa é influenciada pela dependência tecnológica nos mercados do produto, pela complexidade da cadeia de produção e pela capacidade dos concorrentes para responder às iniciativas de mercado do produto.

O uso interativo do sistema de controle visa expandir o aprendizado organizacional e a busca por oportunidades, de modo a auxiliar a empresa a mudar e a sobreviver em um mercado competitivo. Além disso, apoia a implementação de uma estratégia diferenciada, ao mesmo tempo em que identifica novas ideias e estimula a inovação (Acquaah, 2013). Porém, dependendo da estratégia e da visão da gestão para o futuro, as incertezas estratégicas podem ser relacionadas com as seguintes mudanças: preferências dos clientes, ações dos concorrentes, novas tecnologias, regulamentações governamentais ou qualquer outra potencial ameaça e oportunidade encontrada no mercado (Simons, 2000, p. 217). 
Entre as características do uso interativo dos sistemas de controle, Davila e Foster (2008, p. 1328) apontam que estes são sistemas de controle gerencial que possuem mecanismos de apoio à gestão de modo que as organizações se adaptem ao passarem por um processo de mudanças nas condições empresariais. Anthony e Govindarajan (2008) corroboram ao afirmar que, para a sobrevivência de uma organização em um ambiente dinâmico, sujeito a rápidas mudanças, o aprendizado é essencial. Assim sendo, fundamenta-se a necessidade do uso interativo do sistema de controle, cujo propósito é promover um clima de aprendizado na organização. Desta feita, estes mostram resiliência por causa de sua capacidade de adaptação a eventos inesperados e possuem capacidade dinâmica de redesenhar os processos, de capturar e de codificar o conhecimento.

Assim, Simons (2000, p.218) afirma que os gestores utilizam os processos de controle interativo para orientar a busca por novas oportunidades e para obter respostas rápidas, de forma a manter o controle; caso contrário, tal fato se tornaria um processo caótico. Isto posto, observase que o uso interativo dos sistemas de controle permite que uma empresa realize adaptações em sua estratégia. Corroborando, Widener (2007, p.760) afirma que o sistema interativo é destinado a ajudar a empresa na busca por novas maneiras de posicionar-se estrategicamente em um mercado dinâmico e a apoiar a resiliência organizacional. Desta forma, os mecanismos provocam um efeito sobre as pessoas, proporcionando oportunidade de discussão de resultados e planejamento de ações no futuro que implica em redução da percepção de incerteza (Arjaliès \& Mundy, 2013; Tessier \& Otley, 2012), o que se apresenta de forma bastante relevante para que a resiliência seja "justificada" no ambiente de trabalho. Assim sendo, observa-se que, em ambientes incertos, os sistemas de controle gerencial são relevantes para a continuação das atividades empresariais e auxiliam a organização no desenvolvimento de sua capacidade para a resiliência (Davila \& Foster, 2008).

\subsection{Desenvolvimento da Hipótese e do Modelo Teórico}

A resiliência é oriunda da necessidade das organizações de reinventar-se e adaptar-se às mudanças, de forma dinâmica. Assim, a resiliência, na visão dos autores Hamel e Välikangas (2003), promove mudanças nos modelos organizacionais e nas estratégias das organizações. Cabe enfatizar que, com a alta complexidade do cenário empresarial e sua interdependência, as entidades se tornam mais vulneráveis, tendo em vista o alto índice de ameaças e perigos que permeiam o ambiente externo. Whitehorn (2011) aponta que há uma necessidade das empresas de controlar tais eventos de modo que não se transformem em uma situação de emergência, de 
crise ou em uma catástrofe. Corroborando, Lengnick-Hall e Beck (2009) escrevem que o comportamento resiliente permite que as entidades aprendam mais, implementem novas rotinas e utilizem melhor seus recursos em condições de incertezas que podem afetar definitivamente o futuro da organização. De acordo com Bhamra et al. (2011), cultivar os elementos de resiliência pode ser fundamental para uma organização obter vantagem competitiva, o que é denominado pelos pesquisadores de "resiliência estratégica".

Sheffi e Rice (2005) e Acquaah et al. (2011) apontam que o desenvolvimento da resiliência organizacional deve ser oriundo de uma iniciativa estratégica destinada a reduzir as vulnerabilidades provocadas pelas mudanças no ambiente competitivo. Assim sendo, a organização resiliente alinha eficazmente a sua estratégia, suas operações, seus sistemas de gestão, sua estrutura de governança, e suas capacidades de suporte à decisão, de modo a adaptarse continuamente aos riscos, o que acarreta uma vantagem competitiva (Starr, Newfrock, \& Delurey, 2003; Sheffi, 2005; Salgado, 2013).

Dentro da percepção de incertezas estratégicas apresentadas por Simons (2000), observa-se que, na percepção de resiliência organizacional, Whitehorn (2011) e Nogueira e Gonçalo (2014) afirmam que o principal desafio das organizações está na busca por estratégias alternativas que resguardem as dimensões sociais, econômicas e ambientais, pois faz-se necessário que compreendam a natureza dinâmica dos seus ambientes de negócios que incluem os concorrentes, a tecnologia, a disponibilidade e o custo do financiamento, a fiscalização e a política governamental, as necessidades e expectativas de seus clientes (Sheffi, 2005; Salgado, 2013). Além disso, as organizações precisam ser capazes e estarem dispostas a se adaptar às mudanças bruscas em relação ao ambiente em que estão inseridas. Corroborando, Hamel e Välikangas (2003) argumentam que, para as entidades terem continuidade e serem bem sucedidas, devem evoluir como sistemas empresariais resilientes, em constante adaptação para refletir as mudanças no ambiente. Complementando, tem-se a definição de resiliência apresentada por Allenby e Fink (2000) e Rose (2007) que é a capacidade de um sistema manter suas funções e estrutura em face das mudanças internas e externas.

De acordo com Anthony e Govindarajan (2008), os sistemas de controle gerencial auxiliam os gestores a movimentarem a organização na direção de seus objetivos estratégicos, promovendo condições à empresa para antecipar-se ao futuro, garantindo que os objetivos sejam alcançados. Os sistemas de controle gerencial são relevantes para a continuação das atividades organizacionais à medida que direcionam as estratégias adotadas pela organização (Berry et al., 2005). 
A configuração dos sistemas das organizações atua como antecedente da resiliência organizacional, pois a influencia diretamente (Beuren \& Santos, 2017; Ignatiadis \& Nandhakumar, 2007). O papel dos sistemas de controle gerencial como o gerador (na gestão) da resiliência organizacional instiga as instituições a desenvolverem os seguintes atributos da resiliência organizacional apresentados por Whitehorn (2011): antecipar ameaças emergentes e compreender seu efeito sobre os objetivos da organização e os objetivos estratégicos; assumir uma liderança forte que articula e incentiva a implementação de metas organizacionais e objetivos estratégicos; estimular e apoiar sua força de trabalho; promover um network com alianças estratégicas; e desenvolver a capacidade de responder e recuperar-se de forma rápida.

De acordo com Burnard e Bhamra (2011), por meio do cultivo dos elementos da resiliência nos sistemas organizacionais, pode-se desenvolver não só uma tolerância ao risco, mas também uma habilidade inata para se ajustar de forma proativa num cenário de incerteza ambiental. Para os autores, as organizações não só seriam mais bem posicionadas e preparadas para lidar com as demandas de eventos de alto impacto, como também poderiam buscar oportunidades e ganhos por meio da incerteza, ou seja, a partir do desenvolvimento da resiliência organizacional, as empresas estariam mais preparadas para assumir e gerir riscos, o que traria melhor posicionamento no contexto mercadológico.

Desta feita, a presente pesquisa investiga como o uso dos Sistemas de Controle Gerencial (SCG) auxilia a empresa a desenvolver a sua capacidade de resiliência à medida que esta passa a compreender o contexto de seu ambiente operacional, a reconhecer suas principais vulnerabilidades, a adaptar-se no ambiente dinâmico, complexo e interconectado na qual está inserida, e a ser flexível à proporção que se adequa a tais mudanças (McManus, Seville, Brunsdon, \& Vargo, 2007). Conforme apresentado anteriormente, a escolha pelo modelo teórico "Levers of Control” de Robert Simons (1995, 2000) está conectada ao seu propósito que é analisar quais são os sistemas de controle gerencial utilizados para implementar, controlar e promover direcionamento para a renovação da estratégica organizacional, ao mesmo tempo que exerce controle de modo que os objetivos estratégicos sejam alcançados (Arjaliès \& Mundy, 2013; Simons, 1995).

A seguir, a Figura 2.4, a seguir, ilustra o modelo teórico testado nesta pesquisa, com as relações propostas entre o sistema de controle gerencial com suas quatro alavancas de controle e a resiliência estratégica. Cabe enfatizar que o desenho teórico foi elaborado tendo por base as discussões teórico-empíricas apontadas na literatura. 
Figura 2.4 - Modelo teórico

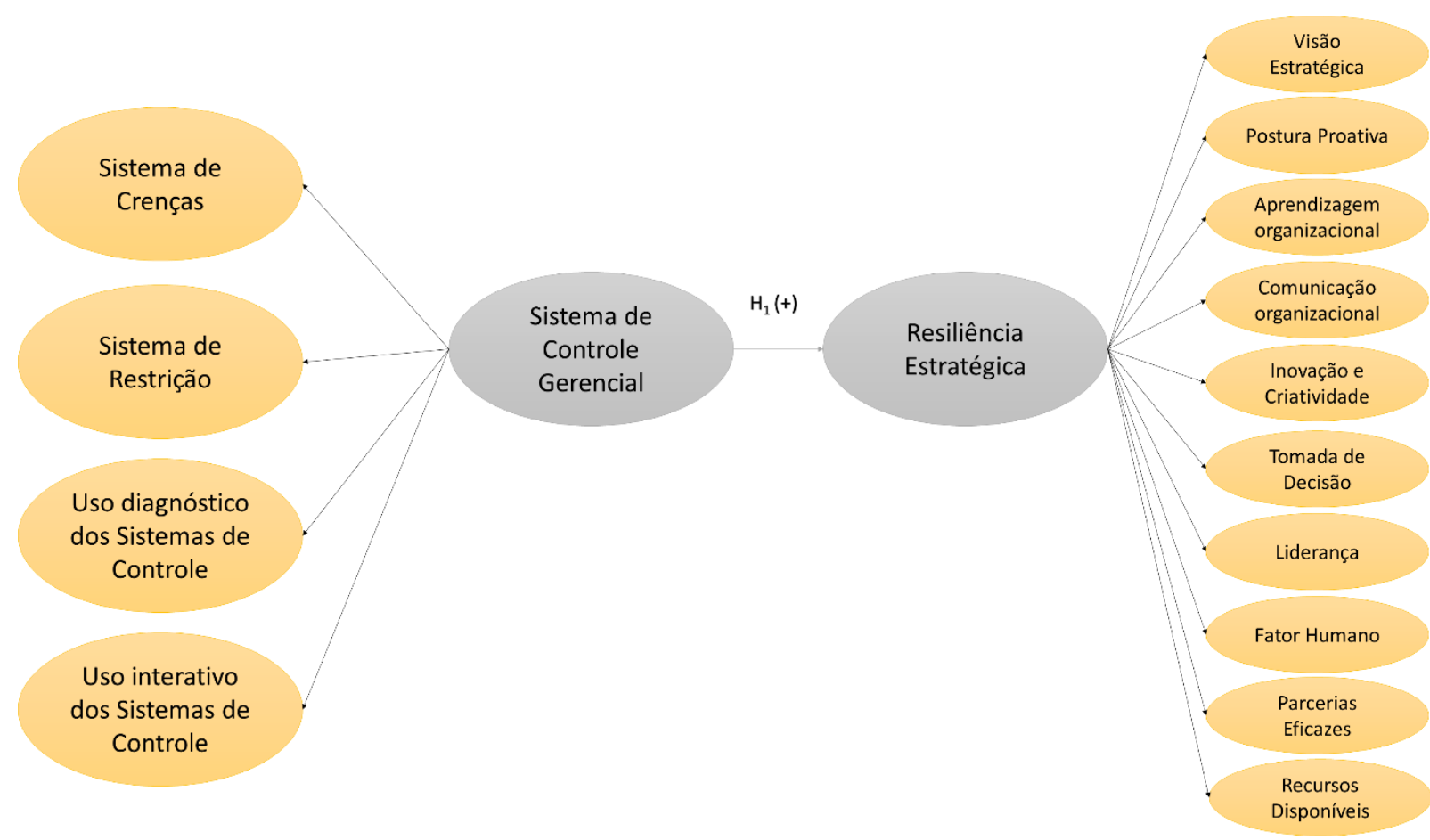

Fonte: Elaborada pela autora.

Com base nos argumentos expostos, formulou-se a hipótese da presente pesquisa, sugerindo-se assim a $\mathrm{H}_{1}$ : $\mathrm{O}$ uso dos sistemas de controle gerencial impacta positivamente a resiliência estratégica. Em adição, ressalta-se que a expectativa da $\mathrm{H}_{1}$ se deve ao fato de a investigação desta pesquisa ocorrer no nível organizacional. Assim, a organização que detém sistemas de controle gerencial facilita a adaptação à novidade, impulsiona mudanças e a inovação estratégica (Arjaliès \& Mundy, 2013; Bisbe \& Otley, 2004; Davila \& Foster, 2008), promovendo a resiliência como vantagem competitiva, ou seja, como a capacidade da organização de adaptar-se, ser flexível e recuperar-se de problemas diários (Bhamra et al., 2011; Lengnick-Hall et al., 2011; Salgado, 2013; Nascimento, 2014; Vargo \& Seville, 2010; Starr et al., 2003). Corroborando, Starr et al. (2003) apontam que, para uma empresa se tornar resiliente, é necessário diagnosticar os riscos e as interdependências para toda a empresa, adaptar a estratégia corporativa e o modelo operacional, suportar o aumento do risco e a complexidade do ambiente. 


\section{PROCEDIMENTOS METODOLÓGICOS}

Este capítulo contempla o planejamento e os elementos necessários para a operacionalização dos procedimentos metodológicos da pesquisa no qual são apresentados: as características da pesquisa, a empresa participante do presente estudo, a escolha da população e da amostra da pesquisa, os procedimentos aplicados na coleta de dados e os métodos de análise e tratamento dos dados.

\subsection{Caracterização da Pesquisa}

A trajetória metodológica da presente pesquisa assume o alcance exploratório contemplando o tema cuja finalidade está em definir, desenvolver, esclarecer e mensurar conceitos que não foram abordados anteriormente em estudos na área da contabilidade gerencial, propondo a formulação de um instrumento para mensurar os constructos investigados e possibilitar que futuras pesquisas possam utilizá-lo. A pesquisa também assume o alcance descritivo ao delinear as propriedades, as características e os elementos essenciais para o entendimento do fenômeno estudado (Sampieri, Collado \& Lucio, 2013). A dimensão temporal nesta pesquisa contempla a coleta e a análise dos dados transversalmente, isto demonstra que o objeto de estudo é analisado em um determinado instante correspondendo à data em que o participante da pesquisa respondeu o questionário (Cooper \& Schindler, 2003). Destaca-se que, para Bryman (2012), este estudo apresenta um desenho de pesquisa em cross-section, em que a coleta de dados aconteceu em um período único no tempo.

Cabe enfatizar que este trabalho se utiliza da estratégia de pesquisa ex post facto que, segundo Martins e Theóphilo (2016), é a mais comum no universo acadêmico das Ciências Sociais Aplicadas. Nesta abordagem, o pesquisador não tem a pretensão de influenciar as variáveis investigadas, pois a realização do estudo visa investigar relações entre variáveis cujos delineamentos são realizados após a ocorrência dos fatos (Cooper \& Schindler, 2003). Isto significa que, na organização, os gestores possuem e utilizam o sistema de controle gerencial no processo de tomada de decisão.

A pesquisa de campo foi realizada no segundo semestre de 2017, a qual contemplou um levantamento interno em uma única organização, cujo objetivo foi promover uma extensão da literatura ao testar empiricamente o modelo teórico proposto nesta tese, que tem como alicerce o framework desenvolvido por Simons (1995, 2000), ou seja, investigar como o uso dos 
sistemas de controle gerencial desta organização contribui para o desenvolvimento da resiliência organizacional. Assim sendo, busca-se compreender com profundidade este fenômeno em um contexto empresarial real e nacional.

O método de pesquisa utilizado neste estudo é denominado de survey single entity, que contempla um levantamento em apenas uma organização. O levantamento (survey) ocorre mediante a interrogação direta, sendo representado por grupo significativo de pessoas, cujo comportamento se deseja conhecer sobre o fenômeno investigado. De acordo com Martins e Theóphilo (2016), o levantamento é apropriado para a análise de fatos e descrições, conforme proposta apresentada na presente tese cujo desenho de pesquisa investiga questões acerca de relações entre características do sistema de controle gerencial e da resiliência que ocorrem em situações reais e no cotidiano empresarial.

De acordo com Mucci, Frezatti e Dieng (2016), um survey single entity tem, como principal método de coleta de dados, o questionário (eletrônico) encaminhado a um grupo de gestores de uma organização, considerando múltiplos respondentes dentro de uma mesma empresa (Van der Stede, Young, \& Chen, 2005). Mucci et al. (2016, p. 290) enfatizam que esta metodologia "estuda os fenômenos de modo mais profundo, tendo a lógica de um único contexto organizacional", visando refletir, além das crenças da organização, também as crenças que permeiam as diversas áreas. Para os pesquisadores, o instrumento de coleta de dados deve apresentar um protocolo de pesquisa com o seu escopo aos responsáveis pela empresa, os procedimentos de coleta de dados e o cronograma de desenvolvimento da pesquisa.

Van der Stede, Young e Chen (2005) afirmam que esta não é a abordagem metodológica mais frequente na área dos estudos gerenciais, porém, desde a década de 1990, o survey single entity tem sido utilizado por pesquisadores de Contabilidade Gerencial, tais como: Aranya (1990), Chalos e Poon (2000), Morschel, Reis, Matos e Costa (2013), Neumann, Machado, Souza, Florenço e Palmeira (2012), Nouri e Parker (1998), Scarpin e Machado (2015), Selto, Renner e Young (1995), e Young e Selto (1993). É notável que a maior parte destes estudos foram publicados internacionalmente nos periódicos Accounting, Organization and Society e Journal of Management Accounting Research; no Brasil, nos periódicos Revista de Administração Contemporânea, Gestão Contemporânea e Revista de Administração e Inovação. Cabe enfatizar que, nos artigos citados, a abordagem não era apresentada com esta terminologia e na maioria dos casos apareceram descritas apenas como pesquisa quantitativa, descritiva, transversal, com aplicação de um questionário autoadministrado em uma empresa de um determinado segmento. 
Van der Stede et al. (2005) enfatizam que, para as pesquisas capturarem a visão da organização, se faz necessário que o pesquisador contemple vários respondentes de uma mesma unidade organizacional. Fato este que complementa a instrução apresentada por Anderson e Widener (2006), ao sugerirem que, antes de incluir todos os tipos de funcionários na amostra, primeiro faz-se necessário realizar entrevistas não estruturadas com os gestores de alta administração para que os potenciais respondentes sejam identificados, bem como as visitas técnicas na organização e, para dar sequência à pesquisa, o questionário autoadministrado seja encaminhado aos respondentes.

A propósito, após autorização da empresa para a realização da pesquisa, seguiu-se com a realização das entrevistas com os gestores e com as visitas técnicas que proporcionaram a observação dos mecanismos internos da empresa antes do desenvolvimento da versão final e do envio do questionário. Os conhecimentos adquiridos durante as visitas preliminares contribuíram com um melhor desenvolvimento do instrumento de pesquisa para capturar o máximo possível a concepção e a utilização dos instrumentos de controle gerencial em toda a organização.

O principal motivo de se realizar um levantamento interno na organização pesquisada é captar a percepção em um escopo mais amplo das diversas áreas da organização sobre o uso dos sistemas de controle gerencial e a resiliência organizacional da empresa estudada, por meio da análise do modelo estrutural com estimação por mínimos quadrados parciais (PLS-PM partial least squares path modeling). O estudo contemplou o mesmo contexto para as seis unidades de trabalho organizacional analisadas (Diretoria do Produto A, Diretoria do Produto B, Diretoria de Planejamento, Diretoria Financeira, Diretoria Operacional, e Presidência e Conselho de Administração).

\subsection{DESCRIÇÃo DA EMPRESA}

Entre os critérios de seleção para escolha da empresa participante na presente pesquisa destaca-se a necessidade de ter uma estrutura organizacional robusta, um quadro de gestores que viabilizaria angariar uma amostra que atendesse ao propósito da presente tese e que apresentasse sistemas de controle gerencial. A busca foi realizada por meio dos documentos públicos emitidos nos sites das organizações, tais como relatórios de sustentabilidade, código de ética, relatórios aos investidores, entre outros. Após a análise dos documentos, iniciaram-se os contatos com os gestores na área de controladoria e contabilidade. 
No primeiro semestre de 2016 realizou-se contato com a empresa "X" que é pioneira no Brasil no seu setor, com atuação de mais de 80 anos no mercado nacional, e cuja trajetória aborda muitas mudanças em sua cultura organizacional desde a sua origem como empresa familiar, até o presente momento como parte de um grupo empresarial de capital aberto. Embora esta empresa tenha um destaque no cenário nacional, mesmo em decorrência das crises econômicas e financeiras, ela se manteve resiliente e com um alto reconhecimento dos seus processos de gestão. A seleção desta empresa considerou os inúmeros prêmios de qualidade de gestão por ela obtidos, em diversos estados brasileiros por vários anos consecutivos e também a presença de diversos sistemas de controle gerencial permitindo que a pesquisa empírica fosse viabilizada de modo a conhecer com profundidade o fenômeno investigado nesta tese.

$\mathrm{O}$ contato com a empresa " $\mathrm{X}$ " foi estabelecido, e foram realizadas visitas técnicas para dar ciência se as informações emitidas por documentos e relatórios públicos se confirmavam no contexto atual da empresa. A pesquisa foi apresentada ao controller da empresa, que se mostrou favorável à participação da empresa na presente pesquisa.

No decorrer de 2016 até o início da coleta de dados no início de 2017, o protocolo ético foi aprovado pela gestão da empresa e a pesquisa já estava autorizada. Porém, mudanças no quadro interno da empresa aconteceram, quando angariou uma nova empreitada envolvendo processo de aquisição de novas empresas ao grupo e o controller, o gestor intermediário que estava responsável pela pesquisa na organização foi alocado para este novo projeto que estava se iniciando. Assim sendo, o gestor que assumiu o intermédio da pesquisa na empresa acabou inviabilizando a sua operacionalidade, à medida que restringiu o público alvo, ou seja, a população, em apenas 20 gestores. Neste momento, retomou-se a busca por uma empresa que apresentasse elementos necessários para que o estudo fosse viabilizado e a empresa que passou por todas as fases de autorização, permitindo a execução da presente pesquisa em consonância com os critérios éticos e acadêmicos estabelecidos pela academia, foi a denominada neste trabalho de empresa "A".

Iniciaram-se, no primeiro semestre de 2017, os primeiros contatos com a empresa "A". Foi viabilizada pela empresa a apresentação da pesquisa, do protocolo ético e das diretrizes metodológicas para seu desenvolvimento. A autorização da pesquisa só foi possível após a assinatura do acordo de confidencialidade entre as partes que aconteceu no início do segundo semestre de 2017. Na sequência, iniciaram-se as visitas técnicas e as reuniões para apurar o contexto atual da empresa de modo a aproximar a ferramenta de coleta de dados ao cenário investigado. A coleta de dados ocorreu durante os meses de outubro a dezembro de 2017, conforme evidenciado no item 3.4. 
O critério de seleção da empresa "A" para constituir o objeto de estudo desta pesquisa foi por conveniência de forma intencional, por se tratar de uma empresa de tradição nacional com um histórico político que marca a evolução do contexto do país, além de apresentar um caso revelador em relação a sua qualidade de gestão, tendo em vista que a empresa “A” possui diversos sistemas de controle gerencial permitindo a realização da pesquisa empírica de modo a conhecer com profundidade este fenômeno pouco conhecido no cenário nacional.

Além disso, a justificativa para escolha da empresa está na notoriedade conquistada no decorrer de sua trajetória de seis décadas de atuação no Brasil, sendo uma das pioneiras na exploração comercial do seu produto A para uso doméstico no cenário internacional; abrange todas as regiões do país; e a empresa conta com aproximadamente três mil empregados diretos.

A empresa destaca, por meio do seu Relatório Anual da Administração e de Demonstrações Contábeis referentes ao período de 2017 que, mesmo com os grandes desafios enfrentados no cenário mercadológico, a continuidade do seu negócio em meio à adversidade política e econômica que permeia o ambiente financeiro e empresarial nacional, tanto a disciplina quanto a resiliência promoveram sustentação para o alinhamento das estratégias estabelecidas. Tal evidência encontra-se de acordo com os conceitos apresentados anteriormente por Starr et al. (2003) ao afirmarem que uma organização resiliente apresenta uma vantagem competitiva à medida que alinha a sua estratégia aos sistemas de gestão dando suporte à decisão, de modo a adaptar-se continuamente às adversidades. Assim, tem-se nesta tese a seguinte premissa: a empresa investigada possui e utiliza o sistema de controle gerencial e apresenta potencial organizacional para a resiliência.

\subsection{População e Amostra da Pesquisa}

A coleta dos dados primários teve início no segundo semestre de 2017. A amostra da presente pesquisa é não probabilística. Segundo Sampieri, Collado e Lucio (2013), a sua seleção é realizada por conveniência tendo por prioridade as causas relacionadas com as características da pesquisa e não dependem da probabilidade. Dentre as características necessárias, destaca-se a necessidade de os respondentes terem acesso e utilizarem os sistemas de controle gerencial em seu cotidiano nos processos de tomada de decisão. Os potenciais respondentes foram elencados a partir das entrevistas não estruturadas e das visitas técnicas feitas por esta pesquisadora à empresa. Desta feita, foi diagnosticada, do universo amostral de aproximadamente 3 mil colaboradores, uma população de 309 gestores organizacionais da 
empresa para compor o escopo do presente estudo, os quais tinham livre arbítrio de participar ou não da presente pesquisa.

\subsection{COLETA DE DAdos}

\subsubsection{Questionário - Instrumento de coleta de dados}

O instrumento utilizado para medir a associação entre o sistema de controle gerencial e o grau de resiliência organizacional consistiu de um questionário eletrônico, estruturado e autoadministrado, disponível no Apêndice F desta tese. Foi constituído por uma série ordenada de perguntas utilizadas para mensurar uma ou mais variáveis; elas reportaram ao fenômeno que a pesquisa se propôs a medir e a descrever, e foi respondido pelos participantes da pesquisa sem a presença da pesquisadora (Sampieri et al., 2013; Martins \& Theóphilo, 2016).

O questionário foi disponibilizado diretamente aos indivíduos, sem intermediários, e as respostas foram marcadas pelos próprios respondentes (Sampieri et al., 2013). Além disso, desenvolveu-se o questionário eletrônico por meio da plataforma online do Survey Monkey ${ }^{\circledR} \mathrm{e}$ foi disponibilizado aos respondentes por meio de um link via e-mail. Desta forma, o entrevistado foi direcionado para o site do questionário, o qual também contemplava informações relevantes sobre a pesquisa e o acordo de confidencialidade firmado junto à empresa, atendendo à prescrição de Bryman (2012). O questionário foi submetido às múltiplas diretorias da organização. Estas foram estabelecidas em conjunto com os gestores da empresa objeto de estudo, tendo em vista que o importante era o respondente trabalhar diretamente com o sistema de controle gerencial e utilizá-lo na tomada de decisão.

Segundo Anderson e Widener (2006), o poder estatístico necessário para realizar a pesquisa de campo quantitativa pode ser realizado por meio do tipo de desenho de pesquisa escolhido para este trabalho, ao mesmo tempo enfatizam que é possível testar teorias considerando um único contexto organizacional, tendo em vista que a unidade de análise para a pesquisa de campo pode ser uma empresa ou diversas equipes de trabalho ou subunidades organizacionais.

Cabe enfatizar que antes da aplicação do questionário foram realizadas visitas técnicas e as entrevistas visaram auxiliar a pesquisadora a compreender o contexto da organização, o cenário no qual estava inserida, ajustar e validar o instrumento utilizado na coleta dos dados. Entre as limitações da utilização do questionário eletrônico para coletar os dados está o distanciamento da pesquisadora no processo de coleta dos dados, impossibilitando o 
esclarecimento de elementos nebulosos aos respondentes. Por outro lado, priorizou-se a neutralidade e confidencialidade dos respondentes, a imparcialidade do ponto de vista da pesquisadora, promovendo maior liberdade de expressão aos respondentes.

A primeira fase do questionário contemplou uma apresentação da pesquisa contendo o objetivo da tese, a contribuição esperada do respondente com o questionário, o tempo estimado para respondê-lo, o acordo de confidencialidade firmado junto à empresa, o compromisso com a confidencialidade, o anonimato, o sigilo e a privacidade das informações coletadas, bem como o compromisso da utilização das respostas exclusivamente para fins acadêmicos. Além destes elementos, buscou-se evidenciar a contribuição prática da pesquisa para a empresa, a fim de motivar o informante a responder o questionário.

Após o respondente concordar com a participação na presente pesquisa, foi direcionado para o primeiro bloco de questões que contemplava os critérios de mensuração construídos por Widener (2007) para explorar os antecedentes do sistema de controle utilizando o framework "Levers of Control" (Simons, 1995, 2000). Os sistemas de controle gerencial foram representados pelas variáveis explicativas que visaram mensurar o uso das quatro alavancas de controle, de acordo com o apresentado no item 2.2.2, e elaborou-se o Quadro 3.1, na página 87. Cabe enfatizar que a escala Likert de 5 pontos foi utilizada para mensurar as quatro alavancas de controle, sendo o nível de concordância em que 1 significa discordo totalmente e 5 concordo totalmente, para mensurar o Sistema de Crença, Sistema de Restrição e o Uso Interativo do Sistema de Controle. Já a escala para mensurar o Uso Diagnóstico do Sistema de Controle contemplou o nível de utilização das ferramentas, sendo 1 para extremamente baixa a utilização, 5 para extremamente alta a utilização, e 0 para não sei dizer ou não se aplica (o qual foi tabulado como missing).

O segundo bloco contemplou as questões sobre a resiliência organizacional (Quadros 3.2, 3.3 e 3.4, nas páginas 88, 89 e 90) que foi construído com base nas pesquisas de McManus (2008), Lee et al. (2013), McManus et al. (2008), Stephenson (2010), Stephenson, Vargo e Seville (2010), Stephenson, Seville, Vargo e Roger (2010), Whitman et al. (2013), Nascimento (2014), Akgün e Keskin (2014), Lengnick-Hall et al. (2011), conforme discutido anteriormente no item 2.1.7. Nesta seção, utilizou-se a escala Likert de cinco pontos, em que 1 representa discordo totalmente, 5 concordo totalmente, e 0 para não sei dizer ou não se aplica (o qual foi tabulado como missing).

O terceiro bloco foi composto por oito questões (Quadro 4.1, na página 131) cuja finalidade foi controlar o viés do método conforme proposto por Chin, Thatcher, Wright e Steel (2013), estas questões são discutidas com maiores detalhes no item 4.5.1. Utilizou-se a mesma 
escala para mensurá-las, ou seja, a escala de concordância de 1 a 5, sendo 1 para discorda totalmente, 5 para concorda totalmente e 0 para não sei dizer ou não se aplica (o qual foi tabulado como missing).

A quarta parte é representada pelas variáveis demográficas, contendo perguntas sobre o nome da unidade de trabalho, gênero, idade, escolaridade, a posição dentro da organização, cargo, tempo em que trabalha no cargo e tempo de trabalho na organização.

\subsubsection{Pré-teste}

A versão preliminar do instrumento utilizado na survey passou pelo processo de préteste, em que dois estudantes de doutorado em Contabilidade Gerencial, quatro docentes doutores que pesquisam na área de contabilidade gerencial, um profissional da área de controladoria não atuante na empresa investigada e três gestores da alta administração da empresa pesquisada forneceram feedback em relação às perguntas elencadas no instrumento. Este processo auxiliou a garantir que a linguagem utilizada no instrumento fosse coerente e significativa, proporcionou ajustes em relação aos aspectos culturais e contextuais da organização, e que não apresentasse perguntas ambíguas. Após estes procedimentos a versão final do questionário foi aplicada. Cabe destacar que antes desta etapa, após definir o instrumento por completo, este passou por um processo de tradução, pois a maior parte dos conteúdos encontrava-se em inglês. Inicialmente a tradução foi realizada pela pesquisadora da presente tese, na sequência foram submetidas à revisão de profissionais e, após o pré-teste, outra revisão de tradução foi realizada, esta denominada de back translation, com a qual se buscou verificar se o conteúdo do item a ser mensurado pelas assertivas havia sido mantido na versão final do questionário. 
Quadro 3.1 - Bloco 1: Sistema de Controle Gerencial

VARIÁ VEIS

Sistema de Crenças (SC): sistema formal em que os gestores comunicam os valores básicos, o propósito e a direção da organização. (Simons, 1995, p.34)

\section{SC3} organização.

QUESTÕES ASSERTIVAS OUE MENSURAM AS VARIÁVEIS

SC1. A missão comunica de forma clara os valores fundamentais da empresa à sua equipe de trabalho.

SC2. Os principais gestores comunicam os valores fundamentais à sua equipe de trabalho.

SC4. Nos momentos de adversidade a missão/visão é observada na tomada de decisão.

Sistema de Restrições (SR) "delineia

o

domínio/comportamento aceitável
dos participantes no

desenvolvimento das atividades

estratégicas da organização" (Simons, 1995, p. 39).

Sistema Diagnóstico de Controle (SD): "um sistema de informação formal que os gestores utilizam para monitorar os resultados organizacionais e corrigir os desvios de padrões préestabelecidos de desempenho" (Simons, 1995, p.59).

Sistema Interativo de Controle

(SI): "são sistemas de informação formal que os gestores utilizam para envolver-se pessoalmente nas atividades de decisões dos subordinados" (Simons, 2000, p.216).

Fonte: Elaborado pela autora.
SR1. Os instrumentos de restrições (tais como código de ética, diretrizes de direcionamento de operações, políticas de compliance) informam sobre os comportamentos que estão fora dos limites aceitáveis pela empresa.

SR3. Não sei exatamente tudo o que devo fazer, mas tenho clareza do que não devo fazer. diretrizes de direcionamento de operações, políticas de compliance) direciona as ações em momento de adversidades.

SD1. Temos planejamento estratégico formalizado.

SD2.O orçamento está alinhado com o planejamento estratégico e decorre dele.

SD3. Temos controle orçamentário: são apresentados os relatórios com o previsto versus o realizado; em reuniões são discutidos os resultados passados e as ações futuras.

SD4. Monitoramos e comparamos os resultados com as expectativas de modo a prever adversidades que impeçam o progresso em direção às metas organizacionais.

SD5. O desempenho individual explicitado pelo controle orçamentário impacta a remuneração variável do executivo.

SI1. Os gerentes operacionais estão frequentemente envolvidos com o sistema de controle.

SI2. Os dados gerados pelo sistema de controle são interpretados e discutidos com superiores, subordinados e pares.

SI3. É dedicada atenção regular e frequente à análise e discussão das adversidades em reuniões por parte dos gestores de todos os níveis.

SI4. A empresa utiliza o sistema de controle para antecipar-se às mudanças com intuito de evitar que as adversidades afetem seus negócios.

SI5. A organização alinha a sua estratégia aos sistemas de controle dando suporte à decisão de modo a adaptar-se continuamente às adversidades.
SR4. A consciência da existência dos instrumentos de restrições (tais como código de ética,
REFERENCIAS

Widener (2007); Kruis, Speklé, \& Widener (2016); Cruz (2014).

Widener (2007); Kruis, Speklé, \& Widener (2016); Cruz (2014).

Widener (2007); Kruis, Speklé, \& Widener (2016); Cruz (2014); Akgün \& Keskin (2014).

Stephenson (2010); McManus (2008);

Whitman et al. (2013).

Widener (2007); Kruis, Speklé, \& Widener

(2016); Cruz (2014).

Widener (2007); Kruis, Speklé, \& Widener (2016); Cruz (2014).

Cruz (2014).

Akgün \& Keskin (2014).

Cruz (2014); Frezatti et al. (2012).

Cruz (2014); Frezatti et al. (2012).

Cruz (2014); Frezatti et al. (2012).

Widener (2007); Kruis, Speklé, \& Widener (2016)

Cruz (2014); Frezatti et al. (2012).

Widener (2007); Cruz (2014).

Widener (2007); Kruis, Speklé, \& Widener (2016); Cruz (2014); Frezatti et al. (2012). Widener (2007); Kruis, Speklé, \& Widener (2016); Cruz (2014); Frezatti et al. (2012).

Kruis, Speklé, \& Widener (2016); Cruz (2014)

Starr, Newfrock, \& Delurey (2003) 
Quadro 3.2 - Bloco 2: Resiliência Estratégica - Parte 1

VARIÁVEIS

Visão Estratégica (VE): conhecer a organização como um todo e os desafios da atividade empresarial, alinhando prioridades organizacionais frente mudanças e aos anseios do mercado. VE5. O entendimento amplo da organização e de sua atividade nos permite diagnosticar, interpretar, compreender e nos anteciparmos às adversidades, aos eventos e às mudanças no cenário empresarial.

Postura Proativa (PP): a PP1. Temos uma estrutura que nos permite agir de forma rápida e eficaz em resposta a uma capacidade da organização de antecipar-se às mudanças de modo a reduzir as vulnerabilidades em ambientes altamente complexos. oportunidade e aos eventos inesperados.

PP2. Temos uma diversidade de ações competitivas disponíveis para adotar em resposta às inesperadas e oportunas mudanças que ocorrem no mercado.

PP3. Tomamos decisões e realizamos investimentos preventivamente para garantir que possamos nos beneficiar de situações futuras que possam surgir em nossa organização.

PP4. Nossa organização monitora proativamente o que está acontecendo em seu setor para agir antecipadamente nas questões emergentes.

PP5. Buscamos oportunidades de crescimento perante as situações de adversidades.

Aprendizagem Organizacional (AO): A organização aprende com os erros e problemas ocorridos, com a experiência vivenciada e com as práticas de gestão que incentivam o questionamento da realidade.

AO1. Durante uma adversidade, somos capazes de identificar um problema, aprender sobre ele, apresentar solução e implantar a solução.

AO2. Aprendemos lições do passado e garantimos que estas lições sejam executadas no futuro, pois evoluímos e nos adaptamos às novas situações.

AO3. Temos estruturas organizacionais que são projetadas para promover a aprendizagem e mudar os comportamentos com base nas novas informações e nos novos insights.

AO4. Temos práticas de gestão e normas organizacionais que incentivam o questionamento do que está acontecendo de modo a exigir uma sólida compreensão da realidade.
REFERENCIAS

Nascimento (2014); Fleury \& Fleury (2001).

Nascimento (2014); Stephenson (2010); Lee et al. (2013); Hamel \& Välikangas (2003).

Nascimento (2014); Minello, Scherer, \& Alves (2012).

Nascimento (2014); Stephenson (2010); Lee et al. (2013).

Starr et al. (2003); Lengnick-Hall \& Beck (2005, 2009); Lengnick-Hall, Beck, \& Lengnick-Hall (2011); Akgün \& Keskin (2014).

Nascimento (2014); Stephenson (2010); Lee et al. (2013).

Akgün \& Keskin (2014).

Akgün \& Keskin (2014).

Stephenson (2010); Lee et al. (2013).

Mallak (1998); Carmeli \& Markman (2011); Lengnick-Hall et al. (2011); Akgün \& Keskin, (2014).

Nascimento (2014)

Stephenson (2010); Lee et al. (2013);

Nascimento (2014); Weick \& Sutcliffe (2007).

Akgün \& Keskin (2014).

Weick \& Sutcliffe (2007); Riolli \& Savicki (2003).

Fonte: Elaborado pela autora. 
Quadro 3.3 - Bloco 2: Resiliência Estratégica - Parte 2

VARIÁVEIS

Organizacional

\section{$(\mathrm{CO})$ :}

Comunicação

processo de interação entre os indivíduos da organização para transmitir e compartilhar

informações, socializar novos conhecimentos e por meio dos sistemas de informação proporcionar a transmissão destes para todos os níveis organizacionais.

Inovação e Criatividade (IC): capacidade de construir soluções inovadoras e criativas para os problemas, processos e produtos.

Autonomia na Tomada de Decisão (TD): Delegar autoridade e poder aos colaboradores da organização visando a uma tomada de decisão com autonomia e responsabilidade por pessoas qualificadas.

Liderança (LD): A liderança é capaz de compreender o ambiente e responder com rapidez e eficácia às mudanças em seu setor adaptando-se à frente dos seus concorrentes. A liderança promove espaço para discussão em que os gestores ouvem os problemas e soluções oriundos dos diversos níveis organizacionais proporcionando feedback constante.

\section{QUESTÕES ASSERTIVAS QUE MENSURAM AS VARIÁVEIS}

CO1. O processo de comunicação compartilha a direção e as estratégias organizacionais nos diversos níveis hierárquicos.

$\mathrm{CO} 2$. Temos uma linguagem comum (ou seja, palavras, imagens e histórias) e predominante que implica capacidade, influência, competência, valores fundamentais consistentes e um sentido claro de direção em nossa organização. CO3.O sistema de informação ao disponibilizar informação com qualidade dá suporte à tomada de decisão rápida e eficaz.

CO4. Funcionários possuem formação para utilizar o sistema, sabem quais informações acessar em situações críticas e têm consciência das implicações para as possíveis soluções.

CO5. As informações cruciais estão disponíveis em diferentes meios.

IC1. Somos estimulados a termos espírito empreendedor visando à mudança.

IC2. Temos capacidade de utilizar o conhecimento de forma inovadora e criativa na solução de problemas.

IC3. Somos incentivados a sermos criativos e a buscarmos oportunidades para desenvolver novas habilidades, ao invés de termos como foco a padronização. IC4. Somos recompensados por "pensar fora da caixa".

TD1. Os líderes delegam responsabilidades e autoridade a sua equipe permitindo aos profissionais autonomia para tomarem decisões.

TD2. Compartilhamos a tomada de decisão amplamente.

TD3. Podemos tomar decisões difíceis rapidamente.

TD4. Caso ocorram problemas, os colaboradores possuem acesso direto a alguém com autoridade que possa tomar decisões.

LD1. Líderes abertos às mudanças contínuas nas estratégias da organização e aos novos desafios; consideram a mudança como oportunidade.

LD2. Os gestores entendem como liderança o próprio exemplo.

LD3. A liderança preza pelo bom relacionamento e incentiva os colaboradores a discutirem problemas junto aos seus gestores.

LD4. A liderança gera feedback constante e desenvolvem uma comunicação aberta entre o líder e sua equipe.
REFERÊNCIAS

Nascimento (2014)

Akgün \& Keskin (2014).

Nascimento (2014).

Nascimento (2014)

Stephenson (2010); Lee et al. (2013).

Nascimento (2014)

Stephenson (2010); Lee et al. (2013);

Nascimento (2014)

Akgün \& Keskin (2014).

Stephenson (2010); Lee et al. (2013)

Nascimento (2014)

Akgün \& Keskin (2014).

Stephenson (2010).

Stephenson (2010).

Nascimento (2014)

Stephenson (2010); Nascimento (2014).

Stephenson (2010).

Nascimento (2014).

Fonte: Elaborado pela autora. 
Quadro 3.4 - Bloco 2: Resiliência Estratégica - Parte 3

\section{VARIÁVEIS}

Fatores Humanos (FH): as pessoas na organização percebem seu ambiente de trabalho como propício para assumir riscos interpessoais, para desenvolver relações interpessoais efetivas e estabelecer responsabilidades tanto individual quanto em grupo sobre a organização, o seu desempenho e os possíveis problemas.

Parcerias Eficazes (PE): a organização possui alianças estratégicas ao desenvolver relacionamentos interpessoais interna e externamente. A empresa apresenta vínculos com seus stakeholders (parceiros) e tem consciência de sua conexão e interdependência no desenvolvimento de suas atividades, especialmente, em situações de adversidade.

Recursos Disponíveis (RD): conhecer os recursos necessários para a organização operar e a capacidade de priorizar e alocar tais recursos de modo a alinhá-los às prioridades da organização.

Fonte: Elaborado pela autora.

\section{QUESTÕES ASSERTIVAS QUE MENSURAM AS VARIÁVEIS}

FH1. As pessoas estabelecem relações com outras pessoas permitindo o compartilhamento de recursos, de objetivos, de conhecimentos e de práticas de respeito mútuo.

FH2. Cada membro da organização tem a descrição e a responsabilidade de assegurar a obtenção dos interesses organizacionais.

FH3. Trabalhamos com outras pessoas independente das fronteiras departamentais e organizacionais.

FH4. As pessoas na organização se sentem responsáveis pela eficácia da organização.

FH5. As pessoas na organização buscam informações, solicitam ajuda, admitem que erraram e ou geraram feedbacks críticos no desenvolvimento de suas atividades.

PE1. Possuímos alianças estratégicas e bom relacionamento com nossos parceiros (stakeholders/agentes) para garantir recursos necessários em apoio às niciativas de mudanças.

PE2. Asseguramos que os vínculos com vários stakeholders (parceiros) sejam mantidos, reforçando assim o capital social além das fronteiras da empresa.

PE3. Entendemos como estamos conectados aos nossos parceiros (stakeholders) e gerenciamos ativamente tanto estas parcerias quanto a possibilidade de angariar novas.

PE4. Entendemos como as ações dos nossos parceiros afetam nossa capacidade de resposta em caso de adversidade.

RD 1. Temos conhecimento sobre os recursos internos e externos disponíveis ao tomarmos uma decisão.

RD2. Realocamos os recursos para os novos produtos e projetos.

RD3. Mantemos recursos suficientes para absorver mudanças inesperadas.

RD4. Temos agilidade em obter a aprovação de recursos adicionais para dar conta do recado em uma situação de adversidades.
REFERÊNCIAS

Nascimento (2014); Akgün \& Keskin

(2014); Gittell, Cameron, Lim \& Rivas (2006)

Akgün \& Keskin (2014); Stephenson (2010)

Stephenson (2010)

Stephenson (2010)

Akgün \& Keskin (2014); Nascimento, (2014).

Akgün \& Keskin (2014)

Akgün \& Keskin (2014); Stephenson (2010); Lee et al. (2013).

Stephenson (2010); Lee et al. (2013).

Stephenson (2010); Lee et al. (2013).

Nascimento (2014)

Nascimento (2014).

Stephenson (2010); Lee et al. (2013)

Stephenson (2010); Lee et al. (2013). 


\subsubsection{Respondentes}

Atendendo ao critério de escolha do público alvo para o desenvolvimento desta pesquisa, os colaboradores da Empresa "A" devem trabalhar em seu cotidiano diretamente com os sistemas de controle gerencial e utilizá-los na tomada de decisão, no planejamento, no monitoramento e na avaliação das atividades organizacionais de modo a alterar o comportamento dos indivíduos inseridos na organização e motivá-los a garantir que os objetivos organizacionais sejam alcançados. Desta feita, tem-se as informações contidas no Gráfico 3.1 que elenca, da população selecionada, os potenciais respondentes vinculados a suas áreas de atuação.

Gráfico 3.1 - Representação da população pelo vínculo empresarial

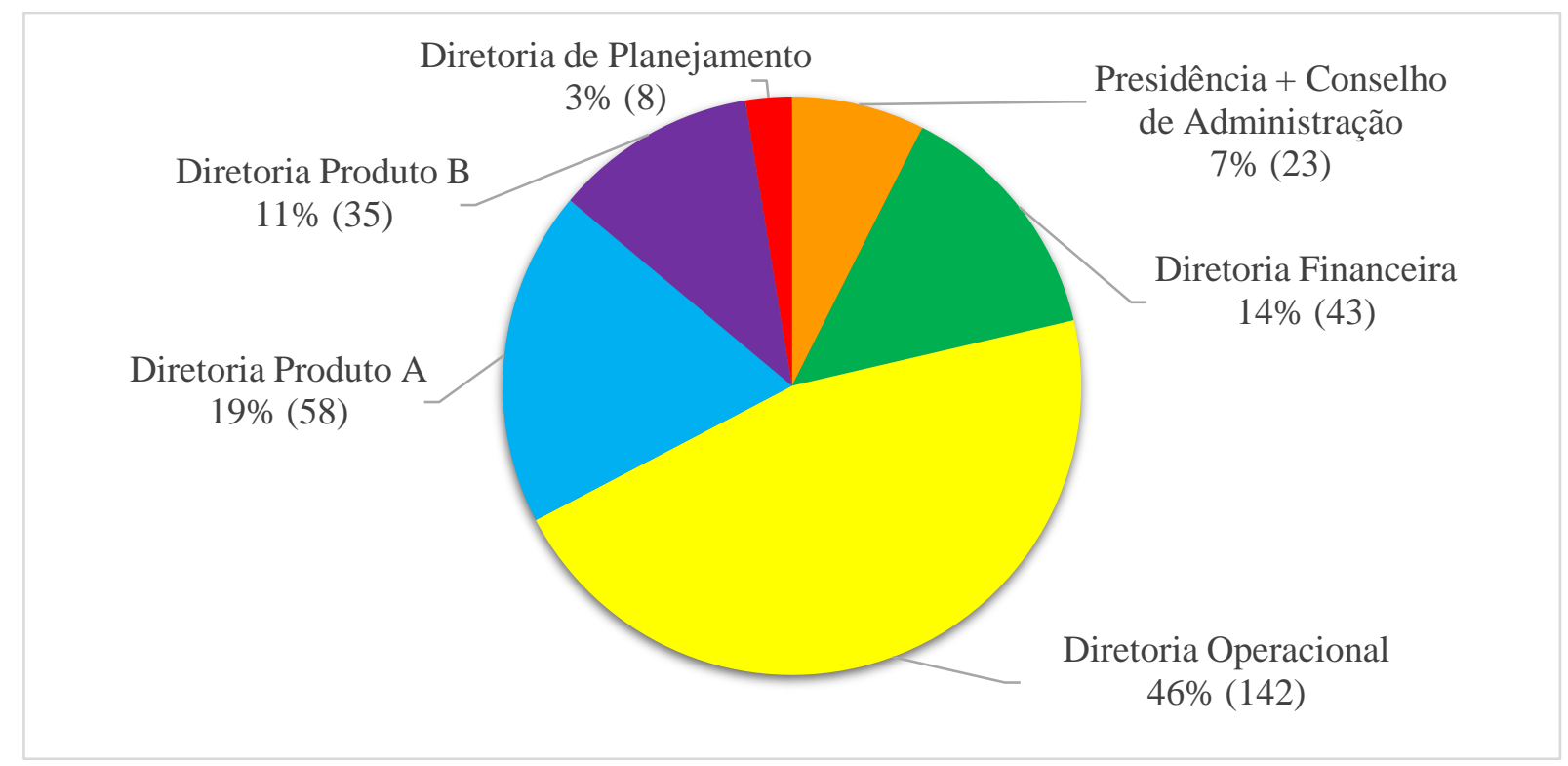

Fonte: Elaborado pela autora.

É possível observar que, do universo amostral de 3 mil colaboradores, o público alvo ficou restrito a 309 gestores organizacionais (diretores, alta gerência, gerentes, supervisores e coordenadores), isto reduziu a quantidade de pessoas aptas a responder o instrumento de coleta de dados. Observa-se no Gráfico 3.1 que a presente pesquisa investigou a percepção dos gestores alocados em cinco diretorias e nas gerências que respondem diretamente ao conselho de administração e à presidência.

O Conselho de Administração e a Presidência alocam vinte e três gestores aptos a participarem da pesquisa, representando $7 \%$ da população investigada. O Conselho de Administração é composto por sete membros, cinco deles indicados pela controladora do grupo 
empresarial, um indicado pelo Ministro de Estado do Planejamento, Orçamento e Gestão e um representante dos colaboradores, os quais não fizeram parte do escopo da pesquisa, tendo em vista que estes não compõem o quadro permanente de funcionários da empresa e não atuam no processo de gestão e decisões diárias da organização. Geralmente são convocados por meio de assembleia para decisões que possam afetar o grupo empresarial como um todo. Foram selecionados para participar da presente pesquisa, os gestores alocados nas duas gerências que respondem diretamente ao Conselho de Administração, a primeira composta por apenas um gestor atuando na ouvidoria e a segunda por três colaboradores responsáveis pela área de auditoria da organização. Foram convidados a participar da pesquisa os dezenove gestores subordinados diretamente à Presidência da organização, os quais atuam nas gerências de gestão de conformidade, recursos humanos, jurídico e relacionamento internacional.

Além das gerências que atuam diretamente vinculadas ao Conselho de Administração e da Presidência da organização "A", fazem parte da população investigada os integrantes da Diretoria Operacional, da Diretoria de Planejamento, da Diretoria Financeira, da Diretoria do Produto A e da Diretoria do Produto B, que respondem a Presidência e que compõem a diretoria executiva da empresa estudada. Conforme evidenciado no Gráfico 3.1, a maioria dos indivíduos aptos a participar da presente pesquisa está vinculado à Diretoria Operacional representando 46\% da população com 142 potenciais respondentes; as atribuições da Diretoria Operacional estão conectadas às operações industriais, envolvendo logística, engenharia, segurança, meio ambiente e saúde.

Por outro lado, a Diretoria de Planejamento é aquela com menor número de pessoas aptas a participar da pesquisa, possuindo apenas 8 gestores (representando 3\% da população), os quais atuam no planejamento estratégico, orçamento, controle gerencial e marketing da organização. A Diretoria Financeira possui 43 gestores aptos a participar da pesquisa divididos nos setores de compra e de serviço da organização, de tecnologia da informação, de formação de preço e de controle financeiro. A Diretoria do Produto A abarca 58 gestores (19\%) e, a Diretoria do Produto B, 35 gestores (11\%) que trabalham com as políticas comerciais e de manutenção dos clientes dos respectivos produtos e dividem-se em gerências alocadas nas cinco regiões do país. 


\subsubsection{Implementação do survey (processo de aplicação do questionário)}

Esta fase da coleta de dados aconteceu entre o período de 03 de outubro de 2017 a 19 de dezembro de 2017, quando a empresa disponibilizou a chave de acesso de cada funcionário para encaminhamento do questionário de modo a garantir o anonimato dos respondentes.

Primeiramente, foi encaminhado um e-mail (Apêndice B desta tese) com o convite aos 309 gestores para participarem da presente pesquisa contendo o link (http://pt.surveymonkey.com/r/feausp_empresaA) para acessar o questionário (ver Apêndice F desta tese), na sequência foram emitidos mais 7 (sete) comunicados intermediários sendo 5 (cinco) realizados via e-mails para incentivar os respondentes (ver Apêndice C desta tese) e 2 (dois) lembretes realizados pela empresa enfatizando a relevância da pesquisa, sendo um face a face no decorrer de um evento interno da organização e outro pelo canal de comunicação interno da empresa.

\subsection{MÉTODOS DE ANÁLISE DOS DADOS}

O tratamento e a análise dos dados quantitativos aconteceram por meio da estatística descritiva; na sequência, realizou-se a avaliação do modelo de mensuração por meio de análise fatorial confirmatória; a terceira fase foi a análise do modelo estrutural com estimação por mínimos quadrados parciais (PLS-PM - partial least squares path modeling); e a discussão dos quadrantes do mapa de prioridade. A escolha do PLS-PM é baseada na possibilidade de testar as relações entre as variáveis latentes sem suposição de normalidade multivariada, devido à complexidade do modelo e ao tamanho da amostra necessária (Nitzl, 2016; Hair Jr., Hult, Ringle, \& Sarstedt, 2014). A avaliação da mensuração do modelo utilizou os constructos definidos no referencial teórico, tendo em vista que todos os itens foram analisados como indicadores reflexivos (Hair Jr. et al., 2014). O tratamento dos dados foi realizado por meio do software SmartPLS ${ }^{\circledR}$.

\subsection{Qualidade da Pesquisa}

Busca-se nesta tese apurar a qualidade da pesquisa quantitativa, por meio dos pressupostos apresentados na pesquisa de Van der Stede, Young e Chen (2006), tais como taxa de resposta, tamanho da amostra e pré-teste. Além disso, foram realizados os testes de validade convergente, de validade discriminante e de validade de confiabilidade. De acordo com Hair 
Jr., Hult, Ringle e Sarstedt (2014), a validade convergente é atestada quando o nível das variáveis latentes for considerado adequado para obter a variância média extraída acima de 0,5. A validade convergente foi utilizada para comparar os resultados obtidos nesta pesquisa com os achados em pesquisas anteriores, bem como o resultado entre as diferentes subunidades investigadas.

A validade discriminante foi observada a partir da matriz de cargas cruzadas (crossloadings), em que todos os itens devem apresentar altas cargas fatoriais em seus respectivos constructos e cargas baixas com os demais constructos da pesquisa, e no nível das variáveis latentes. Além disso, buscou-se analisar a validade discriminante pela matriz de correlações, na qual se espera que os valores da raiz quadrada da variância média extraída (diagonal) sejam superiores aos valores da matriz de correlações. Por fim, a confiabilidade dos dados foi testada utilizando o Alpha de Cronbach e a confiabilidade composta, nos quais buscou-se obter resultados superiores a 0,7 , isto possibilitou mensurar a consistência interna do estudo.

De acordo com Ringle, Silva e Bido (2014), o passo seguinte foi a validação do modelo estrutural que consiste primeiramente na avaliação dos determinantes dos coeficientes de Pearson (verificação do valor do $\mathrm{R}^{2}$ ), o qual representa a percentagem de variância de uma variável latente que é explicado por outras variáveis latentes, de modo a indicar a qualidade do modelo. $\mathrm{Na}$ área das ciências sociais e comportamentais, quando o $\mathrm{R}^{2}$ apresenta valor igual a $2 \%$ significa que o modelo possui um efeito pequeno; o $\mathrm{R}^{2}$ igual a $13 \%$ representa um efeito médio; e o $\mathrm{R}^{2}$ igual a $26 \%$ representa um efeito grande.

Para testar a hipótese de que os coeficientes de regressão são iguais a zero pelo teste T de Student, espera-se que, para um nível de significância de 0,05 , o valor do teste T seja superior a 1,96. A técnica de bootstrapping foi adotada para testar a significância das relações indicadas, que consiste em um tipo de re-amostragem aleatória com 5.000 repetições (Hair Jr. et al., 2014).

A validade preditiva, também denominada de Indicador de Stone-Geisser $\left(Q^{2}\right)$, foi utilizada para avaliar se o modelo está parecido com o proposto inicialmente, ou seja, a proposta deste indicador foi mostrar a qualidade de predição do modelo ou a acurácia do modelo ajustado. Como critério de avaliação, buscou-se obter valores maiores do que zero. Assim, $\mathrm{Q}^{2}$ igual a 1 significa que se obteve o modelo perfeito (Ringle, Silva, \& Bido, 2014). Em seguida, foi investigado o tamanho do efeito $\left(\mathrm{f}^{2}\right)$, também denominado de indicador Cohen, que foi obtido por inclusão e exclusão dos constructos do modelo (um a um). Desta forma, buscou-se avaliar como cada constructo foi "útil" para o modelo. Os valores de 0,02, 0,15 e 0,35 reportam o tamanho do efeito, sendo pequeno, médio e grande, respectivamente (Hair Jr. et al., 2014). 
De acordo com Ringle et al. (2014), após a avaliação da qualidade do modelo, parte-se para a interpretação dos coeficientes, os quais foram interpretados como o beta $(\beta)$ das regressões lineares.

A presente investigação não tem como propósito a generalização dos dados coletados, mas sim a busca por uma análise mais profunda dos fenômenos complexos e das percepções dos indivíduos inseridos na investigação, com intuito de preservar as múltiplas realidades dentro da organização. Deste modo, buscou-se abordar diferentes perspectivas do uso dos sistemas de controle gerencial na empresa estudada. Assim, cabe enfatizar que esta pesquisa seguiu a proposta apresentada por Pierce e O'Dea (2003), ao realizar o levantamento, cujo público alvo contemplou os gestores que atuam diretamente com o sistema de controle gerencial da empresa. Isto corrobora a visão de Langfield-Smith (1997), ao apontar que o potencial do sistema de controle gerencial para apoiar a estratégia existente e para realização das mudanças estratégicas podem ser aferidos por meio da percepção dos gestores.

Para garantir a qualidade da pesquisa buscou-se credibilidade que foi associada à validade interna dos dados e autenticidade da coleta dos dados pela pesquisadora, ou seja, da interação da pesquisadora com o material empírico. No tocante à validade externa, espera-se que os resultados da pesquisa possam ser transferidos para outras unidades de análise dentro do mesmo contexto, ou seja, utiliza-se a lógica da replicação para múltiplas unidades de análise. Além disso, desenvolveu-se um banco de dados de modo a promover confiabilidade, que será mantido por cinco anos e, posteriormente, descartado, permitindo a auditoria dos resultados aferidos. Outrossim, outros pesquisadores poderão utilizar o roteiro deste estudo para futuras pesquisas, de modo a propiciar a comparabilidade dos achados.

O protocolo ético (Apêndice A) corrobora para garantir a qualidade da presente pesquisa, o qual foi regido pelos princípios gerais relativos ao consentimento informado, à reciprocidade que consiste na preocupação em não prejudicar a empresa e as pessoas que nela trabalham, e à confidencialidade da empresa e dos participantes da pesquisa, sempre que demandado, bem como a solicitação de autorização da empresa e dos respondentes. A presente pesquisa não apresentou riscos mentais ou físicos aos participantes associados a este estudo. A participação da empresa e dos respondentes foi voluntária e não foi fornecido qualquer tipo de pagamento ou remuneração aos participantes. A empresa receberá como benefício um feedback composto por um relatório técnico-científico entregue ao gestor contendo as conclusões do presente estudo de modo que a organização estudada possa identificar o poder do uso dos sistemas de controle gerencial em alavancar o seu nível de resiliência organizacional. 


\section{TRATAMENTO E ANÁLISE DOS RESULTADOS}

O tratamento e a análise dos dados aconteceram por meio da estatística descritiva. $\mathrm{Na}$ sequência, realizou-se a avaliação do modelo de mensuração por meio de análise fatorial confirmatória, a qual foi realizada com todos os constructos interligados. O terceiro passo foi a análise do modelo estrutural com estimação por mínimos quadrados parciais (PLS-PM - partial least squares path modeling) e, por fim, foi realizado o exame do mapa de prioridade.

A escolha pela modelagem de equações estruturais com estimação de Partial Least Squares (PLS) para mensurar as relações entre as variáveis latentes dos sistemas de controle gerencial e da resiliência estratégica deu-se pela captura de dados não normais e amostra insuficiente para estimação com outras abordagens para modelagem de equações estruturais com variável latente como o LISREL, e pela comparação com estudos já realizados anteriormente. Observa-se que o instrumento contém 62 indicadores, com uma estrutura predefinida em que 18 mensuram sistemas de controle gerencial e 44 a resiliência estratégica (contido no Apêndice F desta tese). A regra empírica apresentada por Hair Jr., Anderson, Tatham e Black (2005) de 10 casos por variáveis considera a presente amostra de 64 respondentes como insuficiente, sendo este um dos motivos da escolha da modelagem de equações estruturais com estimação de Partial Least Squares (PLS).

A avaliação da mensuração do modelo utilizou os constructos definidos no referencial teórico, tendo em vista que todos os itens foram analisados como indicadores reflexivos (Hair Jr. et al., 2014). O tratamento dos dados foi realizado por meio do software SmartPLS ${ }^{\circledR}$. A análise por meio da modelagem em equações estruturais com estimação de Partial Least Squares (PLS) utilizando Path Modeling tem por alicerce as correlações e regressões. Esta abordagem no tratamento dos dados tem suporte na pesquisa realizada por Chin e Newsted (1999) que apresentam duas vertentes para o cálculo da amostra, uma $a$ priori e a outra $a$ posteriori. Na primeira, o tamanho da amostra deveria ser estipulado por meio do modelo de mensuração ou estrutural que contivesse maior número de preditores e, na segunda, realizar a análise do poder estatístico. Esta, na visão dos autores, é melhor do que as regras empíricas.

Utilizou-se o software $\mathrm{G}^{*}$ Power $^{\circledR}$ versão 3.1.9.2 para realizar a análise do poder estatístico (Faul, Erdfelder, Lang, \& Buchner, 2007; Faul, Erdfelder, Buchner, \& Lang, 2009), cujos parâmetros utilizados foram: nível de significância de 5\% e poder estatístico de $80 \%$ (Hair Jr., Anderson, Tatham, \& Black, 2005). Assim, para uma amostra de 64 observações, apenas correlações iguais ou superiores a 0,24 são consideradas significantes. 


\subsection{CARACTERIZAÇÃO DA AMOSTRA E dOS RESPONDENTES}

A coleta dos dados primários teve início no segundo semestre de 2017, conforme já mencionado no capítulo 3. Os potenciais respondentes foram elencados a partir das entrevistas não estruturadas e das visitas técnicas. Foi diagnosticada uma população de 309 gestores do organizacionais da empresa para compor o escopo do presente estudo, conforme apresentado no item 3.4.3.

Ao realizar a verificação dos outliers e dos casos em que o respondente não completou o questionário gerando os missing values, constatou-se que, dos 125 respondentes, 12 indicaram que não concordam em participar da pesquisa, 38 indicaram que participariam, mas completaram menos de $10 \%$ do questionário e 11 respondentes preencheram cerca de $30 \%$ do questionário apenas. Assim sendo, coletaram-se 64 questionários válidos ${ }^{1}$, com taxa de retorno de $21 \%$. Observa-se que este resultado corrobora com a afirmação de Smith (2015), em que em pesquisas na área contábil são comuns taxas de resposta inferiores a 25\%.

\subsection{PERFIL DO RESPONDENTE}

Os dados demográficos são apresentados a seguir de modo a evidenciar o perfil dos respondentes que compõem a amostra da pesquisa em relação ao universo de coleta de dados (Tabelas 4.1 a 4.3). Majoritariamente, os respondentes são do sexo masculino (92\%) totalizando 59 respondentes e 3 respondentes do sexo feminino. Cabe enfatizar que, dos 309 gestores que compõem o universo da pesquisa, apenas 65 são mulheres, aproximadamente $15 \%$ possui cargos nas gerências vinculadas diretamente à presidência da empresa, 35,8\% na diretoria operacional, $20 \%$ estão alocadas na área de planejamento e financeira e 27,8\% nos setores envolvendo os produtos A e B. Dos 64 respondentes, $46 \%$ possuem curso superior e, destes, $33 \%$ especialização ou MBA, 15\% da amostra possui curso técnico ou apenas ensino médio e $10 \%$ estava cursando o ensino superior ou o iniciou, mas não o havia concluído até a data da pesquisa. No universo investigado as duas pessoas com a titulação de mestre são do sexo feminino, uma com vínculo na área operacional e outra na diretoria do produto B, porém ambas optaram por não responder a presente pesquisa.

\footnotetext{
${ }^{1}$ Dos 64 questionários válidos, dois não preencheram os quesitos referentes a quarta parte do questionário que é representada pelas variáveis demográficas, sendo tabulados como missing, conforme tabelas 4.1 a 4.3.
} 
Tabela 4.1 - Perfil do respondente

\begin{tabular}{c|lccc}
\hline \multicolumn{1}{c}{ GÊNERO } & Universo & \multicolumn{2}{c}{ Respondentes } \\
\hline & Masculino & 244 & 59 & $24 \%$ \\
& Feminino & 65 & 3 & $5 \%$ \\
& Missing & & 2 & \\
& & $\mathbf{3 0 9}$ & $\mathbf{6 4}$ & $\mathbf{2 1 \%}$ \\
& Ensino médio ou técnico & 34 & 5 & $15 \%$ \\
& Ensino superior incompleto & 21 & 2 & $10 \%$ \\
& Ensino superior completo & 144 & 19 & $13 \%$ \\
& Especialização ou MBA & 108 & 36 & $33 \%$ \\
& Mestrado & 2 & 0 & $0 \%$ \\
& Missing & & 2 & \\
& & $\mathbf{3 0 9}$ & $\mathbf{6 4}$ & $\mathbf{2 1 \%}$ \\
\hline
\end{tabular}

Fonte: Elaborada pela autora.

No tocante à faixa etária, observou-se que a maioria $(73,4 \%)$ se encontra entre 36 e 50 anos de idade, sendo $5 \%$ da amostra composta por pessoas com até 35 anos, 13\% entre 51 a 55 anos, 5\% acima de 55 a 60 anos e 2\% acima de 60 anos (deste item não foi possível a comparação com os dados da população, tendo em vista a não disponibilidade da informação pela empresa). Conforme a Tabela 4.2 observa-se que $91 \%$ da amostra atua na empresa há mais de 10 anos.

Tabela 4.2 - Tempo de empresa do respondente

\begin{tabular}{l|ccc}
\hline & Universo & \multicolumn{2}{c}{ Respondentes } \\
\hline Até 5 anos & 3 & 0 & $0 \%$ \\
Acima de 5 a 10 anos & 41 & 6 & $15 \%$ \\
Acima de 10 a 15 anos & 58 & 17 & $29 \%$ \\
Acima de 15 a 20 anos & 100 & 22 & $22 \%$ \\
Acima de 20 a 25 anos & 56 & 9 & $16 \%$ \\
Acima de 25 a 30 anos & 35 & 5 & $14 \%$ \\
Acima de 30 a 35 anos & 10 & 2 & $20 \%$ \\
Acima de 35 a 40 anos & 5 & 0 & $0 \%$ \\
Acima de 40 anos & 1 & 1 & $100 \%$ \\
Missing & & 2 & \\
& $\mathbf{3 0 9}$ & $\mathbf{6 4}$ & $\mathbf{2 1 \%}$ \\
\hline
\end{tabular}

Fonte: Elaborada pela autora.

Em relação ao nível hierárquico, 52\% da amostra (33 respondentes) possui a função de diretor, os demais possuem cargos na alta gerência (11\%), gerente (33\%), supervisor (2\%) e coordenador (2\%). Destes, a Tabela 4.3 evidencia que, embora a Diretoria Operacional 
apresentasse o maior número de potenciais respondentes com $46 \%$ da população, a taxa de retorno foi de apenas $15 \%$, sendo menor que as das Diretoria de Planejamento (38\%), Diretoria do Produto A (29\%), Diretoria do Produto B (26\%) e Diretoria Financeira (23\%).

Tabela 4.3 - Vínculo do respondente na empresa

\begin{tabular}{l|ccc}
\hline & Universo & \multicolumn{2}{c}{ Respondentes } \\
\hline Conselho de Administração e Presidência & 23 & 2 & $9 \%$ \\
Diretoria Financeira & 43 & 10 & $23 \%$ \\
Diretoria Operacional & 142 & 21 & $15 \%$ \\
Diretoria Produto A & 58 & 17 & $29 \%$ \\
Diretoria Produto B & 35 & 9 & $26 \%$ \\
Diretoria de Planejamento & 8 & 3 & $38 \%$ \\
Missing & & 2 & \\
& $\mathbf{3 0 9}$ & $\mathbf{6 4}$ & $\mathbf{2 1 \%}$ \\
\hline
\end{tabular}

Fonte: Elaborada pela autora.

Observou-se, também, que a Diretoria de Planejamento, embora fosse a que continha o menor número de gestores aptos a participar da pesquisa, foi a que apresentou maior representatividade na amostra com 38\% de participação. Cabe enfatizar que a baixa representatividade da presidência está vinculada à baixa participação do universo feminino na pesquisa, tendo em vista que aproximadamente $52 \%$ dos cargos das gerências que respondem diretamente à presidência são ocupados por mulheres, representando $15 \%$ do universo feminino na gestão empresarial.

\subsection{ANÁlise DeSCRITIVA}

\subsubsection{Análise Descritiva do Sistema de Controle Gerencial}

A análise descritiva tem por objetivo organizar e descrever os dados coletados pela pesquisa de forma a descrever tendências de uma população e ilustrar com precisão as dimensões do problema de pesquisa investigado, pois "pretendem unicamente medir ou coletar informação de maneira independente ou conjunta sobre os conceitos ou as variáveis a que se referem" (Sampieri et al., 2013, p. 102).

Conforme já mencionado, a presente pesquisa utilizou escala Likert de 5 pontos em todas as questões que buscam mapear a forma como a organização utiliza o sistema de controle gerencial para manter ou alterar os padrões das atividades organizacionais e para levantar o 
nível de resiliência organizacional da empresa sob a perspectiva estratégica. Desta forma, os valores próximos a 5 evidenciam alta concordância dos respondentes com a afirmativa indicada na questão, alta intensidade do uso das práticas gerenciais na organização e alto nível de desenvolvimento da capacidade da organização de estar atenta às expectativas do mercado, agindo proativamente à medida que percebe os sinais das mudanças, pois tem a habilidade de antecipar, responder, evitar e se adaptar, alternando as suas estratégias de modo a aproveitar as oportunidades, maximizando os ganhos e minimizando os problemas.

Recordando, o Bloco 1 do questionário refere-se às perguntas sobre o uso do sistema de controle gerencial, tendo como base o modelo proposto por Simons (1990, 1991, 1995) operacionalizado pela pesquisa de Widener (2007) formado por quatro alavancas de controle: o sistema de crenças, o sistema de restrições, o uso diagnóstico do sistema de controle e o uso interativo do sistema de controle. O questionário foi complementado por três assertivas (SC4, SR4 e SI5, vide Apêndice F) para identificar o uso do sistema em situação de adversidade.

As questões 1 a 4 foram utilizadas para mapear a percepção dos gestores sobre o sistema de crenças da organização estudada e são evidenciadas na Tabela 4.4. Sabe-se que a organização possui sistema de crenças formalizadas, por meio do planejamento estratégico alinhado ao posicionamento estratégico da controladora do grupo empresarial. As diretrizes estratégicas estão apresentadas no Plano Estratégico (longo prazo visando 2030) que contempla o Plano de Negócios e Gestão (médio prazo até 2022) e o Plano Anual de Negócio (curto prazo), com destaque para missão, visão e valores. A expectativa gerada em relação ao sistema de crenças da organização foi atendida, tendo em vista que a empresa divulga sua missão, visão e valores em materiais institucionais impressos, no site da organização, nos relatórios anuais, nos e-mails e nos canais de comunicações internos. Os resultados da pesquisa apontam para as questões envolvendo sistema de crenças com média superior a 4, demonstrando que a missão realmente comunica os valores fundamentais da empresa, bem como o propósito e a visão da organização, e estes são compartilhados pelos diretores a suas gerências e departamentos (SC1 e SC3).

Cabe enfatizar que, embora seja o item com menor média $(4,22)$, no geral, a missão da organização é observada na tomada de decisão em situações de adversidades conforme evidencia a Tabela 4.4. Destaca-se que, para a variável sistema de crenças, não houve missing e esta variável apresentou menor dispersão entre os respondentes, porém observa-se que o coeficiente de variação está mais elevado para SC2 e SC4. Infere-se que algumas diretorias, como a Diretoria de Planejamento e a Diretoria do Produto A, comunicam com mais frequência os valores a suas equipes (SC2) e observam a missão e a visão da organização no direcionamento de suas decisões, especialmente em momentos de adversidades (SC4). Outras 
diretorias, como as gerências vinculadas ao Conselho de Administração e a Presidência (apresentaram média inferior a 4) e os gestores da Diretoria Operacional (média próxima a 4,3) não os realizam com tanta intensidade; as demais diretorias ficaram acima da média, utilizam o sistema de crenças para estimular mudança estratégica (Margison, 2002), especialmente em momentos de adversidades, e seus gestores comunicam de forma sistemática e formal aos seus subordinados os valores, o propósito e a direção da organização (Simons, 1995, 2000), conforme evidenciado no Gráfico 4.1, na página 1088. Ou seja, pode-se inferir que o sistema de crenças está forte na cultura da empresa pesquisada.

Tabela 4.4 - Análise descritiva do Sistema de Crenças (SC)

\begin{tabular}{clcccc}
\hline Questões & $\begin{array}{l}\text { A extensão na qual os itens a seguir } \\
\text { descrevem as práticas na sua organização. }\end{array}$ & Média & Mediana & $\begin{array}{c}\text { Desvio } \\
\text { Padrão }\end{array}$ & $\begin{array}{c}\text { Coeficiente } \\
\text { de Variação }\end{array}$ \\
\hline Q1 & $\begin{array}{l}\text { SC1: A missão comunica de forma clara os } \\
\text { valores fundamentais da empresa à sua equipe. }\end{array}$ & 4,45 & 5,00 & 0,88 & $20 \%$ \\
Q2 & $\begin{array}{l}\text { SC2: Os principais gestores comunicam os } \\
\text { valores fundamentais à sua equipe. }\end{array}$ & 4,28 & 5,00 & 0,91 & $21 \%$ \\
Q3 & $\begin{array}{l}\text { SC3: A sua equipe está ciente dos valores } \\
\text { fundamentais, do propósito e da visão da } \\
\text { organização. }\end{array}$ & 4,45 & 5,00 & 0,83 & $19 \%$ \\
Q4 & $\begin{array}{l}\text { SC4: Nos momentos de adversidade a } \\
\text { missão/visão é observada na tomada de } \\
\text { decisão. }\end{array}$ & 4,22 & 4,00 & 0,89 & $21 \%$ \\
\hline
\end{tabular}

Fonte: Elaborada pela autora.

Em relação ao sistema de restrições, a Tabela 4.5 evidencia o uso dos instrumentos de controle de comportamento, tais como código de ética, diretrizes de direcionamento de operações, políticas de compliance que impõem os limites e as regras para que as ações na empresa estejam alinhadas de acordo com o seu core business. Assim como no sistema de crenças, todas as questões do sistema de restrições apresentaram média superior a 4 . Atendendo a expectativa da pesquisa, especialmente em relação aos itens SR1 e SR4 terem apresentado grau de concordância maior na percepção dos gestores, pois estes instrumentos são formalizados na organização, são evidenciados nos relatórios anuais e estão disponíveis no site da organização. A empresa adota o Código de Ética, o Guia de Conduta, e ambos estão alinhados aos princípios de ética e de transparência da controladora do grupo empresarial; a Política de Gestão de Riscos Empresariais e a Política de Crédito e Cobrança estão ligadas aos canais de relacionamento, tais como: a Ouvidoria, o Fale Conosco, o Serviço de Informação ao Cidadão e mantém um e-mail exclusivo destinado a disseminar e esclarecer questões relacionadas à conformidade. De acordo com o presidente da organização, "[..] questões que infrinjam os valores da companhia ou normas de compliance são conduzidas com rigor" 
(Relatório anual, 2017). A Comissão de Ética da organização é a responsável por atuar na gestão e na apuração de eventuais transgressões aos instrumentos de controle de comportamento.

Assim como na pesquisa de Cruz (2014), Kruis et al. (2016), Oro (2015) e Widener (2007), estes instrumentos são bastante utilizados para estabelecer os limites na organização pesquisada. Ao investigar como estes mecanismos influenciam o comportamento e a gestão das equipes de trabalho no desenvolvimento das atividades estratégicas da organização, observouse que, em geral, as pessoas têm conhecimento que estes instrumentos informam sobre os comportamentos que estão fora dos limites aceitáveis pela organização (SR1) e que são utilizados para direcionar os comportamentos em situações de adversidades (SR4). Observa-se que o SR1 apresentou as respostas mais próximas da média entre os respondentes, ou seja, comprovou-se, por meio do questionário, que os gestores são conscientes da existência destes instrumentos na organização e que estes direcionam os comportamentos na organização.

Por outro lado, o SR3 apresentou maior dispersão entre os participantes, especialmente entre aqueles vinculados à Diretoria do Produto $\mathrm{B}$, cuja média ficou abaixo da média para a variável latente Sistema de Controle Gerencial. Nos itens 4.4.1, 4.4.2 e 4.5.3 este indicador (SR3) será discutido com mais detalhes, tendo em vista que não foi significante para esta população, apresentando problemas de validade convergente e validade discriminante. Cabe enfatizar que a média atribuída à Presidência e Conselho de Administração para os elementos do sistema de restrição ficaram abaixo da média $(4,30)$ para todas as assertivas, conforme evidenciado no Gráfico 4.1, na página 1088.

Tabela 4.5 - Análise descritiva do Sistema de Restrições (SR)

\begin{tabular}{|c|c|c|c|c|c|}
\hline Questões & $\begin{array}{l}\text { A extensão na qual os itens a seguir } \\
\text { descrevem as práticas na sua organização. }\end{array}$ & Média & Mediana & $\begin{array}{l}\text { Desvio } \\
\text { Padrão }\end{array}$ & $\begin{array}{l}\text { Coeficiente } \\
\text { de Variação }\end{array}$ \\
\hline Q5 & $\begin{array}{l}\text { SR1: Os instrumentos (tais como código de } \\
\text { ética, diretrizes de direcionamento de } \\
\text { operações, políticas de compliance) informam } \\
\text { sobre os comportamentos que estão fora dos } \\
\text { limites aceitáveis pela empresa. }\end{array}$ & 4,59 & 5,00 & 0,71 & $15 \%$ \\
\hline Q6 & $\begin{array}{l}\text { SR2: A organização comunica os riscos a } \\
\text { serem evitados que poderiam ocasionar } \\
\text { adversidades. }\end{array}$ & 4,33 & 4,00 & 0,82 & $19 \%$ \\
\hline Q7 & $\begin{array}{l}\text { SR3: Não sei exatamente tudo o que devo fazer, } \\
\text { mas tenho clareza do que não devo fazer. }\end{array}$ & 4,24 & 4,00 & 0,95 & $22 \%$ \\
\hline Q8 & $\begin{array}{l}\text { SR4: A consciência da existência dos } \\
\text { instrumentos (tais como código de ética, } \\
\text { diretrizes de direcionamento de operações, } \\
\text { políticas de compliance) direciona as ações em } \\
\text { momento de adversidades. }\end{array}$ & 4,45 & 5,00 & 0,91 & $20 \%$ \\
\hline
\end{tabular}

Fonte: Elaborada pela autora. 
A Tabela 4.6 reúne informações sobre o uso diagnóstico do sistema de controle gerencial. De acordo com o desvio padrão apresentado não se pode afirmar que a remuneração variável é uma prática comum na grande parte das diretorias estudadas (SD5), apresentou desvio padrão alto e a menor média dentre as questões envolvendo o uso do sistema de controle gerencial. Indica que a organização possui modelo de reconhecimento, mas não único para seus executivos. Cabe enfatizar que este resultado foi obtido, também, nas pesquisas de Cruz (2014) e Frezatti, Bido, Cruz e Machado (2012). Isto posto, as diretorias utilizam o planejamento estratégico e o orçamento para monitorarem os resultados organizacionais, corrigir os desvios de padrões preestabelecidos de desempenho e para prever adversidades que impeçam que as metas organizacionais sejam alcançadas (Mundy, 2010; Tessier \& Otley, 2012).

Nota-se que esta variável latente do SCG foi a que apresentou maior dispersão entre os respondentes e os itens SD1, SD3 e SD4 foram os que receberam maiores médias $(4,72,4,65$ e 4,59, respectivamente), cujas respostas atribuídas pelos participantes foram as mais homogêneas, apresentando os menores coeficientes de variação (11\% a 12\%). Todavia, a menor média dos indicadores de SCG ficou com a SD5 $(3,35)$, cuja percepção dos respondentes ficou mais divergente apresentando $45 \%$ de coeficiente de variação; é cabível ressaltar que este indicador foi o que apresentou maior missing, ou seja, 15 respondentes (23\% da amostra) indicaram não saber ou não se aplica.

No tocante aos respondentes pertencentes à Presidência e ao Conselho de Administração, indicaram extremamente baixa a utilização, a Diretoria de Planejamento, a Diretoria Financeira, a Diretoria do Produto A e a Diretoria Operacional que apresentaram as seguintes médias 3,0, 2,8, 3,4 e 3,5, respectivamente; apenas a Diretoria do Produto B apresentou média superior a 4,0 para SD5, mostrando maior impacto do desempenho individual na remuneração variável do executivo. Chama atenção ao olhar o Gráfico 4.1, na página 108, que, dentre as alavancas de controle gerencial, as diretorias: Financeira $(4,3)$ e do Produto A $(4,3)$ apresentaram as menores médias para o uso diagnóstico do controle gerencial. Por outro lado, na Diretoria do Produto B, o destaque entre as alavancas é para o uso diagnóstico do controle gerencial apresentando, entre as diretorias, a maior média (4,6). Cabe enfatizar que tal média é atribuída também pela Diretoria de Planejamento que é a responsável por operacionalizar, trabalhar diretamente na formalização destes instrumentos, comunicar as variáveis críticas de desempenho e monitorar a implementação da estratégia (Simons, 2000). 
Tabela 4.6 - Análise descritiva do Uso do Diagnóstico do Sistema de Controle Gerencial (SD)

\begin{tabular}{|c|c|c|c|c|c|}
\hline Questões & $\begin{array}{l}\text { A extensão na qual os itens a seguir } \\
\text { descrevem as práticas na sua organização. }\end{array}$ & Média & Mediana & $\begin{array}{l}\text { Desvio } \\
\text { Padrão }\end{array}$ & $\begin{array}{l}\text { Coeficiente } \\
\text { de Variação }\end{array}$ \\
\hline Q9 & $\begin{array}{l}\text { SD1: Temos planejamento estratégico } \\
\text { formalizado. }\end{array}$ & 4,72 & 5,00 & 0,54 & $11 \%$ \\
\hline Q10 & $\begin{array}{l}\text { SD2: O orçamento está alinhado com o } \\
\text { planejamento estratégico e decorre dele. }\end{array}$ & 4,52 & 5,00 & 0,75 & $17 \%$ \\
\hline Q11 & $\begin{array}{l}\text { SD3: Temos controle orçamentário: são } \\
\text { apresentados os relatórios com o previsto } \\
\text { versus o realizado; em reuniões são discutidos } \\
\text { os resultados passados e as ações futuras. }\end{array}$ & 4,65 & 5,00 & 0,54 & $12 \%$ \\
\hline Q12 & $\begin{array}{l}\text { SD4: Monitoramos e comparamos os } \\
\text { resultados com as expectativas de modo a } \\
\text { prever adversidades que impeçam o progresso } \\
\text { em direção às metas organizacionais. }\end{array}$ & 4,59 & 5,00 & 0,55 & $12 \%$ \\
\hline Q13 & $\begin{array}{l}\text { SD5: O desempenho individual explicitado } \\
\text { pelo controle orçamentário impacta a } \\
\text { remuneração variável do executivo. }\end{array}$ & 3,35 & 4,00 & 1,52 & $45 \%$ \\
\hline
\end{tabular}

Fonte: Elaborada pela autora.

As médias obtidas nas questões da Tabela 4.7 sugerem que o uso interativo do sistema de controle gerencial tem sido o eixo estruturante do envolvimento do pessoal dentro da organização de modo que os gerentes operacionais estejam engajados com os sistemas de controle e os dados gerados pelo sistema de controle sejam repassados e discutidos entre os diversos níveis organizacionais de tal forma que ocorra a articulação de estratégias para atender às demandas da organização, especialmente para antecipar continuamente as adversidades.

A empresa necessita dar mais atenção ao item SI4, que apresentou maior dispersão entre os respondentes, isto significa que embora a empresa utilize o SCG para antecipar as mudanças não é uma percepção homogênea na organização. Os resultados evidenciam que a Presidência e Conselho Administrativo e duas diretorias (Diretoria Operacional e Diretoria Produto B) ficaram abaixo da média, com 3,0, 4,1 e 4,2, respectivamente (Gráfico 4.1). Conforme esperado, as diretorias Financeira e de Planejamento apresentaram médias elevadas para este quesito, 4,6 e 5,0, respectivamente, tendo em vista que a primeira se preocupa com os controles financeiros e, a segunda, com o controle gerencial da organização conforme descrito no item 3.4.3.

No tocante às diretorias, pode-se constatar pelo Gráfico 4.1, na página 108, que os extremos estão relacionados ao uso interativo do sistema de controle gerencial nesta organização, enquanto a Diretoria de Planejamento apresenta o maior uso interativo do sistema de controle gerencial (SI) com média de 4,9, a Presidência e o Conselho de Administração apresentaram a menor, 3,2, isto evidencia a maior média atribuída às alavancas de controle e a menor das médias. Além da Presidência e Conselho de Administração, a Diretoria Operacional 
também apresentou a menor média $(4,2)$ entre as alavancas de controle para a extensão com que utiliza as práticas gerenciais de forma interativa.

Tabela 4.7 - Análise descritiva do Uso Interativo do Sistema de Controle Gerencial (SI)

\begin{tabular}{clcccc}
\hline Questões & $\begin{array}{l}\text { A extensão na qual os itens a seguir } \\
\text { descrevem as práticas na sua organização. }\end{array}$ & Média & Mediana & $\begin{array}{c}\text { Desvio } \\
\text { Padrão }\end{array}$ & $\begin{array}{c}\text { Coeficiente } \\
\text { de Variação }\end{array}$ \\
\hline Q14 & $\begin{array}{l}\text { SI1: Os gerentes operacionais estão } \\
\text { frequentemente envolvidos com o sistema de } \\
\text { controle. }\end{array}$ & 4,44 & 5,00 & 0,75 & $17 \%$ \\
Q15 & $\begin{array}{l}\text { SI2: Os dados gerados pelo sistema de controle } \\
\text { são interpretados e discutidos com superiores, } \\
\text { subordinados e pares. }\end{array}$ & 4,33 & 4,00 & 0,74 & $17 \%$ \\
Q16 & $\begin{array}{l}\text { SI3: É dedicada atenção regular e frequente à } \\
\text { análise e discussão das adversidades em } \\
\text { reuniões por parte dos gestores de todos os }\end{array}$ \\
$\begin{array}{l}\text { níveis. } \\
\text { SI4: A empresa utiliza o sistema de controle } \\
\text { para antecipar-se às mudanças com intuito de } \\
\text { evitar que as adversidades afetem seus } \\
\text { negócios. }\end{array}$ & 4,26 & 4,00 & 0,78 & $18 \%$ \\
$\begin{array}{l}\text { SI5: A organização alinha a sua estratégia aos } \\
\text { sistemas de controle dando suporte à decisão de } \\
\text { modo a adaptar-se continuamente às } \\
\text { adversidades. }\end{array}$ & 4,37 & 4,00 & 0,00 & $21 \%$ \\
Q18 & & & & $17 \%$ \\
\hline
\end{tabular}

Fonte: Elaborada pela autora.

Considerando as quatro alavancas de controle propostas no modelo teórico de Simons (1995) e operacionalizada nesta pesquisa, o sistema de crenças foi o que apresentou maior dispersão (20\%) entre os respondentes da empresa investigada, seguido do sistema de restrições (19\%), o uso diagnóstico e o uso interativo do sistema de controle com $18 \%$ cada de dispersão, conforme evidenciado na Tabela 4.8.

Tabela 4.8 - Análise descritiva das alavancas de controle

\begin{tabular}{cccc}
\hline Alavancas de Controle & Média & $\begin{array}{c}\text { Desvio } \\
\text { Padrão }\end{array}$ & $\begin{array}{c}\text { Coeficiente de } \\
\text { Variação }\end{array}$ \\
\hline Sistema de Crenças (SC) & 4,35 & 0,88 & $20 \%$ \\
Sistema de Restrições (SR) & 4,40 & 0,85 & $19 \%$ \\
Uso Diagnóstico do Sistema de Controle (SD) & 4,37 & 0,78 & $18 \%$ \\
Uso Interativo do Sistema de Controle (SI) & 4,35 & 0,78 & $18 \%$ \\
\hline
\end{tabular}

Fonte: Elaborada pela autora. 
Porém, cabe enfatizar que a média dos quatro sistemas foram bem próximas, cujos valores foram superiores ou iguais a 4,35 para uma escala likert de 5 pontos, em que o 5 representa o maior nível de concordância. Embora, as médias das quatro alavancas de controle tenham ficado bem próximas, o que surpreendeu foi o sistema de restrições apresentar a maior média $(4,404)$ e o sistema de crenças, a menor $(4,352)$. Acredita-se que tal fato tenha ocorrido devido à natureza jurídica da empresa e às limitações que isto gera no processo de tomada de decisão.

Do ponto de vista prático, com a finalidade de elucidar e de auxiliar a análise comparativa entre os diversos níveis de utilização do Sistema de Controle Gerencial (SCG) por diretoria, elaborou-se o Gráfico 4.1. Destaca-se que o gráfico em questão apresenta em seus eixos as seguintes informações: eixo Y - a Escala Likert que, na presente pesquisa, variou de 1 a 5, indicando os índices de utilização do Sistema de Controle Gerencial (SCG), porém, para melhorar o fator de escala do gráfico, foi fixado de 3,00 a 5,00, tendo em vista que não foram encontrados valores menores que 3,00 na presente pesquisa; no eixo $\mathrm{X}$ - foram apresentados os vínculos das classes respondentes com a empresa submetida a esta pesquisa (de acordo com a legenda abaixo do gráfico). Dentro do SCG, o gráfico apresenta o Sistema de Crenças (SC), o Sistema de Restrição (SR), Uso Diagnóstico do Sistema de Controle (SD) e o Uso Interativo do Sistema de Controle (SI).

Observa-se que a Presidência e o Conselho de Administração obtiveram médias 3,75, 3,38, 3,60 e 3,20, para SC, SR, SD e SI, respectivamente. Consecutivamente, obtiveram média, entre todos os índices do Sistema de Controle Gerencial (SCG), de 3,48. A Diretoria Operacional obteve médias 4,31, 4,53, 4,40 e 4,29, para SC, SR, SD e SI, respectivamente e a Diretoria de Produto A obteve médias 4,46, 4,40, 4,32 e 4,35, para SC, SR, SD e SI, respectivamente. Isto posto, observa-se a grande proximidade entre estas duas diretorias, pois ambas obtiveram médias entre todos os itens de SCG de 4,38, isto é, apresentaram níveis altos de utilização de SCG. 
Gráfico 4.1 - Sistema de Controle Gerencial (SCG)

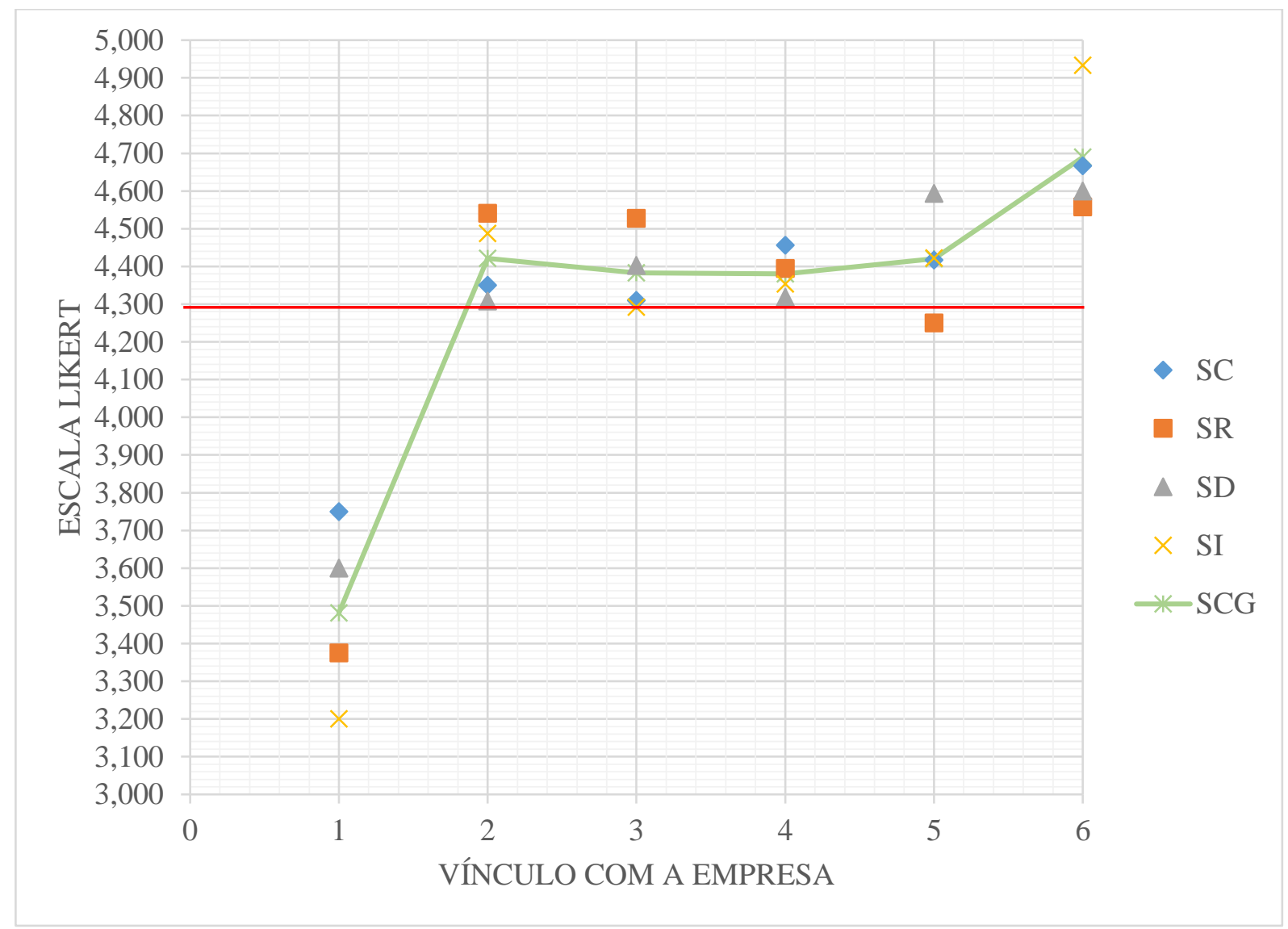

Nota 1: A linha vermelha representa a média geral aritmética entre todas as ferramentas que compuseram os índices de utilização de SCG.

Nota 2: A linha verde representa a média individual de cada diretoria para o constructo Sistema de Controle Gerencial (SCG).

Legenda: 1 = Presidência + Conselho de Administração; $2=$ Diretoria Financeira; $3=$ Diretoria Operacional; 4 = Diretoria Produto A; $5=$ Diretoria Produto B; e $6=$ Diretoria de Planejamento.

Fonte: Elaborado pela autora.

Um olhar atento ao Gráfico 4.1, mostra que a Diretoria Financeira obteve médias 4,35, 4,54, 4,31 e 4,49, para SC, SR, SD e SI, respectivamente. Consecutivamente, obteve média entre todos os índices do Sistema de Controle Gerencial (SCG) de 4,42. A Diretoria de Produto B obteve médias 4,42, 4,25, 4,59 e 4,42, para SC, SR, SD e SI, respectivamente, e obteve também média entre todos os índices do Sistema de Controle Gerencial (SCG) de 4,42. Isto posto, observa-se a grande proximidade entre estas duas diretorias, pois ambas obtiveram média entre todos os itens de SCG de 4,42, isto é, apresentaram níveis altos de utilização do SCG.

Destaca-se que a Diretoria de Planejamento obteve médias 4,67, 4,56, 4,60 e 4,93, para SC, SR, SD e SI, respectivamente. Consecutivamente, obteve média entre todos os índices do Sistema de Controle Gerencial (SCG) de 4,69, sendo esta a média mais alta de utilização de SCG entre todas as diretorias (incluindo a Presidência e o Conselho de Administração). 
O Gráfico 4.1 também apresenta a média geral aritmética entre todas as ferramentas que compuseram os índices de utilização de SCG, isto é, o valor de 4,30 (representado pela linha vermelha no gráfico). Assim sendo, observa-se que, exceto a Presidência e o Conselho de Administração que estão com todos os seus indicadores abaixo da média geral, todas as demais diretorias estão acima da média de utilização do SCG, corroborando a percepção desta pesquisadora, isto é, detecção de um alto nível de utilização do SCG, quando das visitas in loco na empresa estudada.

\subsubsection{Análise Descritiva da Resiliência Estratégica}

A variável latente Resiliência Estratégica é mensurada por meio de 10 dimensões com uma variação de 4 a 5 indicadores em cada uma (vide Quadros 3.2 a 3.4 nas páginas 88 a 900, respectivamente), nas quais se busca mapear a extensão com que estes elementos aparecem na organização, especificamente, em relação às pessoas e ou aos processos dentro da diretoria, da gerência ou do departamento em que o gestor está responsável.

A Tabela 4.9 ilustra as questões VE1 a VE5 do questionário aplicado que mapeiam a Visão Estratégica (VE) da organização. Tem-se o destaque nos indicadores VE1 e VE5 que apresentaram as maiores médias, sendo 4,38 e 4,39, respectivamente, sendo os mais homogêneos entre os respondentes.

Tabela 4.9 - Análise descritiva da Visão Estratégica (VE)

\begin{tabular}{|c|c|c|c|c|c|}
\hline Questões & $\begin{array}{c}\text { A extensão na qual os itens a seguir } \\
\text { descrevem as práticas na sua organização. }\end{array}$ & Média & Mediana & $\begin{array}{l}\text { Desvio } \\
\text { Padrão }\end{array}$ & $\begin{array}{l}\text { Coeficiente } \\
\text { de Variação }\end{array}$ \\
\hline Q19 & $\begin{array}{l}\text { VE1: Temos uma visão ampla } \mathrm{da} \\
\text { organização/do negócio como um todo. }\end{array}$ & 4,38 & 5,00 & 0,82 & $19 \%$ \\
\hline Q20 & $\begin{array}{l}\text { VE2: Dedicamos tempo e energia para } \\
\text { reavaliar regularmente as metas a serem } \\
\text { alcançadas e explorar novas opções } \\
\text { estratégicas, o que nos permite constantemente } \\
\text { mudar a direção da organização. }\end{array}$ & 4,05 & 4,00 & 0,94 & $23 \%$ \\
\hline Q21 & $\begin{array}{l}\text { VE3: Os aspectos de mudança são } \\
\text { identificados como novas oportunidades para a } \\
\text { organização. }\end{array}$ & 4,32 & 5,00 & 0,85 & $20 \%$ \\
\hline Q22 & $\begin{array}{l}\text { VE4: Temos condições e capacidade para } \\
\text { reconhecer as vulnerabilidades e as fraquezas } \\
\text { do negócio para nos ajustar à nova realidade. }\end{array}$ & 4,21 & 4,00 & 0,86 & $20 \%$ \\
\hline Q23 & $\begin{array}{l}\text { VE5: O entendimento amplo da organização e } \\
\text { de sua atividade nos permite diagnosticar, } \\
\text { interpretar, compreender e nos anteciparmos às } \\
\text { adversidades, aos eventos e às mudanças no } \\
\text { cenário empresarial. }\end{array}$ & 4,39 & 5,00 & 0,80 & $18 \%$ \\
\hline
\end{tabular}

Fonte: Elaborada pela autora. 
Isto evidencia que os gestores possuem uma visão ampla da organização permitindo que realizem diagnósticos, interpretações e se preparem antecipadamente para as adversidades, os eventos e as mudanças no cenário empresarial. Por outro lado, mudar as metas e a direção da organização para atender a demanda das adversidades identificadas não é algo tão tranquilo de se operacionalizar nesta organização, conforme mostra o indicador VE2 com média 4,05. Além disso, detectou-se que este indicador apresentou maior divergência entre as diretorias investigadas, recebendo a menor média pela Presidência e a maior pela Diretoria de Planejamento. Observa-se no Gráfico 4.2, na página 119, que, entre os indicadores da RE, as diretorias, presidência e planejamento foram aquelas que apresentaram os maiores níveis de desenvolvimento de VE em relação aos demais indicadores, 3,6 e 4,7, respectivamente. O nível de desenvolvimento de VE para a diretoria de planejamento foi o maior tanto entre as diretorias investigadas, quanto em relação aos demais indicadores de Resiliência Estratégica.

A Tabela 4.10 mostra os indicadores da Postura Proativa (PP) esperada da organização investigada. Chama atenção o indicador PP1 que obteve uma das menores médias da pesquisa no geral $(3,83)$ e o mais heterogêneo dos indicadores de PP, indica que, devido aos processos formais da empresa e a sua natureza jurídica, as ações internas que promovem mudanças, seja para explorar uma oportunidade, seja para evitar determinada adversidade, são mais lentas que o almejado pelos gestores. Outras inferências são: o aspecto cultural dos tipos de controle utilizado pelas diretorias e o entendimento do evento. Os gestores da diretoria de planejamento fazem uso interativo do sistema de controle, estão mais alinhados ao evento e voltados para o impacto futuro do evento na organização do que àqueles que estão alocados na diretoria operacional que realizam o uso diagnóstico do sistema de controle e precisam apresentar um produto. Além disso, observa-se que os gestores apresentaram percepções mais homogêneas ao auxiliar a organização a atuar de forma proativa à medida que monitoram o setor no tocante às questões emergentes (PP4) e realizam a busca constante por oportunidade de crescimento mesmo em situações de adversidades (PP5), cujas médias dos indicadores foram de 4,28 e 4,33, respectivamente. 
Tabela 4.10 - Análise descritiva da Postura Proativa (PP)

\begin{tabular}{clcccc}
\hline Questões & $\begin{array}{l}\text { A extensão na qual os itens a seguir } \\
\text { descrevem as práticas na sua organização }\end{array}$ & Média & Mediana & $\begin{array}{c}\text { Desvio } \\
\text { Padrão }\end{array}$ & $\begin{array}{c}\text { Coeficiente } \\
\text { de Variação }\end{array}$ \\
\hline Q24 & $\begin{array}{l}\text { PP1: Temos uma estrutura que nos permite agir } \\
\text { de forma rápida e eficaz em resposta a uma } \\
\text { oportunidade e aos eventos inesperados. }\end{array}$ & 3,83 & 4,00 & 1,02 & $27 \%$ \\
P22: Temos uma diversidade de ações \\
$\begin{array}{l}\text { competitivas disponíveis para adotarmos em } \\
\text { resposta às inesperadas e oportunas mudanças } \\
\text { que ocorrem no mercado. }\end{array}$
\end{tabular}

Fonte: Elaborada pela autora.

No tocante à Aprendizagem Organizacional (AO), Tabela 4.11, a empresa assume que os erros do passado podem auxiliá-la a evoluir e adaptar-se às novas situações no futuro, bem como em momentos de adversidades. Além disso, busca identificar quais são os problemas, aprende sobre eles, busca soluções e as implanta de modo a reduzir o impacto desta mudança na gestão empresarial. Por outro lado, com média de 3,91 (a menor entre os indicadores de AO), observa-se que as estruturas organizacionais muitas vezes não possibilitam aos gestores mudar seus comportamentos de modo a adaptar-se aos novos cenários. Isto ficou mais evidente na Presidência e no Conselho de Administração e na Diretoria do Produto B, em que ambas apresentaram para este indicador valores inferiores à média, sendo 2,00 e 3,67, respectivamente. Ao olhar AO no tocante às diretorias, observou-se que exceto a Presidência e o Conselho de Administração, as demais diretorias apresentaram alto nível de concordância variando de 4,15 (Diretorias Financeira e do Produto B) a 4,3 (Diretorias Operacional, Produto A e Planejamento. 
Tabela 4.11 - Análise descritiva da Aprendizagem Organizacional (AO)

\begin{tabular}{|c|c|c|c|c|c|}
\hline Questões & $\begin{array}{l}\text { A extensão na qual os itens a seguir } \\
\text { descrevem as práticas na sua organização. }\end{array}$ & Média & Mediana & $\begin{array}{l}\text { Desvio } \\
\text { Padrão }\end{array}$ & $\begin{array}{r}\text { Coeficiente } \\
\text { de Variação }\end{array}$ \\
\hline Q29 & $\begin{array}{l}\text { AO1: Durante uma adversidade, somos } \\
\text { capazes de identificar um problema, aprender } \\
\text { sobre ele, apresentar solução e implantar a } \\
\text { solução. }\end{array}$ & 4,34 & 5,00 & 0,80 & $18 \%$ \\
\hline Q30 & $\begin{array}{l}\text { AO2: Aprendemos lições do passado e } \\
\text { garantimos que estas lições sejam executadas } \\
\text { no futuro, pois evoluímos e nos adaptamos às } \\
\text { novas situações. }\end{array}$ & 4,27 & 4,00 & 0,76 & $18 \%$ \\
\hline Q31 & $\begin{array}{l}\text { AO3: Temos estruturas organizacionais que } \\
\text { são projetadas para promover a aprendizagem } \\
\text { e mudar os comportamentos com base nas } \\
\text { novas informações e nos novos insights. }\end{array}$ & 3,91 & 4,00 & 0,98 & $25 \%$ \\
\hline Q32 & $\begin{array}{l}\text { AO4: Temos práticas de gestão e normas } \\
\text { organizacionais que incentivam o } \\
\text { questionamento do que está acontecendo de } \\
\text { modo a exigir uma sólida compreensão da } \\
\text { realidade. }\end{array}$ & 4,11 & 4,00 & 0,89 & $22 \%$ \\
\hline
\end{tabular}

Fonte: Elaborada pela autora.

No tocante ao processo de comunicação organizacional, a empresa compartilha a direção e as estratégias organizacionais nos diversos níveis hierárquicos, por meio de uma linguagem comum promovendo a divulgação de forma clara dos valores fundamentais e da direção que a organização deseja seguir. Identificou-se, na Tabela 4.12, que isto é operacionalizado pelo sistema de informação que disponibiliza os dados em vários meios com qualidade dando suporte à tomada de decisão rápida e eficaz. Porém, a principal deficiência encontrada em relação a esta variável (CO), que apresentou média inferior a 4, está na formação dos gestores para utilizar o sistema de informação da organização, principalmente nos momentos de maior tensão quando ocorrem as incertezas estratégicas, sendo mais crítico na Presidência e na Diretoria do Produto A. Outro item que chama atenção é a percepção dos respondentes ser mais divergente para o CO5, especialmente na Diretoria de Planejamento, no tocante a disponibilização das informações em diferentes meios. Cabe enfatizar que sob o ponto de vista da diretoria de planejamento várias coisas não são sistematizadas, ou seja, essa diretoria nem sempre apresenta todas as informações no sistema de informações. Por outro lado, a diretoria operacional possui elementos sistematizados, formatados e padronizados. A diretoria de planejamento trabalha mais o uso interativo do que o diagnóstico, já a diretoria operacional tem uma cultura de utilização da informação para diagnóstico (vide Gráfico 4.1). 
Tabela 4.12 - Análise descritiva da Comunicação Organizacional (CO)

\begin{tabular}{|c|c|c|c|c|c|}
\hline Questões & $\begin{array}{c}\text { A extensão na qual os itens a seguir } \\
\text { descrevem as práticas na sua organização }\end{array}$ & Média & Mediana & $\begin{array}{l}\text { Desvio } \\
\text { Padrão }\end{array}$ & $\begin{array}{l}\text { Coeficiente } \\
\text { de Variação }\end{array}$ \\
\hline Q33 & $\begin{array}{l}\text { CO1: O processo de comunicação compartilha } \\
\text { a direção e as estratégias organizacionais nos } \\
\text { diversos níveis hierárquicos. }\end{array}$ & 4,19 & 4,00 & 0,85 & $20 \%$ \\
\hline Q34 & $\begin{array}{l}\text { CO2: Temos uma linguagem comum (ou seja, } \\
\text { palavras, imagens e histórias) e predominante } \\
\text { que implica capacidade, influência, } \\
\text { competência, valores fundamentais } \\
\text { consistentes e um sentido claro de direção em } \\
\text { nossa organização. }\end{array}$ & 4,36 & 4,00 & 0,74 & $17 \%$ \\
\hline Q35 & $\begin{array}{l}\text { CO3: O sistema de informação ao } \\
\text { disponibilizar informação com qualidade dá } \\
\text { suporte à tomada de decisão rápida e eficaz. }\end{array}$ & 4,16 & 4,00 & 0,83 & $20 \%$ \\
\hline Q36 & $\begin{array}{l}\text { CO4: Funcionários possuem formação para } \\
\text { utilizar o sistema, sabem quais informações } \\
\text { acessar em situações críticas e têm consciência } \\
\text { das implicações para as possíveis soluções. }\end{array}$ & 3,97 & 4,00 & 0,90 & $23 \%$ \\
\hline Q37 & $\begin{array}{l}\text { CO5: As informações cruciais estão } \\
\text { disponíveis em diferentes meios. }\end{array}$ & 4,11 & 4,00 & 0,99 & $24 \%$ \\
\hline
\end{tabular}

Fonte: Elaborada pela autora.

Inovação e Criatividade (IC) apresentou a menor média entre os indicadores que mensuram a resiliência estratégica (3,69), vide a Tabela 4.19, na página 118. É relevante atrelar esse resultado ao setor da organização e a percepção do respondente sobre os aspectos conceituais, embora o questionário tenha um direcionamento conceitual padronizado, a cognição de cada indivíduo sobre inovação e criatividade pode acarretar respostas diferentes, pois não é um elemento totalmente padronizado dentro da organização.

Nota-se, na Tabela 4.13, que apenas um dos seus indicadores o IC2 apresentou média superior a 4, evidenciando que os gestores utilizam o conhecimento de forma inovadora e criativa na solução de problemas no cotidiano empresarial. Por outro lado, não há incentivos (IC3) nem recompensas significativas (IC4) por parte da empresa em promover comportamentos que remetam a atitudes inovadoras e criativas por parte dos gestores. Concluise que a inovação e a criatividade são empregadas no dia a dia da gestão por iniciativa de cada indivíduo ao desempenhar suas tarefas e não por incentivo da organização. O indicador IC4 foi o que apresentou menor média $(3,0)$ entre os indicadores da pesquisa, bem como para a RE foi o indicador com maior dispersão entre os respondentes (41\%). Observou-se que apenas a Diretoria do Produto A e a Diretoria Financeira apresentaram valores médios superiores a 3 para este indicador (vide Gráfico 4.2, na página 119). 
Tabela 4.13 - Análise descritiva da Inovação e Criatividade (IC)

\begin{tabular}{clcccc}
\hline Questões & $\begin{array}{l}\text { A extensão na qual os itens a seguir } \\
\text { descrevem as práticas na sua organização. }\end{array}$ & Média & Mediana & $\begin{array}{c}\text { Desvio } \\
\text { Padrão }\end{array}$ & $\begin{array}{c}\text { Coeficiente } \\
\text { de Variação }\end{array}$ \\
\hline Q38 & $\begin{array}{l}\text { IC1: Somos estimulados a ter espírito } \\
\text { empreendedor visando à mudança. }\end{array}$ & 3,76 & 4,00 & 1,19 & $32 \%$ \\
Q39 & $\begin{array}{l}\text { IC2: Temos capacidade de utilizar o } \\
\text { conhecimento de forma inovadora e criativa na } \\
\text { solução de problemas. }\end{array}$ & 4,19 & 4,00 & 0,83 & $20 \%$ \\
$\begin{array}{l}\text { IC3: Somos incentivados a sermos criativos e a } \\
\text { buscarmos oportunidades para desenvolver } \\
\text { novas habilidades, ao invés de termos como } \\
\text { foco a padronização. }\end{array}$ & 3,80 & 4,00 & 1,20 & $32 \%$ \\
QC4: Somos recompensados por "pensar fora da \\
caixa".
\end{tabular}

Fonte: Elaborada pela autora.

O quesito Autonomia para Tomada de Decisão apresentou média geral de 3,87 (vide Tabela 4.19 na página 118), embora haja na organização o acesso direto às autoridades que podem tomar decisão, os gestores apresentam limitações no tocante à autonomia que possuem para tomarem decisões, isto significa que um baixo índice de líderes delegam responsabilidade e autoridade à sua equipe de trabalho, não proporcionando aos gestores agilidade no processo de tomada de decisão (Tabela 4.14). Isto pode ser reflexo do tempo de empresa dos gestores tendo em vista que $91 \%$ estão na empresa a mais de dez anos e a faixa etária da maioria dos gestores (86\%) estar entre 36 e 55 anos. Cabe enfatizar que, assim como a variável Inovação e Criatividade, nenhuma diretoria apresentou alto nível de desenvolvimento para autonomia na tomada de decisão. Destaca-se que a Diretoria do Produto A foi a que apresentou melhor desempenho (Gráfico 4.2 na página 119).

Tabela 4.14 - Análise descritiva da Autonomia na Tomada de Decisão (TD)

\begin{tabular}{clcccc}
\hline Questões & $\begin{array}{l}\text { A extensão na qual os itens a seguir } \\
\text { descrevem as práticas na sua organização }\end{array}$ & Média & Mediana & $\begin{array}{c}\text { Desvio } \\
\text { Padrão }\end{array}$ & $\begin{array}{c}\text { Coeficiente } \\
\text { de Variação }\end{array}$ \\
\hline Q42 & $\begin{array}{l}\text { TD1: Os líderes delegam responsabilidades e } \\
\text { autoridade a sua equipe permitindo aos } \\
\text { profissionais autonomia para tomarem } \\
\text { decisões. }\end{array}$ & 3,88 & 4,00 & 1,01 & $26 \%$ \\
Q43 & $\begin{array}{l}\text { TD2: Compartilhamos a tomada de decisão } \\
\text { amplamente. }\end{array}$ & 4,00 & 4,00 & 0,96 & $24 \%$ \\
Q44 & $\begin{array}{l}\text { TD3: Podemos tomar decisões difíceis } \\
\text { rapidamente. } \\
\text { TD4: Caso ocorram problemas, os } \\
\text { Qolaboradores possuem acesso direto a alguém } \\
\text { comautoridade que possa tomar decisões. }\end{array}$ & 4,23 & 4,00 & 1,12 & $33 \%$ \\
\hline
\end{tabular}

Fonte: Elaborada pela autora. 
No quesito Liderança (LD) a organização obteve a maior média, 4,3 (vide Tabela 4.19 na página 118). O quesito está detalhado na Tabela 4.15, cuja principal ênfase dos líderes na presente organização está em considerar as mudanças como oportunidade, além de incentivarem suas equipes de trabalho a discutirem juntos os problemas. Cabe destacar que os lideres buscam gerar feedback constante para sua equipe de trabalho e muitos lideram pelo próprio exemplo.

Tabela 4.15 - Análise descritiva da Liderança (LD)

\begin{tabular}{clcccc}
\hline Questões & $\begin{array}{l}\text { A extensão na qual os itens a seguir } \\
\text { descrevem as práticas na sua organização }\end{array}$ & Média & Mediana & $\begin{array}{c}\text { Desvio } \\
\text { Padrão }\end{array}$ & $\begin{array}{c}\text { Coeficiente } \\
\text { de Variaçãa }\end{array}$ \\
\hline Q46 & $\begin{array}{l}\text { LD1: Líderes abertos às mudanças contínuas } \\
\text { nas estratégias da organizaça e aos novos } \\
\text { desafios; consideram a mudança como } \\
\text { oportunidade. }\end{array}$ & 4,39 & 5,00 & 0,80 & $18 \%$ \\
Q47 & $\begin{array}{l}\text { LD2: Os gestores entendem como liderança o } \\
\text { próprio exemplo. }\end{array}$ & 4,16 & 4,00 & 0,96 & $23 \%$ \\
Q48 & $\begin{array}{l}\text { LD3: A liderança preza pelo bom } \\
\text { relacionamento e incentiva os colaboradores a } \\
\text { discutirem problemas junto aos seus gestores. }\end{array}$ \\
$\begin{array}{l}\text { LD4: A liderança gera feedback constante e } \\
\text { desenvolve uma comunicação aberta entre o } \\
\text { líder e sua equipe. }\end{array}$ & 4,19 & 4,00 & 0,71 & $16 \%$ \\
\hline
\end{tabular}

Fonte: Elaborada pela autora.

Chama atenção o fato de a Diretoria de Planejamento apresentar desempenho abaixo em relação as demais diretorias para este quesito, vide Gráfico 4.2, na página 119. Além disso, é possível notar que a Diretoria de Planejamento foi a única que apresentou a média de liderança $(4,12)$ abaixo da média de desenvolvimento de $\mathrm{RE}(4,25)$ para a respectiva diretoria e, em contrapartida, a Presidência e o Conselho de Administração mesmo com média 3,5 para liderança, apresentou desempenho superior a outras variáveis de RE.

No tocante ao fator humano (FH), Tabela 4.16, as críticas e a busca por informações na percepção dos gestores são os itens que merecem ser aprimorados no cotidiano empresarial. Por outro lado, as pessoas compartilham recurso, objetivos, conhecimentos e informações mesmo fora de suas fronteiras departamentais e se consideram responsáveis pela eficácia da organização à medida que assumem responsabilidades pelo desempenho da empresa. A percepção dos respondentes foi mais divergente no tocante à busca por informações, a solicitação de ajuda, ao assumirem os erros e ou ao gerarem feedbacks críticos no desenvolvimento de suas atividades, tendo em vista que, na Presidência e no Conselho de Administração, o nível de concordância foi de 2,5, na Diretoria de Planejamento foi de 3,3, nas 
diretorias Financeira, Operacional e do Produto B foi 3,6, 3,9 e 4,0, respectivamente e somente a Diretoria do Produto A apresentou alto nível de desenvolvimento para este item $(4,2)$.

Tabela 4.16 - Análise descritiva do Fator Humano (FH)

\begin{tabular}{|c|c|c|c|c|c|}
\hline Questões & $\begin{array}{c}\text { A extensão na qual os itens a seguir } \\
\text { descrevem as práticas na sua organização }\end{array}$ & Média & Mediana & $\begin{array}{l}\text { Desvio } \\
\text { Padrão }\end{array}$ & $\begin{array}{r}\text { Coeficiente } \\
\text { de Variação }\end{array}$ \\
\hline Q50 & $\begin{array}{l}\text { FH1: As pessoas estabelecem relações com } \\
\text { outras pessoas permitindo o compartilhamento } \\
\text { de recursos, de objetivos, de conhecimentos, de } \\
\text { informações e de práticas de respeito mútuo. }\end{array}$ & 4,31 & 4,00 & 0,77 & $18 \%$ \\
\hline Q51 & $\begin{array}{l}\text { FH2: Cada membro da organização tem a } \\
\text { descrição e a responsabilidade de assegurar a } \\
\text { obtenção dos interesses organizacionais. }\end{array}$ & 4,31 & 4,00 & 0,80 & $18 \%$ \\
\hline Q52 & $\begin{array}{l}\text { FH3: Trabalhamos com outras pessoas } \\
\text { independente das fronteiras departamentais e } \\
\text { organizacionais. }\end{array}$ & 4,32 & 4,00 & 0,81 & $19 \%$ \\
\hline Q53 & $\begin{array}{l}\text { FH4: As pessoas na organização se sentem } \\
\text { responsáveis pela eficácia da organização. }\end{array}$ & 4,21 & 4,00 & 0,89 & $21 \%$ \\
\hline Q54 & $\begin{array}{l}\text { FH5: As pessoas na organização buscam } \\
\text { informações, solicitam ajuda, admitem que } \\
\text { erraram e ou geraram feedbacks críticos no } \\
\text { desenvolvimento de suas atividades. }\end{array}$ & 3,89 & 4,00 & 0,93 & $24 \%$ \\
\hline
\end{tabular}

Fonte: Elaborada pela autora.

Os indicadores da variável parcerias eficazes (PE) apresentaram médias superiores a 4,1, isto corresponde à empresa possuir vínculos e alianças estratégicas com os parceiros (stakeholders), o que traz uma segurança para empresa à medida que precisa de recursos para as iniciativas de mudanças. Além disso, é possível evidenciar, na Tabela 4.17, que a organização gerencia as parcerias já firmadas como a possibilidade de angariar novas, conforme compreende a forma como as ações dos stakeholders podem afetar a capacidade da empresa em casos de adversidades. 
Tabela 4.17 - Análise descritiva da Parceria Eficaz (PE)

\begin{tabular}{|c|c|c|c|c|c|}
\hline Questões & $\begin{array}{c}\text { A extensão na qual os itens a seguir } \\
\text { descrevem as práticas na sua organização. }\end{array}$ & Média & Mediana & $\begin{array}{l}\text { Desvio } \\
\text { Padrão }\end{array}$ & $\begin{array}{l}\text { Coeficiente } \\
\text { de Variação }\end{array}$ \\
\hline Q55 & $\begin{array}{l}\text { PE1: Possuímos alianças estratégicas e bom } \\
\text { relacionamento com nossos stakeholders para } \\
\text { garantir recursos necessários em apoio às } \\
\text { iniciativas de mudanças. }\end{array}$ & 4,10 & 4,00 & 0,82 & $20 \%$ \\
\hline Q56 & $\begin{array}{l}\text { PE2: Asseguramos que os vínculos com vários } \\
\text { stakeholders sejam mantidos, reforçando assim } \\
\text { o capital social além das fronteiras da empresa. }\end{array}$ & 4,18 & 4,00 & 0,87 & $21 \%$ \\
\hline Q57 & $\begin{array}{l}\text { PE3: Entendemos como estamos conectados } \\
\text { aos nossos stakeholders e gerenciamos } \\
\text { ativamente tanto estas parcerias quanto a } \\
\text { possibilidade de angariar novas. }\end{array}$ & 4,12 & 4,00 & 0,83 & $20 \%$ \\
\hline Q58 & $\begin{array}{l}\text { PE4: Entendemos como as ações dos nossos } \\
\text { parceiros afetam nossa capacidade de resposta } \\
\text { em caso de adversidade. }\end{array}$ & 4,24 & 4,00 & 0,85 & $20 \%$ \\
\hline
\end{tabular}

Fonte: Elaborada pela autora.

O resultado evidenciado para a variável recursos disponíveis $(\mathrm{RD})$ reflete o cenário que a empresa estava vivenciando no momento da pesquisa, pois a média ficou em 3,78 (vide Tabela 4.19 na página 118), cujas dificuldades estão ligadas ao grupo empresarial na qual está inserida, prejudicando a obtenção de recursos para absorver mudanças inesperadas, a aprovação para realocar recursos existentes em novos projetos e o maior entrave está em conseguir aprovação de novos recursos. Para a variável RD apenas a Diretoria de Planejamento obteve alto nível de desenvolvimento (4,25), a Presidência apresentou abaixo de 3,00 e as demais diretorias apresentaram variação entre 3,59 (Diretoria do Produto A) a 3,93 (Diretoria Operacional), vide Gráfico 4.2, na página 119.

Tabela 4.18 - Análise descritiva dos Recursos Disponíveis (RD)

\begin{tabular}{clcccc}
\hline Questões & $\begin{array}{l}\text { A extensão na qual os itens a seguir } \\
\text { descrevem as práticas na sua organização. }\end{array}$ & Média & Mediana & $\begin{array}{c}\text { Desvio } \\
\text { Padrão }\end{array}$ & $\begin{array}{c}\text { Coeficiente } \\
\text { de Variação }\end{array}$ \\
\hline Q59 & $\begin{array}{l}\text { RD1: Temos conhecimento sobre os recursos } \\
\text { internos e externos disponíveis ao tomarmos } \\
\text { uma decisão. }\end{array}$ & 4,12 & 4,00 & 0,89 & $22 \%$ \\
Q60 & $\begin{array}{l}\text { RD2: Realocamos os recursos para os novos } \\
\text { produtos e projetos. }\end{array}$ & 3,95 & 4,00 & 0,98 & $25 \%$ \\
Q61 & $\begin{array}{l}\text { RD3: Mantemos recursos suficientes para } \\
\text { absorver mudanças inesperadas. }\end{array}$ & 3,61 & 4,00 & 0,96 & $27 \%$ \\
Q62 & $\begin{array}{l}\text { RD4: Temos agilidade em obter a aprovação de } \\
\text { recursos adicionais para dar conta do recado em } \\
\text { uma situação de adversidade. }\end{array}$ & 3,42 & 3,00 & 1,03 & $30 \%$ \\
\hline
\end{tabular}

Fonte: Elaborada pela autora. 
Considerando os elementos que mensuram o nível de resiliência estratégica na organização investigada, constatou-se que a inovação/criatividade foi a que apresentou maior dispersão (30\%) entre os respondentes, seguida da autonomia de tomada de decisão com $27 \%$ e da disponibilidade de recursos com $26 \%$. Os demais apresentaram dispersões mais baixas, variando de $20 \%$ a $22 \%$, conforme consta na Tabela 4.19 .

Tabela 4.19 - Análise descritiva da Resiliência Estratégica

\begin{tabular}{cccc}
\hline Resiliência Estratégica & Média & $\begin{array}{c}\text { Desvio } \\
\text { Padrão }\end{array}$ & $\begin{array}{c}\text { Coeficiente de } \\
\text { Variação }\end{array}$ \\
\hline Inovação/Criatividade (IC) & 3,69 & 1,12 & $30 \%$ \\
Recursos Disponíveis (RD) & 3,78 & 0,96 & $26 \%$ \\
Autonomia da Tomada de Decisão (TD) & 3,87 & 1,03 & $27 \%$ \\
Postura Proativa (PP) & 4,11 & 0,90 & $22 \%$ \\
Aprendizagem Organizacional (AO) & 4,16 & 0,85 & $21 \%$ \\
Comunicação Organizacional (CO) & 4,16 & 0,86 & $21 \%$ \\
Parcerias Eficazes (PE) & 4,16 & 0,84 & $20 \%$ \\
Fator Humano (FH) & 4,21 & 0,84 & $20 \%$ \\
Visão Estratégica (VE) & 4,27 & 0,85 & $20 \%$ \\
Liderança (LD) & 4,30 & 0,86 & $20 \%$ \\
\hline
\end{tabular}

Fonte: Elaborada pela autora.

Cabe enfatizar que a média dos dez itens que mensuram o nível de resiliência da organização apresentou uma variação de 3,69 a 4,3, lembrando que, quanto mais próximo a 1 representa menor nível de concordância do gestor em que este elemento seja evidenciado na organização e, quanto mais próximo a 5, representa maior nível de concordância. Atendendo à premissa desta tese, esta análise reflete, para a organização investigada, um nível alto de resiliência estratégica.

Do ponto de vista prático, realizou-se uma análise comparativa, envolvendo os diversos índices da Resiliência Estratégica (RE) e o nível de desenvolvimento da RE por diretoria, encontra-se no Gráfico 4.2, a seguir. Destaca-se que o gráfico em questão apresenta em seus eixos as seguintes informações: eixo $\mathrm{Y}$ - a Escala Likert que, na presente pesquisa, variou de 1 a 5, indicando os níveis de desenvolvimento dos indicadores de Resiliência Estratégica (RE), porém, para melhorar o fator de escala do gráfico, foi fixado de 2,50 a 5,00, tendo em vista que não foram encontrados valores menores que 2,70 na presente pesquisa; no eixo $\mathrm{X}$ - foram apresentados os vínculos das classes respondentes com a empresa submetida a esta pesquisa (de acordo a legenda abaixo do gráfico). Dentro da RE, o gráfico apresenta Visão Estratégica (VE), Postura Proativa (PP), Aprendizagem Organizacional (AO), Comunicação 
Organizacional (CO), Inovação e Criatividade (IC), Tomada de Decisão (TD), Liderança (LD), Fator Humano (FH), Parcerias Eficazes (PE) e Recursos Disponíveis (RD).

Gráfico 4.2 - Resiliência Estratégica (RE)

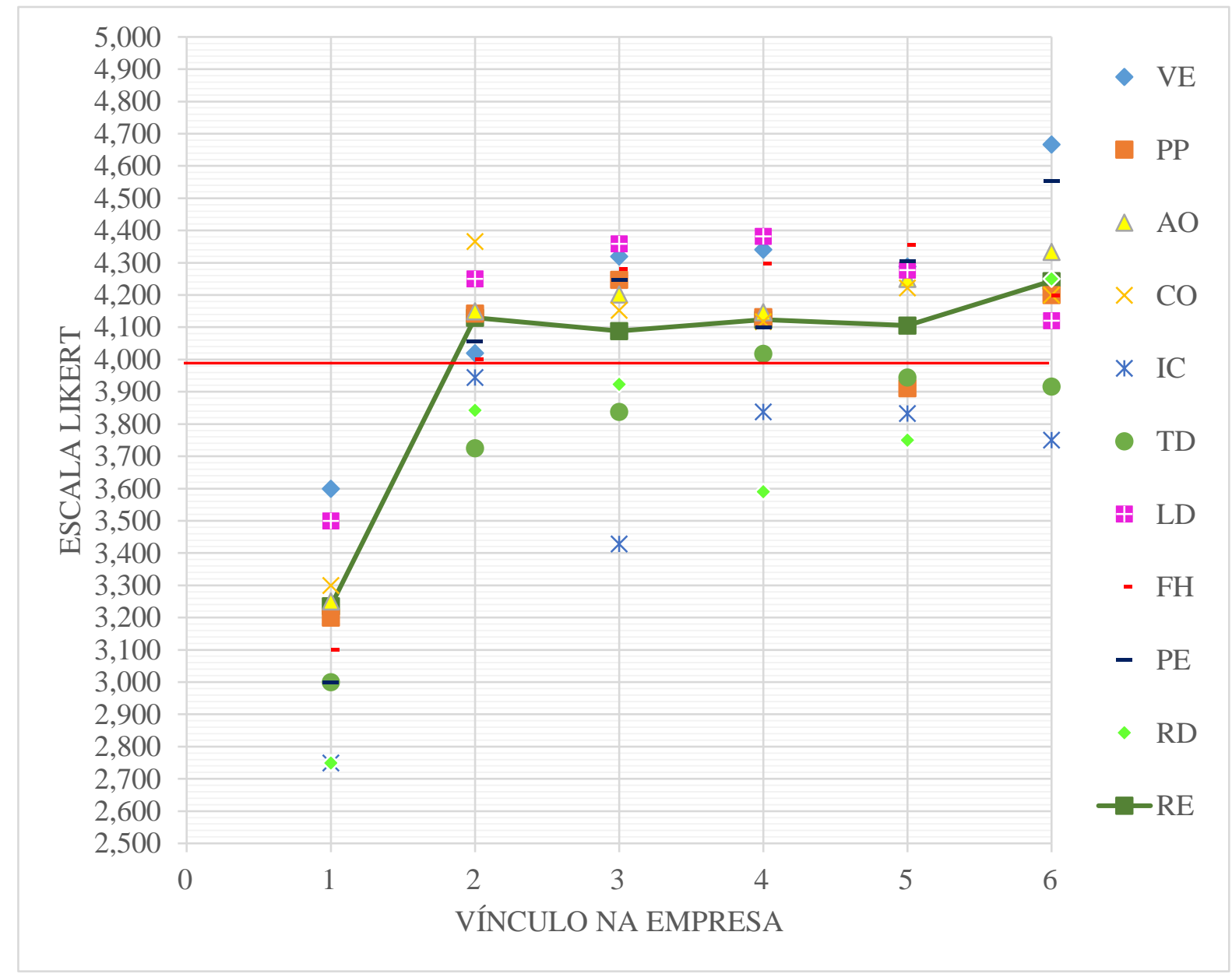

Nota 1: A linha vermelha representa a média geral aritmética entre todas as ferramentas que compuseram os índices de utilização de Resiliência Estratégica.

Nota 2: A linha verde representa a média individual de cada diretoria para o constructo Resiliência Estratégica (RE).

Legenda: 1 = Presidência + Conselho de Administração; $2=$ Diretoria Financeira; $3=$ Diretoria Operacional; 4 = Diretoria Produto A; $5=$ Diretoria Produto B e $6=$ Diretoria de Planejamento. Fonte: Elaborado pela autora.

De acordo com o Gráfico 4.2, novamente a Presidência e o Conselho de Administração apresentam-se com os índices mais baixos, isto é, obtiveram médias 3,60; 3,20; 3,25; 3,30; 2,75; 3,00; 3,50; 3,10; 3,00; e 2,75, para VE, PP, AO, CO, IC, TD, LD, FH, PE e RD, respectivamente. Consequentemente, obtiveram média entre todos os índices para a Gestão de Resiliência Estratégica (RE) de 3,24.

Observa-se que as Diretorias Financeira, Operacional, de Produto A e de Produto B obtiveram médias de todos os índices de 4,13;4,09;4,12; e 4,11, respectivamente. Iluminando 
os resultados, percebe-se que estas diretorias possuem desenvolvimento da Resiliência Estratégica muito próximos. Chamam a atenção, muito embora os resultados em geral apresentem níveis altos para estas quatro diretorias, algumas ferramentas que ainda poderiam ter seu desenvolvimento melhorado, tais como: Inovação e Criatividade (IC), Tomada de Decisão (TD) e Recursos Disponíveis (RD).

A Diretoria de Planejamento destaca-se novamente, pois possui os índices mais altos de Resiliência Estratégica (RE), sendo eles: 4,67; 4,20; 4,33; 4,20; 3,75; 3,92; 412; 4,20; 4,55; e 4,25 para VE, PP, AO, CO, IC, TD, LD, FH, PE e RD, respectivamente. Salta aos olhos que, muito embora esta diretoria possua um nível alto de concordância dos gestores, por outro lado também possui um intervalo de variação bastante significativo (amplitude) para os seus resultados, apresentando o maior índice médio de 4,67 para Visão Estratégica (VE) e 3,75 para Inovação e Criatividade (IC), aspecto este que precisa ser melhorado, em se tratando de uma Diretoria de Planejamento.

O Gráfico 4.2 também apresenta a média geral aritmética entre todas as ferramentas que compuseram os índices de desenvolvimento da RE, isto é, o valor de 3,99 (representado pela linha vermelha no gráfico). Assim sendo, observa-se que, exceto a Presidência e o Conselho de Administração que estão com todos os seus indicadores abaixo da média geral, todas as demais diretorias estão acima da média de desenvolvimento da RE.

\subsection{AnÁlise do Modelo de MenSURAÇão}

Tendo como base o referencial teórico, a definição dos constructos direcionou para a utilização de indicadores reflexivos, tanto para mensurar Sistema de Controle Gerencial (SCG) quanto Resiliência Estratégica (RE), tendo em vista o pressuposto de que a sua construção está relacionada à covariação das variáveis dos respectivos indicadores (Hair Jr. et al., 2014). Destaca-se que, para o SCG, o modelo pode ser reflexivo porque, embora esteja tratando de um único modelo, o poder destas alavancas de controle reside não em como elas são usadas isoladamente, mas em como elas se complementam quando utilizadas juntas (Simons, 2000), conforme evidenciado nas pesquisas de Anderson, Christ, Dekker e Sedatole (2015), Arjaliès e Mundy (2013), Bedford (2015), Cruz et al. (2015), Hoque e Chia (2012), Kruis et al. (2016), Mundy (2010) e Widener (2007). Por outro lado, observa-se que elas podem existir sem um ou mais elementos ou com diferentes ênfases, conforme as pesquisas de Acquaah (2013), Henri (2006), Lavarda e Pereira (2012), Marginson (2002), Oyadomari, Cardoso e Silva (2010), Oyadomari et al. (2011), entre outros. 
Realizou-se a Análise Fatorial Confirmatória (AFC) com todos os indicadores que mensuram os constructos para avaliar o modelo de mensuração que, segundo Onça, Bido e Godoy (2014, p. 8), precede a análise das relações entre constructos ou variáveis latentes. Utilizou-se o software SmartPLS ${ }^{\circledR}$ v.3.2.7, em que todos os constructos foram conectados entre si (Brown, 2006). Na sequência, rodou-se o modelo de mensuração utilizando a ponderação "factor" (Ringle, Wende, \& Becker, 2015) e, dando continuidade, análise da validade convergente, validade discriminante e da confiabilidade.

\subsubsection{Validade convergente}

A matriz de cargas cruzadas, ilustrada pelas Tabelas 4.20 a 4.22, permite averiguar a validade convergente no nível dos indicadores. Ao analisá-las, observou-se que, dos 62 indicadores utilizados no modelo, 4 apresentaram cargas fatoriais inferiores a 0,7 . Isto significa que apresentam problemas de validade convergente, segundo Hair Jr. et al. (2014). Destes, três mensuram o constructo Sistema de Controle Gerencial, sendo eles: SR3 (-0,026), SD3 (0,618) e SD5 $(0,470)$ e um é o indicador VE1 de Resiliência Estratégica com carga fatorial igual a 0,685 . Este já apresentou valor mais próximo do parâmetro esperado $(0,7)$ para a validade convergente. 
Tabela 4.20 - Matriz de Cargas Fatoriais representando os fatores do constructo Sistema de Controle Gerencial e seus respectivos itens de mensuração (variáveis)

\begin{tabular}{|c|c|c|c|c|c|c|c|c|c|c|c|c|c|c|c|c|}
\hline \multirow{2}{*}{$\begin{array}{c}\text { VARIÁVEIS } \\
\text { LATENTES DE } \\
\text { 1ªRDEM }^{\mathrm{a}} \text { ORD }\end{array}$} & \multirow{2}{*}{\multicolumn{2}{|c|}{ INDICADORES }} & \multicolumn{14}{|c|}{ CARGA FATORIAL E CARGA CRUZADA ENTRE AS VARIÁ VEIS } \\
\hline & & & SC & SR & SD & SI & $\mathbf{V E}$ & $\mathbf{P P}$ & AO & Co & IC & TD & LD & FH & $\mathbf{P E}$ & RD \\
\hline \multirow{4}{*}{$\begin{array}{l}\text { Sistema de } \\
\text { Crenças } \\
\text { (SC) }\end{array}$} & $\mathrm{SC} 1$ & A missão comunica de forma clara os valores fundamentais da empresa à sua equipe. & 0,866 & 0,690 & 0,660 & 0,569 & 0,628 & 0,672 & 0,693 & 0,635 & 0,517 & 0,603 & 0,719 & 0,585 & 0,624 & 0,455 \\
\hline & SC2 & Os principais gestores comunicam os valores fundamentais à sua equipe. & 0,871 & 0,672 & 0,620 & 0,571 & 0,587 & 0,631 & 0,637 & 0,600 & 0,346 & 0,468 & 0,643 & 0,638 & 0,562 & 0,397 \\
\hline & SC3 & A sua equipe está ciente dos valores fundamentais, do propósito e da visão da organização. & 0,863 & 0,697 & 0,632 & 0,588 & 0,559 & 0,596 & 0,617 & 0,603 & 0,395 & 0,487 & 0,656 & 0,572 & 0,570 & 0,404 \\
\hline & SC4 & Nos momentos de adversidade a missão/visão é observada na tomada de decisão. & $\mathbf{0 , 8 6 7}$ & 0,666 & 0,581 & 0,635 & 0,652 & 0,678 & 0,657 & 0,622 & 0,475 & 0,573 & 0,711 & 0,680 & 0,693 & 0,529 \\
\hline \multirow{4}{*}{$\begin{array}{l}\text { Sistema de } \\
\text { Restrições } \\
\text { (SR) }\end{array}$} & SR1 & $\begin{array}{l}\text { Os instrumentos (tais como código de ética, diretrizes de direcionamento de operações, políticas de } \\
\text { compliance) informam sobre os comportamentos que estão fora dos limites aceitâveis pela empresa. }\end{array}$ & 0,775 & 0,904 & 0,599 & 0,547 & 0,576 & 0,657 & 0,602 & 0,629 & 0,346 & 0,520 & 0,684 & 0,654 & 0,582 & 0,463 \\
\hline & SR2 & A organização comunica os riscos a serem evitados que poderiam ocasionar adversidades. & 0,642 & 0,890 & 0,637 & 0,606 & 0,632 & 0,663 & 0,640 & 0,680 & 0,507 & 0,483 & 0,697 & 0,681 & 0,696 & 0,611 \\
\hline & SR3 & Não sei exatamente tudo o que devo fazer, mas tenho clareza do que não devo fazer. & 0,023 & $-0,026$ & $-0,023$ & $-0,009$ & 0,145 & 0,014 & $-0,039$ & $-0,051$ & $-0,037$ & $-0,013$ & 0,022 & $-0,102$ & $-0,113$ & 0,013 \\
\hline & SR4 & $\begin{array}{l}\text { A consciência da existência dos instrumentos (tais como código de ética, diretrizes de direcionamento } \\
\text { de operaçōes, políticas de compliance) direciona as ações em momento de adversidades. }\end{array}$ & 0,616 & 0,788 & 0,430 & 0,482 & 0,591 & 0,455 & 0,586 & 0,494 & 0,322 & 0,370 & 0,530 & 0,598 & 0,560 & 0,314 \\
\hline \multirow{5}{*}{$\begin{array}{l}\text { Uso do Sistema } \\
\text { Diagnóstico } \\
\text { (SD) }\end{array}$} & SD1 & Temos planejamento estratégico formalizado. & 0,545 & 0,418 & $\mathbf{0 , 7 8 9}$ & 0,499 & 0,572 & 0,524 & 0,535 & 0,515 & 0,441 & 0,458 & 0,572 & 0,422 & 0,428 & 0,314 \\
\hline & SD2 & O orçamento está alinhado com o planejamento estratégico e decorre dele. & 0,696 & 0,684 & $\mathbf{0 , 8 4 8}$ & 0,662 & 0,704 & 0,758 & 0,670 & 0,730 & 0,418 & 0,523 & 0,769 & 0,636 & 0,683 & 0,560 \\
\hline & SD3 & $\begin{array}{l}\text { Temos controle orçamentário: são apresentados os relatórios com o previsto versus o realizado; em } \\
\text { reuniões são discutidos os resultados passados e as açôes futuras. }\end{array}$ & 0,349 & 0,227 & 0,618 & 0,311 & 0,277 & 0,390 & 0,359 & 0,385 & 0,217 & 0,225 & 0,284 & 0,261 & 0,295 & 0,201 \\
\hline & SD4 & $\begin{array}{l}\text { Monitoramos e comparamos os resultados com as expectativas de modo a prever adversidades que } \\
\text { impeçam o progresso em direção às metas organizacionais. }\end{array}$ & 0,480 & 0,397 & $\mathbf{0 , 7 9 7}$ & 0,596 & 0,504 & 0,544 & 0,510 & 0,469 & 0,300 & 0,352 & 0,493 & 0,461 & 0,475 & 0,381 \\
\hline & SD5 & $\begin{array}{l}\text { O desempenho individual explicitado pelo controle orçamentário impacta a remuneração variável do } \\
\text { executivo. }\end{array}$ & 0,413 & 0,520 & 0,470 & 0,198 & 0,273 & 0,317 & 0,375 & 0,318 & 0,234 & 0,241 & 0,233 & 0,339 & 0,365 & 0,364 \\
\hline \multirow{5}{*}{$\begin{array}{l}\text { Uso do Sistema } \\
\text { Interativo } \\
\text { (SI) }\end{array}$} & SI1 & Os gerentes operacionais estão frequentemente envolvidos com o sistema de controle. & 0,350 & 0,263 & 0,349 & $\mathbf{0 , 7 4 6}$ & 0,409 & 0,350 & 0,449 & 0,449 & 0,290 & 0,231 & 0,441 & 0,365 & 357 & 0,229 \\
\hline & S12 & $\begin{array}{l}\text { Os dados gerados pelo sistema de controle são interpretados e discutidos com superiores, } \\
\text { subordinados e pares. }\end{array}$ & 0,588 & 0,622 & 0,605 & $\mathbf{0 , 8 2 8}$ & 0,595 & 0,559 & 0,575 & 0,568 & 0,421 & 0,381 & 0,644 & 0,646 & 0,580 & 0,416 \\
\hline & SI3 & $\begin{array}{l}\text { É dedicada atenção regular e frequente à análise e discussão das adversidades em reuniões por parte } \\
\text { dos gestores de todos os níveis. }\end{array}$ & 0,569 & 0,542 & 0,606 & $\mathbf{0 , 8 5 2}$ & 0,665 & 0,558 & 0,598 & 0,650 & 0,615 & 0,417 & 0,601 & 0,635 & 0,662 & 0,446 \\
\hline & SI4 & $\begin{array}{l}\text { A empresa utiliza o sistema de controle para antecipar-se às mudanças com intuito de evitar que as } \\
\text { adversidades afetem seus negócios. }\end{array}$ & 0,607 & 0,508 & 0,468 & $\mathbf{0 , 8 8 9}$ & 0,569 & 0,514 & 0,588 & 0,590 & 0,427 & 0,308 & 0,563 & 0,496 & 0,493 & 0,430 \\
\hline & SI5 & $\begin{array}{l}\text { A organização alinha a sua estratégia aos sistemas de controle dando suporte à decisão de modo a } \\
\text { adaptar-se continuamente as adversidades. }\end{array}$ & 0,629 & 0,593 & 0,672 & 0,802 & 0,667 & 0,704 & 0,688 & 0,675 & 0,378 & 0,375 & 0,616 & 0,611 & 0,613 & 0,527 \\
\hline
\end{tabular}

Nota 1: Exceto o indicador SR3, os demais indicadores foram significantes a $1 \%$.

Legenda: SC - Sistema de Crenças; SR - Sistema de Restrições; SD - Uso do Sistema Diagnóstico; SI - Uso do Sistema Interativo; VE - Visão Estratéoica; PP - Postura Proativa; AO - Aprendizagem Organizacional; CO - Comunicação Organizacional; IC - Inovação e Criatividade; TD - Autonomia na Tomada de Decisão; LD - Liderança; FH - Fator Humano; PE - Parcerias Eficazes; RD - Recursos Disponíveis.

Fonte: Elaborada pela autora. 
Tabela 4.21 - Matriz de Cargas Fatoriais representando os fatores do constructo Resiliência Estratégica e seus respectivos itens de mensuração (variáveis) Parte 1

\begin{tabular}{|c|c|c|c|c|c|c|c|c|c|c|c|c|c|c|c|c|}
\hline \multirow{2}{*}{$\begin{array}{c}\text { VARIÁVEIS } \\
\text { LATENTES } \\
\text { DE 1ª ORDEM } \\
\end{array}$} & \multirow{2}{*}{\multicolumn{2}{|c|}{ INDICADORES }} & \multicolumn{14}{|c|}{ CARGA FATORIAL E CARGA CRUZADA ENTRE AS VARIÁVEIS } \\
\hline & & & VE & $\mathbf{P P}$ & AO & co & IC & TD & LD & FH & PE & RD & SC & SR & SD & SI \\
\hline \multirow{5}{*}{$\begin{array}{l}\text { Visão Estratégia } \\
\text { (VE) }\end{array}$} & VE1 & Temos uma visão ampla da organização/do negócio como um todo. & 0,685 & 0,479 & 0,480 & 0,464 & 0,260 & 0,322 & 0,480 & 0,506 & 0,470 & 0,298 & 0,474 & 0,484 & 0,526 & 0,462 \\
\hline & VE2 & $\begin{array}{l}\text { Dedicamos tempo e energia para reavaliar regularmente as metas a serem alcançadas e explorar novas } \\
\text { opções estratégicas o que nos permite constantemente mudar a direção da organização. }\end{array}$ & 0,791 & 0,623 & 0,506 & 0,507 & 0,403 & 0,366 & 0,588 & 0,534 & 0,564 & 0,480 & 0,557 & 0,543 & 0,526 & 0,619 \\
\hline & VE3 & Os aspectos de mudança são identificados como novas oportunidades para a organização. & 0,924 & 0,781 & 0,772 & 0,754 & 0,584 & 0,621 & 0,816 & 0,787 & 0,726 & 0,499 & 0,714 & 0,731 & 0,660 & 0,685 \\
\hline & VE4 & $\begin{array}{l}\text { Temos condições e capacidade para reconhecer as vulnerabilidades e as fraquezas do negócio para } \\
\text { nos ajustar a nova realidade. }\end{array}$ & 0,791 & 0,588 & 0,464 & 0,520 & 0,368 & 0,413 & 0,504 & 0,544 & 0,520 & 0,354 & 0,488 & 0,393 & 0,450 & 0,539 \\
\hline & VE5 & $\begin{array}{l}\text { O entendimento amplo da organização e de sua atividade nos permite diagnosticar, interpretar, } \\
\text { compreender e nos anteciparmos às adversidades, aos eventos e às mudanças no cenário empresarial. }\end{array}$ & 0,911 & 0,731 & 0,739 & 0,710 & 0,510 & 0,554 & 0,752 & 0,757 & 0,692 & 0,456 & 0,619 & 0,642 & 0,674 & 0,641 \\
\hline \multirow{5}{*}{$\begin{array}{l}\text { Postura Proativa } \\
\quad(\mathrm{PP})\end{array}$} & PP1 & $\begin{array}{l}\text { Temos uma estrutura que nos permite agir de forma rápida e eficaz em resposta a uma oportunic } \\
\text { aos eventos inesperados. }\end{array}$ & 0,579 & $\mathbf{0 , 8 5 0}$ & 0,587 & 0,673 & 0,481 & 0,541 & 0,623 & 0,588 & 0,568 & 0,534 & 0,567 & 0,558 & 0,606 & 0,532 \\
\hline & PP2 & $\begin{array}{l}\text { Temos uma diversidade de ações competitivas disponíveis para adotarmos em respostas às } \\
\text { inesperadas e oportunas mudanças que ocorrem no mercado. }\end{array}$ & 0,735 & $\mathbf{0 , 8 6 0}$ & 0,648 & 0,699 & 0,425 & 0,585 & 0,678 & 0,669 & 0,629 & 0,461 & 0,610 & 0,558 & 0,553 & 0,536 \\
\hline & PP3 & $\begin{array}{l}\text { Tomamos decisões e realizamos investimentos preventivamente para garantir que possamos nos } \\
\text { beneficiar de situações futuras que possam surgir em nossa organização. }\end{array}$ & 0,694 & 0,922 & 0,620 & 0,761 & 0,459 & 0,640 & 0,754 & 0,649 & 0,682 & 0,562 & 0,684 & 0,676 & 0,637 & 0,648 \\
\hline & PP4 & $\begin{array}{l}\text { Nossa organização monitora proativamente o que está acontecendo em seu setor para agir } \\
\text { antecipadamente nas questões emergentes. }\end{array}$ & 0,729 & $\mathbf{0 , 8 8 0}$ & 0,755 & 0,792 & 0,529 & 0,650 & 0,791 & 0,669 & 0,700 & 0,542 & 0,664 & 0,599 & 0,719 & 0,589 \\
\hline & PP5 & Buscamos oportunidades de crescimento perante as situações de adversidades. & 0,749 & 0,922 & 0,741 & 0,821 & 0,567 & 0,737 & 0,816 & 0,666 & 0,699 & 0,638 & 0,758 & 0,675 & 0,762 & 0,655 \\
\hline \multirow{4}{*}{$\begin{array}{l}\text { Aprendizagem } \\
\text { Organizacional } \\
\text { (AO) }\end{array}$} & AO1 & $\begin{array}{l}\text { Durante uma adversidade, somos capazes de ider } \\
\text { solução e implantar a solução. }\end{array}$ & 0,703 & 0,620 & $\mathbf{0 , 8 7 2}$ & 0,715 & 0,615 & 0,600 & 0,691 & 0,726 & 0,669 & 0,531 & 0,614 & 0,595 & 0,611 & 0,574 \\
\hline & $\mathrm{AO} 2$ & $\begin{array}{l}\text { Aprendemos liçōes do passado e garantimos que essas lições sejam executadas no futuro, pois } \\
\text { evoluímos e nos adaptamos às novas situações. }\end{array}$ & 0,650 & 0,655 & 0,905 & 0,758 & 0,632 & 0,545 & 0,741 & 0,668 & 0,669 & 0,581 & 0,621 & 0,570 & 0,642 & 0,619 \\
\hline & $\mathrm{AO} 3$ & $\begin{array}{l}\text { Temos estruturas organizacionais que são projetadas para promover a aprendizagem e mudar os } \\
\text { comportamentos com base nas novas informações e nos novos insights. }\end{array}$ & 0,618 & 0,763 & $\mathbf{0 , 8 8 6}$ & 0,728 & 0,635 & 0,668 & 0,713 & 0,699 & 0,718 & 0,655 & 0,699 & 0,642 & 0,608 & 0,635 \\
\hline & AO4 & $\begin{array}{l}\text { Temos práticas de gestão e normas organizacionais que ir } \\
\text { acontecendo de modo a exigir uma sólida compreensão d: }\end{array}$ & 0,670 & 0,674 & $\mathbf{0 , 9 1 3}$ & 0,766 & 0,620 & 0,596 & 0,751 & 0,787 & 0,772 & 0,602 & 0,749 &, 712 & 0,669 & 719 \\
\hline \multirow{5}{*}{$\begin{array}{l}\text { Comunicação } \\
\text { Organizacional } \\
\text { (CO) }\end{array}$} & CO1 & $\begin{array}{l}\text { O processo de comunicação compartilha a direção e as estratégias organizacionais nos diversos níveis } \\
\text { hierárquicos. }\end{array}$ & 0,662 & 0,796 & 0,714 & $\mathbf{0 , 8 9 9}$ & 0,570 & 0,644 & 0,748 & 0,647 & 0,680 & 0,611 & 0,632 & 0,611 & 0,693 & 0,689 \\
\hline & $\mathrm{CO} 2$ & $\begin{array}{l}\text { Temos uma linguagem comum (ou seja, palavras, imagens e histórias) e predominante que implica } \\
\text { capacidade, influência, competência, valores fundamentais consistentes e um sentido claro de direção }\end{array}$ & 0,658 & 0,717 & 0,774 & 879 & 0,523 & 0,564 & 0,756 & 0,716 & 0,705 & 0,556 & 0,667 & 0,677 & 0,668 & 0,621 \\
\hline & $\mathrm{CO} 3$ & $\begin{array}{l}\text { O sistema de informaçẫo ao disponibilizar informação com qualidade dá suporte à tomada de c } \\
\text { rápida e eficaz. }\end{array}$ & 0,635 & 0,750 & 0,788 & $\mathbf{0 , 8 4 5}$ & 0,710 & 0,629 & 0,721 & 0,710 & 0,687 & 0,625 & 0,525 & 0,573 & 0,614 & 0,649 \\
\hline & $\mathrm{CO} 4$ & $\begin{array}{l}\text { Funcionários possuem formação para utilizar o sistema, sabem quais informações acessar em } \\
\text { situaçốes críticas e têm consciência das implicações para as possíveis soluçôes. }\end{array}$ & 0,5 & 0,709 & 0,620 & $\mathbf{0 , 8 5 8}$ & 0,585 & 0,644 & 0,665 & 0,599 & 0,625 & 0,527 & 0,545 & 0,504 & 0,532 & 0,561 \\
\hline & CO5 & As informações cruciais estão disponíveis em diferentes meios. & 0,598 & 0,623 & 0,623 & 0,768 & 0,495 & 0,598 & 0,671 & 0,609 & 0,575 & 0,411 & 0,656 & 0,624 & 0,486 & 0,546 \\
\hline \multirow{4}{*}{$\begin{array}{c}\text { Inovação / } \\
\text { Criatividade } \\
\text { (IC) }\end{array}$} & IC1 & Somos estimulados a ter espírito empreendedor visando à mudança. & 0,486 & 0,482 & 0,656 & 0,638 & 0,909 & 0,680 & 0,594 & 0,523 & 0,591 & 0,661 & 0,465 & 0,491 & 0,412 & 0,452 \\
\hline & IC2 & Temos capacidade de utilizar o conhecimento de forma inovadora e criativa na solução de problemas. & 0,518 & 0,544 & 0,648 & 0,601 & $\mathbf{0 , 8 0 1}$ & 0,588 & 0,585 & 0,495 & 0,522 & 0,501 & 0,462 & 0,303 & 0,460 & 0,559 \\
\hline & IC3 & $\begin{array}{l}\text { nos oportunidades para desenvolver novas } \\
\text { onização. }\end{array}$ & 0,449 & 0,488 & 0,6 & 0,619 & 0,904 & 0,700 & 0,578 & 0,483 & 0,498 & 0,524 & 0,424 & 0,383 & 0,418 & 0,446 \\
\hline & IC4 & Somos recompensados por "pensar fora da caix & 0,293 & 320 & 368 & 0,371 & $\mathbf{0 , 7 2 6}$ & 0,407 & 0,306 & 0,345 & 0,467 & 0,517 & 0,310 & 0,364 & 0,237 & 0,275 \\
\hline
\end{tabular}

Nota 1: Todos os indicadores foram significantes a $1 \%$.

Legenda: SC - Sistema de Crenças; SR - Sistema de Restrições; SD - Uso do Sistema Diagnóstico; SI - Uso do Sistema Interativo; VE - Visão Estratégica; PP - Postura Proativa; AO - Aprendizagem Organizacional; CO - Comunicação Organizacional; IC - Inovacão e Criatividade; TD - Autonomia da Tomada de Decisão; LD - Liderança; FH - Fator Humano; PE - Parcerias Eficazes; RD - Recursos Disponíveis.

Fonte: Elaborada pela autora. 
Tabela 4.22 - Matriz de Cargas Fatoriais representando os fatores do constructo Resiliência Estratégica e seus respectivos itens de mensuração (variáveis) Parte 2

\begin{tabular}{|c|c|c|c|c|c|c|c|c|c|c|c|c|c|c|c|c|}
\hline \multirow{2}{*}{$\begin{array}{c}\text { VARIÁVEIS } \\
\text { LATENTES } \\
\text { DE 1a ORDEM }\end{array}$} & \multirow{2}{*}{\multicolumn{2}{|c|}{ INDICADORES }} & \multicolumn{14}{|c|}{ CARGA FATORIAL E CARGA CRUZADA ENTRE AS VARIÁVEIS } \\
\hline & & & $\mathbf{V E}$ & $\mathbf{P P}$ & AO & со & IC & TD & LD & FH & PE & RD & SC & SR & SD & SI \\
\hline \multirow{4}{*}{$\begin{array}{l}\text { Autonomia da } \\
\text { Tomada de } \\
\text { Decisão } \\
\text { (TD) }\end{array}$} & TD1 & $\begin{array}{l}\text { Os líderes delegam responsabilidades e autoridade a sua equipe permitindo aos profissionais } \\
\text { autonomia para tomarem decisões. }\end{array}$ & 0,622 & 0,715 & 0,671 & 0,666 & 0,647 & $\mathbf{0 , 8 9 6}$ & 0,748 & 0,618 & 0,622 & 0,521 & 0,601 & 0,519 & 0,536 & 0,460 \\
\hline & TD2 & Compartilhamos a tomada de decisão amplamente. & 0,333 & 0,559 & 0,483 & 0,559 & 0,520 & 0,861 & 0,538 & 0,403 & 0,432 & 0,380 & 0,513 & 0,386 & 0,411 & 0,324 \\
\hline & TD3 & Podemos tomar decisões difíceis rapidamente. & 0,401 & 0,506 & 0,486 & 0,572 & 0,644 & 0,795 & 0,543 & 0,432 & 0,548 & 0,599 & 0,492 & 0,442 & 0,387 & 0,334 \\
\hline & TD4 & $\begin{array}{l}\text { Caso ocorram problemas, os colaboradores possuem acesso direto a alguém com autoridade que } \\
\text { possa tomar decisões. }\end{array}$ & 0,530 & 0,624 & 0,620 & 0,644 & 0,633 & $\mathbf{0 , 8 4 2}$ & 0,638 & 0,546 & 0,489 & 0,469 & 0,479 & 0,455 & 0,453 & 0,312 \\
\hline \multirow{4}{*}{$\begin{array}{l}\text { Liderança } \\
\text { (LD) }\end{array}$} & LD1 & $\begin{array}{l}\text { Líderes abertos às mudanças contínuas nas estratégias da organização e aos novos desafios; } \\
\text { consideram a mudança como oportunidade. }\end{array}$ & 0,783 & 0,765 & 0,813 & 0,799 & 0,646 & 0,667 & $\mathbf{0 , 9 2 0}$ & 0,791 & 0,727 & 0,600 & 0,723 & 0,706 & 0,661 & 0,670 \\
\hline & LD2 & Os gestores entendem como liderança o próprio exemplo. & 0,641 & 0,743 & 0,597 & 0,738 & 0,467 & 0,651 & $\mathbf{0 , 8 5 4}$ & 0,649 & 0,630 & 0,524 & 0,689 & 0,606 & 0,625 & 0,571 \\
\hline & LD3 & $\begin{array}{l}\text { A liderança preza pelo bom relacionamento e incentiva os colaboradores a discutirem problemas junto } \\
\text { aos seus gestores. }\end{array}$ & 0,677 & 0,703 & 0,748 & 0,745 & 0,540 & 0,606 & $\mathbf{0 , 8 8 6}$ & 0,789 & 0,706 & 0,509 & 0,725 & 0,680 & 0,665 & 0,643 \\
\hline & LD4 & A liderança gera feedback constante e desenvolve uma comunicação aberta entre o líder e sua equipe. & 0,672 & 0,749 & 0,716 & 0,704 & 0,593 & 0,700 & 0,901 & 0,673 & 0,621 & 0,578 & 0,673 & 0,654 & 0,586 & 0,625 \\
\hline \multirow{5}{*}{$\begin{array}{l}\text { Fator Humano } \\
\quad(\mathrm{FH})\end{array}$} & FH1 & $\begin{array}{l}\text { As pessoas estabelecem relações com outras pessoas permitindo o compartilhamento de recursos, de } \\
\text { objetivos, de conhecimentos, de informaçōes e de práticas de respeito mútuo. }\end{array}$ & 0,671 & 0,679 & 0,731 & 0,752 & 0,494 & 0,580 & 0,736 & $\mathbf{0 , 8 7 5}$ & 0,723 & 0,435 & 0,660 & 0,667 & 0,599 & 0,521 \\
\hline & $\mathrm{FH} 2$ & $\begin{array}{l}\text { Cada membro da organização tem a descrição e a responsabilidade de assegurar a obtenção dos } \\
\text { interesses organizacionais. }\end{array}$ & 0,713 & 0,711 & 0,744 & 0,732 & 0,522 & 0,545 & 0,744 & 0,889 & 0,808 & 0,570 & 0,661 & 0,732 & 0,619 & 0,707 \\
\hline & FH3 & Trabalhamos com outras pessoas independente das fronteiras departamentais e organizacionais. & 0,607 & 0,581 & 0,555 & 0,575 & 0,343 & 0,402 & 0,600 & 0,770 & 0,682 & 0,347 & 0,566 & 0,486 & 0,512 & 0,554 \\
\hline & FH4 & As pessoas na organização se sentem responsáveis pela eficácia da organização. & 0,701 & 0,589 & 0,724 & 0,686 & 0,518 & 0,525 & 0,727 & 0,911 & 0,765 & 0,393 & 0,572 & 0,680 & 0,475 & 0,622 \\
\hline & FH5 & $\begin{array}{l}\text { As pessoas na organização buscam informações, solicitam ajuda, admitem que erraram e ou geraram } \\
\text { feedbacks críticos no desenvolvimento de suas atividades. }\end{array}$ & 0,642 & 0,585 & 0,705 & 0,572 & 0,517 & 0,515 & 0,706 & 0,862 & 0,719 & 0,437 & 0,618 & 0,640 & 0,469 & 0,543 \\
\hline \multirow{4}{*}{$\begin{array}{c}\text { Parceria } \\
\text { Eficazes } \\
\text { (PE) }\end{array}$} & PE1 & $\begin{array}{l}\text { Possuímos alianças estratégicas e bom relacionamento com nossos stakeholders para garantir recursos } \\
\text { necessários em apoio as iniciativas de mudanças. }\end{array}$ & 0,692 & 0,686 & 0,662 & 0,700 & 0,556 & 0,579 & 0,706 & 0,763 & 0,909 & 0,586 & 0,659 & 0,613 & 0,530 & 0,564 \\
\hline & PE2 & $\begin{array}{l}\text { Asseguramos que os vínculos com vários stakeholders sejam mantidos, reforçando assim o capital } \\
\text { social além das fronteiras da empresa. }\end{array}$ & 0,679 & 0,752 & 0,794 & 0,771 & 0,656 & 0,606 & 0,761 & 0,829 & 0,949 & 0,647 & 0,691 & 0,718 & 0,653 & 0,680 \\
\hline & PE3 & $\begin{array}{l}\text { Entendemos como estamos conectados aos nossos stakeholders e gerenciamos ativamente tanto essas } \\
\text { parcerias quanto a possibilidade de angariar novas. }\end{array}$ & 0,674 & 0,688 & 0,767 & 0,708 & 0,593 & 0,605 & 0,696 & 0,839 & 0,945 & 0,569 & 0,657 & 0,662 & 0,635 & 0,613 \\
\hline & PE4 & $\begin{array}{l}\text { Entendemos como as ações dos nossos parceiros afetam nossa capacidade de resposta em caso de } \\
\text { adversidade. }\end{array}$ & 0,635 & 0,573 & 0,664 & 0,633 & 0,449 & 0,475 & 0,584 & 0,700 & $\mid 0,849$ & 0,496 & 0,576 & 0,611 & 0,584 & 0,607 \\
\hline \multirow{4}{*}{$\begin{array}{l}\text { Recursos } \\
\text { Disponíveis } \\
\text { (RD) }\end{array}$} & RD1 & Temos conhecimento sobre os recursos internos e externos disponíveis ao tomarmos uma decisão. & 0,380 & 0,527 & 0,578 & 0,618 & 0,629 & 0,575 & 0,508 & 0,381 & 0,546 & 0,879 & 0,451 & 0,418 & 0,515 & 0,456 \\
\hline & RD2 & Realocamos os recursos para os novos produtos e projetos. & 0,510 & 0,551 & 0,609 & 0,586 & 0,532 & 0,443 & 0,563 & 0,517 & 0,589 & 0,905 & 0,423 & 0,477 & 0,484 & 0,486 \\
\hline & RD3 & Mantemos recursos suficientes para absorver mudanças inesperadas. & 0,440 & 0,575 & 0,627 & 0,562 & 0,546 & 0,521 & 0,573 & 0,429 & 0,535 & 0,916 & 0,495 & 0,496 & 0,457 & 0,420 \\
\hline & RD4 & $\begin{array}{l}\text { Temos agilidade em obter a aprovação de recursos adicionais para dar conta do recado em uma } \\
\text { situacão de adversidade. }\end{array}$ & 0,521 & 0,586 & 0,586 & 0,572 & 0,666 & 0,565 & 0,600 & 0,514 & 0,611 & 0,916 & 0,500 & 0,582 & 0,469 & 0,494 \\
\hline
\end{tabular}

Nota 1: Todos os indicadores foram significantes a $1 \%$.

Legenda: SC - Sistema de Crenças; SR - Sistema de Restrições; SD - Uso do Sistema Diagnóstico; SI - Uso do Sistema Interativo; VE - Visão Estratégica; PP - Postura Proativa; AO - Aprendizagem Organizacional; CO - Comunicação Organizacional; IC - Inovação e Criatividade; TD - Autonomia na Tomada de Decisão; LD - Liderança; FH - Fator Humano; PE - Parcerias Eficazes; RD - Recursos Disponíveis.

Fonte: Elaborada pela autora. 
Os motivos deste resultado podem estar atrelados à adaptação semântica realizada no questionário para atender às necessidades culturais da empresa em questão e o fato de o item SR3 não ser observado na população investigada, tendo em vista que não foi estatisticamente significante, conforme destaque em vermelho na Tabela 4.20.

Observam-se, na última linha da Tabela 4.23, os valores da Variância Média Extraída (Average Variance Extracted - AVE) das variáveis latentes de primeira ordem que foram avaliadas no modelo de mensuração por meio da análise fatorial confirmatória, e mesmo as variáveis latentes com problema de validade convergente no nível dos indicadores apresentaram Variância Média Extraída (Average Variance Extracted - AVE) superior a 50\%, o que atinge os critérios da existência da validade convergente para o modelo em geral (Hair Jr. et al., 2014; Henseler, Ringle, \& Sinkovics, 2009; Ringle et al., 2014).

Tabela 4.23 - Matriz de correlações com os constructos de primeira ordem

\begin{tabular}{|c|c|c|c|c|c|c|c|c|c|c|c|c|c|c|}
\hline & SC & SR & $\mathrm{SD}$ & SI & VE & PP & $\mathrm{AO}$ & $\mathrm{CO}$ & IC & TD & LD & FH & PE & $\mathrm{RD}$ \\
\hline Sistema de Crenças (SC) & $\mathbf{0 , 8 6 7}$ & & & & & & & & & & & & & \\
\hline Sistema de Restrições (SR) & 0,786 & 0,747 & & & & & & & & & & & & \\
\hline Uso do Sistema Diagnóstico (SD) & 0,719 & 0,652 & 0,718 & & & & & & & & & & & \\
\hline Uso do Sistema Interativo (SI) & 0,682 & 0,636 & 0,675 & $\mathbf{0 , 8 2 5}$ & & & & & & & & & & \\
\hline Visão Estratégica (VE) & 0,701 & 0,693 & 0,696 & 0,721 & 0,825 & & & & & & & & & \\
\hline Postura Proativa (PP) & 0,745 & 0,694 & 0,744 & 0,671 & 0,789 & $\mathbf{0 , 8 8 7}$ & & & & & & & & \\
\hline Aprendizagem Organizacional (AO) & 0,752 & 0,707 & 0,708 & 0,714 & 0,737 & 0,759 & 0,894 & & & & & & & \\
\hline Comunicação Organizacional (CO) & 0,710 & 0,704 & 0,708 & 0,723 & 0,732 & 0,848 & 0,831 & $\mathbf{0 , 8 5 1}$ & & & & & & \\
\hline Inovação/Criatividade (IC) & 0,503 & 0,460 & 0,467 & 0,529 & 0,532 & 0,557 & 0,700 & 0,679 & $\mathbf{0 , 8 3 8}$ & & & & & \\
\hline Autonomia na Tomada de Decisão (TD) & 0,617 & 0,535 & 0,532 & 0,427 & 0,569 & 0,715 & 0,674 & 0,723 & 0,723 & 0,849 & & & & \\
\hline Liderança (LD) & 0,789 & 0,744 & 0,712 & 0,706 & 0,781 & 0,830 & 0,810 & 0,839 & 0,633 & 0,736 & 0,891 & & & \\
\hline Fator Humano (FH) & 0,715 & 0,749 & 0,622 & 0,686 & 0,775 & 0,732 & 0,806 & 0,773 & 0,559 & 0,599 & 0,817 & 0,863 & & \\
\hline Parcerias Eficazes (PE) & 0,709 & 0,714 & 0,659 & 0,675 & 0,733 & 0,742 & 0,792 & 0,772 & 0,621 & 0,622 & 0,755 & 0,859 & 0,914 & \\
\hline Recursos Disponíveis (RD) & 0,517 & 0,548 & 0,532 & 0,514 & 0,513 & 0,620 & 0,663 & 0,646 & 0,657 & 0,582 & 0,621 & 0,511 & 0,631 & 0,904 \\
\hline Cronbach's Alpha & 0,890 & 0,631 & 0,756 & 0,883 & 0,880 & 0,932 & 0,916 & 0,904 & 0,857 & 0,871 & 0,913 & 0,913 & 0,933 & 0,925 \\
\hline Composite Reliability & 0,924 & 0,787 & 0,837 & 0,914 & 0,913 & 0,949 & 0,941 & 0,929 & 0,904 & 0,912 & 0,939 & 0,936 & 0,953 & 0,947 \\
\hline Average Variance Extracted (AVE) & 0,751 & 0,558 & 0,516 & 0,680 & 0,681 & 0,787 & 0,799 & 0,724 & 0,703 & 0,722 & 0,793 & 0,744 & 0,835 & 0,817 \\
\hline
\end{tabular}

Além disso, ao observar a diagonal da Tabela 4.23 cujos valores são a raiz quadrada da Variância Média Extraída, é possível constatar que todas as variáveis latentes de primeira ordem apresentaram validade convergente adequada em relação aos constructos com cargas superiores a 0,7. Ademais, constatou-se que todas as variáveis latentes de primeira ordem que mensuram tanto Sistema de Controle Gerencial quanto Resiliência Estratégica apresentaram validade convergente, mesmo que, no nível dos indicadores, os itens SR3, SD3, SD5 e VE1 tenham apresentado cargas fatoriais abaixo de 0,7. Este argumento é utilizado como justificativa para a decisão de manter tais itens SR3, SD3, SD5 e VE1 no modelo, dando prioridade à validade de conteúdo do modelo investigado. As decisões de ajuste do modelo de mensuração no tocante à 
validade convergente consistem em melhorar o valor da AVE e da diagonal da matriz de correlações (a raiz quadrada da AVE). Fato este que já está de acordo com os parâmetros estabelecidos, sendo valores superiores a 0,5 e 0,7 , respectivamente. Assim sendo, conclui-se que todas as variáveis de primeira ordem (Tabela 4.23) apresentaram validade convergente adequada em relação aos constructos.

\subsubsection{Validade discriminante}

Utilizaram-se dois instrumentos para avaliar a validade discriminante: a matriz de cargas cruzadas (Tabelas 4.20 a 4.22) e a matriz de correlações (Tabela 4.23).

A análise da validade discriminante no nível dos itens ocorreu por meio das Tabelas 4.20 a 4.22, ao comparar o valor da diagonal que o item possui (carga fatorial) em relação aos valores apresentados em outros indicadores na sua respectiva linha e coluna (cargas cruzadas), ou seja, compara-se a carga fatorial dos itens com as cargas cruzadas apresentadas nos demais indicadores. Quando um item apresenta carga cruzada mais alta do que a sua carga fatorial, há redução de validade discriminante, ou seja, outros itens do modelo mensuram melhor a variável que o item se propôs a medir ou, ainda, podem estar representando o mesmo constructo. Nesta situação, em que as cargas cruzadas são muito elevadas, existem duas alternativas: (i) agrupar os itens em uma mesma variável latente ou (ii) excluí-lo.

Os itens cuja validade convergente foi insatisfatória apresentaram cargas cruzadas altas com outros indicadores promovendo uma redução da validade discriminante. A seguir são apresentados os problemas com os indicadores que mensuram a variável latente Sistema de Controle Gerencial (ver Tabela 4.20):

- $\quad$ SR3 (-0,026) $\rightarrow$ Não foi significante para esta população. Acarretou altas cargas cruzadas com os demais indicadores;

- $\quad$ SD3 $(0,618)$ e SD5 $(0,470) \rightarrow$ Proporcionaram altas cargas cruzadas tanto com itens que mensuram o Sistema de Controle Gerencial, quanto com elementos de Resiliência Estratégica. Porém, estes elementos foram significantes na amostra selecionada.

Estes itens seriam potenciais candidatos à eliminação no modelo ajustado, porém, ao realizar uma análise conjunta entre a matriz de cargas cruzadas para o nível de indicadores e a matriz de correlação (análise apresentada a seguir), optou-se por priorizar a validade de 
conteúdo do modelo investigado, mantendo estes itens no modelo de mensuração, embora se saiba que existam problemas que reduzem tanto a validade convergente quanto a discriminante.

Além disso, ao optar por manter os indicadores no modelo de mensuração priorizou-se a replicabilidade do estudo, tendo em vista que o instrumento que mensura o Sistema de Controle Gerencial com base nas alavancas de controle de Simons (1995) já está consolidado e futuras replicações poderão apresentar melhores resultados.

A seguir, são apresentados os indicadores que mensuram a variável latente Resiliência Estratégica com problemas de validade discriminante, ver Tabela 4.21 e Tabela 4.22:

- $\quad$ VE1 $(\mathbf{0 , 6 8 5}) \rightarrow$ O principal problema de validade discriminante apresentado foi com os itens VE3 e VE5 que apresentaram cargas cruzadas superiores a 0,685 com diversos itens do modelo, sendo o maior impacto em elementos que mensuram Resiliência Estratégica.

- $\quad$ CO5 (0,768) $\rightarrow$ Apresentou carga fatorial superior a 0,7, estando de acordo com o padrão estabelecido para análise. Porém, alguns itens que mensuram Postura Proativa, Liderança e Parcerias Eficazes, apresentaram cargas cruzadas com este indicador superiores a 0,768 .

- $\quad$ FH3 $(\mathbf{0 , 7 7 0}) \rightarrow$ Possui carga fatorial superior a 0,7 gerando cargas cruzadas superiores a este valor para elementos que mensuram as dimensões: Visão Estratégica (VE3); Aprendizagem Organizacional (AO4); Liderança (LD1 e LD3); e Parcerias Eficazes (PE2 e PE3).

Optou-se por manter estes itens no modelo de mensuração, embora possuam alta cargas cruzadas com diversos indicadores do modelo. Tal fato pode ser justificado devido à causa comum, tendo em vista que estes itens compõem a mensuração do mesmo constructo "Resiliência Estratégia". Tal fato é justificado por Hair Jr. et al. (2014), ao afirmarem que, embora haja uma redução da validade discriminante, isto ocorre devido à causa comum entre elas, tendo em vista que a utilização do modelo de medição reflexivo dita que todos os itens refletem a mesma construção, neste caso estes indicadores estão associados a uma construção específica, resiliência estratégica, e desta forma são altamente correlacionados entre si.

Ao analisar a Tabela 4.23, matriz de correlações, é possível averiguar a validade discriminante na maioria das variáveis latentes de primeira ordem, na qual se observa que os valores da diagonal, representado pela raiz quadrada da variância média extraída, é maior do que os valores fora da diagonal (as correlações), conforme asseguram Hair Jr. et al. (2014), exceto para quatro correlações: (i) Sistemas de Crenças e Sistemas de Restrições; (ii) Sistemas 
de Crenças e Uso do Sistema Diagnóstico; (iii) Uso do Sistema Diagnóstico e Postura Proativa; e (iv) Sistema de Restrição e Fator Humano. Nos dois primeiros casos, a correlação foi maior que a raiz quadrada do AVE, apontando falta de validade discriminante entre elas. Bido, Godoy, Araujo e Louback (2010) e Hair Jr. et al. (2014) auxiliam a justificar que, para o presente modelo cujas variáveis latentes foram utilizadas como indicadores reflexivos do mesmo constructo, isto não é um problema, tendo em vista que nas duas situações mensuram o constructo Sistema de Controle Gerencial.

Além disso, utilizou-se o cálculo da correlação desatenuada para justificar a decisão de manter os itens com problemas de validade discriminante no modelo proposto. Na primeira situação, ao dividir o valor da correlação $(0,786)$ apresentada entre as variáveis Sistemas de Crenças e Sistemas de Restrições pela multiplicação da confiabilidade composta da variável Sistemas de Crenças $(0,924)$ pela confiabilidade composta da variável Sistemas de Restrições $(0,787)$, e extrair a raiz quadrada, obteve-se um valor de correlação desatenuada de 0,921. Considerando que o valor ficou inferior a 1, mantêm-se os itens no modelo.

O cálculo da segunda situação evidenciou um valor de correlação desatenuada de 0,818 , cuja correlação entre as variáveis latentes Sistemas de Crenças e Uso do Sistema Diagnóstico é de 0,719 , e as confiabilidades compostas são de 0,924 e 0,837 , respectivamente. Na terceira, a correlação entre o Uso do Sistema Diagnóstico e Postura Proativa foi de 0,744, sendo maior que a raiz quadrada da AVE que foi de 0,718, e encontrou-se o valor de 0,835 para a correlação desatenuada, ao extrair a raiz quadrada da divisão do valor da correlação $(0,744)$ pela multiplicação da confiabilidade composta das respectivas variáveis, 0,837 e 0,949. E, por fim, a correlação desatenuada entre as variáveis Fator Humano e Sistema de Restrições foi de 0,872. Considerando que os valores das correlações desatenuadas também ficaram inferiores a 1 , mantêm-se os itens no modelo.

Tal fato justifica a utilização do modelo de mensuração original mantendo os indicadores propostos no modelo teórico apresentado.

\subsubsection{Confiabilidade}

A confiabilidade foi testada por meio do alfa de Cronbach e da confiabilidade composta apresentado valores de 0,631 a 0,933 e de 0,787 a 0,953, respectivamente. Conforme evidenciado na Tabela 4.23, observa-se que apenas a dimensão Sistema de Restrições do constructo Sistema de Controle Gerencial apresentou alfa inferior a 0,7, cuja confiabilidade composta foi de 0,787, valor este próximo a 0,8 que, de acordo com Hair Jr. et al. (2014) e 
Henseler et al. (2009), é a medida mais indicada para garantir a consistência interna do modelo ao utilizar o PLS-PM. Esta análise corrobora com a decisão de utilizar o modelo de mensuração original mantendo os indicadores propostos no modelo teórico apresentado.

\subsubsection{Avaliação da mensuração no nível das variáveis latentes de $2^{\mathrm{a}}$ ordem.}

Ao observar a Tabela 4.23 é possível identificar que as quatro dimensões do SCG apresentaram correlações altas entre si (0,636 a 0,786), justificando o seu agrupamento como uma variável latente de segunda ordem. Fato este que também é evidenciado para as dimensões que compõem a RE, cujos constructos de primeira ordem apresentaram correlações entre 0,513 e 0,848 . O agrupamento das dimensões em variáveis latentes de segunda ordem atenua o problema de multicolinearidade (Onça \& Bido, 2015).

O modelo de mensuração das variáveis de segunda ordem seguiu as diretrizes apontadas por Wetzels, Odekerken-Schröder e Oppen (2009) e Hair Jr. et al. (2014), para a utilização do SmartPLS ${ }^{\circledR}$, em que se repetem, nas variáveis latentes de segunda ordem, os indicadores que compreendem as variáveis de primeira ordem. Onça, Bido e Carvalho (2018, p. 403) afirmam que "as relações entre as variáveis latentes de segunda ordem e suas variáveis latentes de primeira ordem são interpretadas como cargas fatoriais, as quais são usadas para se calcular a AVE e a confiabilidade composta". Por meio da Tabela 4.24 é possível identificar a presença de validade convergente, validade discriminante e confiabilidade no nível das variáveis latentes de segunda ordem.

Tabela 4.24 - Matriz de correlações com os constructos de segunda ordem

\begin{tabular}{l|r|r}
\hline & \multicolumn{2}{c}{ SCG } \\
\hline Sistema de Controle Gerencial (SCG) & $\mathbf{0 , 8 7 4}$ & \\
Resiliência Estratégica (RE) & 0,874 & $\mathbf{0 , 8 5 7}$ \\
& & \\
Composite Reliability & 0,928 & 0,965 \\
Average Variance Extracted (AVE) & 0,764 & 0,735 \\
\hline
\end{tabular}

Nota 1: Os valores na diagonal são a raiz quadrada da AVE.

Nota 2: Valores de correlação superiores a $|0,246|$ são significantes a 5\% e acima de $|0,319|$ são significantes a $1 \%$.

Nota 3: Todos os constructos foram mensurados com escalas de 5 pontos (1 a 5).

Fonte: Elaborada pela autora.

Observa-se, na Tabela 4.24, que as variáveis latentes de segunda ordem apresentaram variância média extraída superior a 0,735 , isto é, superior a 0,5 ; apresentam os valores diagonal 
da matriz (raiz quadrada da variância média extraída) maiores que os valores fora da diagonal (correlações) e a confiabilidade composta apresenta valores superiores a 0,92, ou seja, as variáveis latentes de segunda ordem apresentaram, respectivamente, validade convergente, validade discriminante e confiabilidade.

\subsection{ANÁlise do Modelo ESTRUTURAL}

O modelo estrutural foi estimado por meio do método dos mínimos quadrados parciais (PLS-PM - Partial Least Squares Path Modeling), utilizando o software SmartPLS 3.2.7, os valores-p foram estimados por bootstrap com 5.000 reamostragens e utilizou-se a opção no sign changes. Destaca-se que todos os indicadores foram mantidos no modelo. A escolha do método de tratamento dos dados ocorreu devido a amostra representar tamanho muito menor do que aquele necessário para a estimação baseada em covariâncias, na possibilidade de testar relações entre variáveis latentes sem a suposição de normalidade multivariada e na capacidade de lidar com modelos complexos (Hair Jr. et al., 2014).

No modelo estrutural, Apêndice $\mathrm{D}$, busca-se identificar o valor mínimo do $\mathrm{R}^{2}$ detectável como significante, tendo como base a classificação realizada por Cohen (1977, p. 413-414): 2\% como baixo, $13 \%$ como médio e $26 \%$ como grande. Utilizou-se o software $\mathrm{G}^{*}$ Power ${ }^{\circledR}$ versão 3.1.9.2 para estimá-lo. O resultado apresentado para o modelo testado foi de 11,23\%, ou seja, considerando o poder estatístico de $80 \%$ e nível de significância de $5 \%$, qualquer $\mathrm{R}^{2}$ superior a este valor é detectado como significante (Faul et al., 2007). Complementando com a análise de sensibilidade do $\mathrm{G}^{*}$ Power $^{\circledR}$, há evidência de que, para uma amostra de 64 casos, qualquer efeito superior a $12,66 \%$ será detectado como significante a $5 \%$, com poder estatístico de $80 \%$.

A análise do modelo estrutural foi executada, tendo em vista que a estimação do modelo estrutural envolveu variáveis de segunda ordem (Sistema de Controle Gerencial e Resiliência Estratégica), inclusão de variáveis de controle (direção em que está alocado o respondente) e a avaliação do viés do método.

\subsubsection{Viés do método}

$\mathrm{O}$ viés do método, também denominado de Common Method Bia (CMB), Common Method Variance (CMV) ou Measured Latent Marker Variable (MLMV), acarreta a correlação superestimada ou subestimada entre a variável dependente e as independentes ao serem coletadas a partir dos mesmos respondentes, cujo instrumento de coleta seja composto pelo 
mesmo estilo de escala para mensurar tanto a variável dependente quanto a variável independente (Podsakoff, Mackenzie, \& Podsakoff, 2012).

De acordo com Chin et al. (2013), o viés do método pode ser avaliado e eliminado ao incluir no modelo uma variável latente formativa denominada pelos pesquisadores de MLMV, contendo de 4 a 12 itens, utilizando a mesma escala de mensuração para medir seus elementos, porém que estes não contemplem o mesmo conteúdo das variáveis incluídas no modelo de pesquisa, ou seja, devem apresentar conteúdos diversos daqueles investigados na pesquisa. Além disso, é importante que questionem sobre uma unidade de análise diferente daquela investigada no modelo de pesquisa, isto significa que os indicadores do MLMV questionem sobre o nível do indivíduo quando a pesquisa está interessada no nível organizacional. Tendo em vista que, ao incluir MLMV no modelo, busca-se garantir que todas as variações exclusivas e de erro sejam independentes entre o conjunto de medidas escolhidas na pesquisa. Sugerem que os indicadores que mensuram o MLMV sejam incluídos no final do instrumento de coleta de dados, tendo em vista que não são o objetivo principal do estudo e minimizariam os efeitos da fadiga do respondente no padrão de respostas relevantes.

No Quadro 4.1 são apresentados os oito indicadores formativos da MLMV que foram utilizados nesta pesquisa para mensurar o viés do método, com respostas em escala de concordância de 1 a 5 , sendo o 1 discorda totalmente, o 5 concorda totalmente, e o 0 para não sei dizer ou não se aplica.

Quadro 4.1 - Indicadores formativos da variável latente de viés do método (MLMV).

\begin{tabular}{|c|c|}
\hline INDICADORES DE MLMV & REFERÊNCIAS \\
\hline $\begin{array}{l}\text { Utilizo o sistema de controle gerencial para } \\
\text { melhorar minha produtividade. }\end{array}$ & Aguiar; Pace \& Frezatti, 2009). \\
\hline $\begin{array}{l}\text { Sinto-me confiante ao contribuir nas discussões } \\
\text { sobre os planos de minha empresa para o futuro. }\end{array}$ & \multirow{5}{*}{ Polizzi Filho (2011); Cavalcante (2013). } \\
\hline $\begin{array}{l}\text { Atualmente eu me vejo em uma fase de sucesso } \\
\text { no trabalho. }\end{array}$ & \\
\hline $\begin{array}{l}\text { Normalmente aceito com calma as coisas } \\
\text { estressantes do trabalho. }\end{array}$ & \\
\hline $\begin{array}{l}\text { Neste momento, acho que posso atingir as } \\
\text { metas de trabalho que fixei para mim mesmo. }\end{array}$ & \\
\hline $\begin{array}{l}\text { Sou otimista sobre o que acontecerá comigo no } \\
\text { futuro em meu trabalho. }\end{array}$ & \\
\hline $\begin{array}{l}\text { A missão da organização está alinhada com os } \\
\text { meus valores. }\end{array}$ & Chen, Lill, \& Vance (2014). \\
\hline $\begin{array}{l}\text { No que diz respeito à minha carreira, quem } \\
\text { toma as decisões sou eu. }\end{array}$ & Cordeiro \& Albuquerque (2016). \\
\hline
\end{tabular}

Fonte: Elaborado pela autora. 


\subsubsection{Teste de hipótese}

A seguir são apresentados os resultados do modelo estrutural proposto: (i) para testar $\mathrm{H}_{1}$; (ii) para avaliar os efeitos da variável de controle; e (iii) para avaliar e eliminar o viés do método.

Observou-se que o fator de inflação da variância denominado de Variance Inflation Index (VIF) foi inferior a 5 para o modelo estrutural, isto aponta para uma situação aceitável de multicolineariedade, segundo Hair, Ringle e Sarstedt (2013), embora, conforme discutido anteriormente, na matriz de correlação das variáveis de primeira ordem (Tabela 4.23), algumas variáveis apresentaram valores altos em si, isto é, a colinearidade existente pode ser explicada pela alta correlação tendo em vista uma causa comum.

O efeito da variável de controle Diretoria que representa a participação do respondente em seu departamento não apresentou relação significante com a Resiliência Estratégica, mesmo havendo pessoas vinculadas às diretorias que estão envolvidas diretamente no processo de gestão da organização e outras voltadas às atividades operacionais da organização como foi evidenciado na Tabela 4.3.

Na Figura 4.1, a variável MLMV foi incluída no modelo para estimar e remover o efeito do viés do método, conforme apresentado por Chin et al. (2013), cujos resultados apresentados são coeficientes estruturais padronizados após a remoção do efeito do viés do método. Desta feita, observou-se que havia uma superestimação do coeficiente estrutural de 0,874 , pois, após a remoção do efeito do viés do método, o coeficiente estrutural passou para 0,523.

Figura 4.1 - Modelo estrutural

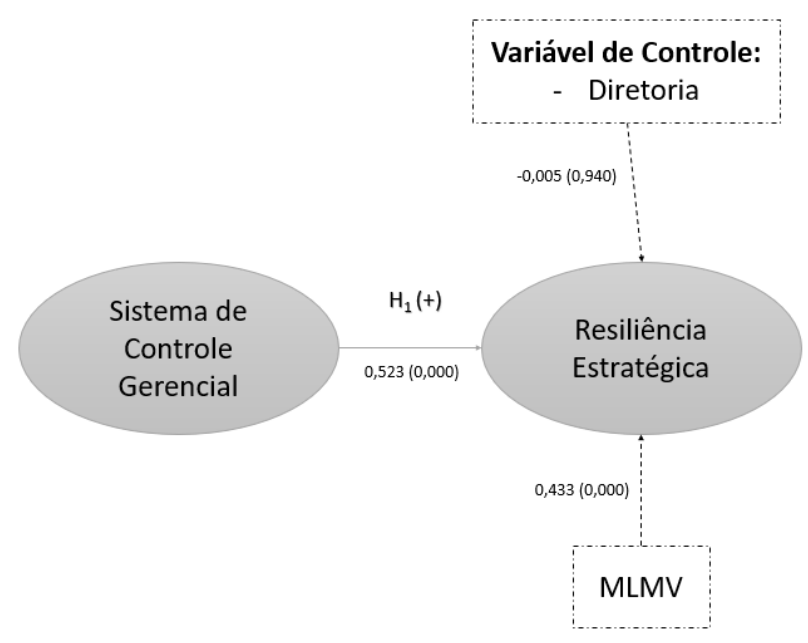

Fonte: Elaborada pela autora. 
O modelo apresentado na Figura 4.1 evidencia o coeficiente estrutural sem viés e estatisticamente significante ( $\mathrm{p}<0,001$ ), o qual suporta a hipótese $\mathrm{H}_{1}$ (vide modelo completo no Apêndice D). É interessante observar que um aumento no uso do Sistema de Controle Gerencial está associado a um aumento na Resiliência Estratégica $\left(\mathrm{R}^{2}\right.$ igual a $\left.83 \%\right)$. O poder explicativo do modelo é evidenciado pelo $\mathrm{R}^{2}$ ajustado que foi de $82,1 \%$, de acordo com a classificação de Cohen (1977) valores de $\mathrm{R}^{2}$ de $13 \%$ representam efeito baixo, superiores a $13 \%$ efeito médio e superior a $26 \%$ como grande.

Os resultados indicam que a forma como a organização utiliza o sistema de controle gerencial, de acordo com os tipos de uso propostos por Simons (1990, 1991 e 1995), têm alto poder explicativo da resiliência estratégica. De modo geral, os resultados evidenciam que a empresa viabiliza as alavancas por meio de uma variedade de mecanismos de controle que são formalizados na organização , tais como: o código de ética, as diretrizes de direcionamento de operações e conduta, as políticas de gestão de risco; nas diretrizes estratégicas da organização estão disseminados a missão, os valores e a visão da organização; o planejamento estratégico é formalizado e o orçamento está alinhado com o planejamento estratégico; a empresa realiza controle orçamentário comparando o previsto versus o realizado; nas reuniões são discutidos os resultados passados e as ações futuras; a organização desenvolve o monitoramento destes instrumentos nas diretorias investigadas e os gerentes operacionais estão frequentemente envolvidos com o sistema de controle de modo a prever adversidades que impeçam o progresso em direção às metas organizacionais.

A seguir é apresentado o Mapa de Prioridade que complementa esta informação ao cruzar os coeficientes estruturais não padronizados com os escores fatoriais padronizados de 0 a 100 (Onça \& Bido, 2015).

\subsubsection{Mapa de prioridade}

O mapa de prioridade, também conhecido por mapa de desempenho-importância e no idioma inglês importance-performance map analysis (IPMA), é emitido por meio do software SmartPLS $^{\circledR}$ v.3.2.7 (Ringle, Wende, \& Becker, 2015). O IPMA tem uma aplicação na prática profissional de modo a auxiliar os gestores a identificar como os indicadores estão sendo desenvolvidos e quais apresentam prioridade de investimentos e recursos para a gestão da organização "A” no contexto investigado (Bido \& Barroso, 2016; Mikulić, Prebežac \& Dabić, 2016). 
O IPMA contrasta os efeitos totais (não padronizados) no eixo $\mathrm{X}$, representando a importância dos constructos predecessores na modelagem de um determinado constructo alvo, com suas pontuações fatoriais médias padronizadas para uma escala de 0 a 100 das variáveis latentes indicando seu desempenho e sua importância. Isto significa que o eixo horizontal (eixo X) demonstra o nível de importância de cada variável preditora na variável dependente e o eixo vertical (eixo Y) representa o desempenho da variável latente de segunda ordem Resiliência Estratégica (Ringle \& Sarstedt, 2016; Bido \& Barroso, 2016). O Apêndice E reporta o relatório emitido pelo software SmartPLS ${ }^{\circledR}$ v.3.2.7 com os resultados dos valores não padronizados dos constructos e indicadores que foram utilizados para a confecção dos mapas de prioridade da presente pesquisa.

De acordo com a recomendação dos pesquisadores Mikulić, Prebežac e Dabić (2016), a análise do mapa de prioridade é realizada por quadrantes cuja ênfase é atribuída para a maior e para a menor prioridade dos elementos conforme evidenciados em cada quadrante, conforme Figura 4.2.

Figura 4.2 - Análise do mapa de prioridade

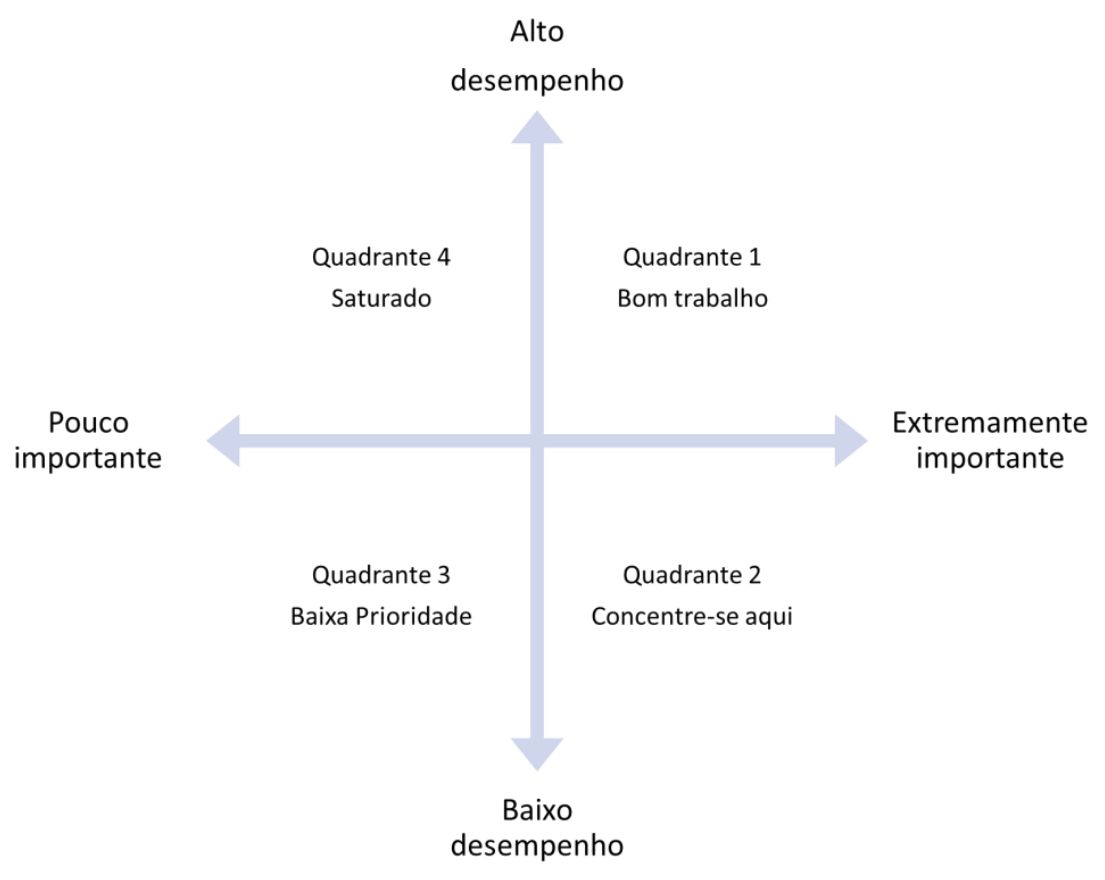

Fonte: Traduzido de Mikulić, Prebežac e Dabić (2016, p. 775)

Observa-se que, no Quadrante 1, são alocados os elementos com maior impacto e alto desempenho na variável dependente, isto significa que a empresa está desenvolvendo um 
trabalho adequado; no Quadrante 2, os itens que demandam maior atenção da organização, pois apresentam valores altos de importância possibilitando uma margem de crescimento que promoverá melhoras no desempenho da variável dependente; o Quadrante 3 contempla os elementos com baixa prioridade, tendo em vista que estes são de menor prioridade e importância; e, por fim, no Quadrante 4 encontram-se os elementos saturados, ou seja, que apresentam alto desempenho na variável dependente, porém com baixa importância para o seu desenvolvimento (Bido \& Barroso, 2016; Mikulić et al., 2016).

O mapa de prioridade complementa os resultados apresentados pelo bootstrapping com re-amostragem aleatória com 5.000 repetições utilizando a opção sem mudança de sinal com intervalos de confiança de 95\% (Hair Jr., Hult, Ringle \& Sarstedt, 2017), cuja evidência é de que os coeficientes são estatisticamente significativos. Desta feita, especificamente para a presente pesquisa, o SCG tem efeito significativo e positivo sobre a RE, conforme é evidenciado no Gráfico 4.3.

Gráfico 4.3 - Mapa de prioridade no nível do constructo

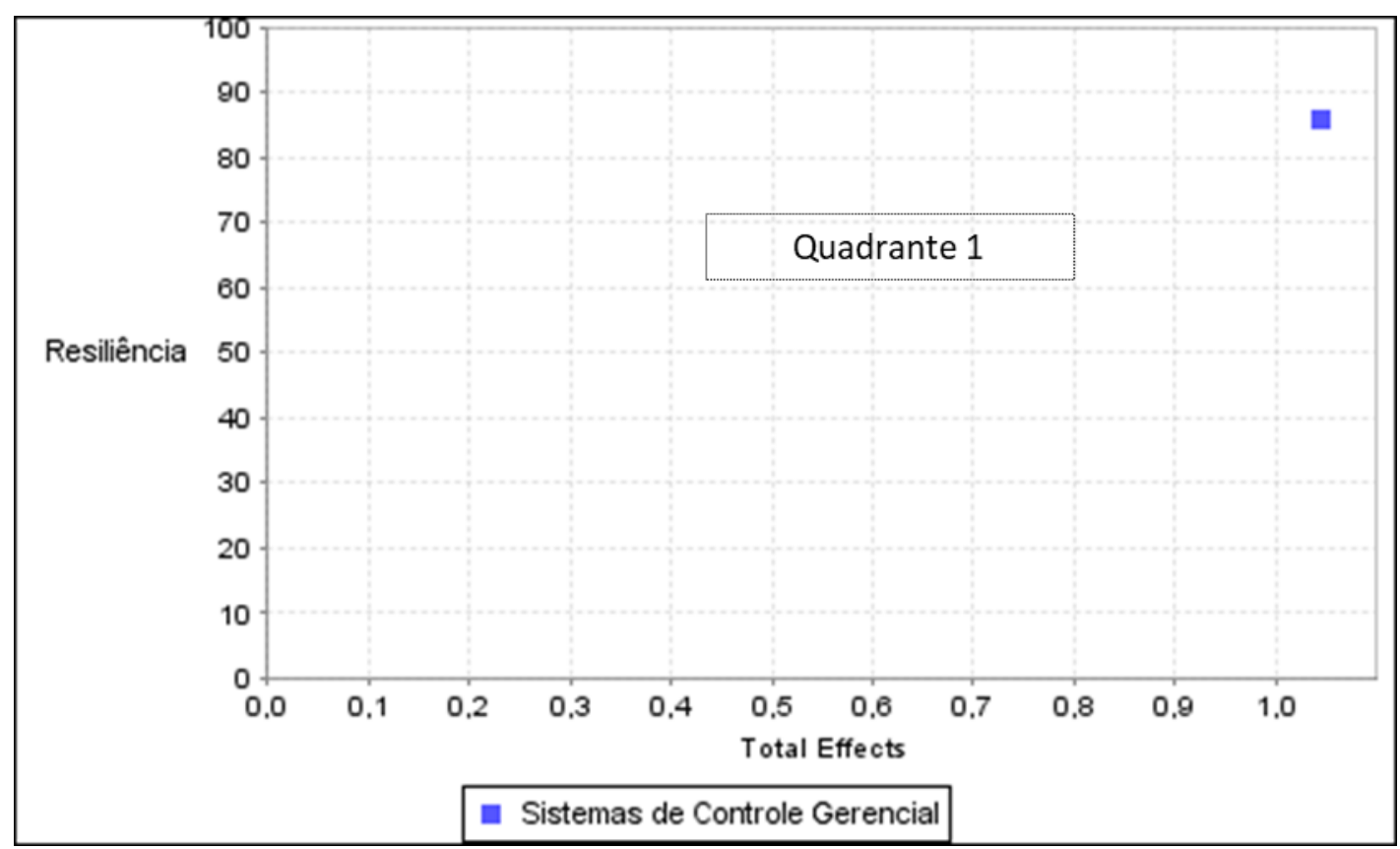

Nota: Apesar de a escala ser de 1 a 5, o SmartPLS 3.2.7 padroniza os escores fatoriais para a faixa de 0 a 100.

Fonte: Elaborado pela autora.

É possível observar, por meio do mapa de prioridades, que o constructo SCG é apresentado no Quadrante 1, segundo Mikulić et al. (2016), indicando que os gestores estão realizando um trabalho adequado, apresentando uma margem para crescimento de aproximadamente $14,34 \%$. Tem-se que o SCG apresenta alto nível de importância e promove 
alto desempenho da RE. Neste sentido, faz-se necessário analisar o mapa de prioridades no nível dos indicadores de modo a averiguar quais indicadores do SCG apresentam maior e menor prioridade de ações por parte da gestão da organização.

O IPMA não está limitado ao nível dos constructos, podendo ser realizado no nível dos indicadores para identificar áreas relevantes e ainda mais específicas que podem auxiliar as decisões práticas, tendo em vista que o objetivo desta ferramenta é identificar predecessores que tenham importância relativamente elevada para a construção da RE (isto é, aqueles que têm um forte efeito total), mas que também apresentem um desempenho relativamente baixo, ou seja, com baixas pontuações fatoriais médias das variáveis latentes (Ringle \& Sarstedt, 2016).

Nota-se que cada elemento do Gráfico 4.4, a seguir, expressa um indicador da variável independente, no modelo representado pela variável latente de segunda ordem denominada Sistema de Controle Gerencial. De acordo com Bido e Barroso (2016) e Mikulić et al. (2016), os itens que estão à direita têm maior importância e aqueles que estão mais à esquerda têm menor importância (Figura 4.2). Na prática, os gestores concentram suas tomadas de decisão em investimentos e recursos para melhorar os itens apresentados no Quadrante 2, tendo em vista que os elementos deste quadrante são importantes e possuem margem de crescimento maior do que aqueles alocados no Quadrante 1.

Observa-se que a maioria dos indicadores apresenta alto nível de importância para a operacionalização da resiliência estratégica, isto acarreta uma influência elevada na resiliência estratégica. Por outro lado, não apresentam muita margem de melhoria, tendo em vista que estão bem próximos a 100\%, sendo que, dos 18 indicadores de SCG, 9 apresentaram desempenho superior à média promovendo impacto elevado na resiliência estratégica. Além disso, 11 indicadores apresentam-se com média de importância elevada assumindo posições nos Quadrantes 1 e 2, os quais demandam maior interesse do ponto de vista prático da pesquisa.

Conforme o esperado encontrou-se vários indicadores de alto nível de importância com destaque para o indicador SD1 "temos planejamento estratégico formalizado", que apresentou maior nível de importância e de desempenho. Além deste indicador no Quadrante 1, que representa os indicadores com maior impacto na RE e alto desempenho, estão alocados os indicadores responsáveis por apresentar maior importância e promoverem o maior desempenho no desenvolvimento da Resiliência Estratégica. 
Gráfico 4.4 - Mapa de prioridade no nível dos indicadores

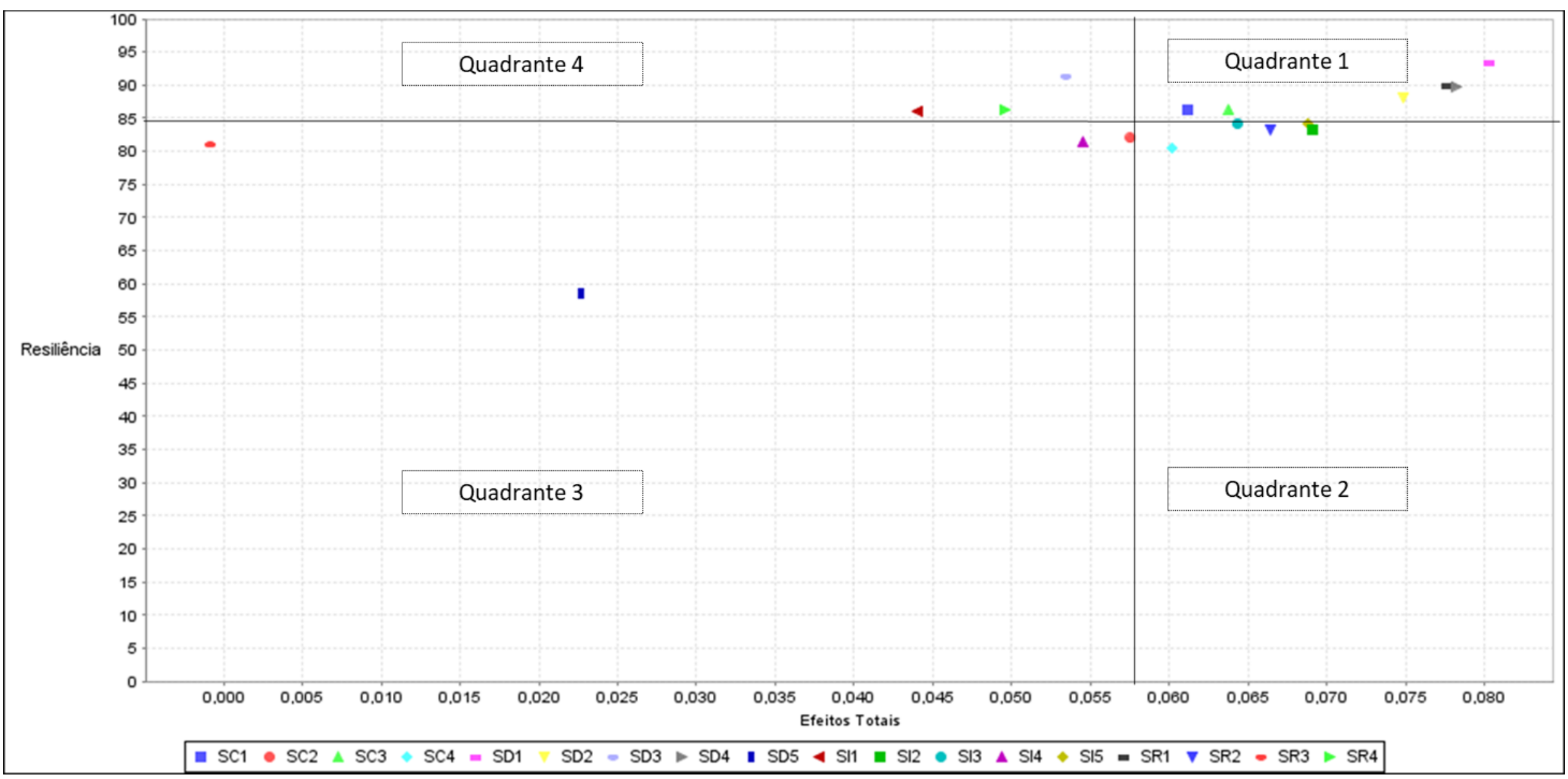

Nota 1: Apesar de a escala ser Likert de 1 a 5 pontos, o SmartPLS 3.2.7 padroniza os escores fatoriais para a faixa de 0 a 100.

Nota 2: Para maior compreensão dos indicadores visualizar Quadro 3.1.

Legenda: SC - Sistema de Crenças; SD - Uso do Sistema Diagnóstico; SI - Uso do Sistema Interativo; SR - Sistema de Restrições.

Fonte: Elaborado pela autora. 
O Quadrante 1 do Gráfico 4.4 mostra que a gestão está desenvolvendo um trabalho adequado em relação aos indicadores de SCG vinculados aos instrumentos de gestão utilizados pela empresa como o planejamento estratégico formalizado (SD1), o orçamento alinhado com o planejamento estratégico (SD2), o código de ética, as diretrizes de direcionamento de operações e conduta e as políticas de gestão de risco para restringir o comportamento e delimitar o campo de ação dos colaboradores da organização (SR1), a disseminação da missão, dos valores e da visão da organização (SC1 e SC3), bem como o monitoramento destes instrumentos dentro da organização nas diretorias investigadas de modo a prever adversidades que impeçam o progresso em direção às metas organizacionais (SD4).

Do ponto de vista prático, os gestores devem concentrar esforços nos indicadores que apresentam maior prioridade, sendo aqueles evidenciados no Quadrante 2, os que possibilitam maior margem de crescimento ao receberem investimentos, pois apresentam valores altos de importância acarretando um forte impacto na RE com margem de crescimento que promoverá melhoras no desempenho do constructo Resiliência Estratégica, sendo os indicadores que atuam na organização de maneira proativa, visando antecipar as adversidades ou se preparar para quando acontecerem.

Destaca-se que, no contexto de ceteris paribus, que a organização "A" estava vivenciando no momento da pesquisa, dificultou que tais indicadores pudessem ser mais bem explorados, e isto pode ser trabalhado no cenário atual. Esta análise direciona um olhar mais atento aos gestores para que observem a missão/visão ao tomar de decisões em momentos de adversidade (SC4), que a organização comunique com maior frequência os riscos a serem evitados, os quais poderiam ocasionar adversidades (SR2), isto acontecerá à medida que os dados gerados pelo sistema de controle forem interpretados e discutidos com superiores, subordinados e pares (SI2). Tal fato passará a ser uma rotina na organização quando os gestores dedicarem atenção regular e frequente à análise e discussão das adversidades em reuniões envolvendo gestores de todos os níveis (SI3) e alinharem a estratégia da organização aos sistemas de controle dando suporte à decisão de modo a adaptar-se continuamente às adversidades (SI5). Destes indicadores, o SC4 é o que demanda maior atenção dos gestores, tendo em vista a sua margem de crescimento (de 80,47\% para 100\%) com importância relativa superior à média dos indicadores e melhor desempenho, isto significa que um aumento de um ponto unitário no desempenho deste indicador irá aumentar o desempenho do constructo RE em 0,06 mantendo as demais condições. Em ordem de prioridade de tem-se os indicadores: SI2, SI5, SR2 e SI3. Os demais elementos mostrados na Gráfico 4.4 são menos relevantes para melhorar o desempenho de RE. 
Por outro lado, existem indicadores que apresentam menor importância para alavancar a resiliência estratégica, que são os indicadores evidenciados nos Quadrantes 3 e 4. Os indicadores do Quadrante 3 são aqueles com baixa prioridade, nos quais os gestores devem investir em última instância, pois, além de apresentarem menor importância, também possuem baixo nível de desempenho, com destaque para o indicador SR3 "não sei exatamente tudo o que devo fazer, mas tenho clareza do que não devo fazer" que não foi significante para esta amostra, ou seja, em uma situação de manutenção das demais condições este indicador não apresentou efeito significativo, isto fornece evidência de que um efeito total é zero na população, o que pode mudar com dados diferentes, ou seja, em contextos alternativos da análise. Além disso, outro indicador, o SD5 apresentou baixa prioridade neste cenário, evidenciando que o desempenho individual explicitado pelo controle orçamentário impacta a remuneração variável do executivo. Tais elementos podem ter apresentado baixa relevância no constructo resiliência tendo em vista que a amostra foi composta por diversas áreas organizacionais, desde áreas diretamente ligadas à gestão da organização com as áreas operacionais, como evidenciado na Tabela 4.3.

Por outro lado, os indicadores SI4 e SC2 também se encontram no Quadrante 3, ambos apresentaram um desempenho superior a $80 \%$ no momento da pesquisa e maior proximidade com o Quadrante 2. Sugere-se à gestão que, após investirem naqueles indicadores elencados no Quadrante 2, e tendo recursos disponíveis, invistam para motivarem os principais gestores a comunicarem os valores fundamentais às suas equipes (SC2) e em treinamentos para que os gestores utilizem o sistema de controle para antecipar-se às mudanças com intuito de evitar que as adversidades afetem os negócios (SI4), tendo em vista que estes indicadores apresentam margem de crescimento e possibilitam uma melhoria no nível de RE da organização.

Por fim, o Quadrante 4 é representado pelos indicadores que apresentaram alto desempenho no constructo resiliência estratégica, porém menor importância. Isto acarreta a sua saturação no contexto da pesquisa, significando que, por mais que se tenha investimentos nestes indicadores por parte da empresa, o seu peso é irrisório e não impactará significativamente na RE. Os indicadores deste quadrante contemplam que os executivos possuem a consciência da existência do código de ética, das diretrizes de direcionamento de operações e conduta e das políticas de gestão de risco, os quais direcionam as ações em momento de adversidades (SR4). Além disso, os gestores utilizam o controle orçamentário de modo que são apresentados os relatórios comparando o previsto versus o realizado, nas reuniões são discutidos os resultados passados e as ações futuras (SD3), e os gerentes operacionais estão frequentemente envolvidos com o sistema de controle (SI1). 
Mesmo que a empresa invista nos indicadores do Sistema de Controle Gerencial e eles revertam em melhoria para a gestão da resiliência estratégica, segundo Onça e Bido (2015), os resultados apontam para escores médios superiores a $80 \%$ e isto significa que o esforço da empresa para alterar seus resultados demanda trabalho. 


\section{DISCUSSÃO DOS RESULTADOS E CONCLUSÕES}

\subsection{RETOMADA}

O objetivo desta pesquisa foi investigar como o uso do sistema de controle gerencial influencia na gestão da resiliência estratégica na organização. Definiu-se, operacionalizou-se, relacionou-se e avaliou-se o impacto que o Sistema de Controle Gerencial promove na Resiliência Estratégica em um contexto que antecede a mudança na sua estrutura e no modo de funcionamento na empresa pesquisada.

Esta pesquisa está alinhada a percepção de Kleine e Weißenberger (2014) de que o SCG reúne um conjunto de mecanismos relevantes para que a organização tenha um direcionamento em relação aos seus objetivos preestabelecidos. Desta feita, o modelo teórico "Levers of Control" proposto por Simons $(1995,2000)$ indica a existência de quatro alavancas de controle que cada organização utiliza de diversas formas combinadas para promover a renovação de sua estratégia e proporcionando mecanismos que as tornam capazes de lidar com incertezas estratégicas de modo a antecipar as adversidades do cenário empresarial que é inerente às suas atividades. A organização que possui e utiliza o sistema de controle gerencial tem facilidade: (i) para adaptar-se perante uma adversidade; (ii) para impulsionar as mudanças exigidas pelo contexto organizacional e pelo ambiente competitivo; (iii) para realizar a inovação estratégica (Arjaliès \& Mundy, 2013; Bisbe \& Otley, 2004; Davila \& Foster, 2008); e (iv) para promover a resiliência como vantagem competitiva (Bhamra et al., 2011; Lengnick-Hall et al., 2011; Salgado, 2013; Nascimento, 2014; Vargo \& Seville, 2010; Starr et al., 2003).

Ao desenvolver o modelo para a percepção de oportunidades para a resiliência estratégica, composto por dez elementos e quarenta e quatro assertivas, foi possível entender o fenômeno da pesquisa, ou seja, identificar o nível de resiliência em cada diretoria da organização no momento da pesquisa e a sua associação com o sistema de controle gerencial por meio da estimação do modelo estrutural. Cabe retomar que o conceito de resiliência estratégica utilizado na tese é: "a capacidade da organização de estar atenta, antecipar, responder, evitar e adaptar-se para atender às expectativas do mercado, agindo proativamente à medida que percebe os sinais das mudanças, alternando as suas estratégias de modo a aproveitar as oportunidades, maximizando os ganhos e minimizando os problemas" (Nascimento, 2014; Lengnick-Hall \& Beck, 2009).

A investigação desta pesquisa ocorreu no nível organizacional e desenvolveu-se sob o prisma da resiliência organizacional, cuja proposta foi discutir estratégia, gestão, sistemas e 
problemas diários que se desencadeiam nas organizações antes da ocorrência de adversidades. Desenvolveu-se um survey single entity em uma empresa brasileira do setor de comércio de derivados de petróleo, com estrutura, porte e sistema de controle gerencial demandados para a investigação e um determinado nível de resiliência organizacional, pois atua no cenário nacional há mais de 60 anos. A empresa escolhida foi conveniente pois, no momento da pesquisa, estava vivenciando uma crise que envolveu a mudança de sua estrutura e do seu modo de funcionamento. Este cenário, pelo fato de sua tensão se prolongar por meses, trouxe o tema resiliência para a realidade do dia-a-dia da organização. A amostra estudada foi não probabilística e a pesquisa não teve como propósito a generalização dos resultados encontrados.

Este estudo empregou um modelo de caminhos (path model) para explorar como o uso do sistema de controle gerencial de uma determinada organização em um contexto de adversidade afeta a resiliência estratégica. A estimação do modelo estrutural foi realizada por meio do método dos mínimos quadrados parciais (PLS-PM - Partial Least Squares Path Modeling), envolvendo variáveis de segunda ordem (Sistema de Controle Gerencial e Resiliência Estratégica), variáveis de controle e variáveis de avaliação do viés do método (Measured Latent Marker Variable - MLMV). O instrumento de coleta de dados continha 62 indicadores, com uma estrutura predefinida em que 18 mensuraram sistemas de controle gerencial e 44 a resiliência estratégica. Todos os itens foram analisados como indicadores reflexivos e os mesmos foram mantidos no modelo final dando prioridade à validade de conteúdo do modelo investigado.

O levantamento dos dados ocorreu a partir de um questionário enviado aos executivos de diversas áreas da organização abrangendo uma amostra de 64 gestores organizacionais . A quantidade de respondentes foi satisfatória, tendo em vista que a taxa de retorno foi de $21 \%$, considerado abrangente em termos do objetivo da pesquisa e do perfil da empresa. Cabe enfatizar que a presente pesquisa captou a percepção dos gestores alocados em cinco diretorias (Diretoria Operacional, Diretoria de Planejamento, Diretoria Financeira, Diretoria do Produto A e Diretoria do Produto B) e nas gerências que respondem diretamente ao Conselho de Administração e à Presidência (Ouvidoria, Auditoria, Gestão de Conformidade, Recursos Humanos, Jurídico e Relacionamento Internacional). 


\subsection{Discussões, ACHados E CONTRibuições}

Observou-se, na empresa investigada, a presença das alavancas de controle por meio de uma variedade de mecanismos de controle, cujos resultados são similares aos encontrados na pesquisa de Arjaliés e Mundy (2013) e Cruz e Frezatti (2014) em que ambos utilizam o framework de Simons (1995, 2000) investigando como as estratégias de Responsabilidade Social Corporativa e o Sistema de Controle Gerencial são utilizados para gerenciar a inovação tecnológica.

Os resultados evidenciados nesta pesquisa suportam a hipótese de que o uso do SCG influencia positivamente a resiliência estratégica $\left(\mathrm{H}_{1}\right)$ e o modelo sinalizou que os tipos de uso do sistema de controle gerencial propostos por Simons $(1995,2000)$ têm alto poder explicativo da variável resiliência estratégica, pois apresentou $\mathrm{R}^{2}$ ajustado de $82,1 \%$. Desta feita, o resultado obtido pela hipótese testada acarreta contribuições relevantes para a pesquisa na área de controle gerencial. Ao confirmar a hipótese desta pesquisa, tem-se a resiliência como um elemento estratégico no modelo de negócio da empresa estudada. Complementando, Vogus e Sutcliffe (2007) afirmam que a resiliência está ancorada nos processos organizacionais, é promovida nas organizações que possuem práticas de gestão permitindo aos gestores questionarem a realidade (Weick \& Sutcliffe, 2007) e influencia as rotinas a medida que fundamenta as escolhas da organização ao responder a uma adversidade (Lengnick-Hall \& Beck, 2005) e promove alterações nos sistemas de controle (Volberda, 1996). Assim, elevados níveis do uso do sistema de controle gerencial aumentam a capacidade da organização para a resiliência estratégica ao atuarem de forma proativa, com visão estratégica frente às adversidades do cenário empresarial. Isto significa que o uso do sistema de controle gerencial nas formas de sistemas de crenças, restrições, uso diagnóstico e o uso interativo associados aos esforços de resiliência estratégica proporciona a renovação estratégica proposta por Simons (1995), auxilia a empresa a desenvolver tolerância ao risco e habilidade para ajustar-se frente a cenários de incertezas melhor posicionando-se no mercado de sua atuação (Burnard \& Bhamra, 2011).

$\mathrm{Na}$ empresa pesquisada percebeu-se o esforço de formatar um sistema de controle gerencial amplo no sentido de: (i) indicar valores que são centrais à organização por um longo período de tempo, (ii) possuir sistemas de controle atuais e conectados com as demandas presentes a ponto de inspirar os colaboradores a agirem proativamente, (iii) a buscarem novas oportunidades, (iv) a ficarem atentos aos riscos e (v) a assegurarem o cumprimento das metas organizacionais. Isto ocorre de modo que as adversidades possam ser antecipadas e a 
organização esteja preparada previamente para as mudanças permitindo adaptar-se continuamente às adversidades, tendo um efeito positivo sobre a resiliência estratégica (Path Coefficient $=0,523 ; \mathrm{p}<0,000)$.

Nesta pesquisa, ao investigar como o SCG pode impactar na resiliência estratégica da organização investigada, constatou-se que, no tocante ao sistema de crença, a missão e a comunicação estabelecida pelos gestores são mecanismos utilizados para compartilhar os valores, o propósito e a visão da organização. Confirmando o ponto de vista de Arjaliés e Mundy (2013) e Cruz (2014), observou-se na empresa pesquisada que o sistema de crenças viabiliza, por meio da comunicação estabelecida na organização, planos que vinculam iniciativas específicas que direcionam os planos operacionais, bem como seus objetivos e adversidades, permitindo à organização aumentar a conscientização sobre o impacto que tais mudanças podem trazer às ações empresariais.

A organização pesquisada possui sistema de crenças e sistema de restrições formalizados (Simons, 2000), conforme evidenciado no item 4.3. Observou-se que todas as diretorias exercem um trabalho no tocante a disseminação de que a missão realmente comunica os valores fundamentais da empresa, bem como o propósito e a visão da organização, e estes são compartilhados pelos diretores às suas gerências e aos seus departamentos. A empresa utiliza o código de ética, as diretrizes de direcionamento de operações e de conduta e as políticas de gestão de risco para restringir o comportamento e delimitar o campo de ação dos colaboradores da organização.

De acordo com os resultados da presente pesquisa, a gestão deve direcionar a atenção para a comunicação dos riscos de modo que sejam evitados antes que as adversidades aconteçam. Cabe aos gestores observarem os limites estratégicos, as regras e as limitações aplicadas a decisões a serem tomadas de como deverão ser empregados os recursos em resposta às oportunidades identificadas no sistema de crenças (Simons, 1995, 2000; Fauzi \& Rahman, 2008). No que se refere as regras de condutas de comportamento todos "tem clareza do que não se deve fazer" (SR1 e SR4), porém "não há clareza sobre tudo o que se deve fazer" (SR3).

A organização pesquisada utiliza planejamento estratégico, orçamento, controle orçamentário e outros para fornecer informações sobre a empresa de modo a assegurar o cumprimento das metas organizacionais. Estes mecanismos, em especial o planejamento, permitem que as pessoas dentro da organização compartilhem objetivos, informações e recursos acarretando benefícios como um comprometimento maior com as metas e solução de problemas de forma criativa (Gittell et al. 2006, Akgun \& Keskin, 2014). Além disso, esta organização utiliza estes mecanismos para proporcionar o monitoramento e a comparação dos resultados 
com as expectativas de modo a prever adversidades que impedem os objetivos organizacionais de serem cumpridos. Desta feita, obteve-se como resultado desta pesquisa que o uso diagnóstico do sistema de controle gerencial, ao fornecer feedback, proporciona o acompanhamento de variáveis críticas de desempenho e auxilia no monitoramento e coordenação das estratégias (Simons, 1995), contribuindo com a resiliência estratégica à medida que auxilia a prever adversidades que impeçam o progresso em direção às metas organizacionais (Widener, 2007; Kruis, Speklé, \& Widener 2016) e permite à liderança desenvolver uma comunicação aberta entre os diversos níveis hierárquicos (Nascimento, 2014). Este sistema permite o acompanhamento de atividades que são facilmente mensuráveis, bem como aquelas cuja mensuração ainda é complexa, como é o caso da resiliência nas organizações.

Salienta-se que, diferente de países como a Austrália e os Estados Unidos que possuem uma discussão mais avançada sobre os elementos de resiliência organizacional, no Brasil ainda é incipiente esta discussão no cenário empresarial. Isto significa que o desenvolvimento destes indicadores pode reduzir lacunas no sistema de controle gerencial das empresas brasileiras, que acarretam dificuldades para monitorar e avaliar os esforços da organização para fins de resiliência. Cabe destacar que o uso diagnóstico do sistema de controle consiste em identificar desvios em relação à estratégia pretendida e articular ações corretivas, faz-se necessário que se tenha objetivos cuja ênfase seja a investigação de riscos iminentes e adversidades de modo a alavancar a capacidade que tal sistema tem de influenciar positivamente a resiliência.

Embora a organização promova reuniões entre gestores que utilizam o SCG para discutir mudanças e adversidades, do ponto de vista prático, os gestores precisam dedicar-se a alinhar a estratégia organizacional aos indicadores do SCG e fazer uso do mesmo para acompanhar as adversidades, ou seja, dedicar atenção regular e frequente à análise e à discussão das adversidades e das mudanças com os gestores dos diversos níveis hierárquicos. Isto acarretará no uso mais intenso do SCG para dar suporte à decisão de modo a adaptar-se continuamente às adversidades. O uso interativo do SCG tem papel relevante no desenvolvimento de ações que permitam articular estratégias correntes e emergentes no processo de resiliência estratégica. Observou-se que os gestores precisam despender tempo e recursos a seus elementos.

Widener (2007) encontrou evidências de que este sistema é utilizado para perceber e diagnosticar o ambiente externo. Isto vai ao encontro das parcerias eficazes, bem como apontam Arjaliès e Mundy (2013), facilitar a troca de experiências, informações e ideias entre os colaboradores em diferentes partes da organização à medida que são capazes de identificar incertezas estratégicas (Cruz, 2014). Isto significa que o uso interativo serve de guia para que a resiliência estratégica seja alcançada na organização investigada, isto é, que a organização 
desenvolva sua capacidade de responder e adaptar-se às expectativas do mercado, alternando as suas estratégias de modo a aproveitar as oportunidades, maximizando os ganhos e minimizando os problemas (Nascimento, 2014; Lengnick-Hall \& Beck, 2009). Desta feita, o uso interativo do SCG tem um papel facilitador no processo da organização desenvolver sua capacidade para a resiliência, assim dispensar atenção à forma como os controles são usados internamente é fundamental para promover a renovação estratégica.

Conforme comentado anteriormente, embora as médias das quatro alavancas de controle tenham ficado bem próximas ( $\geq$ a 4,35), o que surpreendeu foi o sistema de restrições apresentar a maior média $(4,404)$ e o sistema de crenças, a menor $(4,352)$. Acredita-se que tal fato tenha ocorrido devido ao momento de tensão que a empresa estava vivenciando em relação a sua estrutura e modo de funcionamento e às limitações que isto gera no processo de tomada de decisão.

Entre os resultados da presente pesquisa, constatou-se que o controle gerencial permite a empresa gerenciar os elementos de resiliência, com destaque para a gestão da informação em momentos de crise e adversidade assegurando que as pessoas envolvidas no processo de tomada de decisão tenham acesso a informação correta, útil e a receba em tempo hábil (Stephenson, 2010), considerando que cada gestor tem uma necessidade especifica de informação (Nascimento, 2014). O controle gerencial permite a empresa compreender as inter-relações, as interdependências e as ações dos parceiros (governo, fornecedores, concorrentes, entre outros) impactam sua capacidade de reposta perante uma adversidade. Embora o controle gerencial seja o responsável por operacionalizar a dimensão Recursos Disponíveis (RD), a correlação entre as quatro dimensões do sistema de controle gerencial é baixa para esta variável da resiliência estratégica.

Os resultados encontrados refletem o cenário que a empresa estava vivenciando no momento da pesquisa, cujas dificuldades estavam vinculadas ao grupo empresarial na qual estava inserida, dificultando a obtenção de recursos para absorver mudanças inesperadas, a aprovação para realocar recursos existentes em novos projetos e a maior dificuldade está em conseguir aprovação de novos recursos. A empresa estava caminhando em oposição ao que Sutcliffe e Vogus (2003) propõem, pois percebe-se que a organização não tinha intenção de aplicar seus recursos para promover desenvolvimento e crescimento, tendo em vista que a tensão se prolongou por meses e a decisão envolvendo a liberação dos recursos é de responsabilidade do grupo empresarial e não apenas da empresa. Isto impossibilitou a empresa de desenvolver a capacidade para se reorganizar e transferir recursos para superar esta adversidade. 
O contexto empresarial também refletiu nas variáveis "Autonomia para Tomada de Decisão (TD)" e "Inovação e Criatividade (IC)" que, também apresentaram baixa correlação com as quatro dimensões do sistema de controle gerencial. Cabe enfatizar que os relatórios como o planejamento formal permitem que o gestor tenha autonomia e autoridade no processo de tomada de decisão, porém o cenário organizacional no momento da pesquisa, proporcionou uma redução no empowerment na organização pesquisada. Além disso, observou-se que a inovação e a criatividade são empregadas no dia a dia da gestão por iniciativa de cada indivíduo ao desempenhar suas tarefas e não por incentivo da organização.

Constatou-se pela matriz de correlação (Tabela 4.23) que estas dimensões não apresentaram correlação alta com a dimensão "Fator Humano", bem como as correlações cruzadas (isto é, as dimensões de um constructo (RE) com as dimensões do outro (SGC)) foram as menores com as dimensões das alavancas de controle gerencial. Do ponto de vista prático, pode-se perceber que a empresa, ao investir nos mecanismos de controle gerencial, apresenta uma associação mais baixa nestas três dimensões (IC, RD e TD) de RE do que em relação às demais. Tendo em vista que as médias para estas dimensões da RE foram abaixo de 4 , conforme evidenciado na Tabela 4.19, com valores de 3,69, 3,78 e 3,87, respectivamente.

Além disso, são estas variáveis que mensuram RE que apresentaram maiores dispersões entre os respondentes, ou seja, as percepções dos executivos são mais divergentes para estas variáveis. Acarretando, nas diretorias investigadas, desempenhos menores nestas dimensões, conforme evidenciado no Gráfico 4.2. Entre as 10 dimensões da RE, estas 3 variáveis apresentaram baixo desempenho tanto em relação à média geral do constructo Resiliência Estratégica (linha vermelha do gráfico) quanto a média da diretoria (linha verde escura), com duas exceções: a Diretoria de Planejamento apresentou valor superior à média geral para a variável recursos disponíveis, porém dentro da média da diretoria; e a Diretoria do Produto A apresentou valor um pouco acima da média geral para a dimensão Autonomia para Tomada de Decisão, porém, mesmo assim, está abaixo da média da diretoria e entre as três dimensões com menor desenvolvimento.

Cabe destacar que entre as áreas organizacionais investigadas nesta pesquisa as gerências que respondem diretamente ao conselho de administração e à presidência obtiveram valores abaixo da média geral tanto para uso dos mecanismos de controle gerencial quanto para os indicadores de resiliência estratégica acarretando um desenvolvimento de nível alto e médio, respectivamente; as demais diretorias apresentaram nível alto tanto para o uso do sistema de controle gerencial quanto para o desenvolvimento dos elementos da resiliência estratégica, conforme gráficos 4.1 e 4.2 . 
Percebeu-se que a organização pesquisada transforma resiliência em vantagem competitiva, mesmo vivenciando um momento de grande tensão e desafios, a empresa garantiu o alinhamento das estratégias estabelecidas, manteve seu market share e a liderança no mercado do produto A, apresentando um crescimento superior a $11 \%$ em comparação ao ano anterior. Constatou-se que a organização pesquisada vivenciou o desafio gerencial proposto por Sawik (2013) e Annarelli e Nonino (2016) que foi transformar a resiliência organizacional em vantagem competitiva à medida que atuou na gestão com recursos limitados, estratégia proativa e mecanismos de controle gerencial que proporcionaram agilidade no processo de tomada de decisão e a efetividade diária das operações e dos processos. Confirmando a afirmação realizada pelos pesquisadores Bhamra et al. (2011) de que a organização ao cultivar os elementos de resiliência promove vantagem competitiva. Isto significa que a presente empresa pode ser definida como uma organização resiliente de acordo com os pressupostos de Starr, Newfrock, \& Delurey (2003), Sheffi (2005) e Salgado (2013), apresentados anteriormente na página 75, de que a empresa ao alinhar eficazmente a sua estratégia, suas operações, seu sistema de controle gerencial e sua estrutura de governança proporciona suporte ao processo de tomada de decisão possibilitando adaptar-se continuamente às adversidades. Os autores complementam afirmando que ao alinhar estes elementos a organização resiliente gera uma vantagem competitiva.

Do ponto de vista metodológico, este estudo contribuiu para: (i) o desenvolvimento e a validação da escala para mensurar Resiliência Estratégica com dez fatores no nível empresarial que foi desenvolvido nesta tese; (ii) a implementação do procedimento recomendado por Chin et al. (2013), tendo em vista a eliminação do viés do método na coleta dos dados; (iii) o nível de resiliência de modo que as organizações desenvolvam uma cultura de planejamento para a resiliência que visa o desenvolvimento da capacidade da empresa ser proativa ao invés de contornar os problemas e as adversidades que ocorrem no dia a dia empresarial; e (iv) a utilização do mapa de prioridade para alicerçar o ponto de vista prático da presente pesquisa.

A contribuição teórica desta pesquisa ocorreu por meio da extensão dos estudos envolvendo sistemas de controle gerencial sob o prisma das quatro alavancas de controle gerencial de Simons $(1995,2000)$ no cenário nacional e sua associação com a teoria da resiliência organizacional, proporcionando o desenvolvimento de um modelo que visa auxiliar as organizações na gestão da resiliência organizacional por meio dos sistemas de controle gerencial. Do ponto de vista prático, este estudo auxilia os gerentes a decidirem qual padrão de controle melhor se adequa às circunstâncias em que operam e aos seus desafios estratégicos, contribuindo para a compreensão de como o uso de determinado sistema de controle gerencial 
impacta a resiliência no ambiente organizacional. Além disso, promove na organização vantagem competitiva, pois o sistema de controle gerencial auxilia a organização a gerenciar os elementos de resiliência de forma estratégica permitindo à organização ser flexível, adaptarse e recuperar-se de problemas diários.

\subsection{RECOMENDAÇÕES PARA A ORGANIZAÇÃo}

Do ponto de vista prático, apresentam-se a seguir as recomendações da presente pesquisa aos gestores da organização pesquisada, os quais devem concentrar esforços, investimentos e recursos em tomadas de decisão que promovam melhorias nos níveis do uso do sistema de controle gerencial e, consequentemente, aumentem a capacidade da organização para a resiliência estratégica.

Sugere-se que o trabalho de melhoria se inicie com os gestores que atuam diretamente no Conselho de Administração e na Presidência. Para que estes sejam exemplos na organização, reconheçam a sua importância e incentivem as demais diretorias e tendo em vista que é o Conselho de Administração e a Presidência da organização que são os responsáveis pelo processo de decisão que determina o direcionamento estratégico da organização. Trabalhem para manter o sistema de governança corporativo proposto o qual envolve questões não apenas de ordem econômica, mas também, social e ambiental, visando, além da longevidade dos negócios, a criação de valor para a sociedade. Cabe enfatizar que a atuação do Conselho de Administração e da Presidência não ocorre de forma isolada já que a gestão acontece em parceria com as diretorias. Isto significa que ao investir recursos financeiros e humanos para melhorar tanto uso do sistema de controle gerencial quanto o nível de resiliência estratégica do Conselho de Administração e da Presidência, busca-se indiretamente o aumento do nível de utilização do sistema de controle gerencial e do nível de resiliência estratégica das demais diretorias investigadas.

Observa-se que o papel do Sistemas de Controle Gerencial é auxiliar no direcionamento estratégico da organização, ou seja, o SCG é utilizado para apoiar a estratégia existente e a realização das mudanças estratégicas (Langfield-Smith, 1997; Simons, 1995). Assim sendo, para proporcionar uma utilização mais eficaz do sistema de crenças e estimular mudança estratégica, recomenda-se que as diretorias, em especial a Diretoria Operacional, mirem-se nos exemplos da Diretoria de Planejamento e da Diretoria do Produto A, no intuito de realizarem com maior frequência a comunicação dos valores às suas equipes (SC2) e utilizarem a missão e a visão da organização no direcionamento de suas decisões, especialmente em momentos de 
adversidades (SC4). Do ponto de vista prático, cabe retomar a discussão, apresentada no item 4.5.3, de que o indicador SC4 é o elemento do sistema de controle gerencial que demanda maior prioridade para a gestão, tendo em vista que, ao aumentar um ponto, irá proporcionar uma melhoria na resiliência estratégica da organização em 0,06 com uma margem de crescimento de $80,47 \%$ para $100 \%$.

No tocante ao sistema de restrição, sugere-se à organização que mantenha suas políticas que delimitam o campo de ação dos colaboradores da organização, melhore a sua comunicação dos riscos a serem evitados que poderiam ocasionar adversidades (SR2), pois este item tem possibilidade de alavancar a resiliência estratégica da organização, tendo em vista que o mesmo se encontra no quadrante 2, do Gráfico 4.4 da página 137.

Para a organização manter um bom nível de resiliência estratégica, recomenda-se que continuem utilizando o planejamento estratégico e o orçamento para monitorarem os resultados organizacionais, corrigir os desvios de padrões de desempenho preestabelecidos e para prever adversidades que impeçam que as metas organizacionais sejam alcançadas (Mundy, 2010; Tessier \& Otley, 2012). Embora, não se possa afirmar que a remuneração variável seja uma prática comum em grande parte das diretorias estudadas (SD5), não é interessante que a empresa realoque recursos imediatamente para melhorar este elemento, pois o mesmo apresenta-se com menor importância para alavancar a resiliência estratégica, no qual os gestores devem investir em última instância (está alocado no quadrante 3 do gráfico 4.4 da página 137).

Do ponto de vista prático, recomenda-se aos gestores que alinhem a estratégia organizacional aos SCG e façam uso deste para acompanhar as adversidades, ou seja, dedicar atenção regular e frequente à análise e à discussão das adversidades e das mudanças com os gestores dos diversos níveis hierárquicos. Isto acarretará no uso interativo do SCG para dar suporte à decisão de modo a adaptar-se continuamente às adversidades, promovendo assim uma melhoria na gestão da resiliência estratégica na organização investigada. O que será possível por meio de treinamentos e reuniões direcionadas nos diversos níveis organizacionais.

Recomenda-se que as dimensões Inovação e Criatividade (IC), Autonomia para Tomada de Decisão (TD) e Recursos Disponíveis (RD) sejam priorizadas em ações para melhorias dos processos relacionados a Resiliência Estratégica na empresa pesquisada. Para tal, sugere-se que a empresa crie programas de incentivos e recompensas que promova comportamentos que remetam a atitudes inovadoras e criativas por parte dos gestores, bem como, promover treinamentos que visem: (i) motivar seus subordinados a utilizarem o conhecimento de forma inovadora e criativa na solução de problemas no cotidiano empresarial; e (ii) formar gestores que deleguem responsabilidade e autoridade à sua equipe de trabalho. 


\subsection{Limitações e Sugestões Para Futuras Pesquisas}

Tendo em vista que a organização estava passando por um momento de crise com possibilidade de grandes mudanças, as limitações de tempo, os recursos e o acesso às informações, o desgaste dos respondentes em função da insistência nas respostas e a interferência mínima nas atividades cotidianas da organização pesquisada, não foi possível realizar o levantamento multi-grupo por área tendo em vista o número baixo de respostas válidas, sugere-se que pesquisas futuras sejam realizadas dividindo esta população em duas esferas, uma envolvendo as áreas diretamente ligadas à gestão da organização e outra as áreas operacionais.

Sugere-se, também, a realização de uma pesquisa longitudinal que investigue o momento antes e o momento após a adversidade, observando o papel do sistema de controle gerencial, bem como o desenvolvimento dos elementos de resiliência em cada um. Além disso, os resultados apresentados no trabalho podem direcionar para pesquisas que investiguem a resiliência organizacional no nível do indivíduo, especialmente envolvendo as lideranças dentro da organização.

Em futuras pesquisas este modelo poderá também ser utilizado para investigar cenários isolados ou para surveys, assim como para identificação de benchmark nos diversos setores da economia, auxiliando as organizações a mensurarem a forma como operacionalizam a resiliência organizacional por meio dos sistemas de controle gerencial. Recomenda-se a realização de uma investigação empírica que avalie tanto a associação do sistema de controle gerencial com a resiliência estratégica quanto a sua consequência de modo a desenvolver um modelo de mensuração para vantagem competitiva. 


\section{REFERÊNCIAS}

Abernethy, M. A., \& Brownell, P. (1999). The role of budgets in organizations facing strategic change: an exploratory study. Accounting, Organizations and Society, 24(3), 189-204.

Abernethy, M. A., \& Vagnoni, E. (2004). Power, organization design and managerial behaviour. Accounting, Organizations and Society, 29(3), 207-225.

Acquaah, M. (2013). Management control systems, business strategy and performance: a comparative analysis of family and non-family businesses in a transition economy in SubSaharan Africa. Journal of Family Business Strategy, 4, 131-146. Retrieved from http://doi.org/10.1016/j.jfbs.2013.03.002.

Acquaah, M., Amoako-Gyampah, K., \& Jayaram, J. (2011). Resilience in family and nonfamily firms: an examination of the relationships between manufacturing strategy, competitive strategy and firm performance. International Journal of Production Research, 49(18), $5527-5544$.

Aguiar, A. B., Pace, E. S. U., \& Frezatti, F. (2009). Análise do inter-relacionamento das dimensões da estrutura de sistemas de controle gerencial: um estudo piloto. RacEletrônica, 3(1), 1-21.

Akgün, A. E., \& Keskin, H. (2014, September). Organisational resilience capacity and firm product innovativeness and performance. International Journal of Production Research, 52(23), 6918-6937. Retrieved from https://doi.org/10.1080/00207543.2014.910624.

Aleksić, A., Stefanović, M., Arsovski, S., \& Tadić, D. (2013). An assessment of organizational resilience potential in SMEs of the process industry, a fuzzy approach. Journal of Loss Prevention in the Process Industries, 26(6), 1238-1245. Retrieved from http://doi.org/10.1016/j.jlp.2013.06.004.

Alesi, P. (2008). Building enterprise-wide resilience by integrating business continuity capability into day-to-day business culture and technology. Journal of Business Continuity \& Emergency Planning, 2(3), 214-220.

Allenby B, \& Fink, J. (2000). Social and ecological resilience: toward inherently secure and resilient societies. Science, 24(3), 347-64.

Alliger, G. M., Cerasoli, C. P., Tannenbaum, S. I., \& Vessey, W. B. (2015). Team resilience: how teams flourish under pressure. Organizational Dynamics, 44(3), 176-184. Retrieved from https://doi.org/10.1016/j.orgdyn.2015.05.003.

Alves, A. B. (2010). Desenho e uso dos sistemas de controle gerencial e sua contribuição para a formação e implementação da estratégia organizacional. (Dissertação de mestrado. Faculdade de Economia, Administração e Contabilidade. Universidade de São Paulo), São Paulo.

Anderson, S. W., Christ, M. H., Dekker, H. C., \& Sedatole, K. L. (2015). Do extant management control frameworks fit the alliance setting? A descriptive analysis. Industrial Marketing 
$\begin{array}{llll}\text { Management, } & \text { 46, 36-53. } & \text { Retrieved }\end{array}$ https://doi.org/10.1016/j.indmarman.2015.01.004.

Anderson, S. W., \& Widener, S. K. (2006). Doing quantitative field research in management accounting. Handbooks of Management Accounting Research, 1, 319-341. Retrieved from https://doi.org/10.1016/S1751-3243(06)01012-1.

Annarelli, A., \& Nonino, F. (2016). Strategic and operational management of organizational resilience: current state of research and future directions. Omega, 62, 1-18. Retrieved from http://doi.org/10.1016/j.omega.2015.08.004.

Anthony, R. N., \& Govindarajan, V. (2008). Sistemas de controle gerencial. São Paulo: McGraw-Hill.

Antunes, P., \& Mourão, H. (2011). Resilient business process management: framework and services. Expert Systems with Applications: An International Journal, 38(2), 1241-1254. Retrieved from http://doi.org/10.1016/j.eswa.2010.05.017.

Anzilago, M., Beuren, I. M., \& Dal Vesco, D. G. (2015). O uso dos sistemas de controle gerencial nas medidas de desempenho está associado com diminuição da ambiguidade de papéis e aumento de empowerment psicológico? Anais do IX Congresso ANPCONT. Curitiba, 31 de maio a 03 de junho. Recuperado de http://congressos.anpcont.org.br/ix/anais/files/2015-05/ccg251.pdf.

Appelbaum, S. H. \& Gallagher, J. (2000). The competitive advantage of organizational learning. Journal of Workplace Learning: Employee Counselling Today, 12(2), 40-56.

Aranya, N. (1990). Budget instrumentality, participation and organizational effectiveness. Journal of Management Accounting Research, 2(1), 61-11.

Argyris, C. (1990). Overcoming organizational defenses: facilitating organizational learning. Upper Saddle River, Nova Jersey, USA: Prentice Hall.

Arjaliès, D. L., \& Mundy, J. (2013). The use of management control systems to manage CSR strategy: a levers of control perspective. Management Accounting Research, 24(4), 284300. Retrieved from http://doi.org/10.1016/j.mar.2013.06.003.

Avey, J. B., Wernsing, T. S. \& Luthans, F. (2008). Can positive employees help positive organizational change? Impact of psychological capital and emotions on relevant attitudes and behaviors. Journal of Applied Behavioral Science, 44(1), 48-70. Retrieved from https://doi.org/10.1177/0021886307311470.

Ayala, J. C., \& Manzano, G. (2014). The resilience of the entrepreneur. Influence on the success of the business. A longitudinal analysis. Journal of Economic Psychology, 42, 126-135. Retrieved from http://doi.org/10.1016/j.joep.2014.02.004.

Baiardi, A., \& Alencar, C. M. M. D. (2014). Agricultura familiar, seu interesse acadêmico, sua lógica constitutiva e sua resiliência no Brasil. Revista de Economia e Sociologia Rural, 52(1), S045-S062. 
Barbosa, G. S. (2006). Resiliência em professores do ensino fundamental de $5^{a}$ a $8^{a}$ série: validação e aplicação do questionário do índice de resiliência: adultos ReivichShatté/Barbosa. (Tese de doutorado. Pontifícia Universidade Católica), São Paulo.

Barlach, L. (2005). O que é resiliência humana? Uma contribuição para a construção do conceito. (Dissertação de mestrado. Instituto de Psicologia, Universidade de São Paulo), São Paulo.

Bedani, E. R (2008). Resiliência em gestão de pessoas: um estudo a partir da aplicação do "questionário do índice de resiliência: adultos" em gestores de uma organização de grande porte. (Dissertação de mestrado. Faculdade de Ciências Administrativas. Universidade Metodista de São Paulo), São Bernardo do Campo-SP.

Bedford, D. S. (2015). Management control systems across different modes of innovation: implications for firm performance. Management Accounting Research, 28, 12-30. Retrieved from http://doi.org/10.1016/j.mar.2015.04.003.

Berkes, F., \& Ross, H. (2013). Community resilience: toward an integrated approach. Society \& Natural Resources, 26(1), 1-16. Retrieved from https://doi.org/10.1080/08941920.2012.736605.

Berry, A. J., Broadbent, J., \& Otley, D. (2005). Management control: theories, issues and performance. (2nd ed.). New York: Palgrave Macmillan, 2005.

Beuren, I. M., \& Santos, V. (2017). Reflexos das configurações habilitantes e coercitivas do sistema de controle gerencial na resiliência organizacional. Anais do 41 Congresso EnANPAD, São Paulo, SP, Brasil.

Bhamra, R., Dani, S., \& Burnard, K. (2011). Resilience: the concept, a literature review and future directions. International Journal of Production Research, 49(18), 5375-5393. Retrieved from http://doi.org/10.1080/00207543.2011.563826.

Bhimani, A., \& Langfield-Smith, K. (2007). Structure, formality and the importance of financial and non-financial information in strategy development and implementation. Management Accounting Research, 18(1), 3-31. Retrieved from http://doi.org/10.1016/j.mar.2006.06.005.

Bido, D. de S., \& Barroso, A. C. O. (2016). Modelos estruturais em Ciências Sociais Aplicadas: má interpretação dos resultados devido à multicolinearidade. In XL Encontro da ANPAD. 25 a 18 de setembro. Costa do Sauípe/BA. (pp. 1-17).

Bido, D. D. S., Godoy, A. S., Araujo, B. F. V. B., \& Louback, J. C. (2010). Articulação entre as aprendizagens individual, grupal e organizacional: um estudo no ambiente industrial. Revista de Administração Mackenzie, 11(2), 68-95. Recuperado de https://doi.org/10.1590/S1678-69712010000200004.

Bigg, D. (2011). Understanding resilience in a vulnerable industry: the case of reef tourism in Australia. Ecology and Society, 16(1), 1-18. Retrieved from http://www.ecologyandsociety.org/vol16/iss1/art30/. 
Bigley, G. A., \& Roberts, K. H. (2001). The incident command system: high reliability organizing for complex and volatile task environments. Academy of Management Journal, 44(6), 1281-1299.

Bisbe, J., \& Otley, D. (2004). The effects of the interactive use of management control systems on product innovation. Accounting, Organizations and Society, 29(8), 709-737. Retrieved from http://doi.org/10.1016/j.aos.2003.10.010.

Boin, A., \& McConnell, A. (2007). Preparing for critical infrastructure breakdowns: the limits of crisis management and the need for resilience. Journal of Contingencies and Crisis Management, 15(1), 50-59.

Boin, A., \& Van Eeten, M. J. G. (2013). The resilient organization. Public Management Review, 15(3), 429-445. Retrieved from http://doi.org/10.1080/14719037.2013.769856.

Bossidy, L., \& Ram Charan (2005). Execução: a disciplina para atingir resultados. (E. Pepe trad.). Rio de Janeiro: Elsevier.

Brown, T. A. (2006). Confirmatory factor analysis for applied research. New York: The Guilford Press.

Brown, C., Seville, E., \& Vargo, J. (2014). Resilient organizations. Research Report 2014/06. Retrieved from www.resorgs.org.nz/images/stories/pdfs/bay_of_plenty_resilience _benchmark_report.pdf.

Bruining, H., Bonnet, M., \& Wright, M. (2004). Management control systems and strategy change in buyouts. Management Accounting Research, 15(2), 155-177. Retrieved from https://doi.org/10.1016/j.mar.2004.03.003.

Bryman, A. (2012). Social research methods. (4th ed.). New York: Oxford University Press.

Burnard, K., \& Bhamra, R. (2011). Organisational resilience: development of a conceptual framework for organisational responses. International Journal of Production Research, 49(18), 5581-5599.

Canan, I. (2013). Sistemas de controle gerencial e contratos psicológicos. (Tese de doutorado. Faculdade de Economia, Administração e Contabilidade, Universidade de São Paulo), São Paulo.

Caralli, R. A., Allen, J. H., \& White, D. W. (2010). CERT Resilience Management Model (CERT-RMM): a maturity model for managing operational resilience. Addison-Wesley Professional, Pearson Education, Inc. Boston.

Carmeli, A., Friedman, Y., \& Tishler, A. (2013). Cultivating a resilient top management team: the importance of relational connections and strategic decision comprehensiveness. Safety Science, 51(1), 149-159. Retrieved from https://doi.org/10.1016/j.ssci.2012.06.002.

Carmeli, A., \& Markman, G. D. (2011). Capture, governance, and resilience. Strategy implications from the history of Rome. Strategic Management Journal, 32(3), 322-341. Retrieved from https://doi.org/10.1002/smj.880. 
Cavalcante, M. M. (2013). Engajamento no trabalho, bem-estar no trabalho e capital psicológico: um estudo com profissionais da área de gestão de pessoas. (Dissertação de mestrado em Gestão de Organizações). Universidade Metodista de São Paulo, São Bernardo do Campo.

Chalos, P. \& Poon, M. C. C. (2000). Participation and performance in capital budgeting teams. Behavioral Research in Accounting, 12, 199-229.

Chen, C. X., Lill, J. B., \& Vance, T. W. (2014). Why do we work? empirical evidence on work motivation and the effects of management control system design on work motivation. In AAA 2015 Management Accounting Section (MAS) Meeting. December 1, 2014. Available at SSRN: https://ssrn.com/abstract=2481153 or http://dx.doi.org/10.2139/ssrn.2481153.

Chenhall, R. H., Kallunki, J.-P., \& Silvola, H. (2011). Exploring the relationships between strategy, innovation, and management control systems: the roles of social networking, organic innovative culture, and formal controls. Journal of Management Accounting Research, 23(1), 99-128. Retrieved from http://doi.org/10.2308/jmar-10069.

Chin, W. W., \& Newsted, P. R. (1999). Structural equation modeling analysis with small samples using partial least squares. In R. H. Hoyle (Ed.). Statistical strategies for small sample research. (pp. 307-341). California: Thousand Oaks: Sage.

Chin, W. W., Thatcher, J. B, Wright, R. T, \& Steel, D. (2013, Springer). Controlling for common method variance in PLS analysis: the measured latent marker variable approach. In. H. Abdi et al. (Eds.). New perspectives in partial least squares and related methods. Proceedings at 56 Mathematics \& Statistics. (pp. 231-239). New York Science+Business Media. doi: 10.1007/978-1-4614-8283-3_16.

Cho, C. W. (1996). The knowing organization: how organizations use information to construct meaning, create knowledge and make decisions. International Journal of Information Management, 16(5), 329-340.

Coaffee, J. (2008). Risk, resilience, and environmentally sustainable cities. Energy Policy, 36(12), 4633-4638. Retrieved from http://doi.org/10.1016/j.enpol.2008.09.048.

Cohen, J. (1977). Statistical power analysis for the behavioral sciences. (Revised edition). New York: Academic Press.

Cooper, D. R, \& Schindler, P. S. (2003). Métodos de pesquisa em administração. New York: Mc-Graw-Hill.

Cordeiro, H. T. D., \& Albuquerque, L. G. (2016). Validação da escala de atitudes de carreira sem fronteiras e carreira proteana no Brasil. Revista de Carreiras e Pessoas (ReCaPe). 6(2), 118-137.

Coutu, D. L. (2002). How resilience works. Harvard Business Review, 80(5), 46. 
Cox, L. A. (2012). Community resilience and decision theory challenges for catastrophic events. Risk Analysis, 32(11), 1919-1934. Retrieved from http://doi.org/10.1111/j.1539 6924.2012.01881.x.

Crichton, M. T., Lauche, K., \& Flin, R. (2005). Incident command skills in the management of an oil industry drilling incident: a case study. Journal of Contingencies and Crisis Management, 13(3), 116-128.

Cruz, A. P. C. (2014). Estilo de liderança, sistema de controle gerencial e inovação tecnológica: papel dos sistemas de crenças, interativo, diagnóstico e de restrições. (Tese de doutorado. Universidade de São Paulo), São Paulo.

Cruz, A. P. C., \& Frezatti, F. (2014). Estilo de liderança, sistema de controle gerencial e inovação tecnológica: Papel dos sistemas de crenças, interativo, diagnóstico e de restrições. Anais do XXXVIII Encontro da ANPAD. (pp. 1-16). Rio de Janeiro. Recuperado de https://doi.org/10.1017/CBO9781107415324.004.

Cruz, A. P. C., Frezatti, F., \& Bido, D. S. (2015). Estilo de liderança, controle gerencial e inovação: papel das alavancas de controle. Revista de Administração Contemporânea, 19(6), 772-794.

Cugueró-Escofet, N., \& Rosanas, J. M. (2013). The just design and use of management control systems as requirements for goal congruence. Management Accounting Research, 24(1), 23-40. Retrieved from https://doi.org/10.1016/j.mar.2012.11.001.

D'Oliveira, L. M. (2014). Modelo estratégico de gestão de pessoas e resiliência organizacional: uma análise do processo de mudança de uma empresa brasileira de energia. (Dissertação de mestrado. Fundação Getúlio Vargas), Rio de Janeiro.

Dabul, N. J. S. (2012). Características de resiliência e a implementação de uma nova estratégia de comunicação: um estudo de caso. (Dissertação de mestrado. Pontifícia Universidade Católica do Rio de Janeiro), Rio de Janeiro.

Dalziell, E. P., \& McManus, S. T. (2004, December 6-8). Resilience, vulnerability, and adaptive capacity: implications for system performance. International Forum for Enginnering Decision Making (IFED), Stoos, Switzerland. Retrieved from http://ir.canterbury.ac.nz:80/handle/10092/2809.

Davila, T. (2000). An empirical study on the drivers of management control systems' design in new product development. Accounting, Organizations and Society, 25(4-5), 383-409. Retrieved from https://doi.org/10.1016/S0361-3682(99)00034-3.

Davila, A., \& Foster, G. (2008). The adoption and evolution of management control systems in entrepreneurial companies: evidence and a promising future. Handbooks of Management Accounting Research, 3, 1323-1336. Retrieved from http://doi.org/10.1016/S17513243(07)03006-4.

Davila, A., Foster, G., \& Li, M. (2009). Reasons for management control systems adoption: insights from product development systems choice by early-stage entrepreneurial 
companies. Accounting, Organizations and Society, 34(3-4), 322-347. Retrieved from https://doi.org/10.1016/j.aos.2008.08.002.

Denhardt, J., \& Denhardt, R. (2010). Building organizational resilience and adaptive management. In J. W. Reich, A. J. Zautra, \& J. S. Hall (Eds.), Handbook of adult resilience. (pp. 333-349). New York: Guilford Press. Retrieved from http://search.ebscohost.com/login.aspx?direct=true \&db=psyh\&AN=2010-10101016\&site=ehost-live.

Diehl, C. A., \& Souza, M. A. de. (2008). Alavancas de Controle: identificando o alinhamento estratégico. Revista Del Instituto Internacional de Costos, (2), 41-66.

Edmondson, A. C. (1999). Psychological safety and learning behavior in work teams. Administrative Science Quarterly, 44(2), 350-383.

Edmondson, A. C., \& Moingeon, B. (1998). From organizational learning to the learning organization. Management Learning, 29(1), 5-20.

Eisenhardt, K. M. (1989). Building theories from case study research. Academy of Management Review, 14(4), 532-550.

Eisenhardt, K. M., \& Zbaracki, M. J. (1992). Strategic decision making. Strategic Management Journal, 13(S2), 17-37.

Elliott, D., \& Macpherson, A. (2010). Policy and practice: recursive learning from crisis. Group \& Organization Management, 35(5), 572-605.

Emilio, E. R. V. (2011). Impacto do conflito intragrupal, do suporte social no trabalho e do autoconceito profissional sobre a resiliência: um estudo com policiais militares. (Dissertação de mestrado. Universidade Metodista de São Paulo), São Bernardo do Campo-SP.

Engemann, K., \& Henderson, D. (2011). Business continuity and risk management: essentials of organizational resilience. Brookfield: Rothstein Associates, CT.

England, R. (2015). Strategic resilience for through-life engineering services. In Procedia CIRP (Ed.), 4Th International Conference on Through-life Engineering Services (pp. 187-196). Retrieved from https://doi.org/10.1016/j.procir.2015.08.001.

Epstein, M. J., \& Roy, M. J. (2003). Making the business case for sustainability. Journal of Corporate Citizenship, 9(1), 79-96.

Erol, O., Henry, D., Sauser, B., \& Mansouri, M. (2010) Perspectives on measuring enterprise resilience. In: Proceedings of the IEEE international systems conference, SysCon 2010; Article number 5482333, p. 587-92. doi: 10.1109/SYSTEMS.2010.5482333.

Erol, O., Mansouri, M., \& Sauser, B. (2009). A framework for enterprise resilience using service oriented architecture approach. In: Proceedings of the 3rd Annual IEEE international systems conference. Article number 4815785: p. 127-32. doi: 10.1109/SYSTEMS.2009.4815785 
Erol, O., Sauser, B. J., \& Mansouri, M. (2010). A framework for investigation into extended enterprise resilience. Enterprise Information Systems, 4(2), 111-136. Retrieved from http://dx.doi.org/10.1080/17517570903474304.

Everly Jr., G. S. (2011, June). Building a resilient organizational culture. Harvard Business Review, 4 [online]. Retrieved from https://hbr.org/2011/06/building-a-resilient-organizat.

Faul, F., Erdfelder, E., Buchner, A., \& Lang, A. G. (2009). Statistical power analyses using G*Power 3.1: tests for correlation and regression analyses. Behavior Research Methods, 41(4), 1149-1160. Retrieved from https://doi.org/10.3758/BRM.41.4.1149.

Faul, F., Erdfelder, E., Lang, A. G., \& Buchner, A. (2007). G* Power 3: a flexible statistical power analysis program for the social, behavioral, and biomedical sciences. Behavior Research Methods, 39(2), 175-191. Retrieved from https://doi.org/10.3758/BF03193146.

Fauzi, H., \& Rahman, A. (2008). The role of control system in increasing corporate social performance: the use of levers of control. Issues in Social and Environmental Accounting, 2(1), 131-144. Retrieved from http://ssrn.com/abstract=1490994.

Ferreira, A., \& Otley, D. (2009). The design and use of performance management systems: an extended framework for analysis. Management Accounting Research, 20(4), 263-282. Retrieved from https://doi.org/10.1016/j.mar.2009.07.003.

Fleury, A., \& Fleury, M. T. L. (2000). Estratégias empresariais e formação de competências: um quebra-cabeça caleidoscópico da indústria brasileira. São Paulo: Atlas.

Fleury, M. T. L., \& Fleury, A. (2001). Construindo o conceito de competência. Revista de Administração Contemporânea, 5(spe), 183-196. Recuperado de http://dx.doi.org/10.1590/S1415-65552001000500010.

Ford, C. M., \& Gioia, D. A. (2000). Factors influencing creativity in the domain of managerial decision making. Journal of Management, 26(4), 705-732.

Foster, S. P., \& Dye, K. (2005). Building continuity into strategy. Journal of Corporate Real Estate, 7(2), 105-119.

Freeman, S. F., Hirschhorn, L., \& Maltz, M. (2004). Organization resilience and moral purpose: Sandler O'Neill and partners in the aftermath of 9/11/01. Paper presented at the National Academy of Management Meetings. New Orleans, LA. Retrieved from http://cpor.org/ro/Freeman(2003)OrgResilience,MoralPurposeSandlerO'Neill.pdf.

Frezatti, F., Bido, D. S., Cruz, A. P. C., \& Machado, M. J. C. (2012). Inovação como parte do sistema de controle gerencial. Anais do XXXVI Encontro da ANPD. Rio de Janeiro, 22 a 26 de setembro. Recuperado de http://repositorio.furg.br/bitstream/handle/1/5439/Inovação como parte do sistema de controle gerencial.pdf? sequence $=1$ 
Frezatti, F., Junqueira, E., Bido, D. S., Nascimento, A. R., \& Relvas, T. R. S. (2012). Antecedentes da definição do design do sistema de controle gerencial: evidências empíricas nas empresas brasileiras. Brazilian Business Review (BBR), 9(1), 134-155.

Friedman, M. (2005). Organisational Resilience. Accountancy SA, 24-27.

Garcia, D., Mavrodiev, P., \& Schweitzer, F. (2013). Social resilience in online communities. Paper presented at the First ACM Conference on Online Social Networks - COSN '13 (pp. 39-50). ACM Press. Boston. Retrieved from http://arxiv.org/abs/1302.6109\%5Cnhttp: //dl.acm.org/citation.cfm?doid=2512938.2512946.

Gittell, J. H., Cameron, K. G., Lim, S., \& Rivas, V. (2006). Relationships, layoffs, and organizational resilience: airline industry responses to September 11. Journal of Applied Behavioural Science, 42(3), 300-329.

Gooch, M., \& Warburton, J. (2009). Building and managing resilience in community-based NRM groups: an Australian case study. Society and Natural Resources, 22(2), 158-171. Retrieved from https://doi.org/10.1080/08941920801967880.

Graugaard, J. D. (2012). A tool for building community resilience? A case study of the Lewes Pound. The International Journal of Justice and Sustainability, 17(2), 243-260. Retrieved from http://dx.doi.org/10.1080/13549839.2012.660908.

Guimarães, T., \& Langley, K. (1994). Developing innovation benchmarks: an empirical study. Benchmarking for Quality Management \& Technology, 1(3), 3-20.

Hamel, G., \& Välikangas, L. (2003). The quest for resilience. Harvard Business Review, 81(9), 52. Retrieved from http://doi.org/10.1225/R0309C.

Hair Jr., J. F., Anderson, R. E., Tatham, R. L., \& Black, W. C. (2005). Análise multivariada de dados. (5a ed.). Porto Alegre: Bookman.

Hair Jr., J. F., Hult, G. T. M., Ringle, C. M., \& Sarstedt, M. (2014). A primer on partial least squares structural equation modeling (PLS-SEM). Thousand Oaks, CA: Sage Publications, Inc.

Hair Jr., J. F., Hult, G. T. M., Ringle, C. M., \& Sarstedt, M. (2017). A primer on Partial Least Squares Structural Equation Modeling (PLS-SEM). Los Angeles: SAGE Publications.

Hair, J. F., Ringle, C. M., \& Sarstedt, M. (2013). Partial least squares structural equation modeling: rigorous applications, better results and higher acceptance. Long Range Planning, 46(1-2), 1-12. doi: 10.1016/j.lrp.2013.08.016.

Henri, J. F. (2006). Management control systems and strategy: a resource-based perspective. Accounting, Organizations and Society, 31(6), 529-558. Retrieved from http://doi.org/10.1016/j.aos.2005.07.001.

Henseler, J., Ringle, C. M., \& Sinkovics, R. R. (2009). The use of partial least squares path modeling in international marketing. Advances in International Marketing, 20, 277-319. Retrieved from https://doi.org/10.1108/S1474-7979(2009)0000020014. 
Hitt, W. D. (1996). The learning organization: some reflections on organizational renewal. Journal of Workplace Learning, 8(7), 16-25.

Hoopes, L. (2012). Developing personal resilience in organizational settings. In V. Pulla, A. Shatte, \& S. Warren (Eds.). Perspectives on coping and resilience. (pp. 79-99). Author Press. Retrieved from http://resiliencealliance.com/wp-content/uploads/4Developing_Personal_Resilience_in_Organizational_Settings_by_Linda_L._Hoopes_pa ge_79-99.pdf.

Hoque, Z., \& Chia, M. (2012). Competitive forces and levers of control framework in a manufacturing setting: a tale of a multinational subsidiary. Qualitative Research in Accounting \& Management, 9(2), 123-145.

Horne, J. F. III., \& Orr, J. E. (1998). Assessing behaviors that create resilient organizations. Employment Relations Today, 24(4), 29-39.

Hosseini, S., Barker, K., \& Ramirez-Marquez, J. E. (2016). A review of definitions and measures of system resilience. Reliability Engineering and System Safety, 145, 47-61. Retrieved from https://doi.org/10.1016/j.ress.2015.08.006.

Ignatiadis, I., \& Nandhakumar, J. (2007). The impact of enterprise systems on organizational resilience. Journal of Information Technology, 22(1), 36-43. Retrieved from https://doi.org/10.1057/palgrave.jit.2000087.

Ismail, H. S., Poolton, J., \& Sharifi, H. (2011). The role of agile strategic capabilities in achieving resilience in manufacturing-based small companies. International Journal of Production Research, 49(18), 5469-5487. Retrieved from https://doi.org/10.1080/00207543.2011.563833.

Isidoro, C. (2012). O impacto do desenho e uso dos sistemas de controle gerencial na estratégia organizacional. (Dissertação de mestrado. Universidade Federal do Paraná), Curitiba-PR.

Jansen, E. P. (2011). The effect of leadership style on the information receivers' reaction to management accounting change. Management Accounting Research, 22(2), 105-124. Retrieved from http://doi.org/10.1016/j.mar.2010.10.001.

Kachali, H., Stevenson, J. R., Whitman, Z., Seville, E., Vargo, J., \& Wilson, T. (2012). Organizational resilience and recovery for Canterbury organizations after the 4 September 2010 earthquake. Australasian Journal of Disaster and Trauma Studies, 2012(1), 11-19.

Kihn, L. A. (2011). How do controllers and managers interpret budget targets? Journal of Accounting \& Organizational Change, 7(3), 212-236. doi: 10.1108/18325911111164187.

King, R., \& Clarkson, P. (2015). Management control system design, ownership, and performance in professional service organisations. Accounting, Organizations and Society, 45, 24-39. Retrieved from https://doi.org/10.1016/j.aos.2015.06.002. 
King, D. D., Newman, A., \& Luthans F. (2016). Not if, but when need resilience in the workplace. Journal of Organizational Behavior, 37(5), 782-786. Retrieved from https://doi.org/10.1002/job.2063.

Kleine, C., \& Weißenberger, B. E. (2014). Leadership impact on organizational commitment: the mediating role of management control systems choice. Journal of Management Control, 24(3), 241-266. Retrieved from https://doi.org/10.1007/s00187-013-0181-3.

Kominis, G., \& Dudau, A. I. (2012). Time for interactive control systems in the public sector? The case of the every child matters policy change in England. Management Accounting Research, 23(2), 142-155. Retrieved from http://doi.org/10.1016/j.mar.2012.04.002.

Kruis, A. M., Speklé, R. F., \& Widener, S. K. (2016, September). The levers of control framework: an exploratory analysis of balance. Management Accounting Research, 32, 27-44. Retrieved from http://dx.doi.org/10.1016/j.mar.2015.12.002.

Langfield-Smith, K. (1997). Management control systems and strategy: a critical review. Accounting, Organizations and Society, 22(2), 207-232.

Langvardt, G. D. (2007). Resilience and commitment to change: a case study of a on profit organization. (Thesis PhD. School of Business, Capella University), Minneapolis, EUA.

Lavarda, C. E. F., \& Pereira, A. M. (2012). Uso dos sistemas de controles de gestão nas diferentes fases do ciclo de vida organizacional. Revista Alcance -Eletrônica, 19(4), 497 518.

Lee, A. V., Vargo, J., \& Seville, E. (2013, February). Developing a tool to measure and compare organizations' resilience. Natural Hazards Review, 14(1), 29-41.

Lengnick-Hall, C. A., \& Beck, T. E. (2005). Adaptive fit versus robust transformation: how organizations respond to environmental change. Journal of Management, 31(5), 738-757. Retrieved from http://doi.org/10.1177/0149206305279367.

Lengnick-Hall, C. A., \& Beck, T. E. (2009). Resilience capacity and strategic agility: prerequisites for thriving in a dynamic environment. In C. Nemeth, E. Hollnagel, \& S. Dekker (Eds.). Preparation and restoration. (pp. 39-70). Aldershot UK: Ashgate Publishing.

Lengnick-Hall, C. A., Beck, T. E., \& Lengnick-Hall, M. L. (2011). Developing a capacity for organizational resilience through strategic human resource management. Human Resource Management Review, 21(3), 243-255. Retrieved from http://doi.org/10.1016/j.hrmr.2010.07.001.

Linnenluecke, M., \& Griffiths, A. (2010). Beyond adaptation: resilience for business in light of climate change and weather extremes. Business \& Society, 49(3), p. 477-511. Retrieved from https://doi.org/10.1177/0007650310368814.

Linnenluecke, M. K. \& Griffiths, A. (2013). The 2009 Victorian bushfires: a multilevel perspective on organizational risk and resilience. Organization \& Environment, 26(4), 386-411. Retrieved from https://doi.org/10.1177/1086026613508126. 
Linnenluecke, M. K. (2017, January). Resilience in business and management research: a review of influential publications and a research agenda. International Journal of Management Reviews, 19(1), 4-30. Retrieved from https://doi.org/10.1111/ijmr.12076.

Livramento, T. F. S., Oliveira, E. A. de A. Q., \& Moraes, M. B. de M. (2015). Empresas resilientes: o desafio de estabelecer uma cultura inovativa como fator de proteção. Latin American Journal of Business Management, 6(2), 237-255.

Luthans, F., Avey, J. B., Avolio, B. J., \& Peterson, S. J. (2010, Spring). The development and resulting performance impact of positive psychological capital. Human Resource Development Quarterly, 21(1), 41-67. Retrieved from https://doi.org/10.1002/hrdq.20034.

Luthans, F., Vogelgesang, G. R., \& Lester, P. B. (2006). Developing the psychological capital of resiliency. Human Resource Development Review, 5(1), 25-44.

Mallak, L. (1998). Putting organization resilience to work. Industrial Management, 40(6), 813.

Malmi, T., \& Brown, D. A. (2008). Management control systems as a package: opportunities, challenges and research directions. Management Accounting Research, 19(4), 287-300.

Mantovani, F. R. (2012). Desenho e uso de sistemas de controle gerencial focados no cliente: um estudo em empresas brasileiras sob a perspectiva da teoria da contingência. (Tese de doutorado. Universidade de São Paulo), São Paulo.

Marginson, D. E. W. (2002). Management control systems and their effects on strategy formation at middle-management levels: evidence from a U.K. organization. Strategic Management Journal, 23(11), 1019-1031. Retrieved from http://doi.org/10.1002/smj.271.

Martins, G. A., \& Theóphilo, C. R. (2016). Metodologia da investigação científica para ciências sociais aplicadas. (3a ed.). São Paulo: Atlas.

Mayunga, J. S. (2007, July). Understanding and applying the concept of community disaster resilience: a capital-based approach. Summer Academy for Social Vulnerability and Resilience Building, p. 1-16, Munich, Germany. Retrieved from https://www.ucursos.cl/usuario/3b514b53bcb4025aaf9a6781047e4a66/mi_blog/r/11._Joseph_S._Mayu nga.pdf.

McAllister, M., \& McKinnon, J. (2009). The importance of teaching and learning resilience in health disciplines: a critical review of the literature. Nurse Education Today, 29(4), 371379. Retrieved from https://doi.org/10.1016/j.nedt.2008.10.011.

McCann, J. (2004). Organizational effectiveness: changing concepts for changing environments. Human Resource Planning, 27(1), 42-50.

McManus, S. (2008). Organisational resilience in New Zealand. (Thesis PhD. University of Canterbury), New Zealand. 
McManus, S., Seville, E., Brunsdon, D., \& Vargo, J. (2007). Resilience management: $a$ framework for assessing and improving the resilience of organizations executive summary. New Zealand: Research Report, Resilient Organizations Programme.

McManus, S., Seville, E., Vargo, J., \& Brunsdon, D. (2008). Facilitated process for improving organizational resilience. Natural Hazards Review, 9(2), 81-90.

Meneghel, I., Salanova, M., \& Martínez, I. M. (2013). El camino de la resiliencia organizacional. Una revisión teórica. Aloma, 31(2), 13-24. Retrieved from http://www.revistaaloma.net/index.php/aloma/article/view/197/130.

Merchant, K. A., \& Otley, D. T. (2007). A review of the literature on control and accountability. In A. G. Chapman, C. S. Hopwood, \& M. D. Shields (Eds.). Handbooks of Management Accounting Research, v.2 (pp. 785-802). Amsterdam: Elsevier Ltd. Retrieved from https://doi.org/10.1016/S1751-3243(06)02013-X.

Merchant, K. A., \& Van der Stede, W. A. (2007). Management control systems: performance measurement, evaluation and incentives. (2nd ed.). London: PrenticeHall.

Meyer, A. D. (1982). Adapting to environmental jolts. Administrative Science Quarterly, 27(4), 515-527. Retrieved from http://doi.org/10.2307/2392528.

Mikulić, J., Prebežac, D., \& Dabić, M. (2016). Importance-performance analysis: common misuse of a popular technique International Journal of Market Research, 58(6), 775-778. Retrieved from https://doi.org/10.2501/IJMR-2016-05.

Miles, R., Snow, C., Meyer, A., \& Coleman Jr., H. (1978). Organizational strategy, structure and process. Academy of Management Review, 3(3), 546-562.

Minello, I. F. (2010). Resiliência e insucesso empresarial: um estudo exploratório sobre o comportamento resiliente e os estilos de enfrentamento do empreendedor em situações de insucesso empresarial, especificamente em casos de descontinuidade do negócio. (Tese de doutorado. Universidade de São Paulo), São Paulo.

Minello, I. F., \& Scherer, I. B. (2014). Características resilientes do empreendedor associadas ao insucesso empresarial. Revista de Ciências da Administração, 16(38), 228-245. Recuperado de http://dx.doi.org/10.5007/2175-8077.2014v16n38p228.

Minello, I. F., Scherer, L. A., \& Alves, L. C. (2012). Competências do empreendedor: uma análise com empreendedores que vivenciaram o insucesso empresarial. Revista de Negócios, 17(4), 74-90.

Mistry, J., Sarkis, J., \& Dhavale, D. G. (2014). Multi-criteria analysis using latent class cluster ranking: an investigation into corporate resiliency. International Journal of Production Economics, 148, 1-13. Retrieved from http://doi.org/10.1016/j.ijpe.2013.10.006.

Modell, S. (2005). Triangulation between case study and survey methods in management accounting research: an assessment of validity implications. Management Accounting Research, 16(2), 231-254. 
Moresi, E. A. (2000). Delineando o valor do sistema de informação de uma organização. Ci. Inf. [online], 9(1), 14-24. Recuperado de http://dx.doi.org/10.1590/S010019652000000100002 .

Morschel, E. L., dos Reis, D. R., de Matos, E. A. S. Á., \& Costa, V. L. (2013). A influência da cultura organizacional no processo de inovação: o caso da Águia Sistemas de Armazenagem em Ponta Grossa, Paraná. Revista de Administração e Inovação, 10(2), 219-237.

Mucci, D. M. (2014). Influência do estilo de uso do orçamento empresarial sobre as percepções de seus usuários. (Dissertação de mestrado. Universidade de São Paulo), São Paulo.

Mucci, D. L. M., Frezatti, F., \& Dieng, M. (2016). As múltiplas funções do orçamento empresarial. RAC, 20(3), 283-304. doi: http://dx.doi.org/10.1590/19827849rac2016140121.

Mundy, J. (2010). Creating dynamic tensions through a balanced use of management control systems. Accounting, Organizations and Society, 35(5), 499-523. Retrieved from http://doi.org/10.1016/j.aos.2009.10.005.

Nascimento, R. M. C. S. V. (2014). Resiliência estratégica: uma contribuição para o desenvolvimento das organizações. (Tese de doutorado. Faculdade de Ciências e Tecnologia, Universidade Nova de Lisboa), Lisboa, Portugal.

Neumann, M., Machado, D. D. P. N., Souza, E. C. L., Florenço, A. L., \& Palmeira, E. D. S. (2012). Ambiente de inovação e cultura organizacional em uma organização hospitalar: suas manifestações por meio das práticas organizacionais. Gestão Contemporânea, edição especial (1), 1-27.

Nisiyama, E. K., \& Oyadomari, J. C. T. (2012). Sistemas de controle gerencial e o processo de inovação. Revista de Administração e Inovação, 9(1), 106-125. Recuperado de http://doi.org/10.5773/rai.v1i1.634.

Nitzl, C. (2016). The use of partial least squares structural equation modelling (PLS-SEM) in management accounting research: Directions for future theory development. Journal of Accounting Literature, 37, 19-35. Retrieved from https://doi.org/10.1016/j.acclit.2016.09.003.

Nogueira, M. da G. S., \& Gonçalo, C. R. (2014). Resiliência organizacional como capacidade estratégica para inovação: um estudo em empresa de equipamentos médicos. Revista Eletrônica Faculdades Integradas de Itaraé - FAFIT/FACIC, 5(1), 41-55.

Nogueira, M. da G. S., \& Hallal, D. R. (2013). Resiliência organizacional como capacidade estratégica para um melhor desempenho: um estudo em empresas de tecnologia da informação da cidade de Caçador/SC. Anais do VI Encontro de Estudos em Estratégia ANPAD. (p. 12). Bento Gonçalves-RS.

Norris, F. H., Stevens, S. P., Pfefferbaum, B., Wyche, K. F., \& Pfefferbaum, R. L. (2008). Community resilience as a metaphor, theory, set of capacities, and strategy for disaster readiness. American Journal of Community Psychology, 41(1-2), 127-150. 
Nouri, H. \& Parker, R. J. (1998). The relationship between budget participation and job performance: the role of budget adequacy and organizational commitment. Accounting, Organizations and Society, 23(5-6), 467-483.

Nussbaum, M. (2016). Assessing resilience: how plans, strategies, and after action reports can improve our understanding of organizational preparedness. (Master of Arts). Naval Postgraduate School, Monterey, California.

O’Connor, N. G., Vera-Muñoz, S. C., \& Chan, F. (2011). Competitive forces and the importance of management control systems in emerging-economy firms: the moderating effect of international market orientation. Accounting, Organizations and Society, 36(45), 246-266. Retrieved from http://doi.org/10.1016/j.aos.2011.04.004.

Oakland, J. S. (2004). Oakland on quality management. Oxford: Elsevier Butterworth e Heinemann. Retrieved from https://doi.org/10.1016/B978-0-7506-5741-9.50022-6.

Oliveira, M. A., \& Nakano, T. C. (2011). Revisão de pesquisas sobre criatividade e resiliência. Temas em Psicologia, 19(2), 467-479.

Onça, S. S. (2011). Resiliência em trabalhadores: impacto da auto-eficácia e da percepção de suporte social. (Dissertação de mestrado. Universidade Metodista de São Paulo), São Bernardo do Campo-SP.

Onça, S. da S., \& Bido, D. de S. (2015). Bases de poder do gestor e conflitos intragrupais como antecedentes da aprendizagem grupal. Anais do XXXIX Encontro ANPAD. (pp. 1-18). 13 a 16 setembro. Recuperado de https://www.researchgate.net/publication/304636303_Bases_de_Poder_do_Gestor_e_Co nflitos_Intragrupais_como_antecedentes_da_Aprendizagem_Grupal

Onça, S. S., Bido, D. de S., \& Carvalho, A. S. C. (2018). Clima e comportamentos de aprendizagem grupal. Revista Organizações \& Sociedade, 25(86), 392-412. https://doi.org/10.1590/1984-9250863

Onça, S. da S., Bido, D. de S., \& Godoy, A. S. (2014). Impacto da potência das equipes de trabalho e dos conflitos intragrupais na aprendizagem grupal. XXXVIII Encontro Nacional Da ANPAD 2014, 1-16.

Oro, I. M. (2015). Interação dos sistemas de controle gerencial com a estratégia e o desempenho organizacional em empresa familiar. (Tese de doutorado. Universidade Regional de Blumenau), Blumenau-SC.

Otley, D. (1999). Performance management: a framework for management control systems research. Management Accounting Research, 10(4), 363-382.

Oyadomari, J. C. T. (2008). Uso do sistema de controle gerencial e desempenho: um estudo em empresas brasileiras sob a ótica da VBR (visão baseada em recursos). (Tese de doutorado. Universidade de São Paulo), São Paulo. 
Oyadomari, J. C. T., Cardoso, R. L., Silva, B. O. T., \& Perez, G. (2010). Sistemas de controle gerencial: estudo de caso comparativo em empresas inovadoras no Brasil. Revista Universo Contábil, 6(4), 21-34. Recuperado de https://doi.org/10.4270/ruc.2010429.

Oyadomari, J. C. T., Frezatti, F., Cardoso, R. L., \& Aguiar, A. B. de. (2009). Análise dos trabalhos que usaram o modelo Levers of Control de Simons na literatura internacional no período de 1995 A 2007. Revista de Contabilidade e Organizações (RCO), 3(7), 25-42. Recuperado de http://dx.doi.org/10.11606/rco.v3i7.34748

Oyadomari, J. C. T., Frezatti, F., Mendonça Neto, O. R. de, Cardoso, R. L., \& Bido, D. de S. (2011). Uso do sistema de controle gerencial e desempenho: um estudo em empresas brasileiras sob a perspectiva da resource-based view. REAd, 69(17), 298-329.

Pal, R. (2013). Organizational resilience through crisis strategic planning. (Thesis PhD. Tampere University of Technology), Finland.

Pal, R., Torstensson, H., \& Mattila, H. (2014, January). Antecedents of organizational resilience in economic crises. An empirical study of Swedish textile and clothing SMEs. International Journal of Production Economics, 147(Part B), 410-428. Retrieved from http://doi.org/10.1016/j.ijpe.2013.02.031.

Pal, R., Torstensson, H., \& Mattila, H. (2011). Organisational resilience and health of business systems. International Journal of Business Continuity and Risk Management, 2(4), 372398.

Pariès, J. (2006). Complexity, emergence, resilience. In E. Hollnagel. et al. (Eds.). Resilience engineering: concepts and precepts. (pp. 43-53). Burlington, Vt.: Ashgate.

Pasteur, K. (2011). From Vulnerability to Resilience: a framework for analysis and action to build community resilience. Rugby, Warwickshire, UK: Practical Action Publishing. Retrieved from http://www.jstor.org/stable/j.ctt1hj5968.

Pavlovska, O., \& Kuzmina-Merlino, I. (2013). Evolution of management controlling framework: literature review. Procedia -Social and Behavioral Sciences, 99(6), 10441053. Retrieved from http://doi.org/10.1016/j.sbspro.2013.10.578.

Pelling, M. (2003). The vulnerability of cities: natural disasters and social resilience. London: Earthscan.

Pettit, T. J. (2008). Supply chain resilience: development of a conceptual framework, an assessment tool and an implementation process. (Thesis $\mathrm{PhD}$. Ohio State University), Columbus, USA.

Pettit, T. J., Fiksel, J. \& Croxton, K. L. (2010). Ensuring supply chain resilience: Development of a conceptual framework. Journal of Business Logistics, 31(1), 1-22.

Pierce, B., \& O'Dea, T. (2003). Management accounting information and the needs of managers. The British Accounting Review, 35(3), 257-290. Retrieved from http://doi.org/10.1016/S0890-8389(03)00029-5. 
Pinzón, P. A., Vázquez, J. M. S., Elorza, M. V., \& Espejo, C. Á.-D. (2011). Sistemas de control para la gestión de los canales de exportación independientes: un análisis exploratorio sobre su diseño y uso. Revista de Contabilidad-Spanish Accounting Review, 14(2), 1436-97.

Plant, R., \& Murrell, S. (1997). The agile organization: technology and innovation. Paper presented at the 2nd Using AI in Electronic Commerce, April 2008. Retrieved from http://www.usc.edu/schools/business/atisp/AI/AI-Bus/AI-Meetings/aaai1997/paper.doc.

Podsakoff, P. M., Mackenzie, S. B., \& Podsakoff, N. (2012). Sources of method bias in social science research and recommendations on how to control it. Annual Review of Psychology, 63, 539-569. Retrieved from https://doi.org/10.1146/annurev-psych-120710-100452.

Polizzi Filho, A. (2011). O impacto de bem-estar no trabalho e de capital psicológico sobre intenção de rotatividade: um estudo com professores. (Dissertação de mestrado em gestão de organizações. Universidade Metodista de São Paulo). São Bernardo do Campo.

Quarantelli, E. L. (1995). Emergent behavior and groups in the crisis time of disasters. (Preliminary Papers 226). Newark, Delaware, USA: Disaster Research Center, University of Delaware.

Rankin, A., Lundberg, J., \& Woltjer, R. (2011). Resilience strategies for managing everyday risks. Paper presented at the 4th Resilience Engineering Symposium, 18(4), 213-5. Sophia Antipolis, France. Retrieved from http://www.ncbi.nlm.nih.gov/pubmed/22173714.

Rees, C. S., Breen, L. J., Cusack, L., \& Hegney, D. (2015, February). Understanding individual resilience in the workplace: the international collaboration of workforce resilience model. Frontiers in Psychology, 6(73), 1-7. Retrieved from https://doi.org/10.3389/fpsyg.2015.00073.

Reich, J. W. (2006). Three psychological principles of resilience in natural disasters. Disaster Prevention and Management, An International Journal, 15(5), 793-798. Retrieved from https://doi.org/10.1108/09653560610712739.

Reinmoeller, P., \& Baardwijk, N. V. (2005). The link between diversity and resilience. MIT Sloan Management Review, 46(4), 61-65.

Resilient Organisation (2014). Resilient organizations resilience benchmark tool. Version April 2014. Resilient Organization Research Programmer. New Zealand: University of Canterbury. Retrieved from: http://www.resorgs.org.nz/benchmark-resilience-tool.

Rieckhof, R., Bergmann, A., \& Guenther, E. (2015). Interrelating material flow cost accounting with management control systems to introduce resource efficiency into strategy. Journal of Cleaner Production, 108(Part B), 1-17. Retrieved from http://doi.org/10.1016/j.jclepro.2014.10.040.

Ringle, C. M., Da Silva, D., \& Bido, D. D. S. (2014). Modelagem de equações estruturais com utilização do SmartPLS. REMark, 13(2), 54. 
Ringle, C. M., \& Sarstedt, M. (2016). Gain more insight from your PLS-SEM results: the importance-performance map analysis. Industrial Management and Data Systems, 116(9), 1865-1886. Retrieved from https://doi.org/10.1108/IMDS-10-2015-0449.

Ringle, C. M., Wende, S., \& Becker, J. M. (2015). "SmartPLS 3." Boenningstedt: SmartPLS $\mathrm{GmbH}$. Retrieved from http://www.smartpls.com.

Riolli, L., \& Savicki, V. (2003). Information system organizational resilience. Omega, 31(3), 227-233. Retrieved from http://doi.org/10.1016/S0305-0483(03)00023-9.

Robb, D. (2000). Building resilient organizations. OD Practitioner, 32(3), 27-32. Retrieved from http://learninginaction.com/PDF/ResilientRobb.pdf.

Rose, A. (2007). Economic resilience to natural and man-made disasters: multidisciplinary origins and contextual dimensions. Environ Hazard, 7(4), 383-98.

Salanova, M., Llorens, S., Acosta, H., \& Torrente, P. (2013). Positive interventions in positive organizations. Terapia Psicológica. 31(1), 101-113. Retrieved from https://doi.org/10.4067/S0718-48082013000100010.

Salgado, C. O. M. (2013). Componentes da resiliência organizacional. (Dissertação de mestrado. Universidade do Minho), Braga, Portugal.

Sampieri, R. H., Collado, C. F, \& Lucio, M. P. B. (2013). Metodologia da pesquisa. (5a ed.). Porto Alegre: Penso.

Santos, A. C. M. (2011). Um estudo da associação da resiliência do gestor e o sucesso do empreendimento no contexto das micro e pequenas empresas. (Dissertação de mestrado. Faculdade Campo Limpo Paulista), Campo Limpo Paulista-SP.

Santos, C. B., \& Kato, H. T. (2014). Ambiente e resiliência organizacional: possíveis relações sob a perspectiva das capacidades dinâmicas. Desafio Online, 2(1), 564-579.

Sapountzaki, K. (2007). Social resilience to environmental risks: a mechanism of vulnerability transfer? Management of Environmental Quality, 18(3), 274-297.

Sawalha, I. H. S. (2015). Managing adversity: understanding some dimensions of organizational resilience. Management Research Review, 38(4), 346-366. Retrieved from http://doi.org/http://dx.doi.org/10.1108/MRR-01-2014-0010.

Sawik, T. (2013). Selection of resilient supply portfolio under disruption risks. Omega (United Kingdom), 41(2), 259-269. Retrieved from https://doi.org/10.1016/j.omega.2012.05.003.

Scarpin, M. R. S., \& Machado, D. D. P. N. (2015). O impacto da cultura sobre ambiente propício ao desenvolvimento de inovações. Revista de Administração e Inovação, 12(1), 148-173.

Scherer, I. B., \& Minello, I. F. (2014). Características do comportamento empreendedor durante o insucesso. Revista Pensamento Contemporâneo em Administração, 8(3), 23-36. 
Seeger, M. W., Ulmer, R. R., Novak, J. M., \& Sellnow, T. (2005). Post-crisis discourse and organisational change, failure and renewal. Journal of Organizational Change, 18(1), 7895.

Selto, F. H., Renner, C. J., \& Young, S. M. (1995). Assessing the organizational fit of a just-intime manufacturing system: testing selection, interaction and systems models of contingency theory. Accounting, Organizations and Society, 20(7), 665-684.

Senge, P. M. (1990). The leader's new work: building learning organizations. Sloan Management Review, 32(1), 7-22.

Seville, E., Brunsdon, D., Dantas, A., Le Masurier, J., Wilkinson, S., \& Vargo, J. (2006). Building organizational resilience: a New Zealand approach. Engineering: Reports. Resilient Organisations Research Programm. University of Canterbury. New Zealand Retrieved from http://hdl.handle.net/10092/649.

Seville, E., Brunsdon, D., Dantas, A., Le Masurier, J., Wilkinson, S., \& Vargo, J. (2008). Organizational resilience: researching the reality of New Zealand organizations. Journal of Business Continuity \& Emergency Planning, 2(2), 258-266.

Sheffi, Y. (2005). The resilient enterprise: overcoming vulnerability for competitive advantage. London: MIT Press Books.

Sheffi, Y. (2006). Resilience reduces risk. Logistics Quarterly, 12(1), 12-14.

Sheffi, Y., \& Rice Jr., J. B. (2005). A supply chain view of the resilient enterprise. MIT Sloan Management Review, 47(1), 41-48. Retrieved from http://search.ebscohost.com/login.aspx?direct=true \&db=buh\&AN=18837361\&site=ehos t-live.

Simons, R. (1987). Accounting control systems and business strategy: an empirical analysis. Accounting, Organizations and Society, 12(4), 357-374. Retrieved from https://doi.org/10.1016/0361-3682(87)90024-9.

Simons, R. (1990). The role of management control systems in creating competitive advantage: new perspectives. Accounting, Organizations and Society, 15(1/2), 127-143. Retrieved from http://doi.org/10.1016/0361-3682(90)90018-P.

Simons, R. (1991). Strategic orientation and top management attention to controle system. Strategic Management Journal, 12(1), 49-62.

Simons, R. (1994). How new top managers use control systems as levers of strategic renewal. Strategic Management Journal, 15(3), 169-189.

Simons, R. (1995). Levers of control: how managers use innovative control systems to drive strategic renewal. Boston, Massachusetts: Harvard Business School Press.

Simons, R. (2000). Performance measurement and control systems for implementing strategy. New Jersey: Prentice Hall PTR. 
Smith, M. (2015). Research methods in accounting. (3rd ed.). Los Angeles: Sage Publication Ltd.

Somers, S. (2009). Measuring resilience potential: an adaptive strategy for organizational crisis planning. Journal of Contingencies and Crisis Management, 17(1), 12-23.

Speklé, R. F. (2001). Explaining management control structure variety: a transaction cost economics perspective. Accounting, Organizations and Society, 26(4-5), 419-441.

Spiegler, V. L. M., Naim, M. M., \& Wikner, J. (2012). A control engineering approach to the assessment of supply chain resilience. International Journal of Production Research, 50(21), 6162-6187.

Starr, R., Newfrock, J., \& Delurey, M. (2003, Spring). Enterprise resilience: managing risk in the networked economy. Strategy and Business, (30), 70-79.

Staw, B. M., Sandelands, L. E., \& Dutton, J. E. (1981). Threat rigidity effects in organizational behavior: a multilevel analysis. Administrative Science Quarterly, 26(4), 501-524. Retrieved from https://doi.org/10.2307/2392337.

Stephenson, A. (2010). Benchmarking the resilience in organizations. (Thesis PhD. University of Canterbury), New Zealand.

Stephenson, A., Seville, E., Vargo, J., \& Roger, D. (2010). Benchmark resilience: a study of the resilience of organisations in the Auckland Region. Research Report 2010/3b. Resilient Organisations. New Zealand: University of Cantebury. Retrieved from https://ir.canterbury.ac.nz/handle/ 10092/4275.

Stephenson, A. V., Vargo, J., \& Seville, E. (2010). Measuring and comparing organisational resilience in Auckland. The Australian Journal of Emergency Management, 25(2), 27-32. Retrieved from papers2://publication/uuid/4B7798CB-50A9-456F-9348DE1698DE6080.

Sutcliffe, K. M., \& Vogus, T. J. (2003). Organizing for resilience. In: K. S. Cameron, J. E. Dutton, \& R. E. Quinn, (Eds.). Positive organizational scholarship: foundations of new discipline. (pp. 94-121). Berrett-Koehler, San Francisco: Berrett-Koehler.

Tadić, D., Aleksić, A., Stefanović, M., \& Arsovski, S. (2014). Evaluation and ranking of organizational resilience factors by using a two-step fuzzy AHP and fuzzy TOPSIS. Mathematical Problems in Engineering, Article ID 418085, 2014, 1-13. Retrieved from http://dx.doi.org/10.1155/2014/418085.

Tanoue, G. O. (2012). Flexibilidade organizacional e gestão de riscos na cadeia de suprimentos para geração de resiliência na cadeia automotiva. (Dissertação de mestrado. Universidade Federal de São Carlos), São Carlos-SP.

Teixeira, E. de O., \& Werther Junior, W. B. (2013). Resilience: continuous renewal of competitive advantages. Business Horizons, 56(3), 333-342. Retrieved from http://doi.org/10.1016/j.bushor.2013.01.009. 
Tekavčič, M., Peljhan, D., \& Šević, Z. (2008). Levers of control: analysis of management control systems in a Slovenian company. The Journal of Applied Business Research, Fourth Quarter, 24(4), 97-112.

Tenenhaus, M., Vinzi, V. E., Chatelin, Y. M., \& Lauro, C. (2005). PLS path modeling. Computational Statistics and Data Analysis, 48(1), 159-205. Retrieved from https://doi.org/10.1016/j.csda.2004.03.00.

Tessier, S., \& Otley, D. (2012, September). A conceptual development of Simons' Levers of Control framework. Management Accounting Research, 23(3), 171-185. Retrieved from http://doi.org/10.1016/j.mar.2012.04.003.

Utzig, M. J. S. (2012). Relação do uso interativo de instrumentos do sistema de controle gerencial com diferentes modelos de gestão de inovação de empresas. (Dissertação de mestrado. Universidade Regional de Blumenau), Blumenau.

Van der Stede, W. A., Young, S. M., \& Chen, C. X. (2005). Assessing the quality of evidence in empirical management accounting research: the case of survey studies. Accounting, Organizations and Society, 30(7), 655-684. doi: 10.1016/j.aos.2005.01.003.

Van der Stede, W. A., Young, S. M., \& Chen, C. X. (2006). Doing management accounting survey research. In C. S. Chapman, A. G. Hopwood, M. D. Shields (editors). Handbooks of Management Accounting Research, Elsevier (volume 1, chapter 18, p. 445-478). Retrieved from https://doi.org/10.1016/S1751-3243(06)01018-2.

Valastro, J. (2011). Organizational resilience: a position paper for critical infrastructure. Australian Case Studies, Australian Government. Commonwealth of Australia, 1-41. Retrieved from https://www.organisationalresilience.gov.au/resources/Documents/organisationalresilience-position-paper-for-critical-infrastructure-australian-case-studies.pdf.

Välikangas, L. (2004, June 1). Four steps to corporate resilience. Strategy+business. Summer 2004, Issue 35. Retrieved from https://www.strategybusiness.com/article/04215?gko=908d9.

Välikangas, L., \& Merlyn, P (2005). Strategic resilience: staying ahead of a crisis. Handbook of Business Strategy, 6(1), 55-58.

Välikangas, L., \& Romme, A. G. L. R. (2012). Building resilience capabilities at Big Brown, Inc. Strategy \& Leadership, 40(4), 43-45. Retrieved from https://doi.org/10.1108/10878571211242948.

Välikangas, L., \& Romme, A. G. L. (2013). How to design for strategic resilience a case study in retailing. Journal of Organization Design JOD, 2(2), 44-53. Retrieved from https://doi.org/10.7146/jod.7360.

Vargo, J., \& Seville, E. (2010). Resilient organizations: trying to thrive when you are struggling to survive. Paper presented at the 4th Annual Business Continuity Summit 2010 Resilience over Uncertainty, 24-25th March. Sydney, Australia. 
Vasconcelos, I. F. F. G., Cyrino, A. B., D'Oliveira, L. M., \& Prallon, E. P. (2015). Resiliência organizacional e inovação sustentável: um estudo sobre o modelo de gestão de pessoas de uma empresa brasileira de energia. Cadernos EBAPE. BR, 13(4), 910-929. Recuperado de http://dx.doi.org/10.1590/1679-395155896.

Vidal, R., Carvalho, H., \& Cruz-Machado, V. A. (2014). Strategic resilience development: a study using Delphi. In J. Xu, V. A. Cruz-Machado, B. Lev, \& S. Nickel (Eds.), Paper presented at the Eighth International Conference on Management Science and Engineering Management (Vol. 281, pp. 1245-1255). Berlin, Heidelberg: Springer Berlin Heidelberg. Retrieved from http://doi.org/10.1007/978-3-642-55122-2.

Vidal, M. C. R., Carvalho, P. V. R., Santos, M. S., \& Santos, I. J. L. dos. (2009). Collective work and resilience of complex systems. Journal of Loss Prevention in the Process Industries, 22(4), 516-527. Retrieved from https://doi.org/10.1016/j.jlp.2009.04.005.

Vieira, L. (2010). A nova ordem da resiliência. HSM Management, (38), 1-3. Recuperado de http:/www.hsm.com.br/artigos/nova-ordem-da-resiliencia.

Vieira, R. (2004). Comunicação organizacional: gestão de relações públicas. Rio de Janeiro: Mauad.

Vogus, T. J., \& Sutcliffe, K. M. (2007). Organizational resilience: towards a theory and research agenda. Paper presented at the IEEE International Conference on Systems, Man and Cybernetics (pp. 3418-3422). Montreal, Canada. Retrieved from doi: 10.1109/ICSMC.2007.4414160.

Volberda, H. W. (1996). Toward the flexible form: how to remain vital in hypercompetitive environments. Organization Science, 7(4), 359-374. Retrieved from https://www.jstor.org/stable/2635097.

Walker, B. H., Anderies, J. M., Kinzig, A. P., \& Ryan, P. (2006). Exploring resilience in socialecological systems through comparative studies and theory development: introduction to the special issue. Ecology and Society, 11(1), 1-5. Retrieved from http://www.ecologyandsociety.org/vol11/iss1/art12/.

Wang, J., Cooke, F. L., \& Huang, W. (2014). How resilient is the (future) workforce in China? A study of the banking sector and implications for human resource development. Asia Pacific Journal of Human Resources, 52(2), 132-154. Retrieved from https://doi.org/10.1111/1744-7941.12026.

Waterman Jr., R. H., Waterman, J. A., \& Collard, B. A. (1994, July/August). Toward a careerresilient workforce. Havard Business Review, 72(4), 87-95.

Weick, K. E., \& Sutcliffe, K. M. (2007). Managing the unexpected: resilient performance in an age of uncertainty (2nd ed.). San Francisco, CA: Jossey-Bass.

Westrum, R. (2006). A typology of resilience situations. In E. Hollnagel, D. D. Woods, \& N. Leveson (Eds.). Resilience engineering: concepts and precepts. (pp.56-65). Burlington, Vt.: Ashgate. 
Wetzels, M., Odekerken-Schröder, G., \& Oppen, C. van. (2009). Using PLS path modeling for assessing hierarchical construct models: guidelines and empirical illustration. MIS Quarterly, 33(1), 177-195. Retrieved from https://www.jstor.org/stable/20650284.

Whitehorn, G. (2011). Building business resilience. Keeping Good Companies, 63(7), 402-405.

Whitman, Z. R., Kachali, H., Roger, D., Vargo, J., \& Seville, E. (2013). Short-form version of the Benchmark Resilience Tool (BRT-53). Measuring Business Excellence, 17(3), 3-14. Retrieved from http://doi.org/10.1108/MBE-05-2012-0030.

Widener, S. K. (2007). An empirical analysis of the levers of control framework. Accounting, Organizations and Society, 32(7-8), 757-788. Retrieved from http://doi.org/10.1016/j.aos.2007.01.001.

Yin, R. K. (2015). Estudo de caso: planejamento e métodos. Porto Alegre: Bookman.

Young, S. M., \& Selto, F. H. (1993, Fall). Explaining cross-sectional workgroup performance differences in a JIT facility: a critical appraisal of a field-based study. Journal of Management Accounting Research, 5, 300.

Youssef, C. M., \& Luthans, F. (2007). Positive organizational behavior in the workplace: the impact of hope, optimism, and resilience. Journal of Management, 33(5), 774-800. Retrieved from http:// doi.org/10.1177/0149206307305562.

Yunes, M. A. M. (2003). Psicologia positiva e resiliência: o foco no indivíduo e na família. Psicologia Em Estudo, 8, número especial (75-84). Recuperado de http://doi.org/10.1590/S1413-73722003000300010. 
APÊNDICE A - O PROTOCOLO ÉTICO 


\section{PROTOCOLO ÉTICO DA PESQUISA}

\section{Ao Senhor XXXXXX}

Diretor da Empresa A

O presente protocolo ético, visa solicitar a concordância da empresa na participação da pesquisa de campo desenvolvido pelo projeto de doutorado intitulado "Capacidade para Resiliência Organizacional por meio dos Sistemas de Controle Gerencial: um estudo no cenário brasileiro" da pesquisadora Daiana Bragueto Martins do Programa de Pós-Graduação em Controladoria e Contabilidade da Universidade de São Paulo, sob a orientação do Professor Titular Fábio Frezatti e co-orientação da Professora Tania Casado. O projeto de tese possui as seguintes diretrizes:

\section{OBJETIVO DA PESQUISA}

O objetivo da pesquisa é investigar como o uso dos Sistemas de Controle Gerencial contribui para o desenvolvimento da resiliência organizacional no ambiente corporativo brasileiro.

\section{PROPOSTA DA PESQUISA}

A participação da empresa é fundamental para testar empiricamente os conceitos apresentados no ambiente acadêmico. Ou seja, para averiguar como ocorre o no dia-a-dia empresarial o relacionamento entre os elementos do controle gerencial e a resiliência organizacional.

Assim sendo, nesta pesquisa, a tese está no argumento de que o uso dos sistemas de controle gerencial impacta a resiliência. Desta forma, a proposta da presente pesquisa é auxiliar a empresa a entender o quão resiliente está no momento da pesquisa, para que a mesma possa desenvolver estratégias para aumentar o seu nível de resiliência de modo a sobreviver e prosperar no ambiente competitivo. Isto é, buscar-se-á observar quais sistemas de controle gerencial são utilizados na organização e como o uso destes sistemas de controle gerencial influencia na gestão da resiliência organizacional e, também, no apoio às mudanças estratégicas em cada uma das áreas de atuação. 


\section{BENEFÍCIOS PARA A EMPRESA}

A empresa, além do benefício da investigação, verificado com processo de coleta de dados, terá como benefício formal um feedback composto por um relatório técnico-científico entregue à empresa, contendo as conclusões da presente pesquisa de modo que a organização investigada possa identificar o poder do uso dos sistemas de controle gerencial em alavancar o seu nível de resiliência. Bem como sendo de interesse da empresa, a realização de workshop no qual os pesquisadores apresentarão os resultados evidenciados pela coleta e análise dos dados.

\section{BENEFÍCIOS PARA A PESQUISADORA}

As informações coletadas na empresa no decorrer da pesquisa têm por finalidade a produção da tese de doutorado da pesquisadora Daiana Bragueto Martins do Programa de PósGraduação em Controladoria e Contabilidade da Universidade de São Paulo, sob a orientação do Professor Titular Fábio Frezatti. Os resultados da presente pesquisa serão disseminados por meio de artigos científicos apresentados em congressos nacionais e ou internacionais e, posteriormente, publicados em periódicos acadêmicos-científicos nacionais e ou internacionais.

\section{CONTRIBUIÇÕES DA PESQUISA}

Entre as contribuições e os impactos da presente pesquisa, destaca-se que na perspectiva da empresa investigada este estudo visa, auxilia-la a identificar o impacto dos elementos do controle gerencial sobre a resiliência que é de extrema relevância para legitimar a identificação e a utilização dos mesmos no controle gerencial. A pesquisa utilizará a percepção e a experiência dos gestores e de suas equipes de trabalho para identificar como a empresa utiliza os sistemas de controle gerencial e, também, para apurar as características da resiliência. De modo, a proporcionar uma reflexão sobre cada área da organização e em seus diversos níveis organizacionais.

O presente estudo apresentará a interface entre estes constructos, isto é, quais sistemas de controle gerencial promovem a resiliência organizacional no momento da pesquisa. A contribuição gerada pela parceria com a empresa investigada promove o desenvolvimento da pesquisa científica que tenha consonância com as atividades organizacionais que emergem do cenário corporativo brasileiro no tocante ao sistema de controle gerencial. Porém, não se 
encontraram evidências empíricas que que relacionem o conjunto de elementos do controle gerencial e a capacidade de resiliência das empresas.

Espera-se que os achados da presente pesquisa proporcionem contribuições à literatura que acontecerá por meio da extensão dos estudos envolvendo sistemas de controle gerencial, ao passo que o presente estudo proporcionará através da lente da teoria da resiliência organizacional um modelo emergente de variância que será construído por meio dos dados coletados. Além disso, este modelo será utilizado para mensurar, comparar e identificar benchmark em um determinado departamento dentro da organização ou entre suas diferentes regiões de atuação.

Assim sendo, os resultados da presente pesquisa visam abordar lacunas na literatura, particularmente, aquelas relacionadas ao uso dos sistemas de controle gerencial no cenário brasileiro. No tocante a resiliência organizacional, ainda são incipientes as pesquisas na área de contabilidade, tanto no cenário nacional quanto internacional. A interdependência e o entrelaçamento das quatro alavancas de controle gerencial com os indicadores de resiliência organizacional, ajudarão a entender como o uso de determinado sistema de controle gerencial afeta a resiliência no ambiente organizacional.

\section{PROCEDIMENTOS ÉTICOS}

Esta pesquisa é regida pelos princípios gerais relativos ao consentimento informado, à reciprocidade que consiste na preocupação em não prejudicar a empresa e as pessoas que nela trabalham, e à confidencialidade da empresa e dos participantes da pesquisa, sempre que demandado. Em termos específicos, os seguintes procedimentos serão adotados:

- Não haverá a identificação da empresa e do grupo empresarial: tanto em relação a razão social, nome fantasia e marca, quanto as informações numéricas sobre seus resultados econômico-financeiros e ou outras informações que permitam identificar a presente empresa e/ou o grupo empresarial;

- Não haverá a identificação dos participantes: serão atribuídos códigos às pessoas e à organização de modo a evitar quaisquer riscos de identificação;

- Os pesquisadores se comprometem a manter confidencialidade e o anonimato quanto as informações coletadas por ocasião das entrevistas e dos questionários; 
- Apenas a equipe de pesquisadores (Professor Fábio Frezatti e Daiana Bragueto Martins) terá acesso aos registros das entrevistas e aos resultados obtidos por meio dos questionários;

- A gravação de entrevistas apenas acontecerá após a ciência e a concordância do entrevistado;

- O banco de dados gerado por meio das entrevistas e dos questionários serão mantidos sob a guarda dos pesquisadores;

- Não há riscos mentais ou físicos aos participantes associados a este estudo, bem como serão tomados os devidos cuidados para não prejudicar e não causar danos à imagem da empresa e do grupo empresarial e aos integrantes da mesma que participarem da presenta pesquisa; e

- A participação será voluntária e não forneceremos por ela qualquer tipo de pagamento ou remuneração aos participantes. Somente serão encaminhados os resultados finais à empresa, conforme já especificado anteriormente.

\section{PROCEDIMENTOS METODOLÓGICOS}

A pesquisa realizar-se-á por meio de visitas técnicas e guiadas na organização, entrevistas com gestores, questionário com diferentes equipes de trabalho e análise documental. As visitas técnicas visam auxiliar os pesquisadores a compreender o contexto da organização, o cenário no qual a mesma está inserida. O questionário será submetido por meio eletrônico aos diversos setores da organização, contemplando diferentes níveis organizacionais, a amostra será definida em conjunto com a empresa. A empresa encaminhará ou fornecerá meios para que o questionário eletrônico atinja os potenciais respondentes, cujo objetivo é capturar a percepção das pessoas nas diversas áreas da organização, bem como nas diferentes regiões de atuação, sobre o uso dos sistemas de controle gerencial e a resiliência no ambiente corporativo da empresa estudada. Cabe destacar que o instrumento será desenvolvido por meio de pesquisas anteriores, contendo, também, questões demográficas. O respondente participará da pesquisa de forma voluntária e terá o direito de não responder quesitos que julgar inapropriado em quaisquer questões, sem providenciar justificativas para as mesmas, bem como desistir da participação da pesquisa em qualquer momento. Porém, os pesquisadores reforçarão a importância da participação dos potenciais respondentes.

As entrevistas serão realizadas com diretores e gerentes a serem definidas em conjunto com a empresa. As entrevistas terão duração entre 30 a 40 minutos. O entrevistado participará 
da pesquisa de forma voluntária e terá o direito de não responder quesitos que julgar inapropriado em quaisquer questões, sem providenciar justificativas para as mesmas, bem como desistir da participação da pesquisa no decorrer da entrevista. O roteiro de entrevista será elaborado pela pesquisadora tendo como suporte a literatura existente sobre o objeto de estudo, contendo questões sobre a formação profissional e experiência na organização.

A análise documental contemplará documentos de acesso ao público disponíveis em mídias eletrônicas, tais como: informações contidas no site da organização, no site da BM\&FBovespa, relatórios anuais de sustentabilidade e relatórios financeiros, publicidades realizadas pela empresa e prêmios concedidos a empresa. Além disso, no decorrer da pesquisa outros documentos não citados acima podem emergir, bem como aqueles de acesso privado. Assim sendo, poderão ser contemplados documentos que a empresa juntamente com os pesquisadores julgarem necessários para o melhor desenvolvimento da pesquisa.

\section{CRONOGRAMA DA PESQUISA DE CAMPO NO AMBIENTE CORPORATIVO}

A pesquisa de campo acontecerá no segundo semestre de 2017, em que a pesquisadora estará em contato com o ambiente real corporativo para coleta dos dados, que contemplará:

\begin{tabular}{|c|c|c|c|c|c|c|}
\hline ATIVIDADE & $\begin{array}{l}\text { DESCRIÇÃO DO } \\
\text { OBJETIVO }\end{array}$ & $\begin{array}{l}\text { O QUE A EMPRESA } \\
\text { PRECISA } \\
\text { DISPONIBILIZAR }\end{array}$ & ago. & set. & $\begin{array}{l}2017 \\
\text { out. }\end{array}$ & nov. \\
\hline $\begin{array}{l}\text { Visitas } \\
\text { técnicas }\end{array}$ & $\begin{array}{l}\text { Aprofundar os estudos no } \\
\text { entendimento do contexto } \\
\text { organizacional. }\end{array}$ & $\begin{array}{l}\text { Apresentação da pesquisa, } \\
\text { reuniões sobre o } \\
\text { desenvolvimento da pesquisa e } \\
\text { apresentação do relatório } \\
\text { técnico. }\end{array}$ & & & & \\
\hline Pré-teste & $\begin{array}{c}\text { Auxiliar na garantia que a } \\
\text { linguagem utilizada no } \\
\text { instrumento seja coerente e } \\
\text { significativa, que não tenha } \\
\text { perguntas ambíguas. } \\
\end{array}$ & $\begin{array}{c}2 \text { a } 5 \text { gestores da empresa para } \\
\text { fornecer um feedback das } \\
\text { perguntas elencadas no } \\
\text { questionário. }\end{array}$ & & & & \\
\hline Questionários & $\begin{array}{l}\text { Capturar informações de } \\
\text { diferentes setores e níveis } \\
\text { organizacionais. }\end{array}$ & 80 a 120 respostas válidas & & & & \\
\hline Entrevistas & $\begin{array}{c}\text { Compreender como a empresa } \\
\text { faz uso dos sistemas de controle } \\
\text { gerencial e identificar os } \\
\text { indicadores de resiliência. } \\
\text { Validar as respostas obtidas } \\
\text { pelos questionários }\end{array}$ & 3 a 8 entrevistas & & & & \\
\hline
\end{tabular}

Todas as atividades e levantamentos propostos são de caráter estritamente acadêmico, e serão demostrados e pré-agendados com a empresa, e o cronograma destas realizações serão de 
comum acordo, no que se refere a datas e períodos. Cabe destacar que a análise e a discussão dos dados acontecerão no ano de 2018 e, concomitantemente, a defesa da tese na Universidade de São Paulo. Será agendado com a empresa uma data para a entrega do relatório técnicocientífico e para a realização do workshop, no qual serão apresentados os resultados das informações coletadas na empresa sobre o uso dos sistemas de controle gerencial e a capacidade da organização para a resiliência.

Qualquer informação adicional poderá ser obtida junto aos pesquisadores Daiana Bragueto Martins, e-mail daianabragueto@usp.br, telefone para contato (043) 99993-1983, Skype daiana_bragueto_martins e Professor Fábio Frezatti e-mail frezatti@usp.br, telefone para contato (011) 3091-5820 - Ramais 157 ou 119, Skype ffrezatti.

A qualquer momento a empresa poderá solicitar esclarecimento sobre o desenvolvimento do projeto de pesquisa que está sendo realizado e, sem qualquer tipo de cobrança, poderá retirar sua autorização. Os pesquisadores aptos a esclarecer estes pontos e, em caso de necessidade, dar indicações para solucionar ou contornar qualquer mal-estar que possa surgir em decorrência da pesquisa.

\section{AUTORIZAÇÃO INSTITUCIONAL}

$\mathrm{Eu}$, responsável pela instituição declaro que fui informado dos objetivos da pesquisa acima, e concordo em autorizar a execução da mesma nesta instituição. Caso necessário, a qualquer momento como instituição CO-PARTICIPANTE desta pesquisa, esta autorização poderá ser revogada. Declaro também, que não haverá qualquer tipo de pagamento, para ambas as partes.

São Paulo, 08 de agosto de 2017.

Daiana Bragueto Martins Pesquisadora
Fábio Frezatti

Orientador $\overline{\text { Responsável pela Instituição }}$ 
APÊNDICE B - E-MAIL CONVITE 


\section{Prezado(a) gestor(a) da Empresa A,}

É com grande satisfação que o convido a participar da pesquisa: "A capacidade para resiliência organizacional por meio dos sistemas de controle gerencial: um estudo no cenário brasileiro". Para participar acesse o link: https://pt.surveymonkey.com/r/feausp empresaA

A pesquisa está sendo desenvolvida por Daiana Bragueto Martins, doutoranda em Controladoria e Contabilidade, da Faculdade de Economia, Administração e Contabilidade da Universidade de São Paulo (FEA/USP), sob a orientação do Professor Titular Fábio Frezatti. O objetivo da ação é identificar a percepção dos colaboradores frente a compreensão e a aplicação tanto das práticas de gestão quanto da resiliência organizacional.

Auxilie a sua empresa a diagnosticar o quão resiliente está. Avalie o quanto a sua diretoria/gerência/unidade/departamento utiliza as ferramentas gerenciais para promover a resiliência estratégica de sua empresa. A sua participação será voluntária, e com a garantia de confidencialidade e anonimato pela pesquisadora.

Acesse https://pt.surveymonkey.com/r/feausp empresaA e deixe a sua opinião!

Ficarei muito grata com a sua participação, pois a sua contribuição promoverá o desenvolvimento dos estudos nesta área e auxiliará na gestão estratégica de sua empresa.

Agradeço a atenção dada à iniciativa e fico à disposição para quaisquer dúvidas.

Atenciosamente,

Daiana Bragueto Martins (daianabragueto@usp.br)

Professora da UEL;

Doutoranda em Controladoria e Contabilidade na FEA/USP;

Mestra em Contabilidade pela UFPR;

Especialista em Contabilidade e Controladoria Empresarial pela UEL.

Currículo Lattes http://lattes.cnpq.br/9227227422400784 
APÊNDICE C - LEMBRETES 


\section{Prezado(a) gestor(a) da Empresa A,}

É com grande satisfação que o convido a participar da pesquisa: "A capacidade para resiliência organizacional por meio dos sistemas de controle gerencial: um estudo no cenário brasileiro". Para participar acesse o link: https://pt.surveymonkey.com/r/feausp empresaA

\section{Caso você já tenha respondido por favor desconsidere este e-mail!}

A pesquisa está sendo desenvolvida por Daiana Bragueto Martins, doutoranda em Controladoria e Contabilidade, da Faculdade de Economia, Administração e Contabilidade da Universidade de São Paulo (FEA/USP), sob a orientação do Professor Titular Fábio Frezatti. O objetivo da ação é identificar a percepção dos colaboradores frente a compreensão e a aplicação tanto das práticas de gestão quanto da resiliência organizacional.

Auxilie a sua empresa a diagnosticar o quão resiliente está. Avalie o quanto a sua diretoria/gerência/unidade/departamento utiliza as ferramentas gerenciais para promover a resiliência estratégica de sua empresa. A sua participação será voluntária, e com a garantia de confidencialidade e anonimato pela pesquisadora.

Acesse https://pt.surveymonkey.com/r/feausp empresaA e deixe a sua opinião!

Ficarei muito grata com a sua participação, pois a sua contribuição promoverá o desenvolvimento dos estudos nesta área e auxiliará na gestão estratégica de sua empresa.

Agradeço a atenção dada à iniciativa e fico à disposição para quaisquer dúvidas.

Atenciosamente,

\footnotetext{
Daiana Bragueto Martins (daianabragueto@usp.br)

Professora da UEL;

Doutoranda em Controladoria e Contabilidade na FEA/USP;

Mestra em Contabilidade pela UFPR;

Especialista em Contabilidade e Controladoria Empresarial pela UEL.
}

Currículo Lattes http://lattes.cnpq.br/9227227422400784 
Olá boa tarde, Gestor(a) da Empresa A,

Estamos aguardando a sua contribuição na pesquisa!!!!

"A capacidade para resiliência organizacional por meio dos sistemas de controle gerencial: um estudo no cenário brasileiro".

Para participar acesse o link: https://pt.surveymonkey.com/r/feausp empresaA

Caso você já tenha respondido por favor desconsidere este e-mail!

E você, que começou e não terminou, por favor, termine de respondê-lo! Para isto, você deverá utilizar o mesmo computador.

Importante: o questionário apenas é considerado respondido quando o respondente chega no final!

Ficarei muito grata com a sua participação.

Daiana Bragueto Martins (daianabragueto@usp.br)

Professora da UEL;

Doutoranda em Controladoria e Contabilidade na FEA-USP;

Mestra em Contabilidade pela UFPR;

Especialista em Contabilidade e Controladoria Empresarial pela UEL.

Currículo Lattes http://lattes.cnpq.br/9227227422400784 


\section{Prezado(a) Gestor(a) da Empresa A,}

É com grande satisfação que o convido a participar da pesquisa: "A capacidade para resiliência organizacional por meio dos sistemas de controle gerencial: um estudo no cenário brasileiro". Para participar acesse o link: https://pt.surveymonkey.com/r/feausp empresaA

Caso você já tenha respondido por favor desconsidere este e-mail!

E você, que começou e não terminou, por favor, termine de respondê-lo! Para isto, você deverá utilizar o mesmo computador.

Importante: o questionário apenas é considerado respondido quando o respondente chega no final!

A pesquisa está sendo desenvolvida por Daiana Bragueto Martins, doutoranda em Controladoria e Contabilidade, da Faculdade de Economia, Administração e Contabilidade da Universidade de São Paulo (FEA/USP), sob a orientação do Professor Titular Fábio Frezatti. 0 objetivo da ação é identificar a percepção dos colaboradores frente a compreensão e a aplicação tanto das práticas de gestão quanto da resiliência estratégica.

A sua participação será voluntária, e com a garantia de confidencialidade e anonimato pela pesquisadora.

Acesse https://pt.surveymonkey.com/r/feausp empresaA e deixe a sua opinião!

Ficarei muito grata com a sua participação.

Agradeço a atenção dada à iniciativa e fico à disposição para quaisquer dúvidas.

Atenciosamente,

Daiana Bragueto Martins (daianabraqueto@usp.br)

Professora da UEL;

Doutoranda em Controladoria e Contabilidade na FEA-USP;

Mestra em Contabilidade pela UFPR;

Especialista em Contabilidade e Controladoria Empresarial pela UEL.

Currículo Lattes http://lattes.cnpq.br/9227227422400784 


\section{Olá Gestor(a) da Empresa A, boa tarde!}

Agradeço a você que já participou da pesquisa "A capacidade para resiliência organizacional por meio dos sistemas de controle gerencial: um estudo no cenário brasileiro".

Caso você não tenha participado, ainda há tempo!

Acesse o link: https://pt.surveymonkey.com/r/feausp_empresaA

Auxilie a sua empresa a entender como as práticas gerenciais contribuem na gestão da resiliência organizacional.

Bom feriado!

Daiana Bragueto Martins (daianabragueto@usp.br)

Professora da UEL;

Doutoranda em Controladoria e Contabilidade na FEA-USP;

Mestra em Contabilidade pela UFPR;

Especialista em Contabilidade e Controladoria Empresarial pela UEL.

Currículo Lattes http://lattes.cnpq.br/9227227422400784 


\section{Olá Gestor(a) da Empresa A, boa tarde!}

Agradeço a você que já participou da pesquisa "A capacidade para resiliência organizacional por meio dos sistemas de controle gerencial: um estudo no cenário brasileiro".

\section{Caso você não tenha participado, ainda há tempo!}

Acesse o link: https://pt.surveymonkey.com/r/feausp empresaA

E você, que começou e não terminou, por favor, termine de respondê-la! Para isto, você deverá utilizar o mesmo computador para acessar o

link https://pt.surveymonkey.com/r/feausp_empresaA

Auxilie a sua empresa a entender como as práticas gerenciais contribuem na gestão da resiliência organizacional.

Uma ótima semana!

Daiana Bragueto Martins (daianabragueto@usp.br)

Doutoranda em Controladoria e Contabilidade na FEA-USP;

Mestra em Contabilidade pela UFPR;

Especialista em Contabilidade e Controladoria Empresarial pela UEL.

Professora da UEL;

Currículo Lattes http://lattes.cnpq.br/9227227422400784 


\section{Olá Gestor(a) da Empresa A, boa tarde!}

Agradeço a você que já participou da pesquisa "A capacidade para resiliência organizacional por meio dos sistemas de controle gerencial: um estudo no cenário brasileiro".

\section{Caso você não tenha participado, ainda há tempo!}

Acesse o link: https://pt.surveymonkey.com/r/feausp empresaA

E você, que começou e não terminou, por favor, termine de respondê-la! Para isto, você deverá utilizar o mesmo computador para acessar o

link https://pt.surveymonkey.com/r/feausp_empresaA

Auxilie a sua empresa a entender como as práticas gerenciais contribuem na gestão da resiliência organizacional.

Um ótimo fim de semana!

Daiana Bragueto Martins (daianabragueto@usp.br)

Professora da UEL;

Doutoranda em Controladoria e Contabilidade na FEA-USP;

Mestra em Contabilidade pela UFPR;

Especialista em Contabilidade e Controladoria Empresarial pela UEL.

Currículo Lattes http://lattes.cnpq.br/9227227422400784 
APÊNDICE D - MODELO ESTRUTURAL SmartPLS 


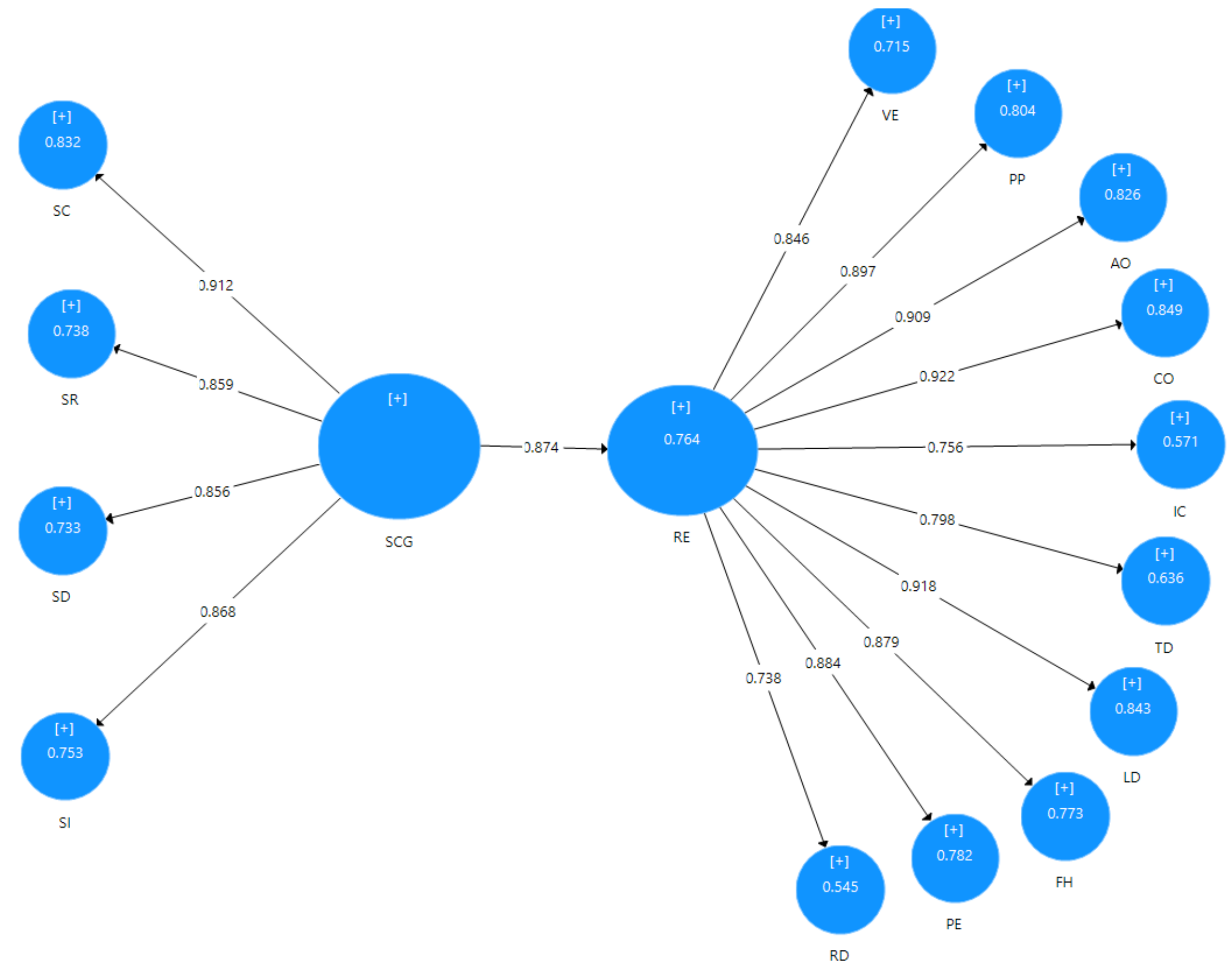




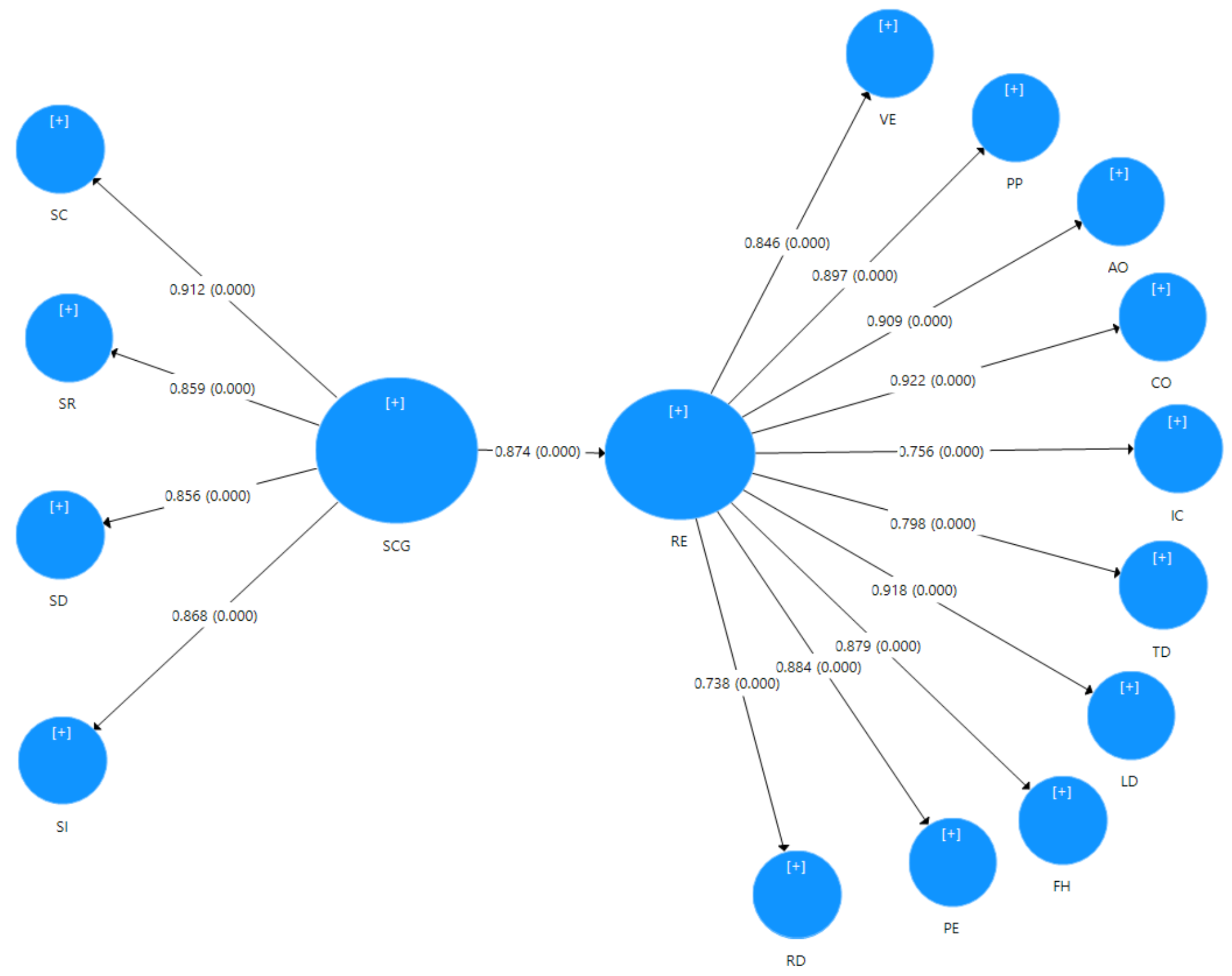




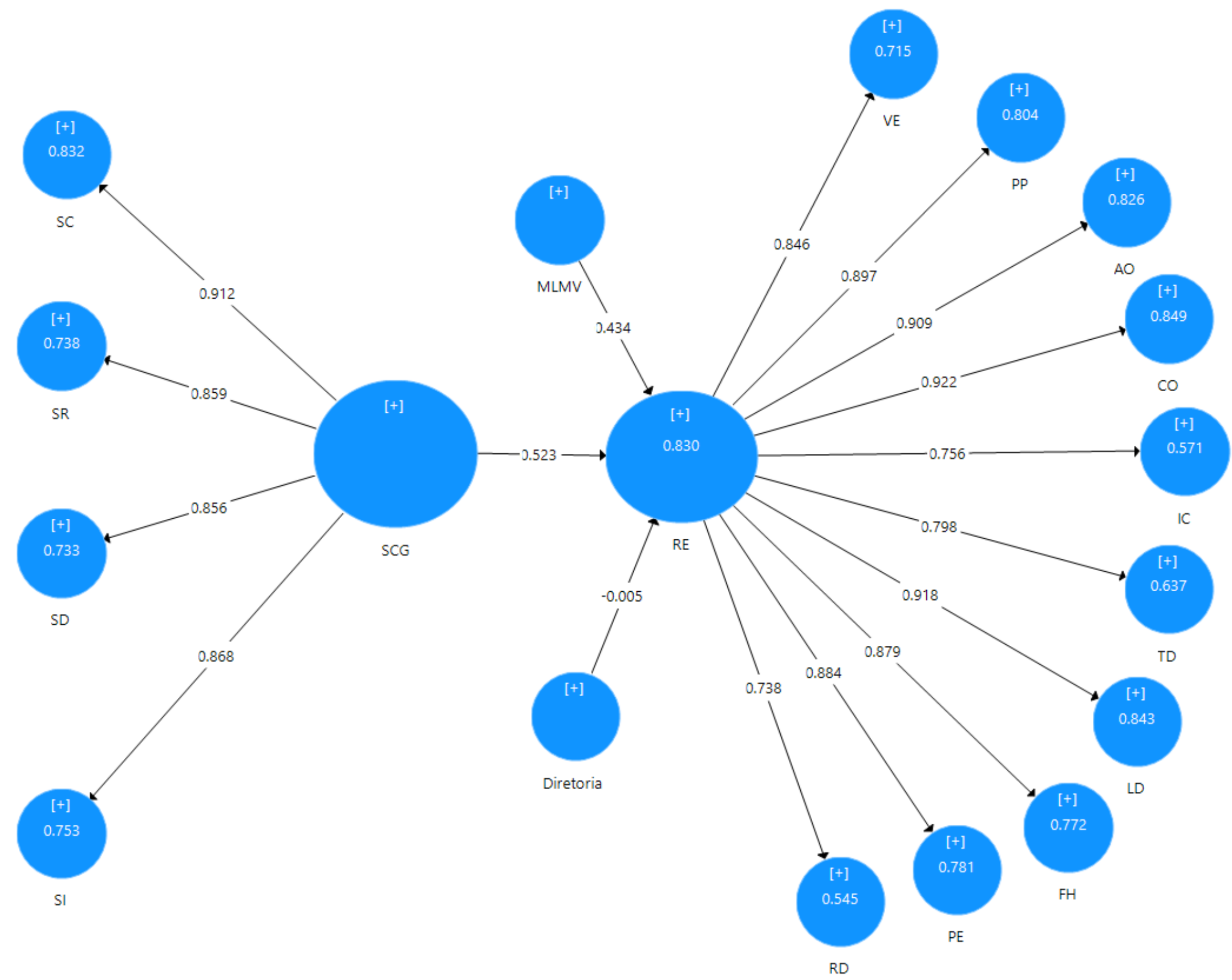




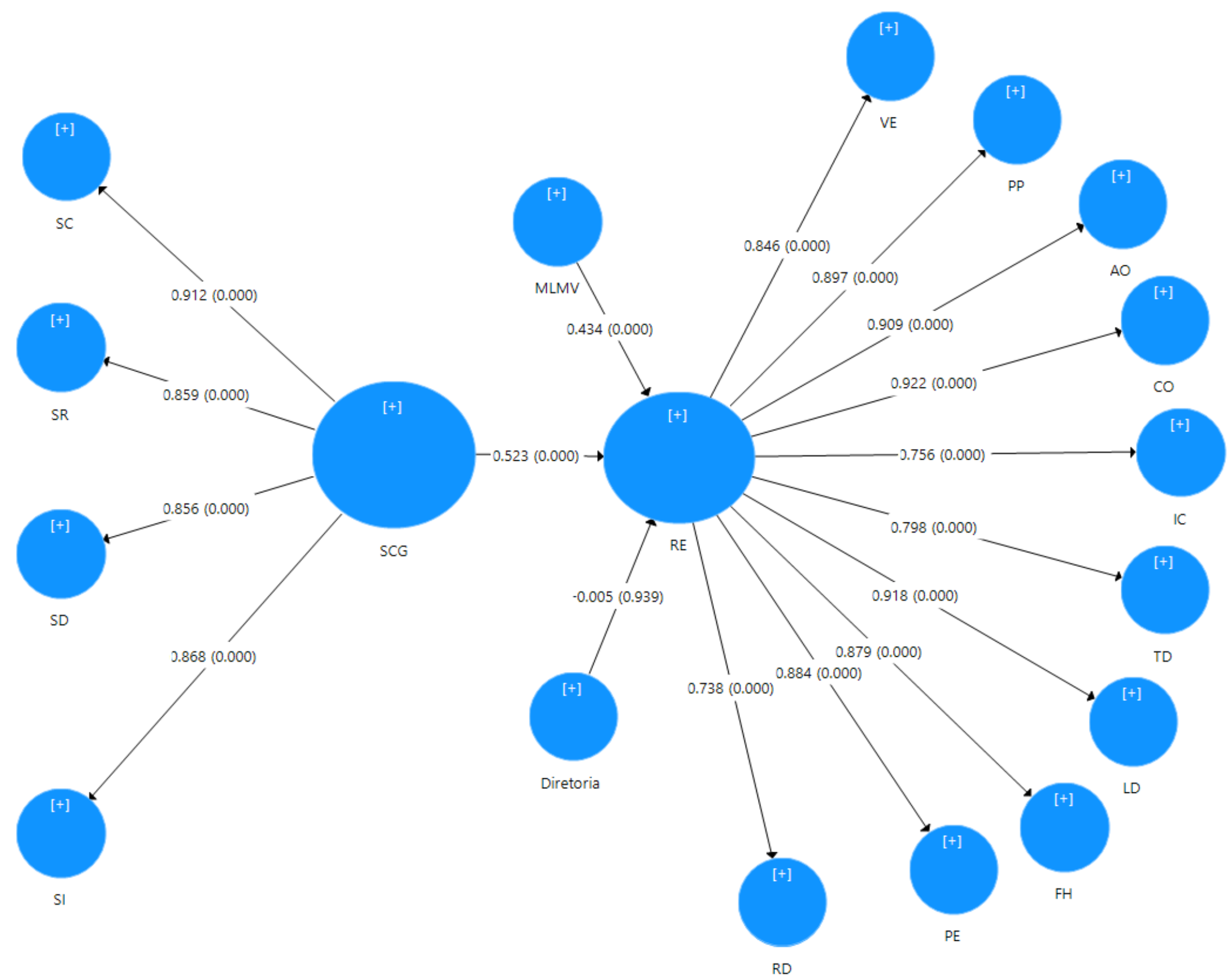


APÊNDICE E - RELATÓRIO EMITIDO PELO SMARTPLS 


\section{SmartPLS Report}

Please cite the use of SmartPLS: Ringle, C. M., Wende, S., and Becker, J.-M. 2015.

"SmartPLS 3." Boenningstedt: SmartPLS GmbH, http://www.smartpls.com.

\section{Quality Criteria}

Importance-Performance Map [RE_2 ${ }^{\text {a }}$ Ordem] (constructs, unstandardized effects)

Construct Total Effects for [RE_2를 Ordem]

\begin{tabular}{|l|r|}
\hline & RE_2 ${ }^{\text {a }}$ Ordem \\
\hline SCG_2 & 1,046 \\
\hline
\end{tabular}

Construct Performances for [RE_2 $2^{\text {a }}$ Ordem]

\begin{tabular}{|l|r|}
\hline & Performances \\
\hline SCG_2a Ordem & 85,663 \\
\hline
\end{tabular}

Importance-Performance Map [RE_2 ${ }^{\text {a }}$ Ordem] (indicators, unstandardized effects)

Indicator Total Effects for [RE_2 $2^{\text {a }}$ Ordem]

\begin{tabular}{|c|r|}
\hline & \multicolumn{1}{|c|}{ RE_2 ${ }^{\mathbf{a}}$ Ordem } \\
\hline SC1 & 0,0612 \\
\hline SC2 & 0,0575 \\
\hline SC3 & 0,0638 \\
\hline SC4 & 0,0602 \\
\hline SR1 & 0,0777 \\
\hline SR2 & 0,0664 \\
\hline SR3 & $-0,0008$ \\
\hline SR4 & 0,0496 \\
\hline SD1 & 0,0803 \\
\hline SD2 & 0,0749 \\
\hline SD3 & 0,0535 \\
\hline SD4 & 0,0782 \\
\hline SD5 & 0,0226 \\
\hline SI1 & 0,0440 \\
\hline SI2 & 0,0691 \\
\hline SI3 & 0,0643 \\
\hline SI4 & 0,0545 \\
\hline SI5 & 0,0688 \\
\hline
\end{tabular}

Indicator Performances for [RE_2를 Ordem]

\begin{tabular}{|c|r|}
\hline & MV Performances \\
\hline SC1 & 86,328 \\
\hline SC2 & 82,031 \\
\hline SC3 & 86,328 \\
\hline SC4 & 80,469 \\
\hline SR1 & 89,754 \\
\hline SR2 & 83,333 \\
\hline SR3 & 81,048 \\
\hline SR4 & 86,290 \\
\hline SD1 & 93,359 \\
\hline SD2 & 88,095 \\
\hline SD3 & 91,270 \\
\hline SD4 & 89,844 \\
\hline SD5 & 58,673 \\
\hline SI1 & 86,111 \\
\hline SI2 & 83,333 \\
\hline SI3 & 84,127 \\
\hline SI4 & 81,452 \\
\hline SI5 & 84,127 \\
\hline
\end{tabular}


APÊNDICE F - QUESTIONÁRIO 


\section{Prezado(a) gestor(a),}

Participe da pesquisa acadêmica intitulada: "A capacidade para resiliência organizacional por meio dos sistemas de controle gerencial: um estudo no cenário brasileiro", que está sendo desenvolvida na FEAUSP e auxilie a sua empresa a entender como as suas práticas gerenciais contribuem na gestão da resiliência organizacional.

A pesquisa está sendo desenvolvida por Daiana Bragueto Martins, doutoranda em Controladoria e Contabilidade, da Faculdade de Economia, Administração e Contabilidade da Universidade de São Paulo (FEA/USP), sob a orientação do Professor Titular Fábio Frezatti.

A pesquisa foi autorizada e vem sendo apoiada pela empresa. Acesse o Acordo de Confidencialidade firmado entre a empresa e a pesquisadora. Há o comprometimento de apresentar os resultados estatísticos da pesquisa à empresa.

O objetivo da pesquisa é investigar como o uso dos sistemas de controle gerencial contribui para o desenvolvimento da resiliência organizacional no ambiente corporativo.

A sua participação é muito importante. A contribuição solicitada refere-se ao preenchimento do questionário, cuja previsão de resposta é de aproximadamente $\underline{30 \text { minutos. }}$

Ao clicar em SIM, você estará autorizando a utilização de suas respostas no desenvolvimento deste projeto de tese vinculado ao Programa de Pós-Graduação em Controladoria e Contabilidade da FEAUSP, no qual a pesquisadora se compromete a manter a confidencialidade, o anonimato, o sigilo e a privacidade quanto as respostas coletadas nos questionários, sem o risco de que seus dados individuais sejam identificados. Em qualquer etapa da pesquisa você terá o direito de se retirar, sem qualquer penalidade ou prejuízo. Suas informações serão analisadas em conjunto com as de outros participantes.

Caso você tenha alguma consideração ou dúvida sobre os aspectos éticos da pesquisa, entre em contato com a pesquisadora responsável, Daiana Bragueto Martins, pelo e-mail daianabragueto@usp.br.

\section{* Diante desses esclarecimentos, assinale uma das duas alternativas a seguir:}

SIM. Li e declaro minha ciência sobre os procedimentos desta pesquisa e minha disposição de participar voluntariamente.

NÃO concordo em participar. 


\section{Sistema de Controle Gerencial e Resiliência Organizacional}

Nesta sessão, as perguntas têm a finalidade de mapear por meio da sua percepção a forma como a organização utiliza os sistemas de controle gerencial.

Sistemas de Controle Gerencial: são rotinas formais e informais que os gestores utilizam para manter ou alterar os padrões das atividades organizacionais.

\section{Responda sob a perspectiva da sua diretoria/gerência/departamento.}

As assertivas visam mensurar o nível de concordância, caso você não saiba responder alguma das questões, por favor escolha a opção "não sei dizer".

* Indique a extensão na qual os itens a seguir descrevem aspráticas na sua organização.

Discordo

totalmente

1

A missão comunica de forma clara os valores fundamentais da empresa à sua equipe.

Os principais gestores comunicam os valores fundamentais à sua equipe.

A sua equipe está ciente dos valores fundamentais, do propósito e da visão da organização.

Nos momentos de adversidade a missão/visão é observada na tomada de decisão.
Concordo Não sei Totalmente dizer

5

$0=00000$


* Indique a extensão na qual os itens a seguir descrevem o seu comportamento e o de sua equipe no desenvolvimento das atividades estratégicas da organização, a respeito dos instrumentos de controle de comportamento (tais como código de ética, diretrizes de direcionamento de operações, políticas de compliance, entre outros) que impõem os limites e as regras para que as ações na empresa estejam alinhadas com o seu core business (o ponto forte e estratégico de atuação da organização).

$\begin{array}{cccccc}\begin{array}{c}\text { Discordo } \\ \text { totalmente }\end{array} & & & \begin{array}{c}\text { Concordo } \\ \text { Totalmente }\end{array} & \begin{array}{c}\text { Não sei } \\ \text { dizer }\end{array} \\ 1 & 2 & 3 & 4 & 5 & 0\end{array}$

Os instrumentos (tais como código de ética, diretrizes de direcionamento de operações, políticas de compliance) informam sobre os comportamentos que estão fora dos limites aceitáveis pela empresa.

A organização comunica os riscos a serem evitados que poderiam ocasionar adversidades.

Não sei exatamente tudo o que devo fazer, mas tenho clareza do que não devo fazer.

A consciência da existência dos instrumentos (tais como código de ética, diretrizes de direcionamento de operações, políticas de compliance) direciona as ações em momento de adversidades.

* Indique com qual intensidade a sua diretoria/gerência/departamento utiliza o sistema de informação formal para monitorar os resultados organizacionais e corrigir os desvios de padrões pré-estabelecidos de desempenho.

Eaixa a
Temos planejamento estratégico formalizado.
O orçamento está alinhado com o planejamento
estratégico e decorre dele.
Temos controle orçamentário: são apresentados
os relatórios com o previsto versus o realizado; em
reuniões são discutidos os resultados passados e
as ações futuras.
Monitoramos e comparamos os resultados com as
expectativas de modo a prever adversidades que
impeçam o progresso em direção às metas
organizacionais.
O desempenho individual explicitado pelo controle
orçamentário impacta a remuneração variável do
executivo.


* Indique a extensão na qual os itens a seguir descrevemas práticas na sua organização.

Discordo

totalmente

Os gerentes operacionais estão frequentemente envolvidos com o sistema de controle.
Concordo Não sei totalmente dizer

5

Os dados gerados pelo sistema de controle são interpretados e discutidos com superiores, subordinados e pares.

É dedicada atenção regular e frequente à análise e discussão das adversidades em reuniões por parte dos gestores de todos os níveis.

A empresa utiliza o sistema de controle para anteciparse às mudanças com intuito de evitar que as adversidades afetem seus negócios.

A organização alinha a sua estratégia aos sistemas de controle dando suporte à decisão de modo a adaptar-se continuamente as adversidades.

\section{Você tem algum outro comentário, dúvida ou preocupação?}


Nesta seção, as perguntas têm a finalidade de mapear por meio da sua percepção a resiliência organizacional na sua empresa sob a perspectiva estratégica.

Resiliência Estratégica: é a capacidade da organização de estar atenta às expectativas do mercado agindo proativamente a medida que percebe os sinais das mudanças, pois tem a habilidade de antecipar, responder, evitar e adaptar, alternando as suas estratégias de modo a aproveitar as oportunidades, maximizando os ganhos e minimizando os problemas.

As assertivas visam mensurar o nível de concordância, caso você não saiba responder alguma das questões, por favor escolha a opção "não sei dizer".

Responda sob a perspectiva da sua diretoria/gerência/departamento.

* Baseado em sua percepção, indique a extensão na qual os itens abaixo descrevem a visão estratégica da sua organização (em relação às pessoas elou aos processos dentro da sua diretoria/gerência/departamento). Quando falamos de "visão estratégica", estamos nos referindo a capacidade de conhecer a organização como um todo e os desafios da atividade empresarial, alinhando as prioridades organizacionais frente às mudanças e aos anseios do mercado.

Temos uma visão ampla da organização/do negócio
como um todo.
Dedicamos tempo e energia para reavaliar
regularmente as metas a serem alcançadas e explorar
novas opções estratégicas o que nos permite
constantemente mudar a direção da organização.
Os aspectos de mudança são identificados como novas
oportunidades para a organização.
Temos condições e capacidade para reconhecer as
vulnerabilidades e as fraquezas do negócio para nos
ajustar a nova realidade.
O entendimento amplo da organização e de sua
atividade nos permite diagnosticar, interpretar,
compreender e nos anteciparmos às adversidades, aos
eventos e às mudanças no cenário empresarial.


* Indique a extensão na qual os itens abaixo descrevem a postura proativa de sua organização (em relação às pessoas elou aos processos dentro da sua diretoria/gerência/departamento). Quando falamos de "postura proativa", estamos nos referindo a capacidade da organização de antecipar-se as mudanças de modo a reduzir as vulnerabilidades em ambientes altamente complexos.

$\begin{array}{cccccc}\begin{array}{c}\text { Discordo } \\ \text { totalmente }\end{array} & & & \begin{array}{c}\text { Concordo } \\ \text { Totalmente }\end{array} & \begin{array}{c}\text { Não sei } \\ \text { dizer }\end{array} \\ 1 & 2 & 3 & 4 & 5 & 0\end{array}$

Temos uma estrutura que nos permite agir de forma rápida e eficaz em resposta a uma oportunidade e aos eventos inesperados.

Temos uma diversidade de ações competitivas disponíveis para adotarmos em respostas às inesperadas e oportunas mudanças que ocorrem no mercado.

Tomamos decisões e realizamos investimentos preventivamente para garantir que possamos nos beneficiar de situações futuras que possam surgir em nossa organização.

Nossa organização monitora proativamente o que está acontecendo em seu setor para agir antecipadamente nas questões emergentes.

Buscamos oportunidades de crescimento perante as situações de adversidades.

* Indique a extensão na qual os itens abaixo descrevemos recursos disponíveis de sua organização (em relação às pessoas elou aos processos dentro da sua diretoria/gerência/departamento). Quando falamos de "recursos disponíveis", estamos nos referindo ao conhecimento sobre os recursos necessários para a organização operar e a capacidade de priorizar e alocar tais recursos de modo alinha-los as prioridades da organização.

Temos conhecimento sobre os recursos internos e
externos disponíveis ao tomarmos uma decisão.
Realocamos os recursos para os novos produtos e
projetos.
Mantemos recursos suficientes para absorver
mudanças inesperadas.
Temos agilidade em obter a aprovação de recursos
adicionais para dar conta do recado em uma situação
de adversidade.


* Indique a extensão na qual os itens abaixo descrevem a inovação e a criatividade de sua organização (em relação às pessoas elou aos processos dentro da sua diretoria/gerência/departamento). Quando falamos de "inovação e criatividade", estamos nos referindo a capacidade de construir soluções inovadoras e criativas para os problemas, processos e produtos.

Somos estimulados a ter espírito empreendedor
visando à mudança.
Temos capacidade de utilizar o conhecimento de forma
inovadora e criativa na solução de problemas.
Somos incentivados a sermos criativos e a buscarmos
oportunidades para desenvolver novas habilidades, ao
invés de termos como foco a padronização.
Somos recompensados por "pensar fora da caixa".

* Indique a extensão na qual os itens abaixo descrevem a autonomia na tomada de decisão de sua organização (em relação às pessoas e/ou aos processos dentro da sua diretoria/gerência/departamento). Quando falamos de "autonomia na tomada de decisão", estamos nos referindo a capacidade de delegar autoridade e poder aos colaboradores da organização visando uma tomada de decisão com autonomia e responsabilidade por pessoas qualificadas.

$\begin{array}{cccccc}\begin{array}{c}\text { Discordo } \\ \text { totalmente }\end{array} & & & \begin{array}{c}\text { Concordo } \\ \text { Totalmente }\end{array} & \begin{array}{c}\text { Não sei } \\ \text { dizer }\end{array} \\ 1 & 2 & 3 & 4 & 5 & 0\end{array}$

Os líderes delegam responsabilidades e autoridade a sua equipe permitindo aos profissionais autonomia para tomarem decisões.

Compartilhamos a tomada de decisão amplamente.

Podemos tomar decisões difíceis rapidamente.

Caso ocorram problemas, os colaboradores possuem acesso direto a alguém com autoridade que possa tomar decisões.

Observações, comentários, dúvidas ou sugestões: 
Nesta seção, as perguntas têm a finalidade de mapear por meio da sua percepção a resiliência organizacional na sua empresa sob a perspectiva estratégica.

Resiliência Estratégica: é a capacidade da organização de estar atenta às expectativas do mercado agindo proativamente a medida que percebe os sinais das mudanças, pois tem a habilidade de antecipar, responder, evitar e adaptar, alternando as suas estratégias de modo a aproveitar as oportunidades, maximizando os ganhos e minimizando os problemas.

As assertivas visam mensurar o nível de concordância, caso você não saiba responder alguma das questões, por favor escolha a opção "não sei dizer".

Responda sob a perspectiva da sua diretoria/gerência/departamento.

* Indique a extensão na qual os itens abaixo descrevem a aprendizagem organizacional de sua organização (em relação às pessoas elou aos processos dentro da sua diretoria/gerência/departamento). Quando falamos de "aprendizagem organizacional", estamos nos referindo a capacidade da organização aprender com os erros e problemas ocorridos, com a experiência vivenciada e com as práticas de gestão que incentivam o questionamento da realidade.

$\begin{array}{cccccc}\begin{array}{c}\text { Discordo } \\ \text { totalmente }\end{array} & & & & \begin{array}{c}\text { Concordo } \\ \text { Totalmente }\end{array} & \begin{array}{c}\text { Não sei } \\ \text { dizer }\end{array} \\ 1 & 2 & 3 & 4 & 5 & 0\end{array}$

Durante uma adversidade, somos capazes de identificar um problema, aprender sobre ele, apresentar solução e implantar a solução.

Aprendemos lições do passado e garantimos que essas lições sejam executadas no futuro, pois evoluímos e nos adaptamos às novas situações.

Temos estruturas organizacionais que são projetadas para promover a aprendizagem e mudar os comportamentos com base nas novas informações e nos novos insights.

Temos práticas de gestão e normas organizacionais que incentivam o questionamento do que está acontecendo de modo a exigir uma sólida compreensão da realidade. 
* Indique a extensão na qual os itens abaixo descrevem a comunicação organizacional de sua organização (em relação às pessoas elou aos processos dentro da sua diretoria/gerência/departamento). Quando falamos de "comunicação organizacional", estamos nos referindo ao processo de interação entre os indivíduos da organização para transmitir e compartilhar informações, socializar novos conhecimentos e por meio dos sistemas de informação proporcionar a transmissão destes para todos os níveis organizacionais.

$\begin{array}{cccccc}\begin{array}{c}\text { Discordo } \\ \text { totalmente }\end{array} & & & \begin{array}{c}\text { Concordo } \\ \text { Totalmente }\end{array} & \begin{array}{c}\text { Não sei } \\ \text { dizer }\end{array} \\ 1 & 2 & 3 & 4 & 5 & 0\end{array}$

O processo de comunicação compartilha a direção e as estratégias organizacionais nos diversos níveis hierárquicos.

Temos uma linguagem comum (ou seja, palavras, imagens e histórias) e predominante que implica capacidade, influência, competência, valores fundamentais consistentes e um sentido claro de direção em nossa organização.

O sistema de informação ao disponibilizar informação com qualidade dá suporte à tomada de decisão rápida e eficaz.

Funcionários possuem formação para utilizar o sistema, sabem quais informações acessar em situações críticas e têm consciência das implicações para as possíveis soluções.

As informações cruciais estão disponíveis em diferentes meios.

* Indique a extensão na qual os itens abaixo descrevem a liderança de sua organização (em relação às pessoas elou aos processos dentro da sua diretoria/gerência/departamento). Quando falamos de "liderança", estamos nos referindo a capacidade de compreender o ambiente e responder com rapidez e eficácia as mudanças em seu setor adaptando-se à frente dos seus concorrentes. A liderança promove espaço para discussão em que os gestores ouvem os problemas e soluções oriundos dos diversos níveis organizacionais proporcionando feedback constante.

\section{Discordo totalmente}

1
2
Concordo Não sei Totalmente dizer

Líderes abertos às mudanças contínuas nas estratégias da organização e aos novos desafios; consideram a mudança como oportunidade.

Os gestores entendem como liderança o próprio exemplo.

A liderança preza pelo bom relacionamento e incentiva os colaboradores a discutirem problemas junto aos seus gestores.

A liderança gera feedback constante e desenvolve uma comunicação aberta entre o líder e sua equipe. 
* Indique a extensão na qual os itens abaixo descrevem o fator humano de sua organização (em relação às pessoas e/ou aos processos dentro da sua diretoria/gerência/departamento). Quando falamos de "fator humano ", estamos nos referindo as pessoas na organização que percebem seu ambiente de trabalho como propício para assumir riscos interpessoais, para desenvolver relações interpessoais efetivas e estabelecer responsabilidades tanto individual quanto em grupo sobre a organização, o seu desempenho e os possíveis problemas.

$\begin{array}{cccccc}\begin{array}{c}\text { Discordo } \\ \text { totalmente }\end{array} & & & \begin{array}{c}\text { Concordo } \\ \text { Totalmente }\end{array} & \begin{array}{c}\text { Não sei } \\ \text { dizer }\end{array} \\ 1 & 2 & 3 & 4 & 5 & 0\end{array}$

As pessoas estabelecem relações com outras pessoas permitindo o compartilhamento de recursos, de objetivos, de conhecimentos, de informações e de práticas de respeito mútuo.

Cada membro da organização tem a descrição e a responsabilidade de assegurar a obtenção dos interesses organizacionais.

Trabalhamos com outras pessoas independente das fronteiras departamentais e organizacionais.

As pessoas na organização se sentem responsáveis pela eficácia da organização.

As pessoas na organização buscam informações, solicitam ajuda, admitem que erraram e ou geraram feedbacks críticos no desenvolvimento de suas atividades.

* Indique a extensão na qual os itens abaixo descrevem asparcerias eficazes de sua organização (em relação às pessoas elou aos processos dentro da sua diretoria/gerência/departamento). Quando falamos de "parcerias eficazes", estamos nos referindo a organização possuir alianças estratégicas ao desenvolver relacionamentos interpessoais interna e externamente. A empresa apresenta vínculos com seus stakeholders (parceiros/agentes) e tem consciência de sua conexão e interdependência no desenvolvimento de suas atividades, especialmente, em situações de adversidade.

\section{Discordo totalmente}

1
Concordo Não sei Totalmente dizer

Possuímos alianças estratégicas e bom relacionamento com nossos stakeholders para garantir recursos necessários em apoio as iniciativas de mudanças.

Asseguramos que os vínculos com vários stakeholders sejam mantidos, reforçando assim o capital social além das fronteiras da empresa.

Entendemos como estamos conectados aos nossos stakeholders e gerenciamos ativamente tanto essas parcerias quanto a possibilidade de angariar novas.

Entendemos como as ações dos nossos parceiros afetam nossa capacidade de resposta em caso de adversidade. 
Observações, comentários, dúvidas ou sugestões:

* Indique a extensão na qual os itens abaixo descrevem o seu trabalho atual.

\section{Discordo \\ Totalmente}

1

Utilizo o sistema de controle gerencial para melhorar minha produtividade.

Sinto-me confiante ao contribuir nas discussões sobre os planos de minha empresa para o futuro.

Atualmente eu me vejo em uma fase de sucesso no trabalho.

Normalmente aceito com calma as coisas estressantes do trabalho.

Neste momento, acho que posso atingir as metas de trabalho que fixei para mim mesmo.

Sou otimista sobre o que acontecerá comigo no futuro em meu trabalho.

A missão da organização está alinhada com os meus valores.

No que diz respeito à minha carreira, quem toma as decisões sou eu.
Concordo Não sei

Totalmente dizer

$\begin{array}{lllll}2 & 3 & 4 & 5 & 0\end{array}$

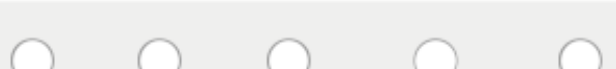

○ 0000

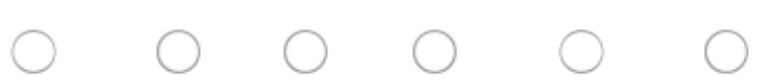


* Há quanto tempo você trabalha nesta organização? (especificar anos e meses, ex.: 10 anos e 5 meses)

* Quantos colaboradores estão subordinados diretamente a você?

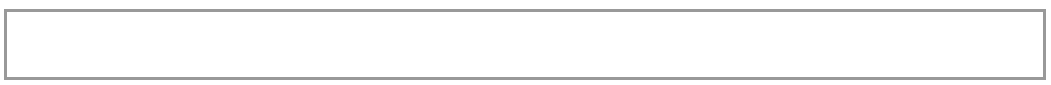

* Qual das seguintes opções melhor representa o seu cargo atual nesta organização?

Alta gerência

Diretor

Gerente

Supervisor

Analista

Outro (especifique)

* Há quanto tempo você ocupa o seu cargo atual? (especificar anos e meses)

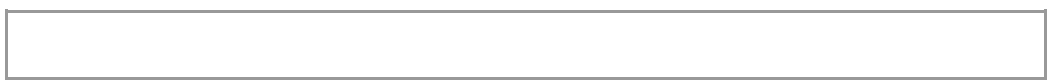

* A qual diretoria você está subordinado?

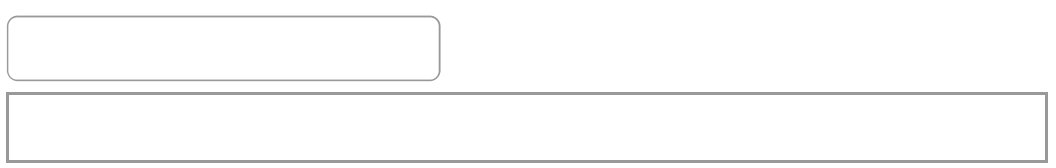

* Dentro da Diretoria, indique a qual gerência você está vinculado(a)?

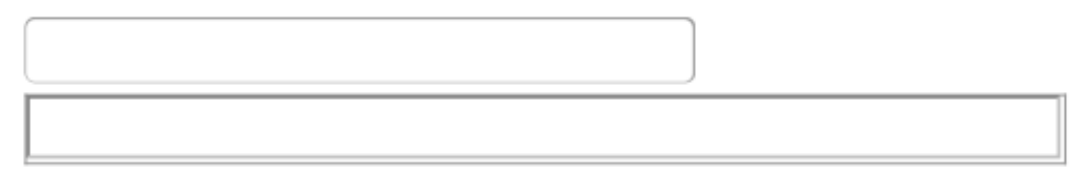


* Qual é o nível de escolaridade mais alto que você concluiu?

Ensino médio

Ensino técnico ou tecnológico

Ensino superior completo

Especialização ou MBA

Mestrado

Doutorado

Outro (especifique)

* Qual é a sua área de formação?

Administração

Ciências Contábeis

Direiro

Econômia

Engenharia Civil

Engenharia de Produção

Outro (especifique)

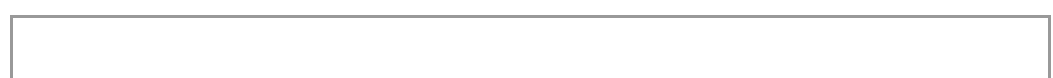

* Qual é a sua idade?

\section{* Gênero:}

Feminino

Masculino

Outro (especifique) 
Muito obrigado por participar da presente pesquisa! 